NBER WORKING PAPER SERIES

\title{
HOW DO CAMPAIGNS SHAPE VOTE CHOICE? MULTI-COUNTRY EVIDENCE FROM 62 ELECTIONS AND 56 TV DEBATES
}

\author{
Caroline Le Pennec \\ Vincent Pons \\ Working Paper 26572 \\ http://www.nber.org/papers/w26572 \\ NATIONAL BUREAU OF ECONOMIC RESEARCH \\ 1050 Massachusetts Avenue \\ Cambridge, MA 02138 \\ December 2019, Revised December 2022
}

For suggestions that have improved this article, we are grateful to Alberto Alesina, David Broockman, Ernesto Dal Bo, Ruth Dassonneville, Rafael Di Tella, Andrew Eggers, Benjamin Enke, Aaron Erlich, Frederico Finan, Alexander Fouirnaies, Gregory Martin, Benjamin Marx, Sendhil Mullainathan, Benjamin Olken, Torsten Persson, Nicolas Sauger, Andrei Shleifer, Edoardo Teso, and MatthewWeinzierl, as well as seminar participants at Stanford University, Houston University, Université Libre de Bruxelles, the 2018 Annual Meeting of the American Political Science Association, the 2019 Galatina Summer Meetings, the 2021 Annual Meeting of the American Economic Association, the 2021 IEB Workshop on Political Economy, the Quebec Political Economics Webinar Series, the 2021 LACEA-LAMES Annual Meeting, the 2022 RIDGE Political Economy Workshop, and the 2022 NBER Political Economy Summer Institute. We also thank Sudeshna Barman, Ashley Liu, Jack Oster, and Irina Vlasache for great research assistance. The views expressed herein are those of the authors and do not necessarily reflect the views of the National Bureau of Economic Research.

NBER working papers are circulated for discussion and comment purposes. They have not been peer-reviewed or been subject to the review by the NBER Board of Directors that accompanies official NBER publications.

(C) 2019 by Caroline Le Pennec and Vincent Pons. All rights reserved. Short sections of text, not to exceed two paragraphs, may be quoted without explicit permission provided that full credit, including $(\odot)$ notice, is given to the source. 
How Do Campaigns Shape Vote Choice? Multi-Country Evidence from 62 Elections and 56 TV Debates

Caroline Le Pennec and Vincent Pons

NBER Working Paper No. 26572

December 2019, Revised December 2022

JEL No. D72,D83

\begin{abstract}
We use two-round survey data from 62 elections in ten countries since 1952 to study the formation of vote choice, beliefs, and policy preferences, and assess how televised debates contribute to this process. Our data include 253,000 observations. We compare the consistency between vote intention and vote choice of respondents surveyed at different points before, and then again after, the election, and show that $17 \%$ to $29 \%$ of voters make up their mind during the final two months of campaigns. Changes in vote choice are concomitant to shifts in issues voters find most important and in beliefs about candidates, and they generate sizeable swings in vote shares. In contrast, policy preferences remain remarkably stable throughout the campaign. Finally, we use an event study to estimate the impact of TV debates, in which candidates themselves communicate with voters, and of shocks such as natural and technological disasters which, by contrast, occur independently from the campaign. We do not find any effect of either type of event on vote choice formation, suggesting that information received throughout the campaign from other sources such as the media, political activists, and other citizens, is more impactful.
\end{abstract}

\author{
Caroline Le Pennec \\ HEC Montreal \\ 3000 Chemin De La Cote-Sainte-Catherine \\ Montreal, Quebec H3T 2A7 \\ Canada \\ caroline.le-pennec@hec.ca \\ Vincent Pons \\ Harvard Business School \\ Morgan Hall 289 \\ Soldiers Field \\ Boston, MA 02163 \\ and CEPR \\ and also NBER \\ vpons@hbs.edu
}




\section{INTRODUCTION}

Elections are the distinctive feature of representative democracies. In theory, citizens can use their vote to hold incumbents accountable and to choose new representatives that are competent and aligned with their preferences (Ferejohn, 1986; Besley and Coate, 1997). In practice, elections only generate such desirable outcomes insofar as voters rely on adequate information to make their choice (e.g., Delli Carpini and Keeter, 1997; Ferraz and Finan, 2008). Whether or not that is the case can have dramatic social and economic consequences, since the quality and ideology of elected officials tend to affect the policies they implement (e.g., Pettersson-Lidbom, 2008; Besley et al., 2011). It is thus critical to assess which information voters use in their choice.

One longstanding view is that the weeks immediately preceding elections represent a crucial period, during which the electorate is flooded with information (e.g., Holbrook, 1996). Elections often feature new parties and candidates, and even the propositions and track records of those who have stood for office before may have changed since then. Campaign information can help voters assess incumbents, compare the qualities and positions of all candidates, and reconsider their own policy preferences. While candidates expend great effort to communicate with voters, interpersonal discussions and the coverage of the campaign by the media also provide rich information. An alternative view is that campaigns have minimal effects as most people have decided whom to vote for long in advance, based on group identities and party attachments (e.g., Lazarsfeld et al., 1944).

We disentangle these contrasting views using two-round surveys in 62 elections around the world since 1952. Our analysis is guided by the idea, consistent with both views, that campaigns' influence will largely depend on the relative importance voters give to their longstanding partisan leanings vs. election-specific information on the party platforms and the candidates of the day.

Our paper makes three distinct contributions. First, we use a novel method to determine the fraction of people that form their vote choice in the last two months before an election, and measure heterogeneity over time and across countries and voters with varying levels of preexisting knowledge and party attachments. Second, we explore whether changes in vote intentions are driven by changes in voters' beliefs about candidates or by other mechanisms, such as changes in their policy preferences or in issue salience. Third, we use an event study to assess how TV debates - which provide rich information on the candidates - contribute to vote choice formation.

Existing studies have generally sought to isolate the impact on vote choice of one particular source of information, such as newspapers or television (e.g., DellaVigna and Kaplan, 2007; Martin and Yurukoglu, 2017), or one specific type of campaign communication, such as field visits or TV 
ads (e.g., Pons, 2018; Broockman and Kalla, 2018). By contrast, our first set of results relate to the overall impact of information received during campaigns. ${ }^{1}$ The more election-specific information voters incorporate in their choice of candidate, the more likely they should be to make up their mind during the campaign. To estimate the share of the electorate who form their vote choice only shortly before elections, we assembled a dataset of nationally representative surveys conducted around 62 elections from 1952 to 2017 in ten countries: Austria, Canada, Germany, Italy, the Netherlands, New Zealand, Sweden, Switzerland, the United Kingdom, and the United States. The dataset includes a total of 253,000 observations. All of the surveys entailed interviewing a new set of people every day prior to the election to elicit their vote intention, then surveying these same people again after the election to record their actual vote choice. By comparing voters' responses in the two rounds, we can ascertain whether they had already settled on their final choice by the time of the pre-electoral survey without having to rely on their own recollection of the date when they formed their decision, unlike previous research. In addition, most of our data come from surveys that allocated respondents' survey date randomly, facilitating the interpretation of outcome differences over time.

We find that the fraction of people with identical vote declaration pre- and post-election increases by 17 percentage points over the 60 days leading up to the election, from a baseline of $71 \%$. On the last day before the election, $12 \%$ of voters still do not know (or will not say) whom they will vote for, or state a different vote intention than their ultimate choice. This brings the total fraction of voters making up their mind during the final two months of campaigns to between $17 \%$ (if none of these voters surveyed on the last day are really last-minute deciders) and 29\% (if all of them are). Within a given election, younger and less educated voters are more influenced by campaign information, and voters who identify strongly with a party less so. Across elections, the influence of campaigns on vote choice has been relatively stable for the last 70 years, but it varies substantially from one country to another. Notably, vote choice consistency increases less in the two months preceding the election in the U.S. than in all the other countries in the sample, even though American campaigns spend much more money to communicate with voters. One possible explanation is that the U.S. two-party system is characterized by strong partisan attachments, making vote choices less malleable than in multiparty settings.

\footnotetext{
${ }^{1}$ As is common in the literature, we use "campaign" interchangeably with "electoral season" to designate the period preceding an election and to refer to all factors which may influence voters in that period, including both candidates' campaigns and factors beyond their control.
} 
The increase in individual vote choice consistency is concomitant with aggregate trends in the relative strength of competing candidates. We compute each candidate's daily predicted vote share based on the vote intentions of respondents surveyed on that day, and compare it to their final vote share measured in the post-electoral survey. The total distance between predicted and final vote shares decreases by about 5 percentage points over the last 60 days before the election, indicating that vote choice formation during the campaign season can change elections' outcomes. We argue that our results are primarily driven by information acquired and/or processed during the final two months of campaigns and, therefore, that they provide a good measure of this information's overall impact on vote choice formation.

Our second set of results sheds light on the mechanisms through which information affects people's vote choice. To the extent that changes in vote intention are due to election-specific information on competing candidates and on parties' current platforms, one may first expect changed beliefs on candidates to be an important mediating factor. In fact, using a set of questions asked in both the pre- and post-electoral surveys, we find that the consistency in beliefs concerning candidates' quality and the issues they stand for increases over the campaign. This type of beliefs seems to matter more than beliefs on the relative chances of the contenders that could lead to strategic voting.

Second, voters may be primed by campaign communication to think about certain policy issues and they may change their vote choice after reassessing their distance with the different candidates based on these issues. We find that the consistency between the issue that respondents consider the most important in the pre- and post-electoral survey increases by more than half of the increase in vote choice consistency.

Third, information shared during the electoral season may affect voter choice by changing their policy preferences. However, using policy questions asked again both pre- and post-election, we do not find any increase in the consistency in policy preferences expressed before and after an election. Furthermore, we show that increases in both daily mean issue salience consistency and belief consistency are associated with strong increases in mean vote choice consistency, contrasting with the lack of significant relationship between the latter and policy preference consistency.

Our third set of results provides evidence on the relative importance of different sources of information. Given the mediating effects of beliefs on candidates, a plausible hypothesis is that changes in these beliefs and, in turn, changes in vote intentions occur as a result of events in which the candidates themselves communicate with voters such as televised debates. TV debates between 
candidates for president or prime minister are now part of the electoral cycle in many countries, and have a strong apparent potential to inform voters: they give direct and simultaneous exposure to candidates and allow voters to compare their policy positions and performance. Debates draw larger audiences than any other campaign event and they can also influence non-watchers through subsequent discussions, social media posts, and media commentaries.

We use an event-study approach pooling $56 \mathrm{TV}$ debates in 31 elections and seven countries of our sample. We do not find any significant impact of TV debates on individual consistency between vote intention and vote choice. The fact that we investigate effects on vote choice consistency rather than vote intentions means that we would even uncover effects going in opposite directions for different debates (e.g., with some debates benefitting the incumbent and others a challenger) or different people (e.g., with some voters rallying behind one candidate and others their opponent), which could otherwise remain undetected - yet we find none. Furthermore, at the aggregate level, debates do not significantly affect the distance between predicted and final vote shares. Our null effects are precisely estimated. Considering the $95 \%$ confidence intervals, we find that, on average, a TV debate contributes no more than $3 \%$ of the total increase in vote choice consistency over the final two months of campaigns and $2 \%$ of the total decrease in the distance to final vote shares.

Remarkably, we do not find that debates contribute to vote choice formation for any group of voters - including those who report watching them and those most likely to form their vote choice shortly before the election - or when focusing on types of debates which could be expected to be more impactful: the first debate held during the campaign, or debates held in close races, fluctuating races, or multiparty systems. Finally, debates do not impact the predicted vote share even of lesser-known candidates, who benefit from the campaign the most overall.

After documenting the null effects of TV debates, we ask whether elections are swayed by shocks such as natural and technological disasters, which, by contrast, occur independently from the campaign. We focus on 27 disasters that occurred before elections in the sample and are included in the EM-DAT International Disasters Database. Using the same event-study design, we do not find that disasters contribute to vote choice formation more than TV debates, in the elections included in the sample.

From the null effects of both TV debates and disasters, we conclude that the type of information that impacts voter choice the most is likely neither information directly provided by candidates, nor shocks exogenous to the campaign and on which candidates do not have any control, but information provided throughout the campaign by third parties. As the election 
approaches, we observe that voters receive a growing stream of information from the media, campaign activists, and discussions with family members, friends, and coworkers. While candidates can try to influence these sources of information (e.g., by communicating with the media), they do not control them entirely.

Our paper makes three important contributions to the large literature on the effects and drivers of persuasive communication (DellaVigna and Gentzkow, 2010).

First, we estimate the impact on vote choice of a major type of partisan communication, on which the existing evidence is not conclusive: TV debates. A large number of studies explore the effects of TV debates by focusing on a unique election or a small number of races and comparing individual vote intentions, aggregate polls shares, or betting odds before and after debates (e.g., Shaw, 1999; Hillygus and Jackman, 2003; Shaw and Roberts, 2000). While many studies find modest or null effects, others conclude that debates truly matter (Benoit et al., 2003; McKinney and Carlin, 2004; Birdsell, 2017). However, these studies' simple pre/post difference designs fail to control for underlying trends. By contrast, we take advantage of the large number of debates which took place in the periods covered by our surveys and of the variation in their timing to flexibly control for the time to the election. This novel strategy provides more reliable estimates of debates' impact. The fact that our event study includes debates held in a large number of elections and countries also increases our statistical power and the external validity of our estimates well beyond that of any preexisting work.

Our study is related to recent experimental evidence on a different type of debate: non-televised debates opposing parliamentary candidates in low-income democracies (Brierley et al., 2019; Bidwell et al., 2019). Scarce political information characterizing these studies' contexts may help explain the substantial effects on vote choices they find. Using randomized experiments to measure the impact of presidential or prime-ministerial TV debates has proven more difficult. Mullainathan et al. (2009) encourage a random selection of New York City voters to watch the final 2005 mayoral election debate and do not find any significant impact on opinions on candidates but acknowledge that subsequent discussions and media commentaries may explain this null result. Instead, Fridkin et al. (2007) use a lab experiment to measure both the impact of watching live the final 2004 U.S. presidential TV debate and of media's instant analysis following it. Measuring participants' immediate reactions, the authors report large effects on candidates' evaluations. In contrast, we find null effects on vote intentions one to three days afterward, suggesting that debates' effects quickly fade away. 
While most existing research on vote choice seeks to isolate the impact of a specific source of information, our second contribution is to provide an estimate of their overall influence in the last two months before an election. We build on Wlezien and Erikson (2002) and Jennings and Wlezien (2016), who show that polls become increasingly predictive of actual results as the election comes closer. Our finding that the distance between predicted and final vote shares decreases over time replicates this result in our set of elections. Using individual-level two-round surveys instead of aggregate polls enables us to: determine the fraction of voters who arrive at their final choice during the campaign, which is generally larger than the reduction in the distance between predicted and final vote shares; compare the patterns of vote choice formation across different types of voters; and investigate the mechanisms through which information affects vote choice.

Most prior work studying the timing of vote decisions with individual-level data uses respondents' own recall of the date when they made their decision or their declared level of certainty about their vote intention (e.g., Chaffee and Choe, 1980; Fournier et al., 2004). But voters surveyed before the election may not know how they will respond to information that is yet to come. Post-election recalls are also prone to error, due to people failing to remember when they made their decision or not consciously recording this moment in the first place. A smaller set of studies including Henderson and Hillygus (2016) define the time of decision as the date from which panel respondents select the same candidate across all subsequent interviews. While these studies, like ours, are based on the comparison of respondents' answers over time, they use data limited to a single election and cannot provide daily estimates of vote choice consistency, which are our main object of investigation. In addition, they focus on the level of consistency, which may be biased by misreporting (see Section III.A), rather than its change.

Finally, we build on prior work showing that information received by voters can affect their vote choice by changing their beliefs, whether on candidates or on the state of the economy (e.g., Gelman and King, 1993; Kendall et al., 2015). Recent studies also document instances of people changing their actual preferences based on campaign interactions (Minozzi et al., 2015). Overall, we show that campaign information tends to affect vote choices and election outcomes by changing beliefs and issue salience more than policy preferences.

The remainder of the paper proceeds as follows. Section II describes our data. Sections III and IV study the formation of vote choice, beliefs, policy preferences, and issue salience in the campaign. Section V estimates the impact of debates and disasters on these outcomes, and Section VI concludes. 


\section{DATA}

\section{II.A Campaign Surveys}

We assembled a new dataset of nationally representative surveys conducted around 62 elections in ten countries, from 1952 to 2017. The data come from the American National Election Studies (1952 to 2016), the Canadian Election Studies (1988 to 2015), the British Election Studies (2001 to 2016), the New Zealand Election Studies (1996 to 2002), the Dutch Parliamentary Election Studies (1998 to 2006), the National Annenberg Election Surveys (2000 to 2008), the German Longitudinal Election Studies (2009 to 2017), the Swiss Electoral Studies (2011 and 2015), the Italian National Election Studies (2013), the Austrian National Election Studies (2013), and the Swedish National Election Studies (2014). ${ }^{2}$ We keep all respondents surveyed 60 days before the election or less as only few surveys started earlier. Integrating the responses collected with independent questionnaires into a common empirical framework marks an important effort.

A few surveys cover multiple elections because multiple offices were on the ballot on the same day (for instance President and Member of Congress in the U.S.) or because voters can cast multiple ballots (for instance Germany's first and second votes). We define each of these offices or ballots as a separate election. Conversely, the 2000, 2004, and 2008 U.S. presidential elections are covered both by the American National Election Studies (henceforth ANES) and the National Annenberg Election Surveys (henceforth NAES). Appendix Table B.1 shows the full list of elections, their date, type, voting rule, as well as key features of the corresponding surveys. $27 \%$ of the elections were for President, 58\% for lower house, 5\% for upper house, 5\% for governor, $2 \%$ for European Parliament, and $3 \%$ were referenda. $76 \%$ used the plurality rule and $24 \%$ the proportional rule. We refer indifferently to the individual candidates competing in plurality elections and party lists competing in proportional elections as "candidates."

To build this dataset, we searched for all electoral surveys around the world that satisfy three criteria. First, they must survey respondents twice: once before the election, to elicit their vote intention, and once afterwards, to record their ultimate choice. We observe 253,000 pre-election vote intentions (including people who say they do not know who they will vote for) from 217,000 unique respondents, and post-electoral responses for $201,000(80 \%)$ of these observations. ${ }^{3}$ The

\footnotetext{
${ }^{2}$ The full list of links at which the surveys can be downloaded and the corresponding references are available in Appendix B.1.

${ }^{3}$ The fraction of respondents surveyed twice should not be read as a success rate in re-surveying respondents. Indeed, while most surveys attempt to reach all respondents surveyed before the election a second time afterwards,
} 
median length between the election and the post-electoral survey was 14 days on average. Second, surveys must interview a new set of respondents every day until the election and record the corresponding date. Third, respondents surveyed on different dates must be as similar as possible.

To satisfy the third criterion, most of our sample comes from rolling cross-sections - surveys that allocate each respondent's survey date randomly. This design implies that the set of respondents surveyed on any particular day can be treated as an independently drawn random sample and it reduces the risk that answers from respondents surveyed on different dates differ because of differences in their characteristics (Johnston and Brady, 2002). To increase statistical power, we complemented our sample with surveys that were not designed as rolling cross-sections but are statistically close to daily random sampling. Specifically, we include surveys that do not show too large imbalances in pairwise comparisons of daily respondents' observable characteristics (Appendix A.1 for additional details).

Our key variables of interest are respondents' pre- and post-election vote declaration. We further use questions on policy preferences, issue salience, and beliefs on candidates that were asked in the same way before and after the election, allowing us to use the same specifications as for the formation of vote choice. We identified 46 questions from 12 surveys that recorded the policy preferences of a total of 106,000 respondents, and 76 questions from 11 surveys that elicited the beliefs of 112,000 respondents on the quality and policy positions of competing candidates. The full list of these questions is available in Appendix Tables B.3 and B.4. To measure changes in issue salience, we use open-ended questions in 12 surveys asking a total of 61,000 respondents which issue they find the most important in this election. We rank all possible answers in all surveys under 10 categories: economic policy, social policy, foreign policy, public safety, civil rights, moral values, institutions, politics, electoral issues, and other issues.

Finally, we keep the following covariates for heterogeneity and other analyses and standardize them across surveys: respondents' education, age, gender, income, and employment status, which are recorded by the vast majority of surveys, as well as their consumption of different media, the party they identify with, the strength of their party identification, their propensity to watch TV debates and read polls, whether they have recently been contacted or visited by a party, and how frequently they have discussions about politics, when available (Appendix Table B.2). To construct all our variables homogeneously across surveys, we follow a set of common rules, detailed in Appendix B.2.

others only attempt to re-survey a subset of pre-election respondents, bringing the fraction down. Conversely, a few surveys only release data for respondents successfully surveyed twice, bringing the fraction up. 


\section{II.B Complementary Data}

We supplement the survey data with information that we collected from separate sources including ParlGov and the Manifesto Project on competing candidates' party, their incumbency status, and whether they were on the ballot for the first time or not (Appendix Table B.5).

In addition, we systematically searched for the existence and dates of all TV debates between presidential or prime-ministerial candidates during the periods covered by the surveys. We used and cross-checked the following sources: academic papers, TV channels archives, newspaper articles, and Wikipedia. The full list of debates included in the analysis is shown in Appendix Table B.6.

Finally, we used the EM-DAT International Disasters Database to identify natural disasters (e.g., wildfires and floods) and technological disasters (e.g., industrial and transportation accidents) that occurred before the elections in the sample. We provide more information on EM-DAT in Appendix B.3, and show the full list of disasters included in the analysis in Appendix Table B.7.

\section{The Formation of Vote Choice}

Information released during campaigns may help voters decide whom to vote for and, in turn, increase the predicted vote shares of some candidates at the expense of others. Therefore, to assess how much campaign information matters, we use two distinct metrics: one based on individuallevel data, and measuring how many individuals make up their mind in the last two months of the campaign, the other assessing how much aggregate vote shares change during this period.

Importantly, our goal is to measure the overall impact of all campaign information, not the quantity of it. This information may come from many sources, ranging from campaign organizations' messaging to discussions with family and friends. While previous work has sought to isolate the effect of specific types of information, studying the timing of vote choice formation enables us to account for all information shared during campaigns, without having to observe which particular pieces of information people receive.

Our approach would overestimate the impact of campaigns if some individuals made up their mind during the electoral season for other reasons than the information they receive. To provide evidence on the predominant role of campaign information, we check whether vote choice formation is concentrated when and where the campaign is most intense and salient. Furthermore, campaign information should be expected to matter more for voters who have less preexisting political knowledge and less for those who identify strongly with a party. Similarly, one may 
expect campaign effects to be stronger in countries with multiparty systems, where partisan attachments are weaker and vote choices may be more malleable than in countries with a two-party system like the U.S. To test these predictions, we compare campaign effects across voter types and across countries.

We conclude this section by addressing possible threats to the validity of our results and discussing alternative interpretations.

\section{III.A Individual Vote Choice Formation}

The fraction of people who decide which candidate to vote for in the last weeks before an election is difficult to estimate directly. Indeed, it is hard for voters to assess the likelihood that they will stick to their vote intention, ex ante, or to recall the exact date they made up their mind, ex post. We overcome this issue with a novel method using questions recording vote intention and vote choice, which are easier to respond to, and comparing each respondent's answers to both.

Formally, we define vote choice consistency as a dummy equal to 1 if the respondent's preand post-election vote declaration coincide and 0 if they differ or if the respondent said they did not know whom they would vote for in the first survey. Voters receiving a stream of information and incorporating it into their evaluation of candidates should be expected to show increasing consistency between their pre-election vote intention and their vote choice over time for two reasons. First, voters surveyed later in the campaign will have received more information. Accordingly, their posterior on candidates will be more precise, making them more likely to state a vote intention and less likely to change it afterwards. ${ }^{4}$ Second, the later voters are given the pre-electoral survey, the less time there is for them to receive new information liable to change their vote intention afterwards.

We estimate the share of respondents surveyed on any day who will vote according to their intention with the following OLS specification:

$$
C_{i t}^{e}=\sum_{t=-60}^{-1} \beta_{t} D_{t}+\alpha^{e}+W_{i t}^{\prime} \lambda+u_{i t}^{e},
$$

\footnotetext{
${ }^{4}$ Competing parties may provide conflicting information, leading some voters to remain uncertain about their choice until late in the campaign. However, even this type of information may strengthen others' confidence in their choice. For instance, voters who initially lean towards a certain candidate may feel more certain about their choice after that candidate responds to a competitor's attacks. Furthermore, pieces of information from sources other than parties and candidates may be less likely to cancel each other out.
} 
where $C_{i t}^{e}$ is the vote choice consistency of respondent $i$, surveyed for the first time $t$ days before election $e, D_{t}$ 's are 60 fixed effects indicating the number of days relative to the election, $\alpha^{e}$ are election fixed effects, and $W_{i t}$ is a vector of controls. $W_{i t}$ includes fixed effects for the day of the week in which the pre-electoral survey took place and for the number of days separating the postelectoral survey from the election and, in some specifications, sociodemographic characteristics. ${ }^{5}$

The key coefficients of interest are the $\beta_{t}$ 's. We center all control variables around their mean value at $t=-1$ and do not include a constant, so that $\beta_{-1}$ is equal to the outcome's sample average among respondents surveyed one day before the election and, for any $t \neq 1, \beta_{t}$ is the (conditional) expected outcome for respondents surveyed $t$ days before. Our sample includes all respondents surveyed both before and after the election who said that they intended to vote, in the first survey, and who reported that they actually voted and gave a vote choice declaration, in the second. Standard errors are clustered at the survey level. ${ }^{6}$

We plot the $\beta_{t}$ coefficients against time in Figure I. We find that 60 days before the election, $71 \%$ of voters state a vote intention corresponding to their final vote choice, suggesting that they vote based on earlier information or along party lines. The fraction of people with identical preand post-election vote declaration increases to $88 \%$ during the final two months of campaigns. The $12 \%$ of voters surveyed on the last day before the election whose vote intention and vote choice remain different are of two types: half of them still do not know (or will not say) whom they will vote for, and the other half state a vote intention but later report a different vote choice.

Next, we estimate the following equation to measure the daily average increase in vote choice consistency and test whether the trend is linear or convex:

$$
C_{i t}^{e}=\beta t+\delta t^{2}+\alpha^{e}+W_{i t}^{\prime} \lambda+u_{i t}^{e}
$$

where $t$ is defined as negative the number of days separating the pre-electoral survey from the election, so that higher values of $t$ indicate closer proximity to the election. Convexity should be expected if the stream of information available to voters increases as the election gets closer, either due to increasing demand (by voters eager to make up their mind) or supply (by candidates, the media, friends and family members, etc.). The results are reported in Table I. We find that

\footnotetext{
${ }^{5}$ In place of election fixed effects, we include two separate fixed effects (or survey*election fixed effects) for U.S. elections covered both by ANES and NAES, to also control for survey effects.

${ }^{6}$ Our results are robust to allowing for correlation of the error terms with the wild cluster bootstrap procedure, as shown in Appendix C.1, and to clustering the standard errors at the level of the election date, as shown in Appendix C.2. Respondents in the 2008 wave of both the ANES and the NAES are then included in the same cluster, for instance.
} 
Figure I: Individual vote choice consistency, vote intention, and conditional consistency

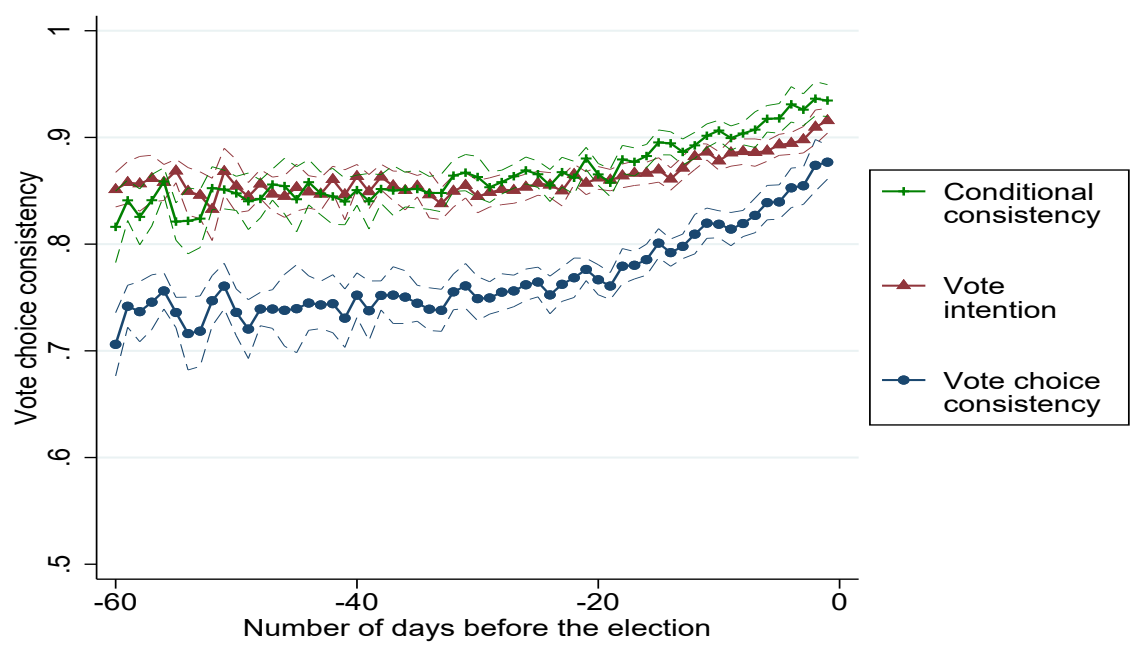

Notes: We show point estimates and 95\% confidence intervals from specifications in the form of equation [1], regressing vote choice consistency $(\mathrm{N}=200,916)$, vote intention $(\mathrm{N}=253,489)$, and conditional vote choice consistency $(\mathrm{N}=178,176)$ on 60 fixed effects indicating the number of days relative to the election and control variables listed in the text.

each additional day increases vote choice consistency by 0.25 percentage point on average, an estimate that is significant at the $1 \%$ level (column 1), and that the increase in consistency follows a convex pattern, with a significant acceleration in the last weeks preceding the election (column 2). This pattern confirms that the process of vote choice formation is concentrated shortly before the election, when the intensity and salience of the campaign are at their peak. ${ }^{7}$

Our survey data may suffer from self-reporting biases. We address this concern in two ways. First, the fact that we define vote choice consistency by comparing the intention and ultimate choice of the same individual eliminates any bias present in both declarations. Most expressions of survey demand effects and of social acceptability bias likely fall in this category.

Second, one may still be concerned by the possibility that some voters misreport their vote intention while reporting their actual vote choice, or the reverse. In particular, voters may misreport their vote choice because they forgot, or out of the desire to say they voted for the winner (e.g., Wright, 1993), leading to an inflated fraction of inconsistent voters measured on any

\footnotetext{
${ }^{7}$ Furthermore, Appendix Figure A.1 replicates Figure I for a period that is twice as long, by including respondents surveyed more than 60 days before the election in 18 surveys in our original sample and in "pre-campaign" surveys that preceded six of our pre-electoral surveys (listed in Appendix Table B.8). We do not observe any increase in vote choice consistency between 120 and 60 days before the election. The daily change in vote choice consistency in this period is non-significant and ten times smaller than during the last 60 days before the election (Appendix Table A.1).
} 
Table I: Vote choice consistency and distance to final vote shares

\begin{tabular}{|c|c|c|c|c|c|c|c|c|}
\hline & \multicolumn{2}{|c|}{$\begin{array}{l}\text { Vote choice } \\
\text { consistency }\end{array}$} & \multicolumn{2}{|c|}{$\begin{array}{c}\text { Vote } \\
\text { intention }\end{array}$} & \multicolumn{2}{|c|}{$\begin{array}{l}\text { Conditional } \\
\text { consistency }\end{array}$} & \multicolumn{2}{|c|}{$\begin{array}{l}\text { Distance between predicted } \\
\text { and final vote shares }\end{array}$} \\
\hline & (1) & (2) & (3) & (4) & (5) & (6) & (7) & (8) \\
\hline Time & $\begin{array}{c}0.0025^{* * *} \\
(0.0003)\end{array}$ & $\begin{array}{c}0.0061^{* * *} \\
(0.0008)\end{array}$ & $\begin{array}{c}0.0010^{* * *} \\
(0.0002)\end{array}$ & $\begin{array}{c}0.0031^{* * *} \\
(0.0005)\end{array}$ & $\begin{array}{c}0.0018^{* * *} \\
(0.0003)\end{array}$ & $\begin{array}{c}0.0038^{* * *} \\
(0.0007)\end{array}$ & $\begin{array}{c}-0.0008^{* * *} \\
(0.0002)\end{array}$ & $\begin{array}{c}-0.0013^{* * *} \\
(0.0004)\end{array}$ \\
\hline Time $^{2}$ & & $\begin{array}{c}0.0001^{* * *} \\
(0.0000)\end{array}$ & & $\begin{array}{c}0.0000^{* * *} \\
(0.0000)\end{array}$ & & $\begin{array}{c}0.0000^{* * *} \\
(0.0000)\end{array}$ & & $\begin{array}{l}-0.0000 \\
(0.0000)\end{array}$ \\
\hline Observations & 200916 & 200916 & 253489 & 253489 & 178176 & 178176 & 3125 & 3125 \\
\hline$R^{2}$ & 0.070 & 0.071 & 0.072 & 0.073 & 0.041 & 0.041 & 0.520 & 0.523 \\
\hline Mean at day -1 & 0.8768 & 0.8768 & 0.9157 & 0.9157 & 0.9346 & 0.9346 & 0.0324 & 0.0324 \\
\hline Election fixed effects & $\mathrm{x}$ & $\mathrm{x}$ & $\mathrm{x}$ & $\mathrm{x}$ & $\mathrm{x}$ & $\mathrm{x}$ & $\mathrm{x}$ & $\mathrm{x}$ \\
\hline Individual controls & $\mathrm{x}$ & $\mathrm{x}$ & $\mathrm{x}$ & $\mathrm{x}$ & $\mathrm{x}$ & $\mathrm{x}$ & & \\
\hline Aggregate controls & & & & & & & $\mathrm{x}$ & $\mathrm{x}$ \\
\hline
\end{tabular}

Notes: Standard errors clustered at the survey level are in parentheses $(* * *, * *, *$ indicate significance at 1,5 , and $10 \%$, respectively). Time is defined as negative the number of days separating the pre-electoral survey from the election. In columns 1 through 6, we use one observation per respondent and estimate a specification in the form of equation [2]. In columns 7 and 8, we use one observation per election per day and estimate a specification in the form of equation [5]. Individual controls include fixed effects for the day of the week in which the pre-electoral survey took place and, in columns $1,2,5$, and 6 , fixed effects for the number of days separating the post-electoral survey from the election. Aggregate controls include fixed effects for the day of the week in which the pre-electoral survey took place and the average number of days separating the post-electoral survey from the election. In this table and others, respondents included in the sample (and, therefore, sample sizes) vary across outcomes, as explained in the text.

day. However, vote choice misreporting should not bias our estimate of the change in consistency over time. To see why, first note that taking the difference between the vote choice consistency of respondents surveyed at different dates eliminates any constant level of misreporting in and of itself. Misreporting could still vary over time: for instance, response accuracy could decrease with the time between the election and the post-electoral survey, which is in turn correlated with the date of the pre-electoral survey (Appendix Figure A.2). But we address this possibility by controlling flexibly for the post-electoral survey lag. Conditional on the dummies for the number of days separating the post-electoral survey from the election, included in equations [1] and [2], vote choice misreporting should be uncorrelated with the timing of the pre-electoral survey, and the estimated change in consistency should be fully accurate. ${ }^{8}$

\footnotetext{
${ }^{8}$ Some forms of vote choice misreporting may depend on the distance between the pre- and the post-electoral survey more than the distance between the election and the post-electoral survey. For instance, some respondents may try to give a post-electoral answer identical to their pre-electoral answer, instead of truthfully reporting whom they voted for. But providing identical answers may be easier when the two surveys were closer to each other. Therefore, in Appendix Figure A.3, we replace the dummies for the post-electoral survey lag with dummies for the number of days separating the two surveys. Reassuringly, we observe a similar increase in vote choice consistency over time as in Figure I.
} 
In sum, our method insulates the estimated 17 percentage point increase in vote choice consistency from 60 days to one day before the election from multiple plausible sources of reporting bias. In contrast, we may overestimate the share of voters who remain inconsistent on the day before the election if some of them misreport their vote choice but not their vote intention. We conclude that the fraction of voters forming their vote choice during the last two months before the election is between $17 \%$ (if none of the $12 \%$ of inconsistent voters surveyed the last day before the election are really last-minute deciders) and 29\% (if all of them are).

It is instructive to compare these estimates with the fraction of voters who self-report making up their mind during the campaign. We identified post-electoral questions asking respondents to recall the timing of their decision in 45 of the 62 elections in our sample. Overall, $48 \%$ of the voters in these elections said that they decided whom to vote for during the campaign, which is much larger than our estimates. While our estimates indicate strong campaign effects, trusting voters' recollection of the moment when they formed their decision would exaggerate the importance of campaigns. ${ }^{9}$

\section{III.B Stating a Vote Intention and Conditional Consistency}

The increase in vote choice consistency can result either from an increased fraction of people stating any vote intention or from increased vote choice consistency conditional on stating one. Indeed, campaign information may both help undecided voters pick a candidate and change the vote intention of those who already had a candidate in mind. Accordingly, we estimate equation [1] using as outcome a dummy equal to 1 if the respondent states a vote intention and 0 otherwise. We then restrict the sample to respondents stating a vote intention and use a dummy equal to 1 if their final vote choice corresponds. ${ }^{10}$

\footnotetext{
${ }^{9}$ At the individual level, mistakes go in both directions, which could further lead to mischaracterize the types of voters most influenced by campaigns. Using our main sample, we find that $11 \%$ of the voters who report that they knew whom they would vote for before the campaign had still not converged to their final vote choice by the time of their pre-electoral interview, 60 days or less before the election. Conversely, $66 \%$ of the respondents interviewed as part of the surveys starting more than two months before the election, and who said that they made their vote choice during the campaign, were already consistent by the time of their pre-electoral interview, 120 to 60 days before the election.

${ }^{10}$ Our sample for the first outcome includes all respondents surveyed before the election who said that they intended to vote. We do not control for fixed effects for the number of days separating the post-electoral survey from the election when using this outcome. For the second outcome, our sample includes all respondents surveyed before and after the election who said that they intended to vote and stated a vote intention, in the first survey, and who reported that they actually voted and gave a vote choice declaration, in the second.
} 
As shown in Figure I, both the probability of stating a vote intention and conditional vote choice consistency increase in the last two months before the election, up to $92 \%$ and $93 \%$ respectively. Furthermore, both outcomes follow an increasing and convex pattern similar to vote choice consistency (Table I, columns 3 through 6).

We derive two key insights from these results. First, the increase in vote choice consistency shown in Section III.A could be generated by multiple processes of information aggregation, including one where people's vote choice is entirely swayed by the latest information. However, voters' increasing likelihood to express a vote intention suggests that they accumulate information and only state a vote intention when they feel sufficiently confident. Consistent with this view, people's certainty about their vote intention increases as well (Appendix Figure A.4). Second, the increase is larger for conditional consistency than for stating a vote intention, suggesting that vote choice formation during the campaign is driven by a decrease in the fraction of voters changing their mind at least as much as by a decrease in the fraction of undecided voters.

\section{III.C Heterogeneity across Countries and Election Years}

To test whether the increase in vote choice consistency measured in Section III.A varies across countries and over time, we estimate equation [2] for each election separately, without quadratic term. Figure II plots each election-specific daily increase in vote choice consistency against election year, along with country-level linear fits.

The extent to which people form their vote choice during the last two months before the election has been remarkably stable over time in the U.S. and in Canada, the two countries with the largest number of elections in the sample (44\% and 16\%, respectively, accounting for $28 \%$ and $13 \%$ of respondents). It has decreased slightly, in some countries with fewer elections (New Zealand and the U.K.), but increased slightly in others (Germany, the Netherlands, and Switzerland). Overall, the propensity to form one's vote choice in the campaign season has been relatively stable for the last 70 years, suggesting that campaigns continue to matter as much as before. ${ }^{11}$ This constancy is all the more striking as campaign methods have undergone major changes in this period, including

\footnotetext{
${ }^{11}$ Differences in average daily increase in vote choice consistency within countries and over time could partly be affected by differences in survey length. Indeed, our main specifications keep all respondents surveyed 60 days before the election or less, but some surveys start later than that, and we have shown in Table I that vote choice consistency increases faster shortly before the election. To address this concern, we identify the minimum number of days covered by any survey, country by country, and then restrict the sample to the respondents surveyed on or after that countryspecific minimum. Reassuringly, Appendix Figure A.5, obtained after this homogenization, shows stable patterns over time, similarly as Figure II.
} 
Figure II: Increase in vote choice consistency across countries and over time

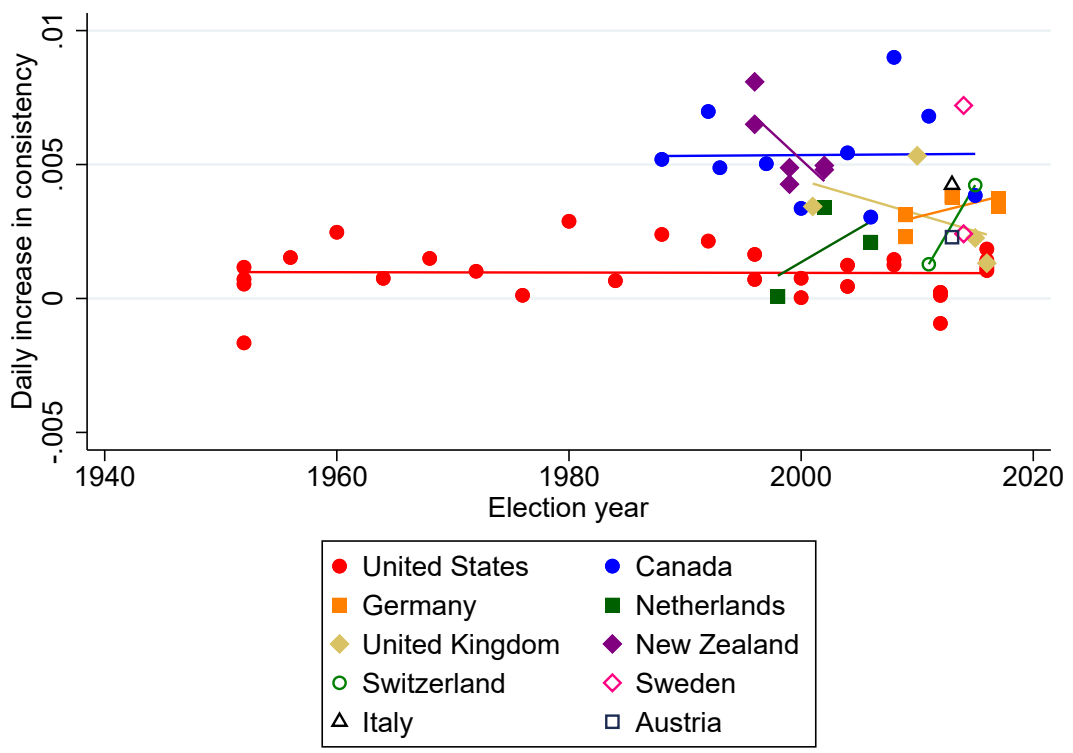

Notes: We show point estimates from election-level regressions of consistency on time against election year. Each point comes from a separate regression. Each regression controls for fixed effects for the day of the week in which the pre-electoral survey took place and for the number of days between the post-electoral survey and the election. Elections covered by two different surveys are represented by two different point estimates. We also show country-level linear fits of the point estimates, estimated by regressing the point estimates on election year, for all countries with two election years or more. $\mathrm{N}=65$.

the long decline and recent revival of campaign strategies focusing on the mobilization of nonvoters rather than the persuasion of active voters (Panagopoulos, 2016), new types of media have emerged, and ideological polarization has risen in many countries (Boxell et al., 2022).

Second, even though campaigns are universally relevant, the size of the daily change in consistency differs substantially across countries. In particular, vote choice consistency increases less in the last two months before the election in the U.S. than in all other countries. To investigate the size and statistical significance of this difference, we use the following specification:

$$
C_{i t}^{e}=\beta t+\gamma \Omega^{e} t+\alpha^{e}+W_{i t}^{\prime} \lambda+u_{i t}^{e},
$$

where $\Omega^{e}$ is a dummy equal to 1 for the U.S. As shown in Appendix Table A.2, column 1, the fraction of voters forming their vote choice during the electoral season in U.S. elections remains positive and significantly different from 0 , but it is substantially lower (by about two thirds) than in other countries. The fact that electoral campaigns spend much more money per capita in the U.S. 
than in other countries makes this result particularly puzzling. We do observe a larger increase in vote choice consistency by about 50\% (which is significant at the $10 \%$ level) in U.S. swing states, where the campaign intensity is higher, than in non-swing states (Appendix Table A.3, column 1). However, even in swing states, vote choice formation during the campaign remains lower than in other countries.

A possible interpretation is that the vast majority of U.S. elections are bipartisan, making vote choices less malleable, while all other countries have multiparty systems. In multiparty settings, a larger number of candidates are on the ballot, sometimes including candidates of new parties, which campaign information helps voters learn about. The diversity of candidates and frequent changes in the party system result in weaker partisan attachments, and voters can change their vote choice by switching between candidates with similar ideologies without having to cross the aisle.

Since the U.S. two-party system stems in part from using the plurality rule, an alternative interpretation is that cross-country differences in vote choice formation come from differences not between party systems, but between plurality and proportional elections. For instance, switching sides could be more common in proportional elections if contests between party lists are less conflictual and polarized than face-offs between individual candidates. The presence in the sample of countries such as Canada and the U.K., which use plurality voting like the U.S. yet have multiparty settings, enables us to test this hypothesis. We do not find any significant difference between plurality and proportional rule elections, in specifications also controlling for time interacted with the U.S. dummy (Appendix Table A.2, column 3).

Other factors may drive the difference between the U.S. and other countries, including the fact that U.S. voters can start forming their choice during lengthy primary elections. Regardless of the exact reason, this result suggests that lessons from U.S. studies on drivers of voter behavior and electoral results, which account for most of the existing literature, may not extend to other contexts.

\section{III.D Heterogeneity across Voters}

Voters who identify strongly with a party are likely to vote for this party's candidate in any case and, so, to be less influenced than others by campaign information. We should thus expect their vote choice consistency to be high 60 days before the election and to show little increase afterward. By contrast, voters with low preexisting knowledge on candidates or on the state of the economy may show a larger increase in vote choice consistency before the election than those who are more 
knowledgeable if they are more impacted by the information they receive in this period, as Bayesian updating would predict.

To test these predictions, we compare the timing of vote choice formation for voters with different strengths of partisan attachments as well as different age and education levels, which are two strong correlates of political informedness (e.g., Angelucci and Prat, 2021). We also test for differences along three additional dimensions available across most surveys and known to predict vote choices: gender, income, and employment status.

We use the following specification separately for each characteristic:

$$
C_{i t}^{e}=\beta t+\Omega_{i}+\gamma \Omega_{i} t+\alpha^{e}+W_{i t}^{\prime} \lambda+u_{i t}^{e},
$$

where $\Omega_{i}$ is a dummy variable equal to 1 if respondent $i$ is a "type-a" voter - defined as male, above the median age of that survey's respondents, college-educated, above the median income, not employed, or strongly identifying with a party - and zero if they are "type-b" - female, below median age, not college-educated, below median income, employed, or not identifying with any party or only weakly so. $\gamma$ measures the differential increase in $C_{i t}^{e}$ for type-a voters over time.

We find that vote choice consistency increases substantially for all groups during the last 60 days before the election but that the increase is faster for younger voters and those without a college degree, and slower for those who strongly identify with a party (Appendix Table A.4, columns 1 through 6). These differences remain significant (at the 1\% level) in a specification including all characteristics and their interaction with the time trend (column 7). As predicted, other characteristics equal, voters with strong party identification are initially more consistent than those with weak or no party identification, and their vote choice consistency increases by 0.13 percentage point less per day on average (or $52 \%$ of the average daily change).

Conversely, voters without a college degree and younger voters show lower initial levels of vote choice consistency than college degree holders and older voters, but any additional day increases their consistency by an additional 0.05 and 0.07 percentage point respectively on average (20 and $28 \%$ of the average daily change). Much of the differential increase in vote choice consistency for younger voters is driven by voters below 25 years old: this group's vote choice consistency increases by an additional 0.06 percentage point on average, compared to other voters below median age (Appendix Table A.5). The fact that young voters are more susceptible to the influence of campaigns echoes previous studies showing that their political behavior and attitudes are more easily influenced by external factors (Neundorf and Smets, 2017; Cantoni and Pons, 2022). 
Finally, we find that the larger increases in vote choice consistency of younger and less educated voters as well as those without strong party identification are driven by larger changes in both the probability of stating a vote intention and vote choice consistency conditional on stating one (Appendix Table A.6). ${ }^{12}$

\section{III.E Convergence to Final Vote Shares}

Changes in individual vote intentions may partly compensate for each other: voters switching from intending to vote for candidate A to actually voting for candidate B will not affect aggregate vote shares and the outcome of the election if an equal number of voters follow the opposite trajectory. However, voters receiving the same information may update their vote intentions in the same direction, for instance towards candidates who prove to be more competent or to defend propositions closer to their preferences, generating broad shifts in candidate support. We should then expect increased individual consistency between vote intention and vote choice to be concomitant with a convergence from predicted vote shares to final vote shares.

We use vote intentions and vote choices reported in the pre- and post-electoral surveys to compute $\widetilde{V}_{c t}^{e}$, the predicted vote share of candidate $c$ in election $e$ among respondents surveyed at time $t$, and $V_{c t}^{e}$, the candidate's final vote share among the same respondents. ${ }^{13}$ We define the overall distance between predicted and final vote shares as $\Delta V_{t}^{e}=\frac{1}{2} \sum_{c}\left|\widetilde{V}_{c t}^{e}-V_{c t}^{e}\right|$, which corresponds to the minimal share of voters who had to change their vote intention after the pre-electoral survey to explain the difference between predicted and final vote shares.

We measure changes in this outcome with a specification in the form of equation [1], but using only one observation per election per day instead of one observation per individual response:

$$
\Delta V_{t}^{e}=\sum_{t=-60}^{-1} \beta_{t} D_{t}+\alpha^{e}+W_{t}^{e^{\prime}} \lambda+u_{t}^{e},
$$

\footnotetext{
${ }^{12}$ Using voters' own recollection of the date when they formed their decision fails to fully capture the heterogeneity of campaign effects across voter types. For instance, less educated voters are not more likely than college-educated respondents to report that they decided whom to vote for during the campaign (Appendix Table A.7).

${ }^{13}$ Our sample includes all respondents surveyed before and after the election who said that they intended to vote and stated a vote intention different from voting blank or null, in the first survey, and who reported that they actually voted and gave a vote choice declaration different from voting blank or null, in the second.
} 
Figure III: Distance between predicted and final vote shares

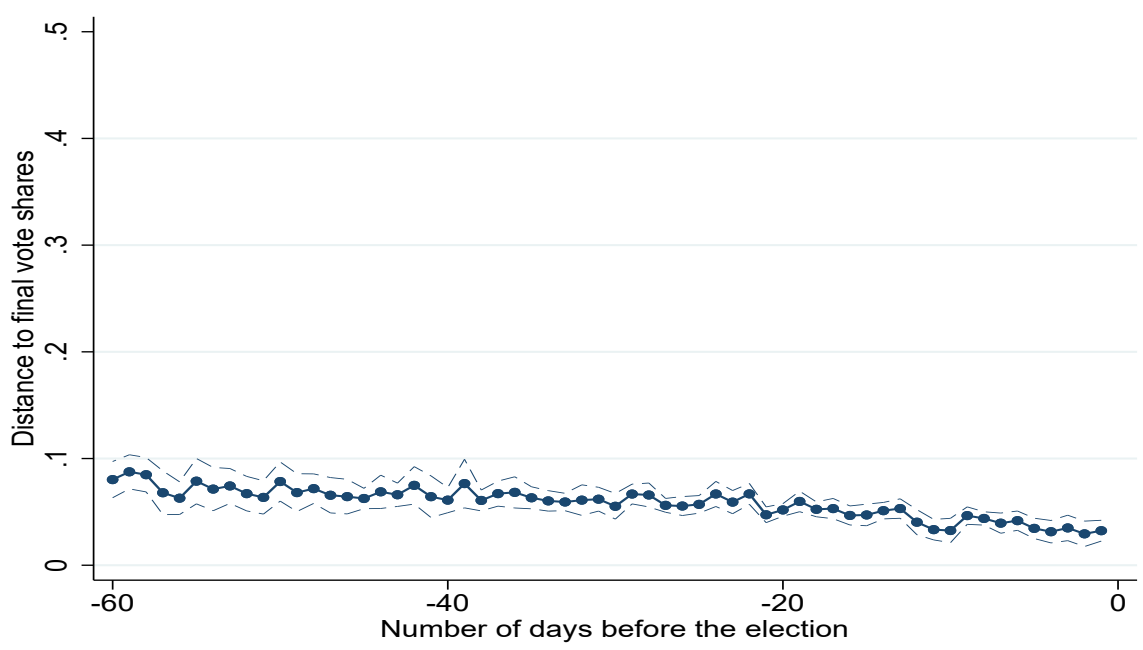

Notes: We show point estimates and 95\% confidence intervals from a specification in the form of equation [5], regressing the distance between predicted and final vote shares on 60 fixed effects indicating the number of days relative to the election and control variables listed in the text $(\mathrm{N}=3,125)$.

where $W_{t}^{e}$ includes pre-electoral survey day-of-the-week fixed effects, the average post-electoral survey lag among respondents who received the pre-electoral survey at time $t$, and, in some specifications, their average sociodemographic characteristics. ${ }^{14}$

We plot the $\beta_{t}$ coefficients on Figure III. The overall distance between predicted and final vote shares is more than halved, from 8 percentage points on average, 60 days before the election, to 3.2 percentage points the day before.

\section{III.F Threats to the Validity of Our Results}

By construction, our sample only includes respondents willing to answer surveys. In addition, we generally do not observe actual turnout and rely on self-reported participation to restrict our analysis to active voters. These two limitations generate possible concerns both for the external and internal validity of our results.

A first concern relates to the validity of our results beyond survey respondents. The fact that all our surveys are nationally representative should alleviate this concern somewhat. The

\footnotetext{
${ }^{14}$ To give more weight to vote shares measured more precisely, we weight each observation by $\frac{N_{t}^{e}}{N_{t}}$, where $N_{t}$ is the total number of respondents surveyed at time $t$ and $N_{t}^{e}$ is the subset of these respondents surveyed for election $e$. We obtain a noisier but very similar graph when we do not weight observations by $\frac{N_{t}^{e}}{N_{t}}$ (Appendix Figure A.6).
} 
representativeness of our surveys is reflected in a strong 0.97 correlation between actual aggregate vote shares and vote shares computed based on survey respondents. In addition, around two-thirds of the surveys provide weights to increase the representativeness of their samples. We do not use these weights in our baseline specifications, since weighting schemes vary substantially across surveys and some surveys do not include any weight, but our main results remain very similar when taking weights into account (Appendix C.3).

A second, symmetric concern is that our sample may include individuals which should actually be excluded from it: respondents who said that they were going to vote before the election and that they did vote after the election, but actually abstained. Three surveys in our sample, the 1980, 1984, and 1988 ANES, enable us to identify nonvoters miscategorized as actual voters because they recorded both self-reported turnout and actual turnout, based on official voting records. We complemented these surveys with the 2008, 2012, and 2016 CCES surveys, which also validate respondents' turnout. ${ }^{15}$

Combining these six surveys, we find that turnout overreporters are 3 percentage points more likely to be inconsistent between their vote intention and vote choice than actual voters, on average. However, the inclusion of these individuals in our sample should not affect the change in vote choice consistency during the last two months, which is our main result. Indeed, we do not find a systematic correlation between the characteristics predicting overreported turnout and those predicting increased vote choice consistency. We estimate the following specification:

$$
T_{i t}^{e}=\Omega_{i}^{\prime} \rho+\sum_{t=-60}^{-1} \beta_{t} D_{t}+\alpha^{e}+W_{i t}^{\prime} \lambda+u_{i t}^{e},
$$

where $T_{i t}^{e}$ is a dummy equal to 1 if the respondent indicated that they intended to vote and that they voted but in reality abstained, $\Omega_{i}$ is a vector of dummies indicating voter characteristics, and the other variables are defined as previously. Younger respondents, whom we found to show a larger increase in vote choice consistency in Appendix Table A.4, are more likely to overreport turnout, but less educated respondents and those with weak or no party identification, who are also more likely to converge to their final choice during the campaign, are less likely to be turnout overreporters (Appendix Table A.8). Moreover, the daily increase in vote choice consistency among

\footnotetext{
${ }^{15}$ The latter surveys are poorly suited to study vote choice formation over time and thus not included in our main sample, because the observable characteristics of their respondents vary tremendously from one day to the next, but they are useful to assess the possible biases related to turnout overreporting.
} 
respondents from ANES 1980, 1984, and 1988 is strikingly similar whether we include turnout overreporters or only validated voters (Appendix Table A.9).

We now turn to threats for the results' internal validity that could ensue from changes in the composition of our daily samples over the electoral season. As indicated in Section II, one of the criteria we used to decide which surveys to include in our sample was that the sociodemographic characteristics of their respondents surveyed on different dates be as similar as possible. This should reduce the risk of sample selection bias. Yet, some of these variables show slight imbalance over time (Appendix Table A.10). Reassuringly, our findings are nearly identical when controlling for them (Appendix C.4). Moreover, we check that our results are robust to restricting the sample to surveys designed as rolling cross-sections, accounting for $69 \%$ of our observations, in which the pre-electoral interview date is allocated randomly across respondents (Appendix C.5). Beyond these general robustness checks, we now address two specific concerns, related respectively to changes over time in turnout intentions in the pre-electoral survey, and in the fraction of respondents who are successfully re-surveyed in the post-electoral survey.

First, our sample is restricted to respondents who said that they intended to vote in the preelectoral survey, and these respondents' proportion and type may change over time. ${ }^{16}$ As shown in Appendix Figure A.7 and Appendix Table A.11 (column 1), the share of respondents who say that they intend to vote increases by about 6 percentage points over the 60 days leading up to the election. This pattern is interesting in itself. It may reflect the mobilizing effects of campaigns (Hillygus, 2005), as well as an increased propensity to overreport voting as the election comes closer. But it leads to increases over time in the fraction of respondents entering in the samples used to measure changes in both vote choice consistency and in the likelihood of stating a vote intention (Appendix Table A.11, columns 2 and 3).

Respondents who only say that they intend to vote (and enter the sample) if they are surveyed close to the election can reasonably be expected to be less interested in politics and less consistent in their vote intention, on average. In particular, our data show that turnout overreporters, who may account for part of the increase in turnout intentions over time, are less consistent than actual voters. Therefore, if anything, we should expect changes in the composition of daily samples to bias the estimated increase in vote choice consistency downward. In fact, the observed increase

\footnotetext{
${ }^{16}$ Excluding respondents who stated that they were unlikely to vote in the pre-electoral survey ensures symmetry with post-electoral surveys, where non-voters are usually not asked whom they would have voted for if they had voted, as well as homogeneity across surveys: while some surveys ask likely non-voters whom they would vote for if they did vote, others only record the vote intention of respondents intending to vote.
} 
in vote choice consistency is slightly larger when we alleviate changes in sample composition by keeping, instead of dropping, respondents who state that they are unlikely to vote, in surveys that record their vote intention (Appendix Table C.19, column 1). More generally, Appendix C.6 shows that our results are qualitatively very similar when including unlikely voters.

Second, the sample we use for individual vote choice consistency and distance between predicted and final vote shares includes all respondents surveyed both before and after the election. A possible concern is that the reinterview rate (the fraction of respondents surveyed in the pre-electoral survey who also appear in the post-electoral survey) is slightly lower for respondents who received the pre-electoral survey closer to the election (Appendix Table A.11, column 4). However, the decrease in reinterview rate is much lower than the increase in vote choice consistency (-0.06 percentage point per day, on average, against 0.25 ), so the former cannot explain much of the latter. Furthermore, reassuringly, the type of respondents who are not reinterviewed does not change over time. Using a specification in the form of equation [4] and a dummy equal to 1 if the respondent is reinterviewed as outcome, we find that the coefficients on sociodemographic characteristics interacted with the distance between the pre-electoral survey and the election are all close to null and non-significant (Appendix Table A.12). Finally, we do not find any systematic pattern across surveys: while some surveys show a negative trend in reinterview rate, others show a positive trend, including within the same series of surveys. As shown in Appendix Table C.23, excluding the quartile of surveys with the largest decreases in reinterview rate yields a daily increase in vote choice consistency of the same magnitude as in Table I.

\section{III.G Alternative Interpretations}

The increase in vote choice consistency and the convergence to final vote shares during the last two months before an election can only be used to assess the impact of information received by voters during this period if they are primarily driven by this information. All our results are consistent with this interpretation, and several heterogeneity analyses provide direct support for it, particularly the faster increase in vote choice consistency in U.S. swing states, in which campaign activities tend to be concentrated; during the final weeks before the election, when the campaign is most intense; and for younger and less-educated voters, who have less preexisting information. Below, we discuss a complementary interpretation and state the case against three alternative ones. 


\section{Cognitive costs of processing information}

Beyond reflecting the influence of new information, changes in vote intentions during campaigns may plausibly also be due to delays in incorporating existing information into vote decisions. In this view, processing information and making one's vote choice takes time and effort, and the fraction of voters who have paid this cognitive cost increases over time. Then, the increase in vote choice consistency and the convergence to final vote shares shown above should be interpreted as an upper bound on the impact of information received during the campaign itself.

We see this interpretation as complementary to our main one. In both interpretations, vote choice consistency increases as voters incorporate information in their choice of candidate. This view contrasts with the rival longstanding view holding that vote choices are based on partisan identification and ideology. Whether the information changing people's mind is received during the last 60 days before the election or earlier is more second-order.

Furthermore, while postponing one's vote choice until shortly before the election could simply be a form of procrastination, it could also be a rational decision by voters who expect to receive useful information to the very last day. Conversely, information received during the campaign may resonate with prior information (Gennaioli and Shleifer, 2010). For instance, voters may update their evaluation of a candidate negatively if new information about an unfolding crisis contradicts that candidate's earlier predictions. The increased consistency observed in the last few weeks should then be attributed jointly to people receiving new information and spending more time to process it in this period.

Finally, it is unlikely that delays in information processing could, alone, fully account for our results. Indeed, the next section provides evidence of convergence for outcomes which do not require that people exert cognitive skills but which are likely to be affected by new information, namely beliefs on candidates, as well as the perceived importance of different issues.

\section{Activation of preexisting partisan loyalties}

An alternative interpretation is that much of the vote choice formation that we observe comes from the activation of preexisting partisan loyalties during the campaign, rather than the influence of information. For instance, voters may wait until later in the campaign to acknowledge that they will vote for the candidate of the party they have long felt close to. While such a thought process is unlikely to explain voters switching between candidates, it could in principle contribute to increase the fraction of voters stating a vote intention (instead of saying they are undecided). 
However, based on this interpretation, we should expect a large fraction of voters who make up their mind during the campaign to have strong partisan attachments and to end up voting for the party that they identified with from the beginning. The fact that the probability of stating a vote intention and vote choice consistency increase less for voters who strongly identify with a party, as shown in Section III.D, provides evidence against the first part of this prediction. We also reject the second part. We compare respondents' actual vote with the party that they say they identify with and estimate a specification in the form of equation [4], where we define people who voted for the party they identify with as type-a voters, and those who voted for a different party as type-b. We find that the increase in vote choice consistency is lower by $64 \%$ or $57 \%$ among the former group, whether respondents' party of identification is defined based on their post- or pre-electoral answers (Appendix Table A.13). ${ }^{17}$ These results suggest that vote choice formation results less from activating one's pre-existing partisan ties than severing them.

\section{Information-free shocks}

Another alternative interpretation is that increased vote choice consistency stems from a stream of shocks containing no relevant information but affecting vote choice, for instance by altering voters' utility function. Voters surveyed closer to an election may be more likely to vote for the candidate they announced simply because fewer shocks will hit them between their survey and the election.

This interpretation may be appealing for its simplicity, yet it is at odds with the observed convergence between predicted and final vote shares. Random shocks affecting different voters should cancel each other out in the aggregate. To account for the convergence to final vote shares, one would need to assume that shocks are correlated across voters. Shocks affecting the electorate at large may of course exist, and they play a central role in models such as probabilistic voting

\footnotetext{
${ }^{17} \mathrm{~A}$ possible concern with defining party identification based on post-electoral answers is that voters may indicate that they identify with the party that their vote choice converged to during the campaign season, even though they did not identify with that party beforehand. Using pre-electoral answers yields another concern: party identification recorded before the election may change due to campaign information, leading the sample of people categorized as having voted for the party that they identified with ex ante to also vary over time. If party identification did change due to the campaign, we should expect the consistency in this outcome to increase over time: voters surveyed later in the campaign would be more likely to have already converged to their final party identification. Reassuringly, party identification remains stable during the last two months before the election (Appendix Figure A.8).
} 
(Lindbeck and Weibull, 1987). However, it is difficult to see how they could change the views of a large fraction of voters without containing any relevant information. ${ }^{18}$

\section{Signals about the state of the world}

A third alternative interpretation for our results is that voters do not make up their mind before the election based on information provided as part of the campaign but based on another type of information: signals about the underlying state of the world which would have been released even absent the election. While such signals do not contain direct information on candidates, they could affect voters' views on their relative suitability to the current situation. For instance, voters may rally behind economically savvy candidates if they learn that the global economy is slowing down, affecting their country's economic outlook. In that case, it would be inaccurate to attribute the increase in vote choice consistency and decreased distance to final vote shares taking place in the last two months before the election to campaign effects.

However, signals about the state of the world are released all year long, not just during campaigns. And yet, the convergence from vote intentions to vote choices mostly takes place shortly before the election, when the electoral campaign is most intense. Furthermore, natural and technological disasters are an example of signals about the state of the world which, albeit exogenous to the campaign, could plausibly increase the appeal of some candidates. But, anticipating on the results shown in Section V, we do not find any effect of such shocks.

\section{Formation of Beliefs, Policy Preferences, and ISSUE SALIENCE}

Information can affect vote choice through multiple mechanisms. To the extent that a campaign's influence hinges on the importance voters give to election-specific information on the candidates on the ballot vs. their longstanding partisan leanings, one may expect the large increase in vote choice consistency shown in Section III to result from voters updating their beliefs on candidates' issue positions and quality. This may lead them to favor a new candidate that they find more competent or whom they find themselves ideologically closer to than they thought initially.

\footnotetext{
${ }^{18}$ In fact, many versions of the probabilistic voting model use political scandals or economic downturns, which are rich in information about candidates' probity and about the competence of the incumbent, as examples of aggregate shocks (e.g., Galasso and Nannicini, 2017).
} 
We compare the importance of this mechanism with three others. First, voters' own policy preferences might change over the course of the campaign, estranging them from certain candidates. Second, campaign information may increase the salience of some issues and prime voters to evaluate candidates based on them. Finally, polls may clarify the identity of the front-runners and lead strategic voters to desert candidates with little chance of winning.

\section{IV.A Formation of Policy Preferences}

To investigate the role played by policy preferences, we test whether the formation of vote choice is mirrored by changes in this outcome. We define individual $i$ 's preference consistency on question $q$ as:

$$
C_{i t}^{q}=1-\frac{\left|\widetilde{A}_{i t}^{q}-A_{i t}^{q}\right|}{\overline{A^{q}}-\underline{A^{q}}},
$$

where $\widetilde{A}_{i t}^{q}$ (resp. $A_{i t}^{q}$ ) is the respondent's answer to the question before (resp. after) the election and $\overline{A^{q}}-\underline{A^{q}}$ is the range of possible answers. This normalization allows us to use questions with different answer scales in the same regression.

We estimate equations [1] and [2] using preference consistency as outcome. ${ }^{19}$ As shown in Figure IVa and Appendix Table A.14, Panel a, policy preferences remain remarkably stable in the last two months before an election. The probability of stating a policy preference does not change over time either. Simply put, the persuasive communication voters receive in the campaign season does not alter their policy preferences.

The fact that vote choice formation during the campaign is not mirrored by a similar process of policy preference formation indicates, of course, that the latter is unlikely to explain the former. It also suggests that the reverse relationship, whereby voters adjust their policy preferences to their choice of candidate (Lenz, 2012), does not play an important role in the elections we study. Furthermore, this result supports the assumption of stable preferences, which is a cornerstone of most models of electoral competition.

\footnotetext{
${ }^{19}$ Our sample includes all respondents surveyed before and after the election who stated a policy preference in the second survey, and we replace election fixed effects with question fixed effects. Unlike vote choice, the accuracy of reported policy preferences should not depend on the time lapsed since the election. A more likely source of variation in policy preference changes is the distance between the pre- and post-electoral survey. Therefore, in this specification and in all regressions in this section, we control for dummies indicating the number of days separating the pre- and post-electoral survey instead of the distance between the latter and the election.
} 
Figure IV: Consistency in policy preferences, issue salience, and beliefs on candidates

(a) Policy preferences

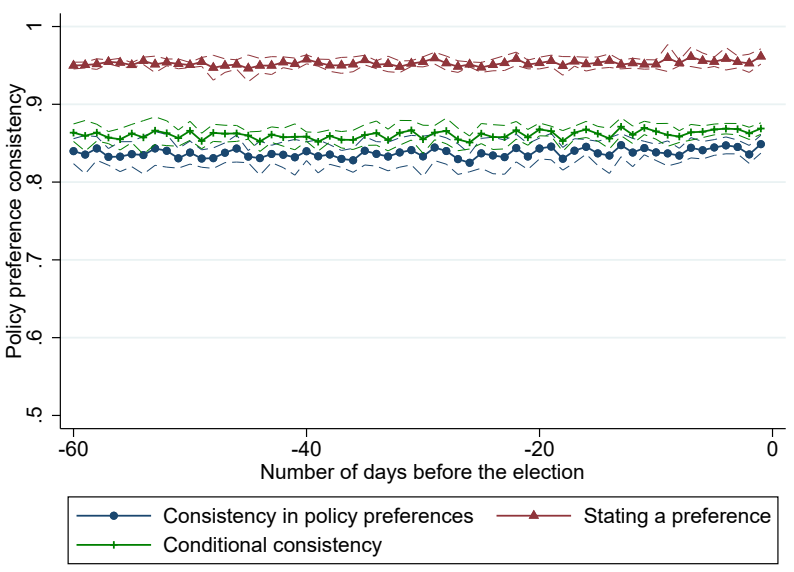

(b) Issue salience

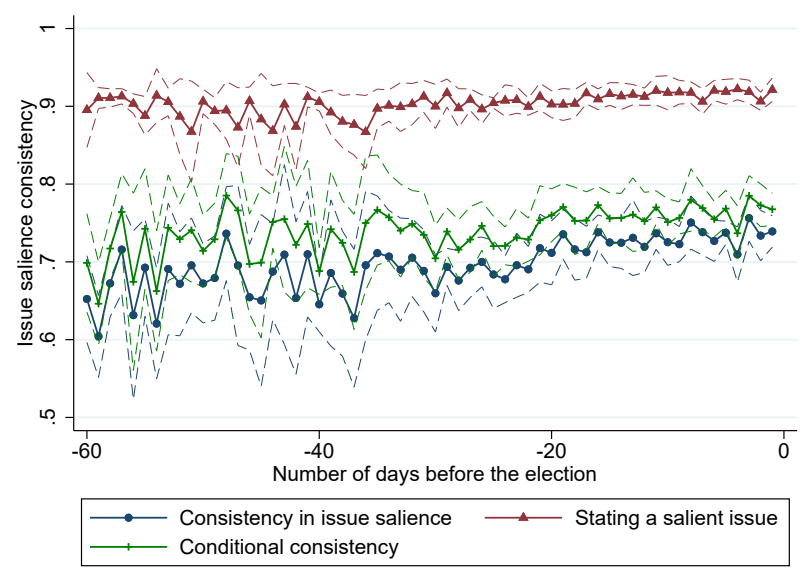

(c) Beliefs on candidates

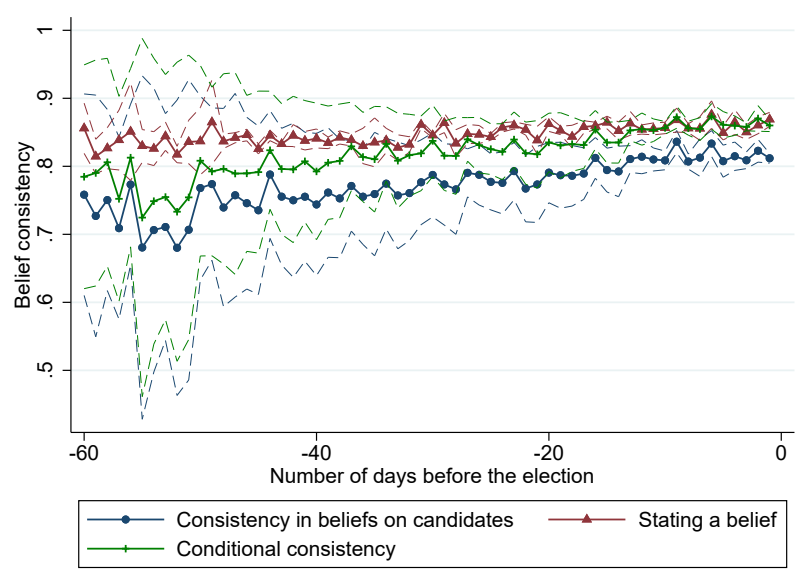

Notes: We show point estimates and 95\% confidence intervals from specifications in the form of equation [1], regressing consistency in policy preferences (Figure IVa), issue salience (Figure IVb), and beliefs on candidates (Figure $\mathrm{IVc}$ ) on 60 fixed effects indicating the number of days relative to the election and control variables listed in the text. We use one observation per respondent per policy question in Figure IVa, one observation per respondent in Figure $\mathrm{IVb}$, and one observation per respondent per belief question in Figure IVc. In each figure, we consider three outcomes: consistency $(\mathrm{N}=228,562 ; 46,108$; and 478,039); stating a preference (resp. a salient issue or a belief) $(\mathrm{N}=330,843$; 60,713; and 809,037); and conditional consistency ( $\mathrm{N}=222,785 ; 44,049$; and 440,771). 


\section{IV.B Changes in Issue Salience}

We use a similar method to explore the role of priming. We define issue salience consistency as a dummy equal to 1 if the respondent mentions an issue that they consider to be the most important in the pre-electoral survey and if they provide the same answer in the post-electoral survey.

As shown in Figure IVb, consistency in issue salience increases by 9 percentage points during the two months before voting. This outcome's daily increase is significant at the 5\% level and equal to more than half the daily increase in vote choice consistency shown in Table I (Appendix Table A.14, Panel b, columns 1 and 2). It is driven by increases both in the probability of stating an important issue and in consistency conditional on stating an issue (columns 3 through 6).

These results indicate that electoral season information increases the salience of some issues while decreasing the importance of others, and they suggest that priming mechanisms may contribute to vote choice formation.

\section{IV.C Changes in Beliefs on Candidates}

We finally investigate whether increased vote choice consistency in the period leading to an election is also driven by changes in beliefs voters hold about candidates.

Using questions recording beliefs on candidates' issue positions and quality, we find that the average daily increase in belief consistency in the last two months before the election is about two-thirds of the daily change in vote choice consistency but that it falls short of statistical significance (Figure IVc and Appendix Table A.14, Panel c, columns 1 and 2). ${ }^{20}$ The increase in the probability of stating a belief over time (instead of responding "I don't know") is estimated more precisely and significant at the $1 \%$ level (columns 3 and 4). We observe similar patterns when we distinguish the beliefs voters hold about candidates' issue positions and about their quality: increases in respondents' likelihood to state a belief on candidates' issue positions and on their quality are of comparable magnitudes and both significant at the $1 \%$ level (Appendix Table A.15).

\footnotetext{
${ }^{20}$ Questions recording beliefs on candidates are of two types. Some ask voters to select one of the candidates, e.g., the candidate that talks the most about a particular issue. Belief consistency is then defined as a dummy equal to 1 if the respondent provides the same answer in the pre- and post-electoral survey. Other questions survey voters about a particular candidate, e.g., how competent this candidate is. Belief consistency is then defined similarly as preference consistency, using the range of possible answers as denominator. Our estimates pool both types of questions. Again, we replace election fixed effects with question fixed effects.
} 
We complement this evidence by comparing changes in vote choice consistency across supporters of different types of candidates. This approach is less direct but it has the advantage of using all our data, not just surveys recording voters' beliefs both before and after the election. In addition, it enables us to distinguish information and beliefs on candidates' positions and quality from beliefs on their relative chances (e.g., based on polls). The first type of information can be expected to benefit the candidates on whom voters have less prior knowledge, including candidates of new parties and small candidates, as well as any candidate challenging the incumbent. If changes in related beliefs are responsible for vote choice formation, people who eventually vote for lesser-known candidates should be more likely to make up their minds during the electoral season, and these candidates should see their predicted vote share increase over time. Instead, information on the relative chances of the contenders should lead strategic voters to rally to the strongest candidates, increasing these candidates' predicted vote shares and overall vote share concentration. ${ }^{21}$ We now test these opposite predictions.

First, we compare individual vote choice formation between voters who end up voting for wellestablished candidates and for initially lesser-known candidates. We estimate specifications in the form of equation [4] where we define as type-a people voting for a challenger, a small candidate, or the candidate of a new party; and as type-b people voting for the party that won the last election, an initially strong candidate (with an average predicted vote share larger than $10 \%$ in the first five days of the survey), or for a party that had competed in earlier elections. Vote choice consistency begins lower and increases faster among those who eventually vote for challengers, small candidates, and new parties (Appendix Table A.17). ${ }^{22}$ These differential increases remain statistically significant in a specification controlling for all candidate types as well as their interaction with the time trend, with or without sociodemographic controls (columns 4 and 5).

Second, we compare changes in the predicted vote share of different types of candidates in the 60 days leading up to the election, using the individual likelihood to vote for these candidates as outcome, the same specification and sample of elections, and excluding respondents who do not state a vote intention or announce that they will cast a blank or null vote. We find that the support for challengers and small candidates increases as the election gets closer (Appendix Table A.18,

\footnotetext{
${ }^{21}$ We define voting strategically as voting based on likely outcomes of the election rather than expressively, for one's favorite candidate. Outside of strategic considerations, information on candidates' chances may affect voters if they use it as a signal of quality or if they desire to vote for the winner (Granzier et al., 2021).

${ }^{22}$ The fractions of voters who report voting for a challenger, a small candidate, or a new party in the post-electoral survey are stable over time, suggesting that our results are not driven by changes in sample composition (Appendix Table A.16).
} 
columns 1 through 4). We also measure changes in the following index of vote share

concentration: $M_{t}^{e}=\sum_{c}\left(\widetilde{V}_{c t}^{e}\right)^{2}$. As shown in columns 7 and 8 and in Appendix Figure A.9, vote share concentration decreases, on average, in the last two months before an election.

Finally, changes in beliefs on candidates' relative chances should be more consequential for vote choice under plurality rule than under proportional rule, where the incentives to be strategic are weaker. But Appendix Table A.2 does not show a larger change in vote choice consistency in plurality elections.

These results converge to support the view that vote choice changes during campaigns are driven by changed beliefs on candidates' positions and quality more than on their chances. This conclusion echoes recent evidence showing that voters often behave expressively (Pons and Tricaud, 2018).

\section{IV.D Intermediation Analysis}

The fact that consistency in beliefs and issue salience, but not consistency in policy preferences, increase during the campaign indicates that changes in the two former outcomes (and not in the latter) may contribute to vote choice formation. To examine the relationship between these variables more directly, we compute mean vote choice consistency in each election on each day, and regress it on mean consistency in beliefs, issue salience, and policy preferences.

Formally, we estimate the following regression model:

$$
\overline{C_{t}^{e}}=\rho_{P} \overline{C_{t}^{e, P}}+\rho_{S} \overline{C_{t}^{e, S}}+\rho_{B} \overline{C_{t}^{e, B}}+\sum_{t=-60}^{-1} \beta_{t} D_{t}+\alpha^{e}+W_{t}^{e^{\prime}} \lambda+u_{t}^{e},
$$

where $\overline{C_{t}^{e}}$ is the mean vote choice consistency among respondents surveyed $t$ days before election $e$ and $\overline{C_{t}^{e, P}}$ (resp. $\overline{C_{t}^{e, S}}$ and $\overline{C_{t}^{e, B}}$ ) is the mean consistency in policy preferences (resp. in issue salience and in beliefs on candidates).This specification separates the influence of changes in preferences, beliefs, and issue salience consistency on vote choice consistency from two other important sources of correlation. First, individual characteristics such as age and education may affect both vote choice consistency and consistency in beliefs, preferences, and issue salience. The ensuing correlation should not affect our point estimates because our regression is at the day level and our daily samples are generally balanced on these characteristics. The same applies to other individual characteristics such as interest in politics, which we do not observe but which we can expect to be balanced over time in the rolling cross-sections. Second, both mean vote choice consistency and consistency in the regressors may increase over time as the election gets closer 
and more information becomes available, independently of any impact of the latter on the former. The 60 fixed effects indicating the number of days relative to the election, which are included in equation [7], control for this second source of correlation.

It remains that, in addition to capturing the impact of preferences, beliefs, and issue salience consistency on vote choice consistency, our coefficients of interest $\rho_{P}, \rho_{B}$, and $\rho_{S}$ may also reflect the impact of information shocks deviating from the average 60 daily fixed effects and affecting both vote choice consistency and consistency in our regressors, but whose effect on the former outcome is not mediated by the latter.

The results are reported in Table II, Panel a. We do not observe any significant relationship between consistency in policy preferences and in vote choice (column 1). Instead, increases in mean issue salience and belief consistency are both associated with large increases in mean vote choice consistency (columns 2 and 3). Both estimates are significant at the 5\% level. They remain statistically significant (at the 5 and $10 \%$ level) and of very similar magnitude $(0.25$ and 0.13 percentage point) in a specification including all three variables (column 4).

Similarly, Panel b shows that one percentage point increases in the likelihood of stating an important issue or a belief on candidates are associated with 0.20 and 0.24 percentage point increases in the likelihood of stating a vote intention, which are significant at the $1 \%$ level, but that the probability of stating a policy preference is uncorrelated with this outcome.

While these point estimates do not necessarily represent causal evidence, they do support the conclusion that changes in beliefs on candidates and priming mechanisms are likely to contribute to the formation of vote choice, but that policy preferences do not. ${ }^{23}$

These results are consistent with prior evidence established by Lenz (2012) regarding the drivers of changes in vote intentions, except for one important difference: that study does not find that changes in issue salience matter. A possible explanation is that Lenz (2012) does not directly measure the importance that voters give to different issues as we do, but infers it from the strength of the association between people's views on that issue and their vote intention. Furthermore, he explores specific shocks that can be expected to increase the salience of a certain issue, which makes it easier to study the causal relationship with changes in vote choice but also limits the range

\footnotetext{
${ }^{23}$ We note a small discrepancy between the unweighted (baseline) and weighted versions of these results. As shown in Appendix Table C.10, with survey weights, mean consistency in policy preferences also has a significant effect on mean vote choice consistency. However, the result that policy preference consistency does not increase during the campaign remains unchanged, so our conclusion that the observed increase in vote choice consistency is unlikely to be driven by changes in policy preferences holds.
} 
Table II: Drivers of vote choice formation

(a) Mean vote choice consistency

\begin{tabular}{lcccc}
\hline & \multicolumn{3}{c}{ Mean vote choice consistency } \\
\cline { 2 - 5 } & $(1)$ & $(2)$ & $(3)$ & $(4)$ \\
\hline Mean consistency in policy preferences & -0.103 & & & -0.138 \\
& $(0.114)$ & & & $(0.120)$ \\
Mean consistency in issue salience & & $0.255^{* *}$ & & $0.247^{* *}$ \\
& & $(0.095)$ & & $(0.095)$ \\
Mean consistency in beliefs on candidates & & & $0.134^{* *}$ & $0.126^{*}$ \\
& & & $(0.064)$ & $(0.064)$ \\
\hline Observations & 3129 & 3129 & 3129 & 3129 \\
$R^{2}$ & 0.807 & 0.809 & 0.808 & 0.810 \\
Election fixed effects & $\mathrm{x}$ & $\mathrm{x}$ & $\mathrm{x}$ & $\mathrm{x}$ \\
Fixed effects for number of days to election & $\mathrm{x}$ & $\mathrm{x}$ & $\mathrm{x}$ & $\mathrm{x}$ \\
Aggregate controls & $\mathrm{x}$ & $\mathrm{x}$ & $\mathrm{x}$ & $\mathrm{x}$ \\
\hline
\end{tabular}

(b) Mean probability of stating a vote intention

\begin{tabular}{lcccc}
\hline & \multicolumn{3}{l}{ Mean probability of stating a vote intention } \\
\cline { 2 - 5 } & $(1)$ & $(2)$ & $(3)$ & $(4)$ \\
\hline Mean probability of stating a policy preference & 0.005 & & & -0.027 \\
& $(0.151)$ & & & $(0.149)$ \\
Mean probability of stating a salient issue & & $0.200^{* * *}$ & & $0.203^{* * *}$ \\
& & $(0.053)$ & & $(0.052)$ \\
Mean probability of stating a belief on candidates & & & $0.234^{* * *}$ & $0.237^{* * *}$ \\
& & & $(0.076)$ & $(0.075)$ \\
\hline Observations & 3144 & 3144 & 3144 & 3144 \\
$R^{2}$ & 0.840 & 0.840 & 0.841 & 0.841 \\
Election fixed effects & $\mathrm{x}$ & $\mathrm{x}$ & $\mathrm{x}$ & $\mathrm{x}$ \\
Fixed effects for number of days to election & $\mathrm{x}$ & $\mathrm{x}$ & $\mathrm{x}$ & $\mathrm{x}$ \\
Aggregate controls & $\mathrm{x}$ & $\mathrm{x}$ & $\mathrm{x}$ & $\mathrm{x}$ \\
\hline
\end{tabular}

Notes: Standard errors clustered at the survey level are in parentheses $(* * *, * *, *$ indicate significance at 1,5 , and $10 \%$, respectively). We estimate specifications in the form of equation [7], using one observation per election per day. In Panel a, mean vote choice consistency is computed based on all respondents surveyed before and after the election who said that they intended to vote, in the first survey, and who reported that they actually voted and gave a vote choice declaration, in the second. Mean consistency in policy preferences, mean consistency in issue salience, and mean consistency in beliefs on candidates are computed based on all respondents surveyed before and after the election who stated a policy preference, a salient issue, or a belief on candidates in the second survey. In surveys including multiple policy preferences or beliefs questions, consistency in policy preferences and consistency in beliefs are averaged at the respondent level before taking the mean across respondents surveyed on a given day. In Panel b, mean probability of stating a vote intention is computed based on all respondents surveyed before the election who said that they intended to vote. Mean probability of stating a policy preference, a salient issue, or a belief on candidates are computed based on all respondents surveyed before the election. We weight each observation by the number of respondents it was constructed from, relative to the overall number of respßß̊dents surveyed at the same relative time to the election. Aggregate controls include fixed effects for the day of the week in which the pre-electoral survey took place and the average number of days separating the post-electoral survey from the election. We also control for pre-electoral survey day-of-the-week fixed effects, the average post-electoral survey lag among respondents who received the pre-electoral survey at time $t$, and three dummy variables indicating whether $\overline{C_{t}^{e, P}}, \overline{C_{t}^{e, S}}$, and $\overline{C_{t}^{e, B}}$ are missing. 
of priming effects that can be investigated. Our approach may capture the effects of changes in issue salience which take multiple weeks or even the entire campaign to fully materialize.

\section{IMPACT OF TV DEBATES}

Finally, we investigate which of three distinct sources of information are responsible for the formation of vote choice.

Given the mediating role of beliefs on the quality and positions on candidates established in Section IV, a first plausible hypothesis is that changes in these beliefs and, in turn, some of the changes in vote intentions occur as a result of communication from candidates themselves, especially during TV debates. Direct messages from charismatic candidates may be more persuasive than indirect communication organized by their campaign, e.g., with rank-and-file canvassers knocking on doors on their behalf. Beyond TV debates, candidates can also communicate with voters through campaign rallies as well as ads in various media. However, TV debates are more salient and they attract much larger audiences than rallies. ${ }^{24}$ Overall, $71 \%$ of respondents report watching TV debates in our sample, and official TV ratings which we found for 43 out of the $56 \mathrm{TV}$ debates indicate that debate watchers account for an average of $22 \%$ of the population. ${ }^{25}$ Furthermore, voters may find TV debates more informative than scripted rally speeches or TV ads because debates subject all candidates to the same exercise and test their ability to respond in real time to unexpected moderators' questions and opponents' arguments. On the other hand, voters may deem any information provided by candidates about themselves, including through debates, not credible. Indeed, models of Bayesian persuasion suggest that individuals may not be convinced by the information they receive if they believe that the sender has incentives to manipulate it (DellaVigna and Gentzkow, 2010; Kamenica and Gentzkow, 2011).

Second, we compare TV debates' effects with the effects of shocks which, instead, occur independently from the campaign and are entirely outside of candidates' control, such as natural

\footnotetext{
${ }^{24}$ For instance, while Donald Trump's 2016 rallies attracted unusually large crowds, the number of participants in these rallies reached a few tens of thousands at most, against an estimated 84 million for the first debate pitting him against Hillary Clinton.

${ }^{25}$ The sources of TV ratings are provided in Appendix B.4. The discrepancy between self-reports and official ratings may be explained by several factors. First, TV ratings and the estimate based on our surveys are about different objects, watching a specific debate vs. watching debates in general. Second, TV ratings include all viewers above two years old in the U.S., and above 14 in other countries, whereas self-reports are only based on survey respondents above 18 and who intend to vote in the upcoming election. Third, elections with a larger fraction of debate watchers had more respondents. Fourth, TV ratings may underestimate the number of actual debate viewers if they fail to account for those watching in public settings, and survey respondents may overreport watching debates to signal their interest in politics.
} 
and technological disasters. The literature exploring effects of such factors using local variation (e.g., Cole et al., 2012) emphasizes that these factors may change vote intentions for irrational reasons (e.g., Achen and Bartels, 2016) but that they can also provide valuable information on candidates. For instance, voters may learn about incumbents' preparedness and competence from the damages caused by unexpected natural disasters and from the policies announced and implemented in response to them (e.g., Ashworth et al., 2018), and they may adjust their beliefs on other candidates based on statements they issue in reaction to these shocks.

Third, voters may be influenced by information which they receive as part of the campaign but which candidates do not directly control, including messages from the media, political activists, and discussions with friends or family members. Voters may perceive these third parties as more credible and less likely to manipulate information than candidates themselves, generating larger effects. ${ }^{26}$ Indeed, it may be more costly for them to lie (Cho and Kreps, 1987); they often share common interests with the voters they are trying to persuade (Crawford and Sobel, 1982); and their information is more incomplete, making selective transmission more difficult (Fischer and Stocken, 2001). Candidates may be able to influence the information provided by these sources, but only to a certain extent. Indeed, many media outlets remain reluctant to become the mouthpiece for a specific camp, and voters debating the merits of the different candidates will likely misremember some of their propositions. Even political activists campaigning on candidates' behalf may convey a different message to voters than the campaign's official talking points (Enos and Hersh, 2015).

Appendix Figure A.10 and Appendix Table A.19 show the change in the fraction of voters who report getting information frequently from newspapers, TV, radio, and the Internet, having seen election polls recently, discussing politics frequently with others, and having been contacted or visited by a party recently. All these outcomes build up over the electoral season, suggesting that the corresponding sources of information may contribute to the concomitant increase in vote choice consistency. On the other hand, the slow and continuous convergence of vote intentions to final vote choices observed across elections does not preclude the possibility that discrete events such as TV debates and natural disasters, taking place at different times in each race, play a decisive role by changing the mind of many voters. We use an event-study approach to estimate their impact.

\footnotetext{
${ }^{26}$ The prediction that receivers respond more when messages are credible has received empirical support; for instance, in Chiang and Knight (2011).
} 


\section{V.A Estimation Strategy}

Holding TV debates before national elections is the norm in a growing number of countries. After the first presidential TV debate, between Richard Nixon and John F. Kennedy in 1960, TV debates were held in each U.S. election beginning in 1976 and the practice quickly spread to other countries. Debates' ubiquity warrants a multi-country event study to examine their impact.

In some elections, multiple debates take place. We exclude debates held less than three days from one another, to be able to estimate effects up to three days after. ${ }^{27}$ This leaves us with a total of 56 debates. Debates in our sample were held between five and 44 days before the election, with an average of 24 days (Appendix Figure A.11). They are concentrated in the period when vote choice consistency increases the fastest, making them as plausible a driver of vote choice formation as the sources of information shown in Appendix Figure A.10. The full list of debates is included in Appendix Table B.6, together with the following information: whether the debates featured candidates for president or prime minister, their date, and the time to the election.

An observation is a respondent $\times$ debate $\times$ election. A few debates affect several elections, namely the first and second votes in Germany, and the electoral vote and party vote in New Zealand. In addition, for each debate, our estimation uses all respondents in the corresponding survey. As a result, the same response is included multiple times when multiple debates were held before an election. In total, our sample includes 331,000 observations. We cluster standard errors at the debate level to adjust for the correlation between the error terms of all observations related to the same debate. This clustering also accommodates for the fact that some debates preceding the 2000, 2004, and 2008 U.S. presidential elections are covered both by the ANES and the NAES. ${ }^{28}$

Our main specification is as follows:

$$
Y_{i t}^{d}=\sum_{k=-3}^{-1} \mu_{k}+\sum_{k=1}^{3} \mu_{k}+\mu_{4-}+\mu_{4+}+\sum_{t=-1}^{-60} \beta_{t} D_{t}+\alpha^{d}+W_{i t}^{\prime} \lambda+u_{i t}^{d}
$$

where $Y_{i t}^{d}$ is the outcome for respondent $i$, surveyed $t$ days before the election corresponding to debate $d, \mu_{k}(-3 \leq k \leq 3)$ are dummies indicating the number of days relative to the debate, $\mu_{4-}$

\footnotetext{
${ }^{27}$ The results are robust to an extended model excluding debates held less than five days from one another (Appendix C.8).

${ }^{28}$ As in Section III, we also check the robustness of our results to allowing for correlation of the error terms with the wild cluster bootstrap procedure (Appendix Tables C.3 and C.4), and to clustering the standard errors at the level of the election date (Appendix Tables C.7 and C.8).
} 
and $\mu_{4+}$ are dummies equal to 1 for respondents surveyed four days or more before or after the debate, respectively, and $\alpha^{d}$ are debate $\times$ election fixed effects. ${ }^{29}$

The key coefficients of interest are $\mu_{1}, \mu_{2}$, and $\mu_{3}$, which measure the impact of debates one to three days after, relative to the omitted category $\mu_{0} \cdot{ }^{30}$ As this specification makes clear, we do not use elections without debates as our counterfactual. The mere fact of having debates may change the kinds of candidates chosen by parties, the overall amount and type of information provided throughout the campaign, and how much voters pay attention to it. Our estimates do not capture such general equilibrium mechanisms potentially affecting all voters. Instead, we estimate direct effects of debates on voters surveyed afterward relative to those surveyed beforehand. This enables us to assess the extent to which TV debates contribute to the increase in vote choice consistency observed in the corresponding elections. Our estimates capture effects of debates themselves as well as effects of subsequent media commentaries and discussions, both on debate watchers and non-watchers. In Section V.D, we separate effects on these two groups.

Importantly, the fact that debates took place at different times in different elections allows us to control flexibly for the number of days relative to the election, with the 60 daily fixed effects $D_{t}$. This is critical to disentangle the effect of debates from the underlying time trends shown in Section III. In addition, the vector $W_{i t}$ controls again for day-of-the-week and post-electoral survey lag fixed effects and, in some specifications, for sociodemographic characteristics.

Our identifying assumption is that conditional on all these controls, and conditional on having a TV debate during our observation window, the date of the debate is uncorrelated with the outcome. In addition, we assume that any pre-trend before the fourth day preceding the debate or any impact after the fourth day following it are accurately captured by the fixed effects $\mu_{4-}$ and $\mu_{4+} .{ }^{31}$

There are three important potential threats to our identification strategy. First, systematic differences in the characteristics of respondents surveyed before and after debates would violate

\footnotetext{
${ }^{29}$ We include separate fixed effects for distinct elections affected by the same debate. We also include two separate fixed effects for U.S. debates covered both by ANES and NAES.

${ }^{30} \mathrm{We}$ use the day of the debate as reference group because debates take place in the evening. Therefore, the vast majority of respondents surveyed on that day are surveyed before the debate. The exact time of the interview is available for 4,095 respondents surveyed on the day of 26 different debates. We find that only $16 \%$ of them were surveyed after the debate started.

${ }^{31}$ Our results pointing to the lack of increase in vote choice consistency and the lack of decrease in the distance to final vote shares are robust to an alternative specification which does not require this assumption because it uses a sample restricted to a balanced panel of observations for each of the three days preceding and following each debate and excluding all respondents surveyed before or after (Appendix C.9). The drawback of that specification is that we can only control for election fixed effects instead of debate $\times$ election fixed effects because collinearity prevents estimating a full set of debate fixed effects, time fixed effects, and fixed effects for days relative to the debate.
} 
the identifying assumption and could lead us to mistakenly attribute to debates changes in outcomes originating in sample composition differences. The fact that most our surveys are rolling cross-sections, which allocate respondents' survey date randomly, alleviates this risk. It remains that debates, like other campaign events, may affect the characteristics of people willing to answer the survey. To address this concern, Appendix Table A.20 reports balance checks for voter characteristics as well as watching debates. Out of 80 differences, nine are significant at the $10 \%$ level, five at the $5 \%$ level, and none at the $1 \%$ level, which is in line with what would be expected.

A second potential risk arises if unexpected shocks occurring on the same day or immediately before or after the debate bias our estimates. This risk is important for existing studies that use pre/post difference designs and focus on a unique debate or a few debates only. In our case, such shocks would only violate the identifying assumption if they were systematically correlated with debates' dates. Given the large number of debates in the study, and conditional on the daily fixed effects and other controls, this should not be the case.

The third potential violation of the identifying assumption comes from the fact that, of course, debates do not happen unexpectedly. Instead, their dates are known long in advance, so candidates and the media may strategically time their communication around them. This could generate continuous trends in outcomes around debates, which the pre-debate dummies $\mu_{-3}, \mu_{-2}$, and $\mu_{-1}$ allow us to test for. However, these dummies would not capture changes only taking place after the debate. One possibility is that the amount of information increases (or that voters pay significantly more attention to it) after the debate, biasing our estimates upwards. Given our mostly null results, changes susceptible to bias our estimates downwards would be more concerning. Downward bias could occur if candidates decreased the intensity of their campaign and if media decreased their coverage thereof, after the debate (e.g., because they anticipate debate-related information will lower the returns of any other type of communication), or if voters decreased their media consumption.

Appendix Table A.21 tests for changes in media consumption and partisan communication around debates. Columns 1 through 4 use dummies for getting information frequently from newspapers, TV, radio, and the Internet as outcomes. None of the pre-debate or post-debate dummies are significant, providing evidence of stable media consumption around debates. Columns 5 and 6 show no significant effect on the probability of having seen election polls recently or of discussing politics frequently with others. Finally, we obtain only non-significant coefficients when using dummies for having been contacted and having been visited by a party as 
outcomes (columns 7 and 8), except for a small decrease in party contact the day after the debate, significant at the $10 \%$ level. While these results support our identifying assumption, we note that the object of all questions - either overall media consumption or having been contacted by a party recently, not just on the day of the survey - limits the power of these tests.

The next two sections measure mean effects of debates on individual and aggregate outcomes. We then explore potential sources of heterogeneity in debate impact.

\section{V.B Debates' Effects on Individual Outcomes}

We first measure the impact of TV debates on our main outcome, $C_{i t}$, the individual consistency between vote intention and vote choice. ${ }^{32}$

This outcome comparing pre- and post-electoral survey responses is well suited to our eventstudy design. We would not be able to measure the impact of TV debates using only post-electoral responses, since vote choices reported by all respondents may reflect debates' influence. Instead, if debates do help voters decide between candidates, we should expect the fraction of people stating a vote intention identical to their eventual vote to be higher among those who answered the preelectoral survey right after the debate than those surveyed right before.

Furthermore, previous studies estimating the effects of debates and other campaign events have used pre-electoral survey responses, but focusing instead on vote choice consistency should help uncover effects which these outcomes could miss.

To see why, first note that the types of candidates benefiting from TV debates may vary across elections and debates. Using vote intentions as outcome, these effects could get netted out when pooling multiple debates in the same event study. For instance, suppose that in each debate a unique candidate - the incumbent in half of the debates and a challenger in the other half - wins over some voters from the other side. Debates truly change the course of every race, yet overall effects measured on intending to vote for the incumbent would be null. Using as outcomes intention to vote for left-wing versus right-wing candidates or for outsiders versus front-runners could generate similarly misleading null effects. Instead, vote choice consistency, which in this example increases

\footnotetext{
${ }^{32}$ Once again, our sample includes all respondents surveyed before and after the election who said that they intended to vote, in the first survey, and who reported that they actually voted and gave a vote choice declaration, in the second. TV debates marginally affect selection into this sample, with one positive coefficient three days after the debate, significant at the $10 \%$ level (Appendix Table A.22, column 3). However, column 1 shows no significant impact on turnout intention, and Appendix Tables C.21 and C.22 show that our main findings are robust to including unlikely voters in the sample, alleviating the concern that our results may be biased by differential sample selection. Furthermore, column 4 shows that the post-electoral reinterview rate is balanced around debates.
} 
following each debate (since voters persuaded by debate winners are found inconsistent if surveyed before but consistent if surveyed after), would show a positive effect.

Second, the effects of debates may also vary across voters within an election. Once again, effects benefiting different candidates could be netted out using traditional outcomes. Consider for instance a debate increasing the likelihood that voters of opposing sides all express support for the nominee of their preferred party. Our measure of individual vote choice consistency would capture this effect even if the net impact on individual vote intention and predicted aggregate vote shares were null. The ability to detect any type of effects is desirable in general, and especially useful here: because it works against finding a null, it only makes our mostly null results more trustworthy.

We report the coefficients on the $\mu_{k}$ dummies indicating the number of days relative to the debate in Table III, column 1, and plot them in Figure V. We do not observe any pre-trend in vote choice consistency in the three days preceding debates. The dummies for the days following debates are also all close to zero and non-significant. On average, debates decrease individual vote choice consistency by a non-significant 0.7 percentage point in the three following days. Estimates of overall vote choice formation during the final two months of campaigns shown in Section III provide a useful benchmark to interpret this result. Considering the upper bound of the 95\% confidence interval, we can reject any impact of debates on vote choice consistency higher than 0.5 percentage point at the $5 \%$ level, which corresponds to $3 \%$ of the overall 17 percentage point increase over the electoral season (Figure I). ${ }^{33}$ These results are robust to controlling for respondents' sociodemographic characteristics (column 2). ${ }^{34}$

We next measure the impact of debates on stating any vote intention ${ }^{35}$ and on vote choice consistency conditional on stating one. We do not observe any pre-trend in the likelihood to state a vote intention, and the impact on this outcome is not significant on any day after the debate

\footnotetext{
${ }^{33}$ The increase in vote choice consistency during the final two months of campaigns is nearly identical in elections with a TV debate as in the full sample.

${ }^{34} \mathrm{~A}$ potential concern is that our null effects may hide the fact that debates increase the choice consistency of some while decreasing that of others. This scenario is unlikely but not impossible. Consider, for instance, a debate in which a charismatic candidate seduces both voters from their own party and from a rival party. The first group was previously intending to vote for other candidates but they now intend to vote for their party's candidate and will stick to this choice until the election, so that their vote choice consistency increases after the debate. Further assume, by contrast, that the second group of voters from the rival party only temporarily depart from their intention to vote for their candidate, so their vote choice consistency temporarily decreases after the debate. Overall, changes in vote intentions among both groups of voters would lead to null effects on vote choice consistency. However, they would increase the predicted vote share of the charismatic candidate immediately after the debate, which would be captured by the second aggregate outcome examined in Section V.C.

${ }^{35}$ This outcome is defined on the sample of respondents who said that they intended to vote. Column 2 of Appendix Table A.22 shows that TV debates do not affect selection into this sample.
} 


\section{Figure V: Debates' effects on vote choice consistency}

(a) Vote choice consistency

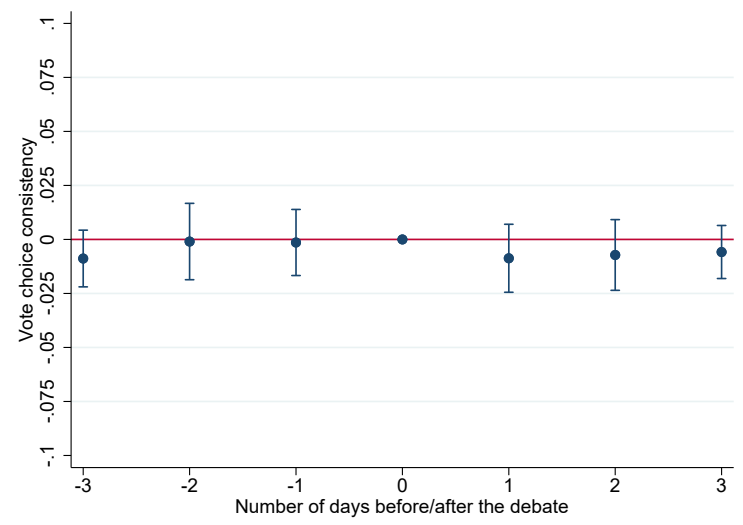

(b) Vote intention

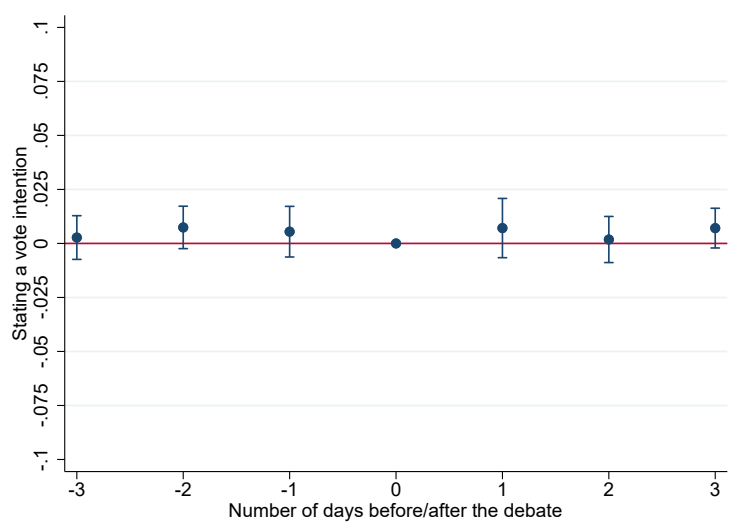

(c) Conditional consistency

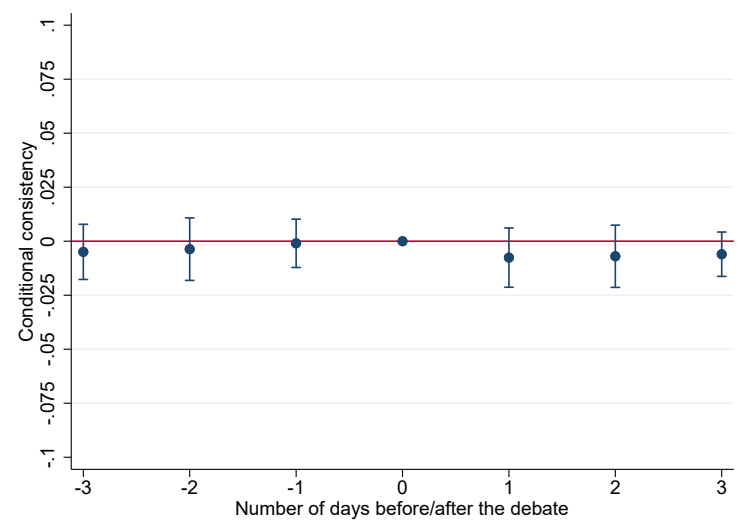

Notes: We show point estimates and 95\% confidence intervals from specifications in the form of equation [8], regressing vote choice consistency, vote intention, and conditional vote choice consistency on dummy variables for being surveyed one, two, or three days before the debate, as well as dummies for being surveyed one, two, or three days after the debate. We also include dummies for being surveyed four days or more before or after the debate, respectively, and omit the dummy for being surveyed on the day of the debate. We control for debate $\times$ election fixed effects as well as fixed effects for the number of days relative to the election and for the day of the week in which the pre-electoral survey took place. In Figures Va and Vc, we also control for fixed effects for the number of days separating the post-electoral survey from the election. Standard errors are adjusted for clustering at the debate level. $\mathrm{N}=263,681 ; 330,621$; and 240,826, respectively. 
Table III: Debates' effects on vote choice consistency

\begin{tabular}{|c|c|c|c|c|c|c|}
\hline & \multicolumn{2}{|c|}{ Vote choice consistency } & \multicolumn{2}{|c|}{ Vote intention } & \multicolumn{2}{|c|}{ Conditional consistency } \\
\hline & (1) & (2) & (3) & (4) & (5) & (6) \\
\hline Before -3 & $\begin{array}{c}-0.014^{* *} \\
(0.006)\end{array}$ & $\begin{array}{c}-0.015^{* *} \\
(0.007)\end{array}$ & $\begin{array}{c}0.003 \\
(0.005)\end{array}$ & $\begin{array}{c}0.002 \\
(0.005)\end{array}$ & $\begin{array}{c}-0.015^{* * *} \\
(0.005)\end{array}$ & $\begin{array}{c}-0.016^{* * *} \\
(0.006)\end{array}$ \\
\hline-3 & $\begin{array}{l}-0.009 \\
(0.007)\end{array}$ & $\begin{array}{l}-0.010 \\
(0.007)\end{array}$ & $\begin{array}{c}0.003 \\
(0.005)\end{array}$ & $\begin{array}{c}0.003 \\
(0.005)\end{array}$ & $\begin{array}{l}-0.005 \\
(0.006)\end{array}$ & $\begin{array}{l}-0.006 \\
(0.007)\end{array}$ \\
\hline-2 & $\begin{array}{c}-0.001 \\
(0.009)\end{array}$ & $\begin{array}{l}-0.002 \\
(0.009)\end{array}$ & $\begin{array}{c}0.007 \\
(0.005)\end{array}$ & $\begin{array}{c}0.007 \\
(0.005)\end{array}$ & $\begin{array}{l}-0.004 \\
(0.007)\end{array}$ & $\begin{array}{l}-0.004 \\
(0.007)\end{array}$ \\
\hline-1 & $\begin{array}{l}-0.001 \\
(0.008)\end{array}$ & $\begin{array}{l}-0.002 \\
(0.008)\end{array}$ & $\begin{array}{c}0.005 \\
(0.006)\end{array}$ & $\begin{array}{c}0.005 \\
(0.006)\end{array}$ & $\begin{array}{l}-0.001 \\
(0.006)\end{array}$ & $\begin{array}{c}-0.002 \\
(0.006)\end{array}$ \\
\hline+1 & $\begin{array}{l}-0.009 \\
(0.008)\end{array}$ & $\begin{array}{l}-0.009 \\
(0.008)\end{array}$ & $\begin{array}{c}0.007 \\
(0.007)\end{array}$ & $\begin{array}{c}0.007 \\
(0.007)\end{array}$ & $\begin{array}{l}-0.008 \\
(0.007)\end{array}$ & $\begin{array}{l}-0.008 \\
(0.007)\end{array}$ \\
\hline+2 & $\begin{array}{l}-0.007 \\
(0.008)\end{array}$ & $\begin{array}{l}-0.008 \\
(0.008)\end{array}$ & $\begin{array}{c}0.002 \\
(0.005)\end{array}$ & $\begin{array}{c}0.001 \\
(0.005)\end{array}$ & $\begin{array}{l}-0.007 \\
(0.007)\end{array}$ & $\begin{array}{c}-0.008 \\
(0.007)\end{array}$ \\
\hline+3 & $\begin{array}{l}-0.006 \\
(0.006)\end{array}$ & $\begin{array}{l}-0.006 \\
(0.006)\end{array}$ & $\begin{array}{c}0.007 \\
(0.005)\end{array}$ & $\begin{array}{c}0.007 \\
(0.005)\end{array}$ & $\begin{array}{l}-0.006 \\
(0.005)\end{array}$ & $\begin{array}{l}-0.006 \\
(0.005)\end{array}$ \\
\hline After +3 & $\begin{array}{l}-0.002 \\
(0.006)\end{array}$ & $\begin{array}{l}-0.003 \\
(0.006)\end{array}$ & $\begin{array}{c}0.008 \\
(0.005)\end{array}$ & $\begin{array}{c}0.008 \\
(0.005)\end{array}$ & $\begin{array}{l}-0.005 \\
(0.005)\end{array}$ & $\begin{array}{l}-0.005 \\
(0.005)\end{array}$ \\
\hline Observations & 263681 & 263681 & 330621 & 330621 & 240826 & 240826 \\
\hline$R^{2}$ & 0.072 & 0.077 & 0.069 & 0.076 & 0.042 & 0.044 \\
\hline Mean, day of the debate & 0.811 & 0.811 & 0.896 & 0.896 & 0.887 & 0.887 \\
\hline Number of debates & 56 & 56 & 56 & 56 & 56 & 56 \\
\hline Debate * election fixed effects & $\mathrm{x}$ & $\mathrm{x}$ & $\mathrm{x}$ & $\mathrm{x}$ & $\mathrm{x}$ & $\mathrm{x}$ \\
\hline Fixed effects for number of days to election & $\mathrm{x}$ & $\mathrm{x}$ & $\mathrm{x}$ & $\mathrm{x}$ & $\mathrm{x}$ & $\mathrm{x}$ \\
\hline Individual controls & $\mathrm{x}$ & $\mathrm{x}$ & $\mathrm{x}$ & $\mathrm{x}$ & $\mathrm{x}$ & $\mathrm{x}$ \\
\hline Sociodemographic controls & & $\mathrm{x}$ & & $\mathrm{x}$ & & $\mathrm{x}$ \\
\hline Linear combination of estimates & & & & & & \\
\hline Average pre-debate dummies $-3,-2$, and -1 & $\begin{array}{c}-0.004 \\
(0.007)\end{array}$ & $\begin{array}{l}-0.005 \\
(0.007)\end{array}$ & $\begin{array}{c}0.005 \\
(0.004)\end{array}$ & $\begin{array}{c}0.005 \\
(0.004)\end{array}$ & $\begin{array}{l}-0.003 \\
(0.005)\end{array}$ & $\begin{array}{l}-0.004 \\
(0.005)\end{array}$ \\
\hline Average post-debate dummies 1,2 , and 3 & $\begin{array}{l}-0.007 \\
(0.006)\end{array}$ & $\begin{array}{l}-0.008 \\
(0.006)\end{array}$ & $\begin{array}{c}0.005 \\
(0.005)\end{array}$ & $\begin{array}{c}0.005 \\
(0.005)\end{array}$ & $\begin{array}{l}-0.007 \\
(0.005)\end{array}$ & $\begin{array}{l}-0.007 \\
(0.005)\end{array}$ \\
\hline
\end{tabular}

Notes: Standard errors clustered at the debate level are in parentheses $(* * *, * *, *$ indicate significance at 1,5 , and $10 \%$, respectively). We use one observation per respondent and estimate specifications in the form of equation [8]. Individual controls include fixed effects for the day of the week in which the pre-electoral survey took place and, in columns 1, 2, 5, and 6, fixed effects for the number of days separating the post-electoral survey from the election. Sociodemographic controls include education (dummies indicating above high school education and college degree), gender, age, income quartiles, and employment status. The mean values of the three pre-debate dummies and of the three post-debate dummies are also reported, along with their standard errors. 
(Figure $\mathrm{Vb}$ and Table III, columns 3 and 4). The average impact of debates on the likelihood to state any vote intention in the three following days is positive but small and not significant in either specification shown in columns 3 and 4 . None of the three pre-debate or post-debate dummies are significant for conditional vote choice consistency either, and the effect of debates on this outcome in the three following days is negative and non-significant (Figure Vc and Table III, columns 5 and $6)$.

Finally, as shown in Appendix Table A.23 as well as in Appendix Figure A.12, none of the relative days dummies are significant when using consistency in issue salience or in beliefs on candidates as outcome, suggesting that debates do not affect the factors found to be likely contributors to vote choice formation in Section IV. Effects on policy preference consistency are not significant either.

All our point estimates measure the impact of debates in the short run. If our estimates were positive and significant, we could be worried about potential subsequent reversion to the mean. Instead, it seems unlikely that the null effects we measure shortly after the debate give way to large effects later on.

\section{V.C Debates' Effects on Aggregate Outcomes}

Debates' lack of impact on individual vote choice consistency does not necessarily preclude effects on aggregate vote shares. Indeed, debates may lead some voters to change their views without fully converging on their final vote choice yet, and nonetheless reduce the distance to final vote shares.

We measure debates' effects on $\Delta V_{t}$, the overall distance between predicted and final vote shares defined in Section III.E, with a specification using only one observation per debate per day:

$$
\Delta V_{t}^{d}=\sum_{k=-3}^{-1} \mu_{k}+\sum_{k=1}^{3} \mu_{k}+\mu_{4-}+\mu_{4+}+\sum_{t=-1}^{-60} \beta_{t} D_{t}+\alpha^{d}+W_{t}^{\prime} \lambda+u_{t}^{d}
$$

As shown in Figure VI and in columns 1 and 2 of Table IV, all pre- and post-debate relative days dummies are close to zero and non-significant. The average effect on this outcome in the three days following debates is positive, small ( 0.1 percentage point), and not statistically significant. Considering the lower bound of the $95 \%$ confidence interval, we can reject any impact lower than -0.1 percentage point at the $5 \%$ level, which corresponds to $2 \%$ of the overall 5 percentage points 
Figure VI: Debates' effects on aggregate vote shares

(a) Distance between predicted and final vote shares

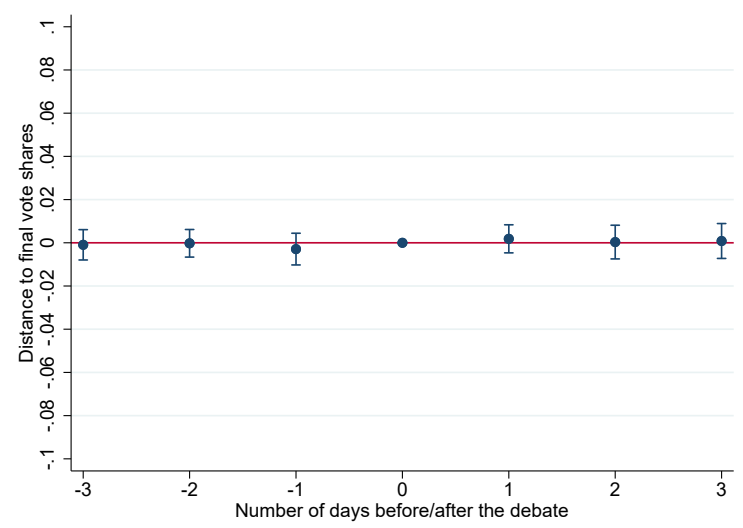

(b) Daily change in predicted vote shares

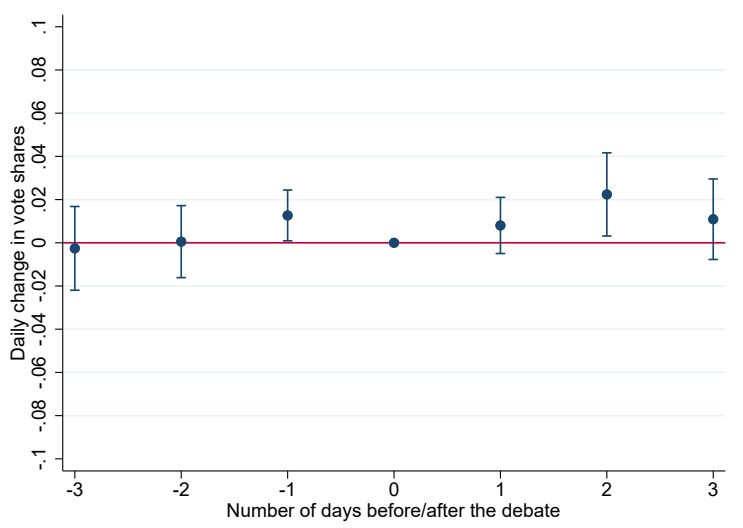

Notes: We show point estimates and 95\% confidence intervals from specifications in the form of equation [9], using the distance between predicted and final vote shares and daily change in predicted vote shares as outcomes. We control for debate $\times$ election fixed effects as well as fixed effects for the number of days relative to the election and for the day of the week in which the pre-electoral survey took place. We also control for the average number of days separating the post-electoral survey from the election in Figure VIa. N=3,802 and 3,749, respectively. Other notes as in Figure V.

decrease in the distance between predicted and final vote shares over the electoral season (Figure III). This result is unchanged when controlling for sociodemographic variables (column 2). ${ }^{36}$

Second, we test whether debates generate short-term shifts in aggregate vote intentions, which may be the case even if they do not contribute to the convergence to final vote shares. We define the overall daily change in predicted vote shares as $\delta V_{t}^{d}=\frac{1}{2} \sum_{c}\left|\widetilde{V}_{c t}^{d}-\widetilde{V}_{c t-1}^{d}\right|$, where $\widetilde{V}_{c t}$ is the predicted vote share of candidate $c$ among time $t$ respondents. $\delta V_{t}$ corresponds to the minimal share of voters who had to change their vote intention to explain the difference between predicted vote shares' distributions at time $t$ and $t-1$. We estimate equation [9] using this outcome, and we show the results in Figure VIb and in columns 3 and 4 of Table IV. ${ }^{37}$ We find some evidence that debates increase the daily change in predicted vote shares: the dummy for the second day after the debate is significant at the 5\% level, and the average effect in the three days following the debate is 1.4 percentage points, significant at the $10 \%$ level. The average of the three post-debate dummies is no longer significant but of similar magnitude in the specification including sociodemographic controls (column 4). However, the dummy for the day preceding the debate is also positive and

\footnotetext{
${ }^{36}$ As in Section III.E, we weight each observation by the number of $t$ respondents it was constructed from, relative to the total number of respondents surveyed at the same time before or after the debate.

${ }^{37}$ In this specification, we weight each observation by the number of $t$ and $t-1$ respondents it was constructed from, relative to the total number of respondents surveyed at the same time before or after the debate.
} 
statistically significant. The post-debate increase may thus be driven in part by an unusually low change in vote shares on the day of the debate.

Debates' positive effects on the daily change in vote shares, together with their (non-significant) negative effects on individual vote choice consistency, suggest that, if anything, they move a small fraction of voters away from their final choice, in the short term. Overall, while debates may generate short term shifts in vote shares, these do not contribute to the overall increase in vote choice consistency established in Section III.

\section{V.D Heterogeneous Effects of Debates}

The mostly null average effects of debates reported heretofore do not rule out the possibility that debates matter relatively more in certain conditions or for certain groups of voters. We first study the potential mediating influence of debates' timing and election type. Debates may affect vote choice more in contexts in which preexisting knowledge about the candidates is low or incentives to pay attention are high, for instance because the race is tight. To test this hypothesis, we compare: the first debate of each race, when voters do not know much about the candidates, to debates taking place later, when the fraction of voters who have already arrived at their final choice is higher; close races to expected landslides; highly fluctuating races to more stable races; the U.S. bipartisan elections to multiparty elections, in which a larger fraction of voters form their vote choice shortly before the election (as shown in Section IV); and plurality rule to proportional rule elections.

Formally, we interact the relative days dummies with indicators of debate type or election type:

$$
\begin{array}{rlc}
Y_{i t}^{d} & = & {\left[\sum_{k=-3}^{-1} \mu_{k}+\sum_{k=1}^{3} \mu_{k}+\mu_{4-}+\mu_{4+}\right] \times \Omega^{d}} \\
& + & {\left[\sum_{k=-3}^{-1} \eta_{k}+\sum_{k=1}^{3} \eta_{k}+\eta_{4-}+\eta_{4+}\right] \times\left(1-\Omega^{d}\right)} \\
& + & \sum_{t=-1}^{-60} \beta_{t} D_{t}+\alpha^{d}+W_{i t}^{\prime} \lambda+u_{i t}^{d}
\end{array}
$$

where $\Omega$ is a dummy equal to 1 for "type-a" races or debates, for which effects may be expected to be larger, and 0 otherwise. We interact the $\mu_{k}$ 's and $\eta_{k}$ 's with $\Omega$ and $(1-\Omega)$, respectively, to directly test the null that neither type-a nor type-b debates have significant effects.

While a few pre- and post-debate relative days dummies are statistically significant, as would be expected given the large number of tests, we do not find any positive and significant effect on vote choice consistency in the three days following early or later debates or debates held in any subset of races we examine (Appendix Table A.24). This is true whether we consider the day related dummies separately or take their average. 
Table IV: Debates' effects on aggregate vote shares

\begin{tabular}{|c|c|c|c|c|}
\hline & \multicolumn{2}{|c|}{$\begin{array}{l}\text { Distance between predicted } \\
\text { and final vote shares }\end{array}$} & \multicolumn{2}{|c|}{$\begin{array}{c}\text { Daily change in } \\
\text { predicted vote shares }\end{array}$} \\
\hline & (1) & (2) & (3) & (4) \\
\hline Before -3 & $\begin{array}{c}0.005 \\
(0.004)\end{array}$ & $\begin{array}{c}0.006 \\
(0.004)\end{array}$ & $\begin{array}{c}0.009 \\
(0.006)\end{array}$ & $\begin{array}{c}0.007 \\
(0.006)\end{array}$ \\
\hline-3 & $\begin{array}{l}-0.001 \\
(0.004)\end{array}$ & $\begin{array}{c}0.000 \\
(0.004)\end{array}$ & $\begin{array}{l}-0.003 \\
(0.010)\end{array}$ & $\begin{array}{l}-0.004 \\
(0.010)\end{array}$ \\
\hline-2 & $\begin{array}{l}-0.000 \\
(0.003)\end{array}$ & $\begin{array}{c}0.000 \\
(0.003)\end{array}$ & $\begin{array}{c}0.001 \\
(0.008)\end{array}$ & $\begin{array}{l}-0.001 \\
(0.009)\end{array}$ \\
\hline-1 & $\begin{array}{l}-0.003 \\
(0.004)\end{array}$ & $\begin{array}{l}-0.002 \\
(0.004)\end{array}$ & $\begin{array}{l}0.013^{* *} \\
(0.006)\end{array}$ & $\begin{array}{l}0.012^{*} \\
(0.006)\end{array}$ \\
\hline+1 & $\begin{array}{c}0.002 \\
(0.003)\end{array}$ & $\begin{array}{c}0.002 \\
(0.003)\end{array}$ & $\begin{array}{c}0.008 \\
(0.006)\end{array}$ & $\begin{array}{c}0.006 \\
(0.007)\end{array}$ \\
\hline+2 & $\begin{array}{c}0.000 \\
(0.004)\end{array}$ & $\begin{array}{c}0.001 \\
(0.004)\end{array}$ & $\begin{array}{l}0.022^{* *} \\
(0.010)\end{array}$ & $\begin{array}{l}0.021^{* *} \\
(0.009)\end{array}$ \\
\hline+3 & $\begin{array}{c}0.001 \\
(0.004)\end{array}$ & $\begin{array}{c}0.002 \\
(0.004)\end{array}$ & $\begin{array}{c}0.011 \\
(0.009)\end{array}$ & $\begin{array}{c}0.009 \\
(0.009)\end{array}$ \\
\hline After +3 & $\begin{array}{c}0.002 \\
(0.003)\end{array}$ & $\begin{array}{c}0.002 \\
(0.004)\end{array}$ & $\begin{array}{c}0.006 \\
(0.005)\end{array}$ & $\begin{array}{c}0.005 \\
(0.005)\end{array}$ \\
\hline Observations & 3802 & 3802 & 3749 & 3749 \\
\hline$R^{2}$ & 0.575 & 0.581 & 0.470 & 0.477 \\
\hline Mean, day of the debate & 0.046 & 0.046 & 0.085 & 0.085 \\
\hline Number of debates & 56 & 56 & 56 & 56 \\
\hline Debate $*$ election fixed effects & $\mathrm{x}$ & $\mathrm{x}$ & $\mathrm{x}$ & $\mathrm{x}$ \\
\hline Fixed effects for number of days to election & $\mathrm{x}$ & $\mathrm{x}$ & $\mathrm{x}$ & $\mathrm{x}$ \\
\hline Aggregate controls & $\mathrm{x}$ & $\mathrm{x}$ & $\mathrm{x}$ & $\mathrm{x}$ \\
\hline Sociodemographic controls & & $\mathrm{x}$ & & $\mathrm{x}$ \\
\hline Linear combination of estimates & & & & \\
\hline Average pre-debate dummies $-3,-2$, and -1 & $\begin{array}{l}-0.001 \\
(0.003)\end{array}$ & $\begin{array}{l}-0.000 \\
(0.003)\end{array}$ & $\begin{array}{c}0.004 \\
(0.007)\end{array}$ & $\begin{array}{c}0.002 \\
(0.007)\end{array}$ \\
\hline Average post-debate dummies 1,2 , and 3 & $\begin{array}{c}0.001 \\
(0.003)\end{array}$ & $\begin{array}{c}0.002 \\
(0.003)\end{array}$ & $\begin{array}{l}0.014^{*} \\
(0.008)\end{array}$ & $\begin{array}{c}0.012 \\
(0.008)\end{array}$ \\
\hline
\end{tabular}

Notes: Standard errors clustered at the debate level are in parentheses $(* * *, * *, *$ indicate significance at 1,5 , and $10 \%$, respectively). We use one observation per election per day and estimate specifications in the form of equation [9]. Aggregate controls include fixed effects for the day of the week in which the pre-electoral survey took place and, in columns 1 and 2, the average number of days separating the post-electoral survey from the election. Sociodemographic controls are averages of the sociodemographic variables included in Table III. Other notes as in Table III. 
We use a similar method to study treatment impact heterogeneity on the overall distance between predicted and final vote shares. Considering the average of the three post-debate dummies, we do not find any significant effect on the distance to final vote shares of any type of debate, or of debates held in any type of race (Appendix Table A.25). Only two individual post-debate dummies are negative and significant, corresponding to the effects of first debates and U.S. debates, two days after the debate (columns 1 and 4). However, in both cases, the coefficients for one and three days after the debate and, again, the average of the three post-debate coefficients are non-significant. In addition, the lower distance between predicted and final vote shares observed two days after the debates is not mirrored by any substantial increase in individual consistency in either case (columns 1 and 4 of Appendix Table A.24).

While we explore heterogeneity along a large number of dimensions, we still may have failed to consider the one dimension that truly matters. Therefore, we make a final attempt using the following, more agnostic approach. We estimate a specification in the form of equation [8], where each relative day dummy is interacted with a full set of debate indicators, yielding a specific set of coefficients $\mu_{-4}, \mu_{-3}, \ldots, \mu_{3}$, and $\mu_{4+}$ for each debate. The mean values of the three debate-specific post-debate dummies $\mu_{1}, \mu_{2}$, and $\mu_{3}$ are plotted in Appendix Figure A.13, for each debate separately and in ascending order. Since the number of observations corresponding to a specific debate and relative day is small, and we have a unique cluster for each debate, we do not report confidence intervals for the debate-specific estimates and refrain from interpreting these estimates individually. Rather, we are interested in the overall shape of the distribution and in the possible presence of outliers - that is, exceptional debates which, unlike the average event, may have changed the course of the corresponding election. We do not find evidence of such events. Instead, we observe that estimates are centered around zero (out of the 52 estimates, 30 are negative and 22 are positive) and smoothly distributed, and we do not detect any clear outlier. Furthermore, the effects of debates held in each country tend to span the full range, with both negative and positive values.

In Appendix Figure A.14, we repeat this exercise, using the distance between predicted and final vote shares as outcome. Once again, the mean debate-specific effects are centered around zero, with no clear outlier. Overall, these two figures strengthen our conclusion that debates' null effects hold across a large number of settings. ${ }^{38}$

\footnotetext{
${ }^{38}$ Consistent with the lack of heterogeneous effects across debates, our main null results are robust to using the difference-in-differences estimator from de Chaisemartin and D'Haultfœuille (2020), which eliminates any bias coming from heterogeneous effects and from dynamic effects over time (Appendix C.10).
} 
We now explore treatment impact heterogeneity along voter characteristics with a specification in the form of equation [10]. First and foremost, we measure effects separately for voters who report watching debates and those who do not. We do not separate watchers from non-watchers based on information recorded in the pre-electoral survey, as this may generate different splits among people surveyed before and after the debate. Instead, we use post-electoral survey questions recording whether the respondents watched any of the debates held before that election. This information is available for half of the debates. Debates could also plausibly have larger effects on voters whom we found to be more likely to form their vote choice during the campaign in Section III.D: voters with weak or no party identification, who may be freer to switch candidates, and those without college education and young voters, who are likely to be less informed before the debate.

Using these four variables and our other sociodemographic characteristics as mediating factors, and considering average effects in the three days following debates, we do not find any significant and positive effect on vote choice consistency or any significant and negative effect on the convergence to final vote shares for any of the 14 subgroups of voters we consider (Appendix Tables A.26 and A.27). The only exception is a negative effect, significant at the $5 \%$ level, on the distance to final vote shares for debate watchers. However, point estimates of similar magnitude and identical sign on pre-debate dummies for this group suggest that this effect is spuriously driven by unusually high distance to final vote shares among debate watchers surveyed on the day of the debate. In addition, this pattern is not mirrored by an increase in vote choice consistency: on average, the sign of the effect on the latter outcome is negative for debate watchers (Appendix Table A.26, column 1). Overall, we do not find any clear evidence that debates contribute to the process of vote choice formation for any type of voters.

Finally, we test whether debates systematically benefit some candidates at the expense of others and, in particular, whether they contribute to the increase in the vote share of lesser-known candidates, shown in Appendix Table A.18. We first run a specification in the form of equation [8] for each type of candidate, using a dummy equal to 1 if the respondent intends to vote for them as outcome. Then, we run a specification in the form of equation [9] to estimate the impact on vote share concentration. Debates affect significantly neither the predicted vote share of challengers, small candidates, or candidates of new parties, nor the concentration of predicted vote shares (Appendix Table A.28). 


\section{V.E Effects of Disasters}

Since TV debates do not contribute to vote choice formation despite being the most salient campaign events and showcasing the candidates themselves, one may wonder whether the increase in vote choice consistency documented in Section III is due instead to shocks occurring independently from the campaign, outside of politicians' control. Using the EM-DAT International Disasters Database, we identified 27 natural and technological disasters that occurred before 15 elections in three countries of the sample (Canada, Germany, and the U.S.), and that started more than three days before and three days after another disaster in the same country. ${ }^{39} \mathrm{We}$ estimate their impact with our event study design including three pre-disaster and post-disaster dummies (as in equation [8]).

The comparison of point estimates for the days preceding and following the disasters does not reveal any systematic impact on vote choice formation. Specifically, we first consider the effects of disasters on vote choice consistency (Appendix Figure A.15a, and Appendix Table A.29, columns 1 and 2). While the dummy for the third day after the disaster is positive and significant at the $5 \%$ level, the average impact of disasters on vote choice consistency in the three following days is non-significant and close to the average of the three pre-disaster dummies. When we extend the analysis to a five-day window, we find that the effects four and five days after a disaster are both small and non-significant (Appendix Table A.30).

Disasters do not have any clear effect on the probability to state a vote intention and on consistency conditional on stating a vote intention, either (Appendix Figures A.15b and A.15c and Appendix Table A.29, columns 3 through 6). In the latter case, the dummy for the first day after a disaster starts is positive and significant at the $10 \%$ level, but the average of the three post-disaster dummies is non-significant and comparable to the average of the three pre-disaster dummies. Next, Appendix Figure A.16a and Appendix Table A.31, columns 1 and 2, show no significant effect of disasters on the distance between predicted and final vote shares: the dummies for the days preceding and following disasters are all close to zero and non-significant. Finally, all preand post-disaster relative days dummies for the impact of disasters on the daily change in vote shares are positive and most of them are significant (Appendix Figure A.16b and Appendix Table A.31, columns 3 and 4), suggesting that disaster days are characterized by unusually low

\footnotetext{
${ }^{39}$ The full list of disasters is provided in Appendix Table B.7. 51\% are storms, 15\% floods, $15 \%$ transport accidents, $11 \%$ miscellaneous accidents (e.g., food contamination outbreak), and $7 \%$ wildfires.
} 
fluctuations in vote intentions relative to neighboring days (rather than disasters having an actual impact on this outcome).

Overall, these results suggest that disasters do not contribute to vote choice formation more than TV debates, but they are imprecise and should be interpreted with caution, given the small number of events (less than half the number of TV debates).

\section{CONCLUSION}

We study vote choice formation during campaigns, using 253,000 observations from two-round surveys in 62 elections around the world since 1952. Our method does not rely on people's own recollection of the date when they made up their mind, but instead on measuring the consistency between individuals' responses to pre- and post-electoral surveys. Focusing on this outcome also enables us to study the effects of specific events while allowing for the possibility that different voters are influenced in divergent ways. We examine TV debates and disasters, but studies measuring the effects of other types of events would benefit from using this same method instead of considering outcomes such as vote intention, which only capture net effects.

Overall, the fraction of people who state a pre-election vote intention identical to their eventual vote choice increases by 17 percentage points on average in the 60 days leading up to the vote. This large increase in individual vote choice consistency is concomitant with a 5 percentage point reduction in the distance between predicted and final vote shares. In other words, voters who make up their mind in this period affect the electoral results. We provide suggestive evidence that changes in vote choice come from changed beliefs about candidates' positions or quality more than beliefs about their chances of victory, and that priming also contributes to vote choice formation. We do find more modest effects of campaigns on voters with strong party attachments and in the U.S. two-party system, echoing the view that longstanding partisan attachments can reduce voters' receptiveness to election-specific information. However, even in these cases, campaign effects remain sizeable.

While our results support the view that campaigns have substantial effects on vote choice, it would be incorrect to infer that voters are swayed by just any information they receive in the electoral season. We were surprised to find that people's policy preferences are not affected by the campaign. In addition, we do not find any clear evidence that shocks occurring independently from the campaign, such as natural and technological disasters, have important effects on vote 
choice formation in the national elections we study. Most importantly, our event study finds that TV debates - for all the interest they generate, the large viewing audience they draw, and the many media commentaries they provoke - neither increase individual vote choice consistency nor reduce the distance to final vote shares. If anything, TV debates move a small fraction of voters away from their final vote choice, in the short term.

The fact that our sample includes data from ten distinct countries makes the external validity of our results unusually broad. This said, we note that all these countries are well-established democracies. The fraction of voters making up their mind during campaigns may be even larger in countries with younger democratic regimes, less stable party systems, and lower baseline levels of political information. Naturally, the effects of TV debates may be different in such countries.

Overall, our results suggest that even if voters sometimes seem relatively uninformed, their vote choice actually aggregates extensive information, beyond just debates, and that other sources are more impactful. A possible interpretation is that voters discard candidates' debate statements because they rationally expect them to be more biased than information coming from the media, discussions with other voters, and other third parties, or that voters only pay attention to statements aligned with their beliefs. An alternative interpretation is that the particular medium through which debates are broadcast is what matters: it is difficult for candidates to change people's minds, and this does not happen via TV or radio communication. This interpretation is consistent with the fact that the evidence on the effects of political ads diffused through these channels on vote choice is mixed (Gerber et al., 2011; Spenkuch and Toniatti, 2018), whereas more personalized contacts such as door-to-door visits or town hall meetings tend to have large persuasive effects (e.g., Fujiwara and Wantchekon, 2013; Pons, 2018).

One implication is that candidates should focus on organizing these more-impactful activities if they want to increase their chances of winning. In the elections we study, only a minority of voters report having been contacted or visited by a party. Our results also have implications for the regulation of campaigns. Since the first presidential TV debate in the U.S. in 1960, there has been a continuous effort to diffuse this innovation to countries which have not adopted it yet, and to improve the format of debates where they have become a tradition. Our results suggest that some of this energy may be better spent in reforming campaign regulations to ensure that all candidates have equal access to voters and in monitoring the most personal and tailored forms of partisan communication, to improve the quality of information available to voters. 


\section{References}

Achen, Christopher H. and Larry M. Bartels, Democracy for Realists: Why Elections Do Not Produce Responsive Government., Princeton University Press, 2016.

Angelucci, Charles and Andrea Prat, "Is Journalistic Truth Dead? Measuring How Informed Voters Are about Political News," 2021.

Ashworth, Scott, Ethan Bueno de Mesquita, and Amanda Friedenberg, "Learning about Voter Rationality," American Journal of Political Science, 2018, 62 (1), 37-54.

Benoit, William L, Glenn J Hansen, and Rebecca M Verser, “A Meta-Analysis of the Effects of Viewing U.S. Presidential Debates," Communication Monographs, 2003, 70 (4), 335-350.

Besley, Timothy and Stephen Coate, "An Economic Model of Representative Democracy," The Quarterly Journal of Economics, 1997, 112 (1), 85-114.

_ , Jose G. Montalvo, and Marta Reynal-Querol, “Do Educated Leaders Matter?," Economic Journal, 2011, 121 (554).

Bidwell, Kelly, Katherine Casey, and Rachel Glennerster, "Debates: Voting and Expenditure Responses to Political Communication," Journal of Political Economy, 2019.

Birdsell, David S, "Political Campaign Debates," in Kate Kenski and Kathleen Hall Jamieson, eds., The Oxford Handbook of Political Communication, Oxford University Press, 2017.

Boxell, Levi, Matthew Gentzkow, and Jesse Shapiro, "Cross-Country Trends in Affective Polarization," Review of Economics and Statistics, 2022.

Brierley, Sarah, Eric Kramon, and George Kwaku Ofosu, "The Moderating Effect of Debates on Political Attitudes," American Journal of Political Science, 2019.

Broockman, David and Joshua Kalla, "The Minimal Persuasive Effects of Campaign Contact in General Elections: Evidence from 49 Field Experiments," American Political Science Review, 2018, 112 (1), 148-166.

Cantoni, Enrico and Vincent Pons, "Does Context Outweigh Individual Characteristics in Driving Voting Behavior? Evidence from Relocations within the United States," American Economic Review, 2022, 112 (4), 1226-1272.

Chaffee, Steven H and Sun Yuel Choe, "Time of Decision and Media Use During the Ford-Carter Campaign,” Public Opinion Quarterly, 1980, 44 (1), 53-69.

Chiang, Chun Fang and Brian Knight, "Media Bias and Influence: Evidence from Newspaper Endorsements," Review of Economic Studies, 2011, 78 (3), 795-820.

Cho, In-Koo and David M. Kreps, "Signaling Games and Stable Equilibria," Quarterly Journal 
of Economics, 1987, 102 (2), 179-222.

Cole, Shawn, Andrew Healy, and Eric Werker, "Do voters demand responsive governments? Evidence from Indian disaster relief," Journal of Development Economics, 2012, 97 (2), 167181.

Crawford, Vincent P. and Joel Sobel, "Strategic Information Transmission," Econometrica, 1982, 50 (6), 1431-1451.

de Chaisemartin, Clément and Xavier D'Haultfouille, “Two-Way Fixed Effects Estimators with Heterogeneous Treatment Effects," American Economic Review, 2020, 110 (9), 2964-2996.

DellaVigna, Stefano and Ethan Kaplan, "The Fox News Effect: Media Bias and Voting," Quarterly Journal of Economics, 2007, 122 (3), 1187-1234.

- and Matthew Gentzkow, "Persuasion: Empirical Evidence," Annual Review of Economics, 2010, 2, 643-649.

Delli Carpini, Michael $\mathbf{X}$ and Scott Keeter, What Americans Know about Politics and Why It Matters, Yale University Press, 1997.

Enos, Ryan D and Eitan D Hersh, "Party Activists as Campaign Advertisers: The Ground Campaign as a Principal-Agent Problem," American Political Science Review, 2015, 109 (2), 252-278.

Ferejohn, John, "Incumbent Performance and Electoral Control," Public Choice, 1986, 50 (1), $5-25$.

Ferraz, Claudio and Frederico Finan, "Exposing Corrupt Politicians: The Effects of Brazil's Publicly Released Audits on Electoral Outcomes," The Quarterly Journal of Economics, 2008, 123 (2), 703-745.

Fischer, Paul E and Phillip C Stocken, "Imperfect Information and Credible Communication," Journal of Accounting Research, 2001, 39 (1), 119-134.

Fournier, Patrick, Richard Nadeau, André Blais, Elisabeth Gidengil, and Neil Nevitte, "Timeof-Voting Decision and Susceptibility to Campaign Effects," Electoral Studies, 2004, 23 (4), 661-681.

Fridkin, Kim L, Patrick J Kenney, Sarah Allen Gershon, Karen Shafer, and Gina Serignese Woodall, "Capturing the Power of a Campaign Event: The 2004 Presidential Debate in Tempe," Journal of Politics, 2007, 69 (3), 770-785.

Fujiwara, Thomas and Leonard Wantchekon, "Can Informed Public Deliberation Overcome Clientelism? Experimental Evidence from Benin," American Economic Journal: Applied 
Economics, 2013, 5 (4), 241-255.

Galasso, Vincenzo and Tommaso Nannicini, "Political Selection under Alternative Electoral Rules," Public Choice, 2017, 171 (3), 257-281.

Gelman, Andrew and Gary King, "Why Are American Presidential Election Campaign Polls So Variable When Votes Are So Predictable?,' British Journal of Political Science, 1993, 23 (4), 409-451.

Gennaioli, Nicola and Andrei Shleifer, "What Comes to Mind," Quarterly Journal of Economics, 2010, 125 (4), 1399-1433.

Gerber, Alan S, James G Gimpel, Donald P Green, and Daron R Shaw, "How Large and Longlasting Are the Persuasive Effects of Televised Campaign Ads? Results from a Randomized Field Experiment," American Political Science Review, 2011, 105 (1), 135-150.

Granzier, Riako, Vincent Pons, and Clémence Tricaud, "The Large Effects of a Small Win: How Past Rankings Shape the Behavior of Voters and Candidates," NBER WP 26599, 2021.

Henderson, Michael and D. Sunshine Hillygus, "Changing the Clock: The Role of Campaigns in the Timing of Vote Decision," Public Opinion Quarterly, 2016, 80 (3), 761-770.

Hillygus, D Sunshine, "Campaign Effects and the Dynamics of Turnout Intention in Election 2000," Journal of Politics, 2005, 67 (1), 50-68.

_ and Simon Jackman, "Voter Decision Making in Election 2000: Campaign Effects, Partisan Activation, and the Clinton Legacy," American Journal of Political Science, 2003, 47 (4), 583596.

Holbrook, Thomas M, Do Campaigns Matter?, SAGE Publications, 1996.

Jennings, Will and Christopher Wlezien, "The Timeline of Elections: A Comparative Perspective," American Journal of Political Science, 2016, 60 (1), 219-233.

Johnston, Richard and Henry E Brady, “The Rolling Cross-Section Design,” Electoral Studies, 2002, 21 (2), 283-295.

Kamenica, Emir and Matthew Gentzkow, "Bayesian Persuasion," American Economic Review, 2011, 101 (6), 2590-2615.

Kendall, Chad, Tommaso Nannicini, and Francesco Trebbi, "How Do Voters Respond to Information? Evidence from a Randomized Campaign," American Economic Review, 2015, 105 (1), 322-353.

Lazarsfeld, Paul Felix, Bernard Berelson, and Hazel Gaudet, The People's Choice: How the Voter Makes Up His Mind in a Presidential Campaign, Duell, Sloan and Pearce, 1944. 
Lenz, Gabriel S, Follow the Leader? How Voters Respond to Politicians' Policies and Performance, University of Chicago Press, 2012.

Lindbeck, Assar and Jörgen W. Weibull, "Balanced-Budget Redistribution as the Outcome of Political Competition,” Public Choice, 1987, 52 (3), 273-297.

Martin, Gregory J. and Ali Yurukoglu, "Bias in Cable News: Persuasion and Polarization," American Economic Review, 2017, 107 (9), 2565-2599.

McKinney, Mitchell S and Diana B Carlin, "Political Campaign Debates," in Lynda Lee Kaid, ed., Handbook of Political Communication Research, Routledge, 2004, pp. 203-234.

Minozzi, William, Michael A Neblo, Kevin M Esterling, and David M J Lazer, "Field Experiment Evidence of Substantive, Attributional, and Behavioral Persuasion by Members of Congress in Online Town Halls," Proceedings of the National Academy of Sciences of the United States of America, 2015, 112 (13), 3937-3942.

Mullainathan, Sendhil, Ebonya Washington, and Julia R Azari, “The Impact of Electoral Debate on Public Opinions: An Experimental Investigation of the 2005 New York City Mayoral Election," in Ian Shapiro, Susan C Stokes, Elisabeth Jean Wood, and Aexander S Kirshner, eds., Political Representation, Cambridge University Press, 2009, pp. 324-341.

Neundorf, Anja and Kaat Smets, "Political Socialization and the Making of Citizens," Oxford Handbooks Online, 2017, (January), 1-28.

Panagopoulos, Costas, “All About that Base: Changing Campaign Strategies in U.S. Presidential Elections," Party Politics, 2016, 22 (2), 179-190.

Pettersson-Lidbom, Per, "Do Parties Matter for Economic Outcomes? A RegressionDiscontinuity Approach," Journal of the European Economic Association, 2008, 6 (5), 10371056.

Pons, Vincent, "Will a Five-Minute Discussion Change your Mind? A Countrywide Experiment on Voter Choice in France," American Economic Review, 2018, 108 (6), 1322-1363.

- and Clémence Tricaud, "Expressive Voting and Its Cost: Evidence from Runoffs with Two or Three Candidates," Econometrica, 2018, 86 (5), 1621-1649.

Shaw, Daron R, “A Study of Presidential Campaign Event Effects from 1952 to 1992," Journal of Politics, 1999, 61 (2), 387-422.

_ and Brian E Roberts, "Campaign Events, the Media and the Prospects of Victory: The 1992 and 1996 US Presidential Elections," British Journal of Political Science, 2000, 30 (2), 259-289.

Spenkuch, Jorg L and David Toniatti, "Political Advertising and Election Results," Quarterly 
Journal of Economics, 2018, 133 (4), 1981-2036.

Wlezien, Christopher and Robert S Erikson, "The Timeline of Presidential Election Campaigns," Journal of Politics, 2002, 64 (4), 969-993.

Wright, Gerald C, "Errors in Measuring Vote Choice in the National Election Studies, 1952-88," American Journal of Political Science, 1993, 37 (1), 291-316. 


\section{Online Appendix to "How Do Campaigns Shape Vote Choice?" (Le Pennec and Pons)}

- Appendix A: Survey Selection and Additional Results

- Appendix A.1: Survey Selection

- Appendix A.2: Formation of Vote Choice: Additional Results

- Appendix A.3: Formation of Beliefs, Policy Preferences, and Issue Salience: Additional Results

- Appendix A.4: Impact of TV Debates: Additional Results

- Appendix B: Additional Information on the Data

- Appendix B.1: Data References and Links to Surveys

- Appendix B.2: Definition of Key Variables

- Appendix B.3: Information on Disasters

- Appendix B.4: Debate Viewership

- Appendix B.5: Sampling Frame

- Appendix C: Additional Robustness Checks

- Appendix C.1: Wild Cluster Bootstrap Standard Errors

- Appendix C.2: Standard Errors Adjusted for Clustering at the Election Date Level

- Appendix C.3: Survey Weights

- Appendix C.4: Sociodemographic Controls

- Appendix C.5: Rolling Cross-Sections

- Appendix C.6: Including Unlikely Voters

- Appendix C.7: Excluding Surveys with the Largest Decrease in Reinterview Rate

- Appendix C.8: Event Study with Five-Day Window

- Appendix C.9: Event Study with Balanced Panel on Three-Day Window

- Appendix C.10: Event Study with de Chaisemartin and D'Haultefoeuille (2020)'s method 


\section{A Survey Selection and Additional Results}

\section{A.1 Survey Selection}

As discussed in Section II.A, our study only includes surveys showing a sufficiently high similarity between respondents surveyed on different dates. Rolling cross-sections satisfy this criterion by design. In these surveys, a random subsample of respondents is drawn from the overall sample on each day. Those who are not successfully reached are either not contacted again (for instance in the BES), or contacted again along with randomly drawn new respondents over the next few days, following a consistent rule (e.g., all respondents are contacted for up to seven days before being removed from the pool in AUTNES 2013). In the latter case, each daily sample combines both easy-to-reach and hard-to-reach respondents. Apart from the very first days, where hard-to-reach respondents tend to be underrepresented, all daily samples are comparable in terms of both observed and unobserved respondents' characteristics.

To increase statistical power, we complemented our sample of rolling cross-sections with surveys that were not designed as rolling cross-sections but showed a sufficiently high similarity between respondents surveyed on different dates nonetheless (in addition to satisfying the two other criteria laid out in the main text). To assess the comparability of daily samples in these surveys, we tested for differences in mean sociodemographic characteristics (education, age, gender, income, and employment status) for any pair of daily samples. We excluded surveys for which we reject the null hypothesis of no difference in mean characteristics more than $15 \%$ of the times, a benchmark defined based on the rolling-cross sections. Surveys from the Cooperative Congressional Election Studies (in the U.S.) and the Israel National Election Studies were excluded because they violated this condition. ${ }^{40}$ Instead, surveys from the American National Election Studies, the Dutch Parliamentary Election Studies, the New Zealand Election Studies and the Swedish National Election Studies passed this test and were included in the study.

All of the surveys entail interviewing a new set of respondents every day until the election, with two minor exceptions. First, some surveys do not interview anyone on weekends and holidays. Second, all surveys end one day before Election Day, except for AUTNES 2013 and ANES 1952, which end two days before.

\footnotetext{
${ }^{40}$ Although they are not included in our main sample, we use the 2008, 2012, and 2016 CCES surveys to determine which voters are most likely to overreport their turnout (see Section III.F and Appendix Table A.8).
} 


\section{A.2 Formation of Vote Choice: Additional Results}

Figure A.1: Vote choice consistency over the last 120 days before the election

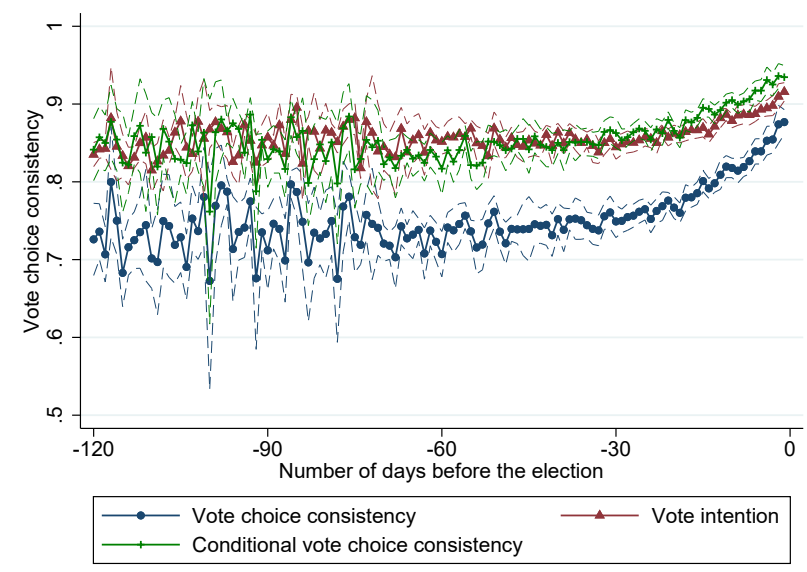

Notes: We show point estimates and 95\% confidence intervals from specifications in the form of equation [1], regressing vote choice consistency $(\mathrm{N}=224,382)$, vote intention $(\mathrm{N}=283,821)$, and conditional vote choice consistency $(\mathrm{N}=199,263)$ on 120 fixed effects indicating the number of days relative to the election. The respondents surveyed more than 60 days before the election come from 18 surveys in our original sample which start earlier than 60 days before the election and from six "pre-campaign" surveys that preceded a few of our pre-electoral surveys. We include different fixed effects for the pre-electoral and pre-campaign waves preceding the same election. Other notes as in Figure I.

Figure A.2: Number of days separating the post-electoral survey from the election

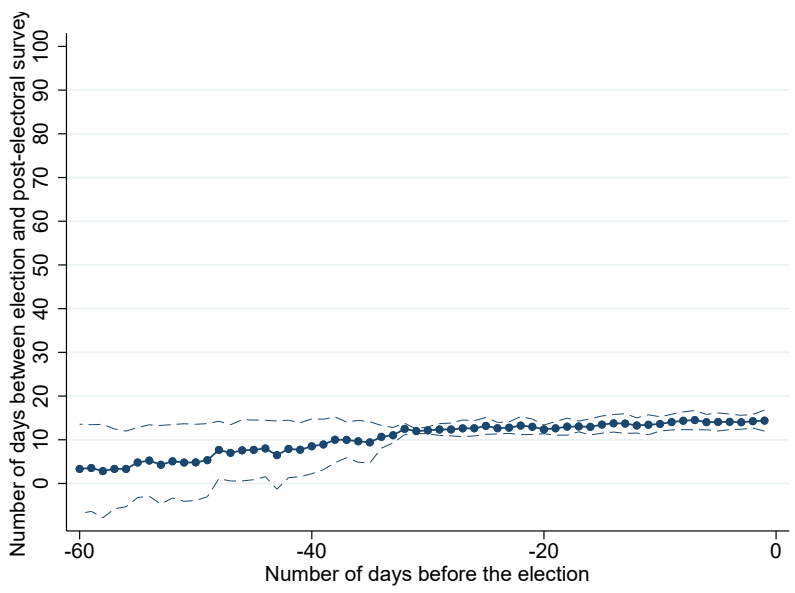

Notes: We show point estimates and 95\% confidence intervals from specifications in the form of equation [1], regressing the number of days separating the post-electoral survey from the election on 60 fixed effects indicating the number of days separating the pre-electoral survey from the election, election fixed effects and fixed effects for the day of the week in which the pre-electoral survey took place. The sample includes all respondents surveyed before and after the election who said that they intended to vote, in the first survey. N=186,639. 
Figure A.3: Vote choice consistency, controlling for the number of days separating the pre- and post-electoral surveys

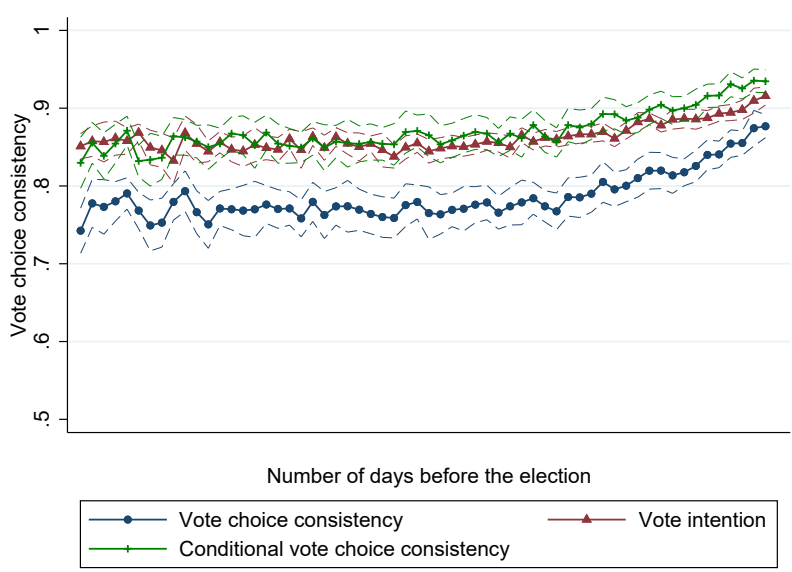

Notes: We control for the number of days separating the pre- and post-electoral surveys instead of the number of days separating the post-electoral survey from the election. Other notes as in Figure I.

Figure A.4: Certainty of vote intention

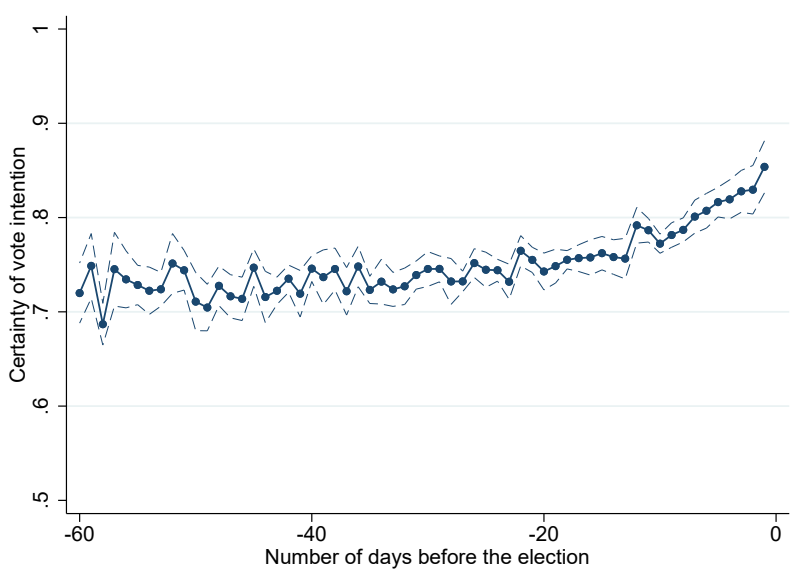

Notes: People's certainty of their vote intention, when available, is normalized to range from 0 to 1 across all surveys and is set to 0 for respondents who do not state a vote intention. The sample includes all respondents surveyed before the election who said that they intended to vote and either stated a vote intention and were asked how certain they were about this intention, or did not state any vote intention. $\mathrm{N}=154,175$. Other notes as in Appendix Figure A.2. 
Figure A.5: Increase in vote choice consistency across countries and over time, homogeneous time periods

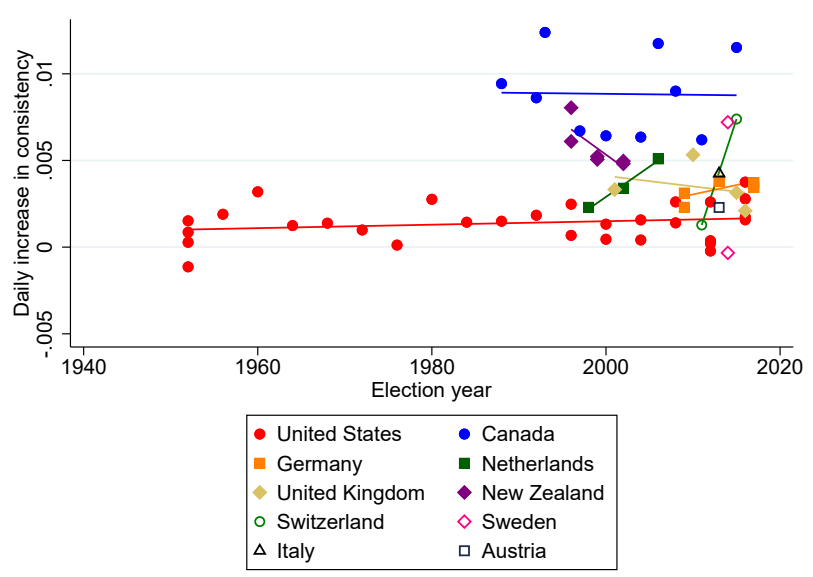

Notes: The sample is restricted to respondents surveyed no earlier than the minimal number of days covered by any survey in the corresponding country. $\mathrm{N}=65$. Other notes as in Figure II.

Figure A.6: Unweighted distance between predicted and final vote shares

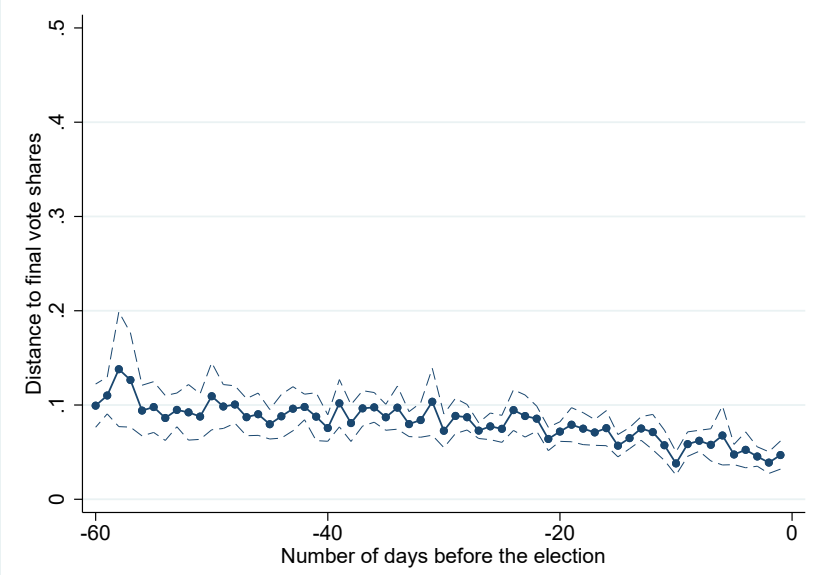

Notes: Observations are unweighted. Other notes as in Figure III. 
Figure A.7: Turnout intention

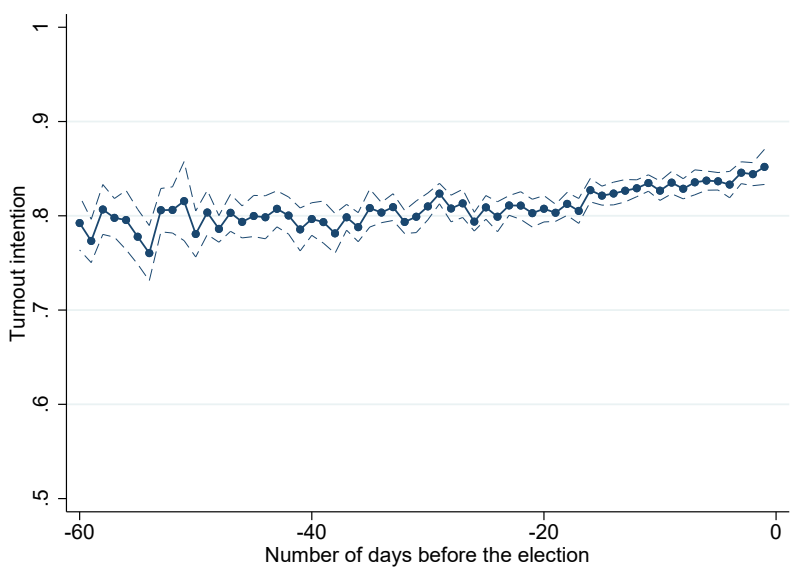

Notes: The sample includes all respondents surveyed before the election who were asked if they intended to vote, and the outcome is a dummy equal to 1 if they said yes. $\mathrm{N}=312,672$. Other notes as in Appendix Figure A.2.

Figure A.8: Consistency in party identification

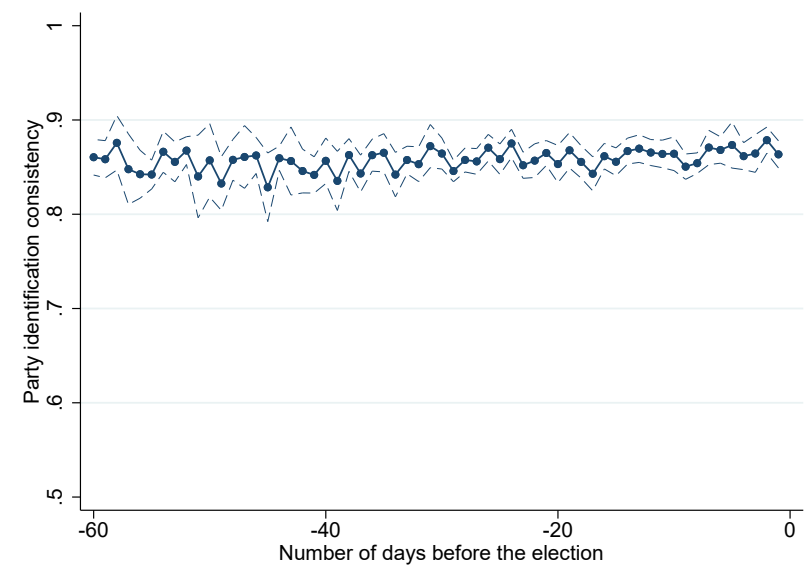

Notes: The sample includes all respondents surveyed before and after the election who provided a valid party identification (namely, we exclude individuals who responded "I don't know" or "No party" when asked which party they identify with) in both surveys. The outcome is a dummy equal to 1 if the respondent indicated the same party before and after the election. $\mathrm{N}=100,195$. Other notes as in Figure I. 
Table A.1: Vote choice consistency and distance to final vote shares between 120 and 60 days before the election

\begin{tabular}{|c|c|c|c|c|c|c|c|c|}
\hline & \multicolumn{2}{|c|}{$\begin{array}{l}\text { Vote choice } \\
\text { consistency }\end{array}$} & \multicolumn{2}{|c|}{$\begin{array}{c}\text { Vote } \\
\text { intention }\end{array}$} & \multicolumn{2}{|c|}{$\begin{array}{l}\text { Conditional } \\
\text { consistency }\end{array}$} & \multicolumn{2}{|c|}{$\begin{array}{c}\text { Distance between predicted } \\
\text { and final vote shares }\end{array}$} \\
\hline & (1) & (2) & (3) & (4) & (5) & (6) & (7) & (8) \\
\hline Time & $\begin{array}{c}0.0002 \\
(0.0001)\end{array}$ & $\begin{array}{c}0.0000 \\
(0.0011)\end{array}$ & $\begin{array}{c}0.0001 \\
(0.0001)\end{array}$ & $\begin{array}{l}-0.0032 \\
(0.0025)\end{array}$ & $\begin{array}{l}-0.0001 \\
(0.0001)\end{array}$ & $\begin{array}{l}0.0018^{*} \\
(0.0010)\end{array}$ & $\begin{array}{c}0.0005 \\
(0.0004)\end{array}$ & $\begin{array}{l}-0.0023 \\
(0.0038)\end{array}$ \\
\hline Time $^{2}$ & & $\begin{array}{l}-0.0000 \\
(0.0000)\end{array}$ & & $\begin{array}{l}-0.0000 \\
(0.0000)\end{array}$ & & $\begin{array}{l}0.0000^{*} \\
(0.0000)\end{array}$ & & $\begin{array}{l}-0.0000 \\
(0.0000)\end{array}$ \\
\hline Observations & 23466 & 23466 & 30332 & 30332 & 21087 & 21087 & 346 & 346 \\
\hline$R^{2}$ & 0.061 & 0.061 & 0.035 & 0.035 & 0.059 & 0.059 & 0.575 & 0.578 \\
\hline Mean at day -61 & 0.7732 & 0.7732 & 0.8702 & 0.8702 & 0.8754 & 0.8754 & 0.0669 & 0.0669 \\
\hline Election fixed effects & $\mathrm{x}$ & $\mathrm{x}$ & $\mathrm{x}$ & $\mathrm{x}$ & $\mathrm{x}$ & $\mathrm{x}$ & $\mathrm{x}$ & $\mathrm{x}$ \\
\hline Individual controls & $\mathrm{x}$ & $\mathrm{x}$ & $\mathrm{x}$ & $\mathrm{x}$ & $\mathrm{x}$ & $\mathrm{x}$ & & \\
\hline Aggregate controls & & & & & & & $\mathrm{x}$ & $\mathrm{x}$ \\
\hline
\end{tabular}

Notes: The sample includes respondents surveyed between 120 and 60 days before the election, including respondents surveyed in six pre-campaign waves that are not included in our original sample. We include different fixed effects for the pre-electoral and pre-campaign waves preceding the same election. Time is defined as the number of days before the election, from 61 to 120 . Other notes as in Table I. 
Table A.2: Vote choice consistency and distance to final vote shares across election types

\begin{tabular}{|c|c|c|c|c|c|c|c|c|}
\hline & \multicolumn{4}{|c|}{ Vote choice consistency } & \multicolumn{4}{|c|}{$\begin{array}{l}\text { Distance between predicted } \\
\text { and final vote shares }\end{array}$} \\
\hline & (1) & (2) & (3) & (4) & (5) & (6) & (7) & (8) \\
\hline Time & $\begin{array}{c}0.0036^{* * *} \\
(0.0003)\end{array}$ & $\begin{array}{l}0.0037^{* * *} \\
(0.0003)\end{array}$ & $\begin{array}{c}0.0037^{* * *} \\
(0.0003)\end{array}$ & $\begin{array}{c}0.0038^{* * *} \\
(0.0003)\end{array}$ & $\begin{array}{c}-0.0012^{* * *} \\
(0.0002)\end{array}$ & $\begin{array}{c}-0.0012^{* * *} \\
(0.0002)\end{array}$ & $\begin{array}{c}-0.0012^{* * *} \\
(0.0002)\end{array}$ & $\begin{array}{c}-0.0012^{* * *} \\
(0.0002)\end{array}$ \\
\hline Time * U.S. & $\begin{array}{c}-0.0025^{* * *} \\
(0.0003)\end{array}$ & & $\begin{array}{c}-0.0025^{* * *} \\
(0.0004)\end{array}$ & $\begin{array}{c}-0.0025^{* * *} \\
(0.0005)\end{array}$ & $\begin{array}{c}0.0007^{* * *} \\
(0.0003)\end{array}$ & & $\begin{array}{l}0.0007^{*} \\
(0.0004)\end{array}$ & $\begin{array}{l}0.0007^{*} \\
(0.0003)\end{array}$ \\
\hline Time * Plurality rule & & $\begin{array}{c}-0.0013^{* * *} \\
(0.0004)\end{array}$ & $\begin{array}{l}-0.0000 \\
(0.0005)\end{array}$ & $\begin{array}{l}-0.0002 \\
(0.0005)\end{array}$ & & $\begin{array}{c}0.0004 \\
(0.0003)\end{array}$ & $\begin{array}{c}0.0000 \\
(0.0004)\end{array}$ & $\begin{array}{c}0.0000 \\
(0.0004)\end{array}$ \\
\hline Observations & 175832 & 175832 & 175832 & 175832 & 3045 & 3045 & 3045 & 3045 \\
\hline$R^{2}$ & 0.068 & 0.066 & 0.068 & 0.073 & 0.482 & 0.476 & 0.482 & 0.484 \\
\hline Mean at day -1 & 0.8639 & 0.8639 & 0.8639 & 0.8639 & 0.0376 & 0.0376 & 0.0376 & 0.0376 \\
\hline Election fixed effects & $\mathrm{x}$ & $\mathrm{x}$ & $\mathrm{x}$ & $\mathrm{x}$ & $\mathrm{x}$ & $\mathrm{x}$ & $\mathrm{x}$ & $\mathrm{x}$ \\
\hline Individual controls & $\mathrm{x}$ & $\mathrm{x}$ & $\mathrm{x}$ & $\mathrm{x}$ & & & & \\
\hline Aggregate controls & & & & & $\mathrm{x}$ & $\mathrm{x}$ & $\mathrm{x}$ & $\mathrm{x}$ \\
\hline Sociodemographic controls & & & & $\mathrm{x}$ & & & & $\mathrm{x}$ \\
\hline Linear combination of estimates & & & & & & & & \\
\hline Time + Time $*$ US & $\begin{array}{c}0.0012^{* * *} \\
(0.0001)\end{array}$ & & $\begin{array}{l}0.0012^{* *} \\
(0.0005)\end{array}$ & $\begin{array}{l}0.0013^{* *} \\
(0.0005)\end{array}$ & $\begin{array}{c}-0.0004^{* * *} \\
(0.0001)\end{array}$ & & $\begin{array}{l}-0.0004 \\
(0.0004)\end{array}$ & $\begin{array}{l}-0.0005 \\
(0.0004)\end{array}$ \\
\hline Time + Time * Plurality rule & & $\begin{array}{c}0.0023^{* * *} \\
(0.0003)\end{array}$ & $\begin{array}{c}0.0036^{* * *} \\
(0.0004)\end{array}$ & $\begin{array}{c}0.0036^{* * *} \\
(0.0005)\end{array}$ & & $\begin{array}{c}-0.0008^{* * *} \\
(0.0002)\end{array}$ & $\begin{array}{c}-0.0012^{* * *} \\
(0.0003)\end{array}$ & $\begin{array}{c}-0.0012^{* * *} \\
(0.0003)\end{array}$ \\
\hline
\end{tabular}

Notes: Standard errors clustered at the survey level are in parentheses $(* * *, * *, *$ indicate significance at 1,5 , and $10 \%$, respectively). The linear time trend is interacted with dummies for being surveyed before a type-a election (U.S. bipartisan system or plurality voting rule) as opposed to a type-b election (multiparty system or proportional rule). Referenda are excluded. Sociodemographic controls include education (dummies indicating above high school education and college degree), gender, age, income quartiles, and employment status. Linear combinations of estimates are also reported, along with their standard errors. Other notes as in Table I. 
Table A.3: Vote choice consistency and distance to final vote shares in U.S. swing and non-swing states

\begin{tabular}{|c|c|c|c|c|c|c|c|c|}
\hline & \multicolumn{2}{|c|}{$\begin{array}{l}\text { Vote choice } \\
\text { consistency }\end{array}$} & \multicolumn{2}{|c|}{$\begin{array}{c}\text { Vote } \\
\text { intention }\end{array}$} & \multicolumn{2}{|c|}{$\begin{array}{l}\text { Conditional } \\
\text { consistency }\end{array}$} & \multicolumn{2}{|c|}{$\begin{array}{l}\text { Distance between predicted } \\
\text { and final vote shares }\end{array}$} \\
\hline & (1) & (2) & (3) & (4) & (5) & (6) & (7) & (8) \\
\hline Time & $\begin{array}{c}0.0010^{* * *} \\
(0.0002)\end{array}$ & $\begin{array}{l}0.0010^{* * *} \\
(0.0002)\end{array}$ & $\begin{array}{c}0.0002 \\
(0.0001)\end{array}$ & $\begin{array}{c}0.0002 \\
(0.0001)\end{array}$ & $\begin{array}{c}0.0008^{* * *} \\
(0.0001)\end{array}$ & $\begin{array}{c}0.0008^{* * *} \\
(0.0001)\end{array}$ & $\begin{array}{c}-0.0005^{* * *} \\
(0.0001)\end{array}$ & $\begin{array}{c}-0.0006^{* * *} \\
(0.0001)\end{array}$ \\
\hline Swing state & $\begin{array}{l}0.0219^{* *} \\
(0.0093)\end{array}$ & $\begin{array}{l}0.0218^{* *} \\
(0.0090)\end{array}$ & $\begin{array}{l}0.0159^{*} \\
(0.0089)\end{array}$ & $\begin{array}{l}0.0160^{*} \\
(0.0086)\end{array}$ & $\begin{array}{c}0.0082 \\
(0.0074)\end{array}$ & $\begin{array}{c}0.0078 \\
(0.0072)\end{array}$ & $\begin{array}{c}0.0033 \\
(0.0044)\end{array}$ & $\begin{array}{c}0.0046 \\
(0.0042)\end{array}$ \\
\hline Time $*$ Swing state & $\begin{array}{l}0.0005^{*} \\
(0.0002)\end{array}$ & $\begin{array}{l}0.0004^{*} \\
(0.0002)\end{array}$ & $\begin{array}{c}0.0002 \\
(0.0002)\end{array}$ & $\begin{array}{c}0.0002 \\
(0.0002)\end{array}$ & $\begin{array}{c}0.0003 \\
(0.0002)\end{array}$ & $\begin{array}{c}0.0002 \\
(0.0002)\end{array}$ & $\begin{array}{l}-0.0002 \\
(0.0002)\end{array}$ & $\begin{array}{l}-0.0001 \\
(0.0002)\end{array}$ \\
\hline Observations & 49397 & 49397 & 64261 & 64261 & 45629 & 45629 & 2856 & 2856 \\
\hline$R^{2}$ & 0.049 & 0.053 & 0.068 & 0.073 & 0.021 & 0.024 & 0.123 & 0.131 \\
\hline Mean at day -1 & 0.9285 & 0.9285 & 0.9462 & 0.9462 & 0.9566 & 0.9566 & 0.0277 & 0.0277 \\
\hline Election fixed effects & $\mathrm{x}$ & $\mathrm{x}$ & $\mathrm{x}$ & $\mathrm{x}$ & $\mathrm{x}$ & $\mathrm{x}$ & $\mathrm{x}$ & $\mathrm{x}$ \\
\hline Individual controls & $\mathrm{x}$ & $\mathrm{x}$ & $\mathrm{x}$ & $\mathrm{x}$ & $\mathrm{x}$ & $\mathrm{x}$ & & \\
\hline Aggregate controls & & & & & & & $\mathrm{x}$ & $\mathrm{x}$ \\
\hline Sociodemographic controls & & $\mathrm{x}$ & & $\mathrm{x}$ & & $\mathrm{x}$ & & $\mathrm{x}$ \\
\hline
\end{tabular}

Notes: Standard errors clustered at the survey level are in parentheses $(* * *, * *, *$ indicate significance at 1,5 , and $10 \%$, respectively). The sample is restricted to U.S. elections. The linear time trend is interacted with a dummy equal to 1 if the respondent lives in a swing state, defined as one of the ten states in which the vote share difference between the top two presidential candidates was the closest in that year, and 0 otherwise. Swing states for each election year are listed in Appendix Table B.9. Sociodemographic controls include education (dummies indicating above high school education and college degree), gender, age, income quartiles, and employment status. A dummy for living in a swing state as well as a dummy for whether the respondent's location is missing and its interaction with the time trend are also included. Other notes as in Table I. 
Table A.4: Vote choice consistency across voter types

\begin{tabular}{|c|c|c|c|c|c|c|c|}
\hline \multirow[b]{2}{*}{ Voter characteristic } & \multicolumn{7}{|c|}{ Vote choice consistency } \\
\hline & $\begin{array}{l}\text { (1) } \\
\text { College degree vs. } \\
\text { no college degree }\end{array}$ & $\begin{array}{l}(2) \\
\text { Above median age } \\
\text { vs. below }\end{array}$ & $\begin{array}{c}\text { (3) } \\
\text { Male vs. } \\
\text { female }\end{array}$ & $\begin{array}{l}\text { (4) } \\
\text { Above median income } \\
\text { vs. below }\end{array}$ & $\begin{array}{c}5) \\
\text { Not employed vs. } \\
\text { employed }\end{array}$ & $\begin{array}{c}(6) \\
\text { Strong vs. weak } \\
\text { party identification }\end{array}$ & $\begin{array}{l}\text { (7) } \\
\text { All }\end{array}$ \\
\hline Time & $\begin{array}{c}0.0024^{* * *} \\
(0.0003)\end{array}$ & $\begin{array}{c}0.0028^{* * *} \\
(0.0003)\end{array}$ & $\begin{array}{c}0.0025^{* * *} \\
(0.0003)\end{array}$ & $\begin{array}{c}0.0025^{* * *} \\
(0.0003)\end{array}$ & $\begin{array}{c}0.0025^{* * *} \\
(0.0003)\end{array}$ & $\begin{array}{c}0.0029^{* * *} \\
(0.0004)\end{array}$ & $\begin{array}{c}0.0033^{* * *} \\
(0.0005)\end{array}$ \\
\hline College degree & $\begin{array}{l}-0.0015 \\
(0.0057)\end{array}$ & & & & & & $\begin{array}{c}0.0033 \\
(0.0055)\end{array}$ \\
\hline Time $*$ College degree & $\begin{array}{c}-0.0006^{* * *} \\
(0.0002)\end{array}$ & & & & & & $\begin{array}{c}-0.0005^{* *} \\
(0.0002)\end{array}$ \\
\hline Above median age & & $\begin{array}{c}0.0221^{* * *} \\
(0.0078)\end{array}$ & & & & & $\begin{array}{c}0.0132 \\
(0.0081)\end{array}$ \\
\hline Time * Above median age & & $\begin{array}{c}-0.0007^{* * *} \\
(0.0002)\end{array}$ & & & & & $\begin{array}{c}-0.0007^{* * *} \\
(0.0002)\end{array}$ \\
\hline Male & & & $\begin{array}{c}0.0351^{* * *} \\
(0.0046)\end{array}$ & & & & $\begin{array}{c}0.0316^{* * *} \\
(0.0047)\end{array}$ \\
\hline Time * Male & & & $\begin{array}{l}-0.0000 \\
(0.0002)\end{array}$ & & & & $\begin{array}{c}-0.0001 \\
(0.0002)\end{array}$ \\
\hline Above median income & & & & $\begin{array}{l}-0.0020 \\
(0.0065)\end{array}$ & & & $\begin{array}{c}0.0011 \\
(0.0068)\end{array}$ \\
\hline Time * Above median income & & & & $\begin{array}{l}-0.0003 \\
(0.0002)\end{array}$ & & & $\begin{array}{c}-0.0003 \\
(0.0002)\end{array}$ \\
\hline Not employed & & & & & $\begin{array}{c}0.0208^{* * *} \\
(0.0051)\end{array}$ & & $\begin{array}{c}0.0193^{* * *} \\
(0.0056)\end{array}$ \\
\hline Time* Not employed & & & & & $\begin{array}{c}-0.0001 \\
(0.0002)\end{array}$ & & $\begin{array}{c}0.0001 \\
(0.0002)\end{array}$ \\
\hline Strong party identification & & & & & & $\begin{array}{c}0.1140^{* * *} \\
(0.0157)\end{array}$ & $\begin{array}{c}0.1043^{* * *} \\
(0.0153)\end{array}$ \\
\hline Time * Strong party id. & & & & & & $\begin{array}{c}-0.0010^{* * *} \\
(0.0003)\end{array}$ & $\begin{array}{c}-0.0013^{* * *} \\
(0.0003) \\
\end{array}$ \\
\hline Observations & 200916 & 200916 & 200916 & 200916 & 200916 & 200916 & 200916 \\
\hline$R^{2}$ & 0.071 & 0.072 & 0.072 & 0.070 & 0.071 & 0.086 & 0.091 \\
\hline Mean at day -1 & 0.8768 & 0.8768 & 0.8768 & 0.8768 & 0.8768 & 0.8768 & 0.8768 \\
\hline Election fixed effects & $\mathrm{x}$ & $\mathrm{x}$ & $\mathrm{x}$ & $\mathrm{x}$ & $\mathrm{x}$ & $\mathrm{x}$ & $\mathrm{x}$ \\
\hline Individual controls & $\mathrm{x}$ & $\mathrm{x}$ & $\mathrm{x}$ & $\mathrm{x}$ & $\mathrm{x}$ & $\mathrm{x}$ & $\mathrm{x}$ \\
\hline \multicolumn{8}{|l|}{ Linear combination of estimates } \\
\hline Time + Time * type-a voter & $\begin{array}{c}0.0019^{* * *} \\
(0.0003)\end{array}$ & $\begin{array}{c}0.0022^{* * *} \\
(0.0003)\end{array}$ & $\begin{array}{c}0.0025^{* * *} \\
(0.0003)\end{array}$ & $\begin{array}{c}0.0023^{* * *} \\
(0.0003)\end{array}$ & $\begin{array}{c}0.0025^{* * *} \\
(0.0003)\end{array}$ & $\begin{array}{c}0.0019^{* * *} \\
(0.0004)\end{array}$ & \\
\hline
\end{tabular}

Notes: Standard errors clustered at the survey level are in parentheses $(* * *, * *, *$ indicate significance at 1,5 , and $10 \%$, respectively). We regress vote choice consistency on a linear time trend, its interaction with dummies for being a type-a voter (having a college degree, being above the median age, a male, above the median income, not employed, and strongly identifying with a party) as opposed to a type-b voter (not having a college degree, being below the median age, a female, below the median income, employed, and not identifying with any party or only weakly so). Dummies for being a type-a voter as well as dummies for whether the characteristics are missing and their interaction with the time trend are also included. Linear combinations of estimates are also reported, along with their standard errors. Other notes as in Table I. 
Table A.5: Vote choice consistency across voter types with detailed age categories

\begin{tabular}{|c|c|c|}
\hline \multirow[b]{2}{*}{ Voter characteristic } & \multicolumn{2}{|c|}{ Vote choice consistency } \\
\hline & $\begin{array}{c}\text { (1) } \\
\text { Very young } \\
\text { vs. others }\end{array}$ & $\begin{array}{l}\text { (2) } \\
\text { All }\end{array}$ \\
\hline Time & $\begin{array}{c}0.0027^{* * *} \\
(0.0003)\end{array}$ & $\begin{array}{c}0.0032^{* * *} \\
(0.0005)\end{array}$ \\
\hline Above median age & $\begin{array}{c}0.0226^{* * *} \\
(0.0068)\end{array}$ & $\begin{array}{l}0.0132^{*} \\
(0.0072)\end{array}$ \\
\hline Time * Above median age & $\begin{array}{c}-0.0006^{* * *} \\
(0.0002)\end{array}$ & $\begin{array}{c}-0.0006^{* * *} \\
(0.0002)\end{array}$ \\
\hline 25 years old or younger & $\begin{array}{c}0.0039 \\
(0.0102)\end{array}$ & $\begin{array}{c}0.0005 \\
(0.0087)\end{array}$ \\
\hline Time $* 25$ years old or younger & $\begin{array}{c}0.0007^{* *} \\
(0.0003)\end{array}$ & $\begin{array}{c}0.0006 \\
(0.0004)\end{array}$ \\
\hline College degree & & $\begin{array}{c}0.0033 \\
(0.0055)\end{array}$ \\
\hline Time $*$ College degree & & $\begin{array}{c}-0.0004^{* *} \\
(0.0002)\end{array}$ \\
\hline Male & & $\begin{array}{c}0.0316^{* * *} \\
(0.0047)\end{array}$ \\
\hline Time $*$ Male & & $\begin{array}{l}-0.0001 \\
(0.0002)\end{array}$ \\
\hline Above median income & & $\begin{array}{c}0.0011 \\
(0.0068)\end{array}$ \\
\hline Time $*$ Above median income & & $\begin{array}{c}-0.0003 \\
(0.0002)\end{array}$ \\
\hline Not employed & & $\begin{array}{c}0.0195^{* * *} \\
(0.0056)\end{array}$ \\
\hline Time* Not employed & & $\begin{array}{c}0.0001 \\
(0.0002)\end{array}$ \\
\hline Strong party identification & & $\begin{array}{c}0.1043^{* * *} \\
(0.0153)\end{array}$ \\
\hline Time * Strong party id. & & $\begin{array}{c}-0.0013^{* * *} \\
(0.0003)\end{array}$ \\
\hline Observations & 200916 & 200916 \\
\hline$R^{2}$ & 0.072 & 0.091 \\
\hline Mean at day -1 & 0.8768 & 0.8768 \\
\hline Election fixed effects & $\mathrm{x}$ & $\mathrm{x}$ \\
\hline Individual controls & $\mathrm{x}$ & $\mathrm{x}$ \\
\hline
\end{tabular}

Notes: Same notes as in Appendix Table A.4. We include an additional dummy for being 25 years old or younger and its interaction with the linear time trend. 
Table A.6: Vote intention and conditional consistency across voter types

\begin{tabular}{|c|c|c|}
\hline & $\begin{array}{c}\begin{array}{c}\text { Stating a } \\
\text { vote intention }\end{array} \\
(1)\end{array}$ & $\begin{array}{l}\begin{array}{l}\text { Conditional } \\
\text { consistency }\end{array} \\
(2)\end{array}$ \\
\hline Time & $\begin{array}{c}0.0014^{* * *} \\
(0.0003)\end{array}$ & $\begin{array}{c}0.0025^{* * *} \\
(0.0004)\end{array}$ \\
\hline College degree & $\begin{array}{c}0.0091^{* *} \\
(0.0044)\end{array}$ & $\begin{array}{c}-0.0000 \\
(0.0049)\end{array}$ \\
\hline Time $*$ College degree & $\begin{array}{l}-0.0002 \\
(0.0002)\end{array}$ & $\begin{array}{c}-0.0003^{* *} \\
(0.0002)\end{array}$ \\
\hline Above median age & $\begin{array}{l}0.0107^{* *} \\
(0.0046)\end{array}$ & $\begin{array}{c}0.0050 \\
(0.0064)\end{array}$ \\
\hline Time * Above median age & $\begin{array}{c}-0.0003^{*} \\
(0.0002)\end{array}$ & $\begin{array}{c}-0.0006^{* * *} \\
(0.0002)\end{array}$ \\
\hline Male & $\begin{array}{c}0.0346^{* * *} \\
(0.0052)\end{array}$ & $\begin{array}{c}0.0053^{* *} \\
(0.0025)\end{array}$ \\
\hline Time * Male & $\begin{array}{c}-0.0002 \\
(0.0002)\end{array}$ & $\begin{array}{c}0.0000 \\
(0.0001)\end{array}$ \\
\hline Above median income & $\begin{array}{c}0.0061 \\
(0.0038)\end{array}$ & $\begin{array}{c}-0.0008 \\
(0.0063)\end{array}$ \\
\hline Time * Above median income & $\begin{array}{c}-0.0001 \\
(0.0001)\end{array}$ & $\begin{array}{c}-0.0002 \\
(0.0002)\end{array}$ \\
\hline Not employed & $\begin{array}{c}0.0156^{* * *} \\
(0.0044)\end{array}$ & $\begin{array}{l}0.0080^{* *} \\
(0.0032)\end{array}$ \\
\hline Time* Not employed & $\begin{array}{c}0.0002 \\
(0.0002)\end{array}$ & $\begin{array}{c}0.0000 \\
(0.0001)\end{array}$ \\
\hline Strong party identification & $\begin{array}{c}0.0739^{* * *} \\
(0.0169)\end{array}$ & $\begin{array}{c}0.0465^{* * *} \\
(0.0078)\end{array}$ \\
\hline Time * Strong party id. & $\begin{array}{c}-0.0009^{* * *} \\
(0.0003)\end{array}$ & $\begin{array}{c}-0.0009^{* * *} \\
(0.0003)\end{array}$ \\
\hline Observations & 253489 & 178176 \\
\hline$R^{2}$ & 0.091 & 0.049 \\
\hline Mean at day -1 & 0.9157 & 0.9346 \\
\hline Election fixed effects & $\mathrm{x}$ & $\mathrm{x}$ \\
\hline Individual controls & $\mathrm{x}$ & $\mathrm{x}$ \\
\hline
\end{tabular}

Notes: Same notes as in Table I (columns 3 and 5) and Appendix Table A.4. 
Table A.7: Self-reported timing of decision across voter types

\begin{tabular}{|c|c|c|c|c|c|c|c|}
\hline \multirow[b]{2}{*}{ Voter characteristic } & \multicolumn{7}{|c|}{ Deciding during the campaign } \\
\hline & $\begin{array}{l}\text { (1) } \\
\text { College degree vs. } \\
\text { no college degree }\end{array}$ & $\begin{array}{c}(2) \\
\text { Above median age } \\
\text { vs. below }\end{array}$ & $\begin{array}{l}\text { (3) } \\
\text { Male vs. } \\
\text { female }\end{array}$ & $\begin{array}{l}\text { (4) } \\
\text { Above median income } \\
\text { vs. below }\end{array}$ & $\begin{array}{l}(5) \\
\text { Not employed vs. } \\
\text { employed }\end{array}$ & $\begin{array}{c}(6) \\
\text { Strong vs. weak } \\
\text { party identification }\end{array}$ & $\begin{array}{l}\text { (7) } \\
\text { All }\end{array}$ \\
\hline College degree & $\begin{array}{c}0.0099 \\
(0.0196)\end{array}$ & & & & & & $\begin{array}{l}-0.0007 \\
(0.0159)\end{array}$ \\
\hline Above median age & & $\begin{array}{c}-0.1016^{* * *} \\
(0.0132)\end{array}$ & & & & & $\begin{array}{c}-0.0855^{* * *} \\
(0.0115)\end{array}$ \\
\hline Male & & & $\begin{array}{c}-0.0462^{* * *} \\
(0.0054)\end{array}$ & & & & $\begin{array}{c}-0.0490^{* * *} \\
(0.0042)\end{array}$ \\
\hline Above median income & & & & $\begin{array}{c}0.0108 \\
(0.0096)\end{array}$ & & & $\begin{array}{c}0.0012 \\
(0.0074)\end{array}$ \\
\hline Not employed & & & & & $\begin{array}{c}-0.0511^{* * *} \\
(0.0103)\end{array}$ & & $\begin{array}{c}-0.0256^{* * *} \\
(0.0062)\end{array}$ \\
\hline Strong party identification & & & & & & $\begin{array}{c}-0.2805^{* * *} \\
(0.0094)\end{array}$ & $\begin{array}{c}-0.2746^{* * *} \\
(0.0102)\end{array}$ \\
\hline Observations & 123548 & 123548 & 123548 & 123548 & 123548 & 123548 & 123548 \\
\hline$R^{2}$ & 0.055 & 0.065 & 0.058 & 0.055 & 0.057 & 0.092 & 0.103 \\
\hline Mean outcome & 0.4752 & 0.4752 & 0.4752 & 0.4752 & 0.4752 & 0.4752 & 0.4752 \\
\hline Election fixed effects & $\mathrm{x}$ & $\mathrm{x}$ & $\mathrm{x}$ & $\mathrm{x}$ & $\mathrm{x}$ & $\mathrm{x}$ & $\mathrm{x}$ \\
\hline Individual controls & $\mathrm{x}$ & $\mathrm{x}$ & $\mathrm{x}$ & $\mathrm{x}$ & $\mathrm{x}$ & $\mathrm{x}$ & $\mathrm{x}$ \\
\hline
\end{tabular}

Notes: Standard errors clustered at the survey level are in parentheses $(* * *, * *, *$ indicate significance at 1,5 , and $10 \%$, respectively). We regress a dummy equal to 1 if the respondent said that they decided whom to vote for during the campaign on voter characteristics. Dummies for whether the characteristics are missing are also included. Individual controls include fixed effects for the number of days separating the post-electoral survey from the election. The sample includes all respondents surveyed before and after the election, who said that they intended to vote, in the first survey, and who reported that they actually voted, gave a vote choice declaration, and said when they decided whom to vote for, in the second. 
Table A.8: Turnout overreporting across voter types in ANES and CCES surveys

\begin{tabular}{lc}
\hline & $\begin{array}{c}\text { Turnout } \\
\text { overreporting }\end{array}$ \\
\cline { 2 - 2 } College degree & $(1)$ \\
& $0.0278^{* * *}$ \\
Above median age & $-0.0472^{* * *}$ \\
& $(0.0024)$ \\
Male & $0.0267^{* * *}$ \\
Above median income & $(0.0023)$ \\
Not employed & $0.0160^{* * *}$ \\
& $(0.0026)$ \\
Strong party identification & $0.0041^{*}$ \\
& $(0.0024)$ \\
\hline Observations & 123022 \\
$R^{2}$ & $0.0340^{* * *}$ \\
Mean outcome & $\mathrm{X}$ \\
Election fixed effects & 0.2053 \\
Individual controls & $\mathrm{X}$ \\
Daily fixed effects & $(0.025)$ \\
\hline
\end{tabular}

Notes: Standard errors clustered at the survey level are in parentheses $(* * *, * *, *$ indicate significance at 1,5 , and $10 \%$, respectively). The sample is restricted to the ANES 1980, 1984, and 1998 surveys and the CCES 2008, 2012, and 2016 surveys and it includes all respondents surveyed before and after the election who were asked if they intended to vote, in the first survey, and if they actually voted, in the second. The outcome is a dummy equal to 1 if the respondent said both that they intended to vote before the election and that they voted after the election, but did not vote according to the voter file. We regress this outcome on voter characteristics. We control for election fixed effects and for 60 fixed effects indicating the number of days relative to the election. Individual controls include fixed effects for the day of the week in which the pre-electoral survey took place and fixed effects for the number of days separating the post-electoral survey from the election. 
Table A.9: Vote choice consistency in ANES 1980, 1984, 1988

\begin{tabular}{lcc}
\hline & \multicolumn{2}{c}{ Vote choice consistency } \\
\cline { 2 - 3 } & $\begin{array}{c}(1) \\
\text { All }\end{array}$ & $\begin{array}{c}(2) \\
\text { Validated } \\
\text { turnout }\end{array}$ \\
\hline Sample & 0.0015 & 0.0016 \\
rime & $(0.0006)$ & $(0.0006)$ \\
\hline Observations & 3207 & 2661 \\
$R^{2}$ & 0.040 & 0.040 \\
Mean at day -1 & 0.9063 & 0.8750 \\
Election fixed effects & $\mathrm{x}$ & $\mathrm{x}$ \\
Individual controls & $\mathrm{x}$ & $\mathrm{x}$ \\
\hline
\end{tabular}

Notes: In column 1, the sample includes all respondents from ANES 1980, 1984, and 1988 surveyed before and after the election who said that they intended to vote, in the first survey, and who reported that they actually voted and gave a vote choice declaration, in the second. In column 2, the sample is further restricted to respondents whose turnout was validated from voting records. Other notes as in Table I, column 1.

Table A.10: Sociodemographic characteristics over time

\begin{tabular}{|c|c|c|c|c|c|c|c|c|}
\hline & $\begin{array}{l}\text { More education } \\
\text { than high school }\end{array}$ & College degree & Male & Age & $\begin{array}{l}\text { 2nd income } \\
\text { quartile }\end{array}$ & $\begin{array}{l}\text { 3rd income } \\
\text { quartile }\end{array}$ & $\begin{array}{l}\text { 4th income } \\
\text { quartile }\end{array}$ & Not employed \\
\hline & (1) & (2) & (3) & (4) & (5) & (6) & (7) & (8) \\
\hline Time to election & $\begin{array}{c}0.0005^{* *} \\
(0.0002)\end{array}$ & $\begin{array}{l}0.0004^{* *} \\
(0.0002)\end{array}$ & $\begin{array}{c}0.0000 \\
(0.0001)\end{array}$ & $\begin{array}{c}-0.0234^{* *} \\
(0.0112)\end{array}$ & $\begin{array}{l}-0.0002 \\
(0.0002)\end{array}$ & $\begin{array}{l}0.0002^{* *} \\
(0.0001)\end{array}$ & $\begin{array}{c}0.0006^{* * *} \\
(0.0002)\end{array}$ & $\begin{array}{c}-0.0008^{* * *} \\
(0.0002)\end{array}$ \\
\hline Observations & 190684 & 185799 & 215967 & 216541 & 163849 & 163849 & 163849 & 193300 \\
\hline$R^{2}$ & 0.088 & 0.085 & 0.010 & 0.043 & 0.015 & 0.016 & 0.009 & 0.018 \\
\hline Mean at day -1 & 0.6134 & 0.3970 & 0.4888 & 49.7849 & 0.2349 & 0.2468 & 0.2462 & 0.4015 \\
\hline Election fixed effects & $\mathrm{x}$ & $\mathrm{x}$ & $\mathrm{x}$ & $\mathrm{x}$ & $\mathrm{x}$ & $\mathrm{x}$ & $\mathrm{x}$ & $\mathrm{x}$ \\
\hline Individual controls & $\mathrm{x}$ & $\mathrm{x}$ & $\mathrm{x}$ & $\mathrm{x}$ & $\mathrm{x}$ & $\mathrm{x}$ & $\mathrm{x}$ & $\mathrm{x}$ \\
\hline
\end{tabular}

Notes: Standard errors clustered at the survey level are in parentheses $(* * *, * *, *$ indicate significance at 1,5 , and $10 \%$, respectively). Time is defined as negative the number of days separating the pre-electoral survey from the election. The sample includes all respondents surveyed before the election who said that they intended to vote. Individual controls include fixed effects for the day of the week in which the pre-electoral survey took place. 
Table A.11: Sample selection tests

\begin{tabular}{|c|c|c|c|c|}
\hline & $\begin{array}{c}\text { Turnout } \\
\text { intention }\end{array}$ & $\begin{array}{c}\text { Sample, } \\
\text { vote intention }\end{array}$ & $\begin{array}{c}\text { Sample, vote } \\
\text { choice consistency }\end{array}$ & $\begin{array}{l}\text { Post-electoral } \\
\text { reinterview rate }\end{array}$ \\
\hline & (1) & (2) & (3) & (4) \\
\hline Time & $\begin{array}{c}0.0010^{* * *} \\
(0.0002)\end{array}$ & $\begin{array}{c}0.0006^{* *} \\
(0.0003)\end{array}$ & $\begin{array}{c}0.0009^{* * *} \\
(0.0002)\end{array}$ & $\begin{array}{c}-0.0006^{* *} \\
(0.0003)\end{array}$ \\
\hline Observations & 312672 & 312672 & 259001 & 312672 \\
\hline$R^{2}$ & 0.074 & 0.079 & 0.078 & 0.090 \\
\hline Mean at day -1 & 0.8519 & 0.8071 & 0.7873 & 0.7928 \\
\hline Election fixed effects & $\mathrm{x}$ & $\mathrm{x}$ & $\mathrm{x}$ & $\mathrm{x}$ \\
\hline Individual controls & $\mathrm{x}$ & $\mathrm{x}$ & $\mathrm{x}$ & $\mathrm{x}$ \\
\hline
\end{tabular}

Notes: Standard errors clustered at the survey level are in parentheses $(* * *, * *, *$ indicate significance at 1,5 , and $10 \%$, respectively). Time is defined as negative the number of days separating the pre-electoral survey from the election. In column 1, the sample includes all respondents surveyed before the election who were asked if they intended to vote, and the outcome is a dummy equal to 1 if the respondent said yes. In column 2, the sample includes all respondents surveyed before the election who were asked if they intended to vote, and the outcome is a dummy equal to 1 if the respondent said yes and answered the vote intention question (including if they said they did not know whom they would vote for). In column 3, the sample includes all respondents surveyed before and after the election who were asked if they intended to vote, in the first survey, and if they actually voted, in the second. The outcome is a dummy equal to 1 if the respondent said that they intended to vote and answered the vote intention question, in the first survey, and reported that they actually voted and gave a vote choice declaration, in the second. In column 4, the sample includes all respondents surveyed before the election who were asked if they intended to vote, and the outcome is a dummy equal to 1 if the respondent appears in the post-electoral survey. Individual controls include fixed effects for the day of the week in which the pre-electoral survey took place and, in column 3 , fixed effects for the number of days separating the post-electoral survey from the election. 
Table A.12: Changes in reinterview rate across voter types

\begin{tabular}{|c|c|c|c|c|c|c|c|}
\hline \multirow[b]{2}{*}{ Voter characteristic } & \multicolumn{7}{|c|}{ Reinterview in the post-electoral survey } \\
\hline & $\begin{array}{c}\text { (1) } \\
\text { College degree vs. } \\
\text { no college degree }\end{array}$ & $\begin{array}{c}\text { (2) } \\
\text { Above median age } \\
\text { vs. below }\end{array}$ & $\begin{array}{c}\text { (3) } \\
\text { Male vs. } \\
\text { female }\end{array}$ & $\begin{array}{l}\text { (4) } \\
\text { Above median income } \\
\text { vs. below }\end{array}$ & $\begin{array}{c}\text { (5) } \\
\text { Not employed vs. } \\
\text { employed }\end{array}$ & $\begin{array}{c}\text { (6) } \\
\text { Strong vs. weak } \\
\text { party identification }\end{array}$ & $\begin{array}{l}\text { (7) } \\
\text { All }\end{array}$ \\
\hline Time & $\begin{array}{c}-0.0006^{* *} \\
(0.0003)\end{array}$ & $\begin{array}{c}-0.0006^{* *} \\
(0.0003)\end{array}$ & $\begin{array}{c}-0.0006^{*} \\
(0.0003)\end{array}$ & $\begin{array}{c}-0.0007^{* *} \\
(0.0003)\end{array}$ & $\begin{array}{c}-0.0006^{* *} \\
(0.0003)\end{array}$ & $\begin{array}{l}-0.0005 \\
(0.0003)\end{array}$ & $\begin{array}{c}-0.0006 \\
(0.0004)\end{array}$ \\
\hline College degree & $\begin{array}{l}0.0155^{* *} \\
(0.0060)\end{array}$ & & & & & & $\begin{array}{l}0.0135^{* *} \\
(0.0053)\end{array}$ \\
\hline Time $*$ College degree & $\begin{array}{l}-0.0003 \\
(0.0002)\end{array}$ & & & & & & $\begin{array}{c}-0.0002 \\
(0.0002)\end{array}$ \\
\hline Above median age & & $\begin{array}{c}0.0410^{* * *} \\
(0.0064)\end{array}$ & & & & & $\begin{array}{c}0.0386^{* * *} \\
(0.0061)\end{array}$ \\
\hline Time * Above median age & & $\begin{array}{c}0.0000 \\
(0.0002)\end{array}$ & & & & & $\begin{array}{c}0.0000 \\
(0.0002)\end{array}$ \\
\hline Male & & & $\begin{array}{c}0.0147^{* * *} \\
(0.0040)\end{array}$ & & & & $\begin{array}{c}0.0077^{* *} \\
(0.0036)\end{array}$ \\
\hline Time * Male & & & $\begin{array}{c}-0.0001 \\
(0.0002)\end{array}$ & & & & $\begin{array}{c}-0.0001 \\
(0.0002)\end{array}$ \\
\hline Above median income & & & & $\begin{array}{l}0.0119^{* *} \\
(0.0054)\end{array}$ & & & $\begin{array}{l}0.0110^{*} \\
(0.0056)\end{array}$ \\
\hline Time $*$ Above median income & & & & $\begin{array}{c}-0.0000 \\
(0.0001)\end{array}$ & & & $\begin{array}{c}0.0000 \\
(0.0001)\end{array}$ \\
\hline Not employed & & & & & $\begin{array}{l}0.0094^{*} \\
(0.0048)\end{array}$ & & $\begin{array}{c}0.0056 \\
(0.0052)\end{array}$ \\
\hline Time* Not employed & & & & & $\begin{array}{c}0.0000 \\
(0.0001)\end{array}$ & & $\begin{array}{c}0.0000 \\
(0.0002)\end{array}$ \\
\hline Strong party identification & & & & & & $\begin{array}{c}0.0184^{*} \\
(0.0093)\end{array}$ & $\begin{array}{c}0.0135 \\
(0.0080)\end{array}$ \\
\hline Time * Strong party id. & & & & & & $\begin{array}{l}-0.0001 \\
(0.0002)\end{array}$ & $\begin{array}{c}-0.0002 \\
(0.0002)\end{array}$ \\
\hline Observations & 312672 & 312672 & 312672 & 312672 & 312672 & 312672 & 312672 \\
\hline$R^{2}$ & 0.091 & 0.094 & 0.091 & 0.093 & 0.098 & 0.094 & 0.107 \\
\hline Mean at day -1 & 0.7928 & 0.7928 & 0.7928 & 0.7928 & 0.7928 & 0.7928 & 0.7928 \\
\hline Election fixed effects & $\mathrm{x}$ & $\mathrm{x}$ & $\mathrm{x}$ & $\mathrm{x}$ & $\mathrm{x}$ & $\mathrm{x}$ & $\mathrm{x}$ \\
\hline Week day fixed effects & $\mathrm{x}$ & $\mathrm{x}$ & $\mathrm{x}$ & $\mathrm{x}$ & $\mathrm{x}$ & $\mathrm{x}$ & $\mathrm{x}$ \\
\hline $\begin{array}{l}\text { Linear combination of estimates } \\
\text { Time + Time * type-a voter }\end{array}$ & $\begin{array}{c}-0.0009^{* * *} \\
(0.0003)\end{array}$ & $\begin{array}{c}-0.0006^{* *} \\
(0.0003)\end{array}$ & $\begin{array}{c}-0.0006^{* *} \\
(0.0002)\end{array}$ & $\begin{array}{c}-0.0007^{* *} \\
(0.0003)\end{array}$ & $\begin{array}{c}-0.0006^{* *} \\
(0.0003)\end{array}$ & $\begin{array}{c}-0.0006^{* * *} \\
(0.0002)\end{array}$ & \\
\hline
\end{tabular}

Notes: The sample includes all respondents surveyed before the election who were asked if they intended to vote and the outcome is a dummy equal to 1 if the respondent appears in the post-electoral survey. The strength of party identification is measured based on pre-electoral answers instead of post-electoral answers. Other notes as in Appendix Table A.4. 
Table A.13: Vote choice consistency among respondents voting for the party they identify with vs. other respondents

\begin{tabular}{|c|c|c|c|c|}
\hline & \multicolumn{4}{|c|}{ Vote choice consistency } \\
\hline & (1) & (2) & (3) & (4) \\
\hline Time & $\begin{array}{c}0.0058^{* * *} \\
(0.0006)\end{array}$ & $\begin{array}{c}0.0058^{* * *} \\
(0.0006)\end{array}$ & $\begin{array}{c}0.0047^{* * *} \\
(0.0009)\end{array}$ & $\begin{array}{c}0.0047^{* * *} \\
(0.0009)\end{array}$ \\
\hline Voted for post-electoral party id. & $\begin{array}{c}0.2276^{* * *} \\
(0.0189)\end{array}$ & $\begin{array}{c}0.2286^{* * *} \\
(0.0184)\end{array}$ & & \\
\hline Time $*$ Voted for post-electoral party id. & $\begin{array}{c}-0.0037^{* * *} \\
(0.0007)\end{array}$ & $\begin{array}{c}-0.0037^{* * *} \\
(0.0007)\end{array}$ & & \\
\hline Voted for pre-electoral party id. & & & $\begin{array}{c}0.2672^{* * *} \\
(0.0253)\end{array}$ & $\begin{array}{c}0.2651^{* * *} \\
(0.0257)\end{array}$ \\
\hline Time * Voted for pre-electoral party id. & & & $\begin{array}{c}-0.0027^{* *} \\
(0.0011)\end{array}$ & $\begin{array}{c}-0.0028^{* *} \\
(0.0011)\end{array}$ \\
\hline Observations & 200916 & 200916 & 200916 & 200916 \\
\hline$R^{2}$ & 0.127 & 0.132 & 0.163 & 0.167 \\
\hline Mean at day -1 & 0.8768 & 0.8768 & 0.8768 & 0.8768 \\
\hline Election fixed effects & $\mathrm{x}$ & $\mathrm{x}$ & $\mathrm{x}$ & $\mathrm{x}$ \\
\hline Individual controls & $\mathrm{x}$ & $\mathrm{x}$ & $\mathrm{x}$ & $\mathrm{x}$ \\
\hline Sociodemographic controls & & $\mathrm{x}$ & & $\mathrm{x}$ \\
\hline
\end{tabular}

Notes: Standard errors clustered at the survey level are in parentheses $(* * *, * *$, * indicate significance at 1,5 , and $10 \%$, respectively). We regress vote choice consistency on a linear time trend and its interaction with a dummy equal to 1 for respondents voting for the party they identify with, as stated in the post-electoral survey (columns 1 and 2 ) or in the pre-electoral survey (columns 3 and 4). A dummy for voting for the party they identify with as well as a dummy for whether their party identification is missing and its interaction with the time trend are also included. The sample includes all respondents surveyed before and after the election who said that they intended to vote, in the first survey, and who reported that they actually voted and gave a vote choice declaration, in the second. Individual controls include fixed effects for the day of the week in which the pre-electoral survey took place and for the number of days separating the post-electoral survey from the election. Sociodemographic controls include education (dummies indicating above high school education and college degree), gender, age, income quartiles, and employment status. 


\section{A.3 Formation of Beliefs, Policy Preferences, and Issue Salience: Additional Results}

Figure A.9: Vote share concentration

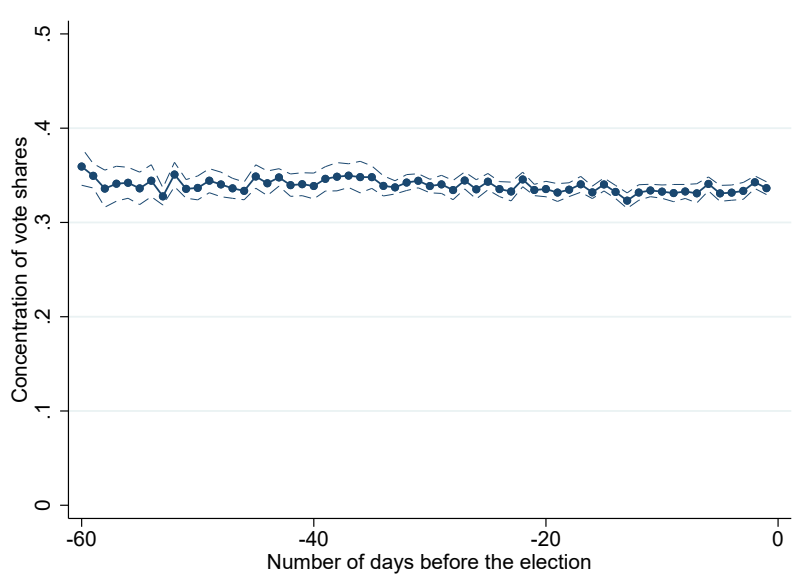

Notes: We show point estimates and 95\% confidence intervals from a specification in the form of equation [5], regressing the vote share concentration on 60 fixed effects indicating the number of days relative to the election and control variables. The outcome is computed based on all respondents surveyed before the election who said that they intended to vote and stated a vote intention different from voting blank or null. We weight each observation by the number of respondents it was constructed from, relative to the total number of respondents surveyed at the same relative time to the election. We control for election fixed effects and fixed effects for the day of the week in which the pre-electoral survey took place. Standard errors are adjusted for clustering at the survey level. N=3,138. 
Table A.14: Consistency in policy preferences, issue salience, and beliefs on candidates

(a) Policy preferences

\begin{tabular}{|c|c|c|c|c|c|c|}
\hline & \multicolumn{2}{|c|}{ Consistency } & \multicolumn{2}{|c|}{ Giving an answer } & \multicolumn{2}{|c|}{ Conditional consistency } \\
\hline & (1) & (2) & (3) & (4) & (5) & (6) \\
\hline Time & $\begin{array}{c}0.0001 \\
(0.0001)\end{array}$ & $\begin{array}{c}0.0001 \\
(0.0001)\end{array}$ & $\begin{array}{c}0.0001 \\
(0.0001)\end{array}$ & $\begin{array}{c}0.0001 \\
(0.0001)\end{array}$ & $\begin{array}{c}0.0001 \\
(0.0001)\end{array}$ & $\begin{array}{c}0.0001 \\
(0.0001)\end{array}$ \\
\hline Observations & 228562 & 228562 & 330843 & 330843 & 222785 & 222785 \\
\hline$R^{2}$ & 0.047 & 0.052 & 0.078 & 0.091 & 0.040 & 0.041 \\
\hline Mean at day -1 & 0.8488 & 0.8488 & 0.9615 & 0.9615 & 0.8689 & 0.8689 \\
\hline Question fixed effects & $\mathrm{x}$ & $\mathrm{x}$ & $\mathrm{x}$ & $\mathrm{x}$ & $\mathrm{x}$ & $\mathrm{x}$ \\
\hline Individual controls & $\mathrm{x}$ & $\mathrm{x}$ & $\mathrm{x}$ & $\mathrm{x}$ & $\mathrm{x}$ & $\mathrm{x}$ \\
\hline Sociodemographic controls & & $\mathrm{x}$ & & $\mathrm{x}$ & & $\mathrm{x}$ \\
\hline
\end{tabular}

(b) Issue salience

\begin{tabular}{lcccccccc}
\hline & \multicolumn{2}{c}{ Consistency } & & \multicolumn{2}{c}{ Giving an answer } & & \multicolumn{2}{c}{ Conditional consistency } \\
\cline { 2 - 3 } & $(1)$ & $(2)$ & & $(3)$ & $(4)$ & & $(5)$ & $(6)$ \\
\hline Time & $0.0015^{* *}$ & $0.0013^{* *}$ & & $0.0006^{*}$ & $0.0006^{*}$ & & $0.0010^{* *}$ & 0.0008 \\
& $(0.0006)$ & $(0.0006)$ & & $(0.0003)$ & $(0.0003)$ & & $(0.0004)$ & $(0.0004)$ \\
\hline Observations & 46108 & 46108 & & 60713 & 60713 & & 44049 & 44049 \\
$R^{2}$ & 0.046 & 0.050 & & 0.063 & 0.085 & & 0.054 & 0.060 \\
Mean at day -1 & 0.7392 & 0.7392 & & 0.9212 & 0.9212 & & 0.7676 & 0.7676 \\
Election fixed effects & $\mathrm{x}$ & $\mathrm{x}$ & & $\mathrm{x}$ & $\mathrm{x}$ & $\mathrm{x}$ & $\mathrm{x}$ \\
Individual controls & $\mathrm{x}$ & $\mathrm{x}$ & & $\mathrm{x}$ & $\mathrm{x}$ & & $\mathrm{x}$ & $\mathrm{x}$ \\
Sociodemographic controls & & $\mathrm{x}$ & & $\mathrm{x}$ & & $\mathrm{x}$ \\
\hline
\end{tabular}

(c) Beliefs on candidates

\begin{tabular}{|c|c|c|c|c|c|c|}
\hline & \multicolumn{2}{|c|}{ Consistency } & \multicolumn{2}{|c|}{ Giving an answer } & \multicolumn{2}{|c|}{ Conditional consistency } \\
\hline & (1) & (2) & (3) & (4) & (5) & (6) \\
\hline Time & $\begin{array}{c}0.0018 \\
(0.0015)\end{array}$ & $\begin{array}{c}0.0018 \\
(0.0014)\end{array}$ & $\begin{array}{c}0.0006^{* * *} \\
(0.0001)\end{array}$ & $\begin{array}{c}0.0006^{* * *} \\
(0.0001)\end{array}$ & $\begin{array}{c}0.0017 \\
(0.0014)\end{array}$ & $\begin{array}{c}0.0016 \\
(0.0014)\end{array}$ \\
\hline Observations & 478039 & 478039 & 809037 & 809037 & 440771 & 440771 \\
\hline$R^{2}$ & 0.074 & 0.084 & 0.101 & 0.139 & 0.095 & 0.097 \\
\hline Mean at day -1 & 0.8119 & 0.8119 & 0.8690 & 0.8690 & 0.8601 & 0.8601 \\
\hline Question fixed effects & $\mathrm{x}$ & $\mathrm{x}$ & $\mathrm{x}$ & $\mathrm{x}$ & $\mathrm{x}$ & $\mathrm{x}$ \\
\hline Individual controls & $\mathrm{x}$ & $\mathrm{x}$ & $\mathrm{x}$ & $\mathrm{x}$ & $\mathrm{x}$ & $\mathrm{x}$ \\
\hline Sociodemographic controls & & $\mathrm{x}$ & & $\mathrm{x}$ & & $\mathrm{x}$ \\
\hline
\end{tabular}

Notes: Standard errors clustered at the survey level are in parentheses $(* * *, * *, *$ indicate significance at 1,5 , and $10 \%$, respectively). Time is defined as negative the number of days separating the pre-electoral survey from the election. We use one observation per respondent per policy question in Panel a, one observation per respondent in Panel b, and one observation per respondent per belief question in Panel c. We estimate specifications in the form of equation [2]. Individual controls include fixed effects for the day of the week in which the pre-electoral survey took place and, in columns 1, 2, 5, and 6, fixed effects for the number of days separating the pre- and post-electoral survey. Sociodemographic controls include education (dummies indicating above high school education and college degree), gender, age, income quartiles, and employment status. 
Table A.15: Consistency in beliefs on candidates' issue positions and quality

(a) Beliefs on candidates' issue positions

\begin{tabular}{|c|c|c|c|c|c|c|}
\hline & \multicolumn{2}{|c|}{ Consistency } & \multicolumn{2}{|c|}{ Giving an answer } & \multicolumn{2}{|c|}{ Conditional consistency } \\
\hline & (1) & (2) & (3) & (4) & (5) & (6) \\
\hline Time & $\begin{array}{c}0.0013 \\
(0.0013)\end{array}$ & $\begin{array}{c}0.0013 \\
(0.0012)\end{array}$ & $\begin{array}{c}0.0007^{* * *} \\
(0.0002)\end{array}$ & $\begin{array}{c}0.0007^{* * *} \\
(0.0002)\end{array}$ & $\begin{array}{c}0.0012 \\
(0.0013)\end{array}$ & $\begin{array}{c}0.0011 \\
(0.0012)\end{array}$ \\
\hline Observations & 294791 & 294791 & 460655 & 460655 & 265245 & 265245 \\
\hline$R^{2}$ & 0.040 & 0.056 & 0.074 & 0.128 & 0.072 & 0.076 \\
\hline Mean at day -1 & 0.7774 & 0.7774 & 0.7857 & 0.7857 & 0.8527 & 0.8527 \\
\hline Question fixed effects & $\mathrm{x}$ & $\mathrm{x}$ & $\mathrm{x}$ & $\mathrm{x}$ & $\mathrm{x}$ & $\mathrm{x}$ \\
\hline Individual controls & $\mathrm{x}$ & $\mathrm{x}$ & $\mathrm{x}$ & $\mathrm{x}$ & $\mathrm{x}$ & $\mathrm{x}$ \\
\hline Sociodemographic controls & & $\mathrm{x}$ & & $\mathrm{x}$ & & $\mathrm{x}$ \\
\hline
\end{tabular}

(b) Beliefs on candidates' quality

\begin{tabular}{|c|c|c|c|c|c|c|}
\hline & \multicolumn{2}{|c|}{ Consistency } & \multicolumn{2}{|c|}{ Giving an answer } & \multicolumn{2}{|c|}{ Conditional consistency } \\
\hline & (1) & (2) & (3) & (4) & (5) & (6) \\
\hline Time & $\begin{array}{c}0.0030 \\
(0.0019)\end{array}$ & $\begin{array}{c}0.0031 \\
(0.0019)\end{array}$ & $\begin{array}{c}0.0005^{* * *} \\
(0.0000)\end{array}$ & $\begin{array}{c}0.0004^{* * *} \\
(0.0001)\end{array}$ & $\begin{array}{c}0.0029 \\
(0.0019)\end{array}$ & $\begin{array}{c}0.0029 \\
(0.0019)\end{array}$ \\
\hline Observations & 183248 & 183248 & 348382 & 348382 & 175526 & 175526 \\
\hline$R^{2}$ & 0.124 & 0.127 & 0.034 & 0.055 & 0.112 & 0.113 \\
\hline Mean at day -1 & 0.8449 & 0.8449 & 0.9395 & 0.9395 & 0.8666 & 0.8666 \\
\hline Question fixed effects & $\mathrm{x}$ & $\mathrm{x}$ & $\mathrm{x}$ & $\mathrm{x}$ & $\mathrm{x}$ & $\mathrm{x}$ \\
\hline Individual controls & $\mathrm{x}$ & $\mathrm{x}$ & $\mathrm{x}$ & $\mathrm{x}$ & $\mathrm{x}$ & $\mathrm{x}$ \\
\hline Sociodemographic controls & & $\mathrm{x}$ & & $\mathrm{x}$ & & $\mathrm{x}$ \\
\hline
\end{tabular}

Notes: In columns 1 and 2, the sample includes all respondents surveyed before and after the election who stated a belief on candidates' issue positions (Panel a), or a belief on candidates' quality (Panel b), in the second survey. In columns 3 and 4, the sample includes all respondents surveyed before the election. In columns 5 and 6 , the sample includes all respondents surveyed before and after the election who stated a belief on candidates' issue positions (Panel a) or a belief on candidates' quality (Panel b) in both the first and the second surveys. Other notes as in Appendix Table A.14, Panel c. 
Table A.16: Voting for lesser-known candidates

\begin{tabular}{|c|c|c|c|}
\hline & $\begin{array}{l}\begin{array}{l}\text { Voted for a } \\
\text { challenger }\end{array} \\
\end{array}$ & $\begin{array}{c}\text { Voted for a } \\
\text { small candidate }\end{array}$ & $\begin{array}{l}\text { Voted for a } \\
\text { new party }\end{array}$ \\
\hline & (1) & (2) & (3) \\
\hline Time & $\begin{array}{c}0.0001 \\
(0.0001)\end{array}$ & $\begin{array}{c}0.0000 \\
(0.0001)\end{array}$ & $\begin{array}{l}-0.0000 \\
(0.0000)\end{array}$ \\
\hline Observations & 174996 & 175606 & 172891 \\
\hline$R^{2}$ & 0.083 & 0.108 & 0.137 \\
\hline Mean at day -1 & 0.6656 & 0.1491 & 0.0215 \\
\hline Election fixed effects & $\mathrm{x}$ & $\mathrm{x}$ & $\mathrm{x}$ \\
\hline Individual controls & $\mathrm{x}$ & $\mathrm{x}$ & $\mathrm{x}$ \\
\hline
\end{tabular}

Notes: Standard errors clustered at the survey level are in parentheses $(* * *, * *, *$ indicate significance at 1,5 , and $10 \%$, respectively). The sample includes all respondents surveyed before and after the election who said that they intended to vote, in the first survey, and who reported that they actually voted and gave a vote choice declaration different from voting blank or null, in the second. Referenda are excluded. We define the outcomes as dummies equal to 1 if voters declared having voted for a challenger, a small candidate, or the candidate of a new party after the election, and use one observation per respondent. The party that won the last election (as opposed to challengers) is defined as the party of the president, the governor, the prime minister (in lower house elections that lead to the designation of a prime minister), or the party with plurality at the house (in other lower house elections and in upper house elections). The party is defined as new if it was absent from any previous presidential election, any previous legislative race in the country (for lower and upper house elections), or any race in that state (for gubernatorial elections). Individual controls include fixed effects for the day of the week in which the pre-electoral survey took place and for the number of days separating the post-electoral survey from the election. 
Table A.17: Vote choice consistency across voters voting for different candidates

\begin{tabular}{|c|c|c|c|c|c|}
\hline \multirow[b]{2}{*}{ Candidate type } & \multicolumn{5}{|c|}{ Vote choice consistency } \\
\hline & $\begin{array}{l}(1) \\
\text { Voted for a challenger } \\
\text { vs. the incumbent }\end{array}$ & $\begin{array}{c}(2) \\
\text { Voted for a small } \\
\text { vs. a bigger candidate }\end{array}$ & $\begin{array}{l}\text { (3) } \\
\text { Voted for a new } \\
\text { vs. known party }\end{array}$ & $\begin{array}{l}\text { (4) } \\
\text { All }\end{array}$ & $\begin{array}{l}\text { (5) } \\
\text { All }\end{array}$ \\
\hline Time & $\begin{array}{c}0.0016^{* * *} \\
(0.0002)\end{array}$ & $\begin{array}{c}0.0019^{* * *} \\
(0.0003)\end{array}$ & $\begin{array}{c}0.0024^{* * *} \\
(0.0003)\end{array}$ & $\begin{array}{c}0.0014^{* * *} \\
(0.0003)\end{array}$ & $\begin{array}{c}0.0014^{* * *} \\
(0.0003)\end{array}$ \\
\hline Voted for a challenger & $\begin{array}{c}-0.0416^{* * *} \\
(0.0124)\end{array}$ & & & $\begin{array}{l}-0.0146 \\
(0.0141)\end{array}$ & $\begin{array}{c}-0.0123 \\
(0.0136)\end{array}$ \\
\hline Time * Voted for a challenger & $\begin{array}{c}0.0016^{* * *} \\
(0.0004)\end{array}$ & & & $\begin{array}{c}0.0011^{* * *} \\
(0.0004)\end{array}$ & $\begin{array}{c}0.0011^{* * *} \\
(0.0004)\end{array}$ \\
\hline Voted for a small candidate & & $\begin{array}{c}-0.0834^{* *} \\
(0.0322)\end{array}$ & & $\begin{array}{c}-0.0718^{* *} \\
(0.0345)\end{array}$ & $\begin{array}{c}-0.0719^{* *} \\
(0.0312)\end{array}$ \\
\hline Time * Voted for a small candidate & & $\begin{array}{c}0.0049^{* * *} \\
(0.0010)\end{array}$ & & $\begin{array}{c}0.0035^{* * *} \\
(0.0010)\end{array}$ & $\begin{array}{c}0.0035^{* * *} \\
(0.0009)\end{array}$ \\
\hline Voted for a new party & & & $\begin{array}{l}-0.0160 \\
(0.0571)\end{array}$ & $\begin{array}{c}0.0029 \\
(0.0441)\end{array}$ & $\begin{array}{c}0.0008 \\
(0.0440)\end{array}$ \\
\hline Time $*$ Voted for a new party & & & $\begin{array}{c}0.0038^{* * *} \\
(0.0012)\end{array}$ & $\begin{array}{c}0.0018^{* * *} \\
(0.0006)\end{array}$ & $\begin{array}{c}0.0018^{* * *} \\
(0.0006)\end{array}$ \\
\hline Observations & 200916 & 200916 & 200916 & 200916 & 200916 \\
\hline$R^{2}$ & 0.078 & 0.095 & 0.082 & 0.100 & 0.105 \\
\hline Mean at day -1 & 0.8768 & 0.8768 & 0.8768 & 0.8768 & 0.8768 \\
\hline Election fixed effects & $\mathrm{x}$ & $\mathrm{x}$ & $\mathrm{x}$ & $\mathrm{x}$ & $\mathrm{x}$ \\
\hline Individual controls & $\mathrm{x}$ & $\mathrm{x}$ & $\mathrm{x}$ & $\mathrm{x}$ & $\mathrm{x}$ \\
\hline Sociodemographic controls & & & & & $\mathrm{x}$ \\
\hline
\end{tabular}

Notes: Standard errors clustered at the survey level are in parentheses $(* * *, * *, *$ indicate significance at 1,5 , and $10 \%$, respectively). We regress vote choice consistency on a linear time trend and its interaction with dummies for voting for a lesser-known candidate (challenger, small candidate, or the candidate of a new party). Dummies for voting for a lesser-known candidate and for an undefined candidate type are also included. Individual controls include fixed effects for the day of the week in which the pre-electoral survey took place and for the number of days separating the post-electoral survey from the election. Sociodemographic controls include education (dummies indicating above high school education and college degree), gender, age, income quartiles, and employment status. 
Table A.18: Likelihood to vote for lesser-known candidates and vote share concentration

\begin{tabular}{|c|c|c|c|c|c|c|c|c|}
\hline & \multicolumn{2}{|c|}{$\begin{array}{l}\text { Support for } \\
\text { challenger }\end{array}$} & \multicolumn{2}{|c|}{$\begin{array}{c}\text { Support for } \\
\text { small candidate }\end{array}$} & \multicolumn{2}{|c|}{$\begin{array}{l}\text { Support for } \\
\text { new party }\end{array}$} & \multicolumn{2}{|c|}{$\begin{array}{c}\text { Vote share } \\
\text { concentration }\end{array}$} \\
\hline & (1) & (2) & (3) & (4) & (5) & (6) & (7) & (8) \\
\hline Time & $\begin{array}{c}0.00046^{* * *} \\
(0.00017)\end{array}$ & $\begin{array}{l}0.00043^{* *} \\
(0.00017)\end{array}$ & $\begin{array}{l}0.00038^{* *} \\
(0.00015)\end{array}$ & $\begin{array}{l}0.00035^{* *} \\
(0.00014)\end{array}$ & $\begin{array}{c}0.00006 \\
(0.00004)\end{array}$ & $\begin{array}{c}0.00005 \\
(0.00004)\end{array}$ & $\begin{array}{c}-0.00021^{* *} \\
(0.00010)\end{array}$ & $\begin{array}{c}-0.00019^{* *} \\
(0.00009)\end{array}$ \\
\hline Observations & 189733 & 189733 & 190329 & 190329 & 187068 & 187068 & 3138 & 3138 \\
\hline$R^{2}$ & 0.079 & 0.085 & 0.089 & 0.094 & 0.145 & 0.146 & 0.932 & 0.933 \\
\hline Mean at day -1 & 0.66015 & 0.66015 & 0.14837 & 0.14837 & 0.02083 & 0.02083 & 0.33637 & 0.33637 \\
\hline Election fixed effects & $\mathrm{x}$ & $\mathrm{x}$ & $\mathrm{x}$ & $\mathrm{x}$ & $\mathrm{x}$ & $\mathrm{x}$ & $\mathrm{x}$ & $\mathrm{x}$ \\
\hline Individual controls & $\mathrm{x}$ & $\mathrm{x}$ & $\mathrm{x}$ & $\mathrm{x}$ & $\mathrm{x}$ & $\mathrm{x}$ & & \\
\hline Aggregate controls & & & & & & & $\mathrm{x}$ & $\mathrm{x}$ \\
\hline Sociodemographic controls & & $\mathrm{x}$ & & $\mathrm{x}$ & & $\mathrm{x}$ & & $\mathrm{x}$ \\
\hline
\end{tabular}

Notes: Standard errors clustered at the survey level are in parentheses $(* * *, * *, *$ indicate significance at 1,5 , and $10 \%$, respectively). In columns 1 through 6 , the sample includes all respondents surveyed before the election who said that they intended to vote and stated a vote intention different from voting blank or null. Referenda are excluded. We define the outcomes as dummies equal to 1 if voters intend to vote for a challenger, a small candidate, or the candidate of a new party, and use one observation per respondent. In columns 7 and 8, we use one observation per election per day and compute vote share concentration based on all these respondents. Referenda are included. We weight each observation by the number of respondents it was constructed from, relative to the total number of respondents surveyed at the same relative time to the election. Individual controls include fixed effects for the day of the week in which the pre-electoral survey took place. Sociodemographic controls include education (dummies indicating above high school education and college degree), gender, age, income quartiles, and employment status. 


\section{A.4 Impact of TV Debates and Disasters: Additional Results}

Figure A.10: Media consumption, political discussions, and partisan communication

(a) Newspapers

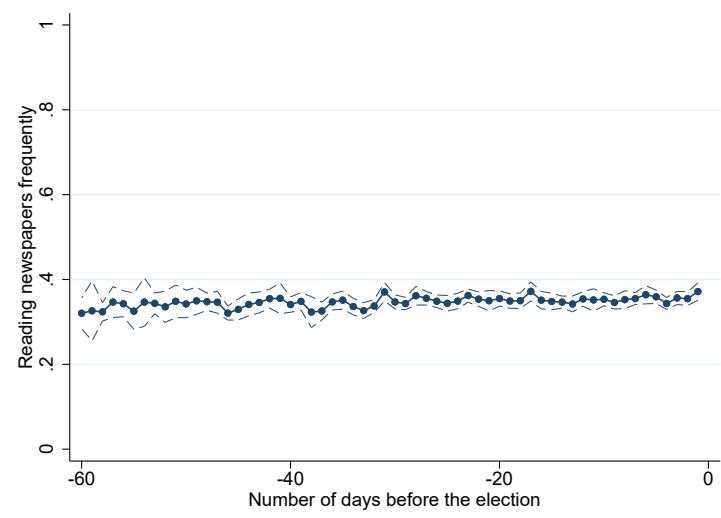

(c) Radio

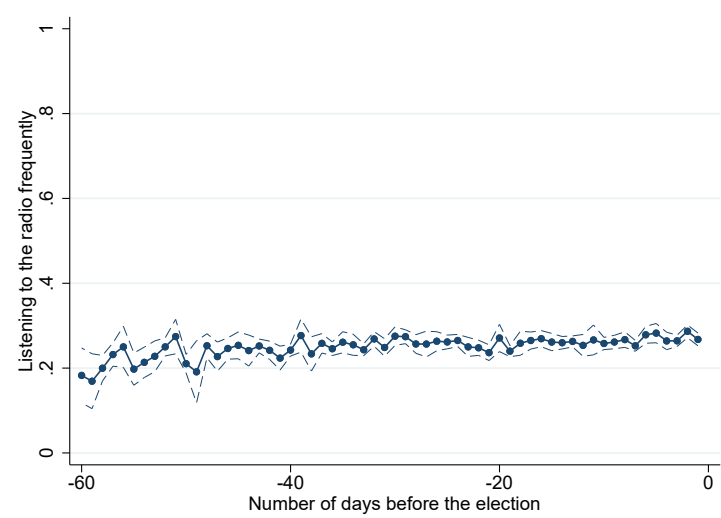

(e) Polls

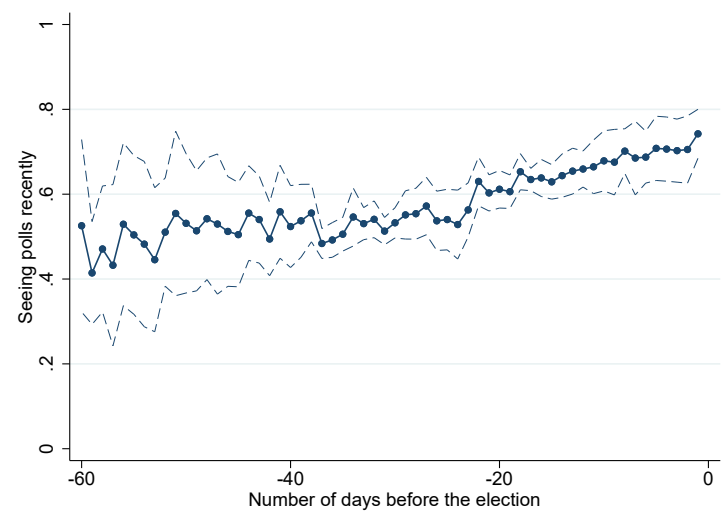

(b) TV

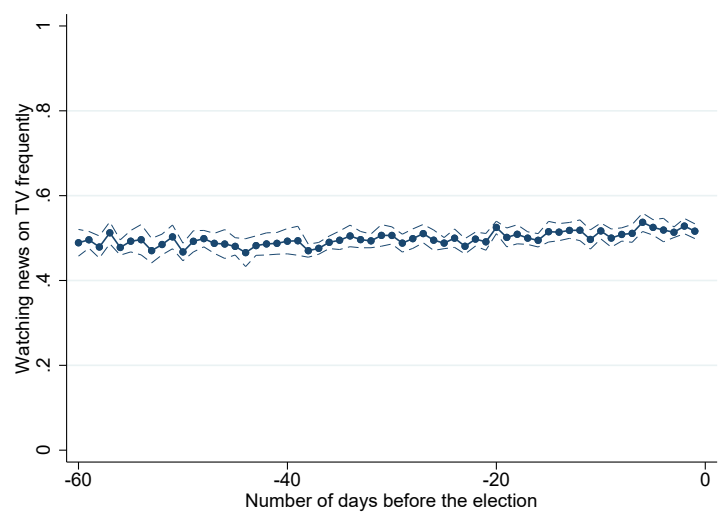

(d) Internet

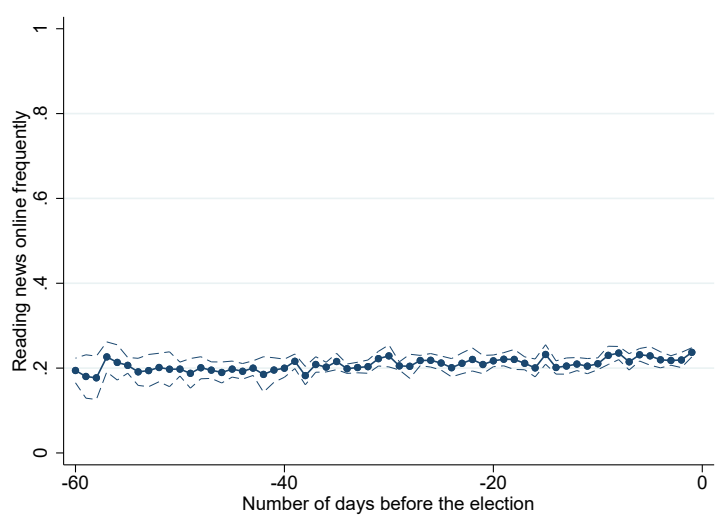

(f) Political discussions

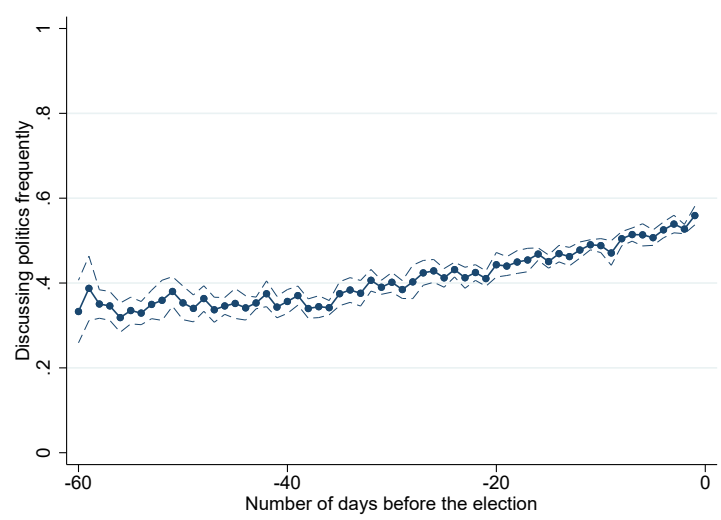


Figure A.10: Media consumption, political discussions, and partisan communication (cont.)

(g) Contacted by a party

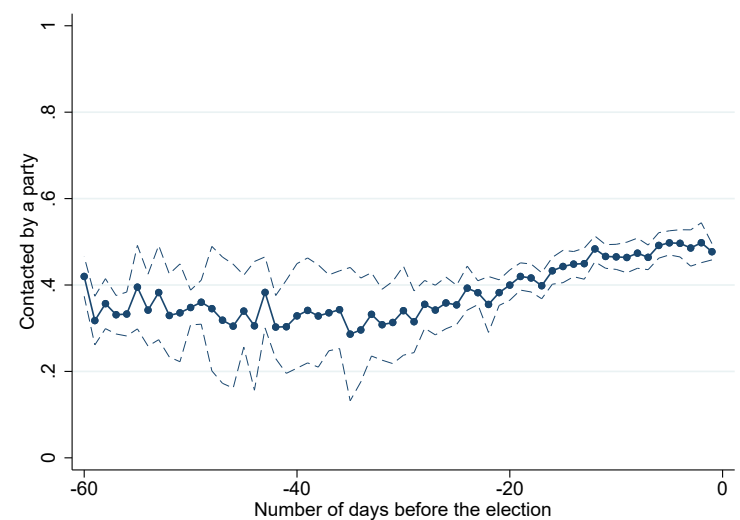

(h) Visited by a party

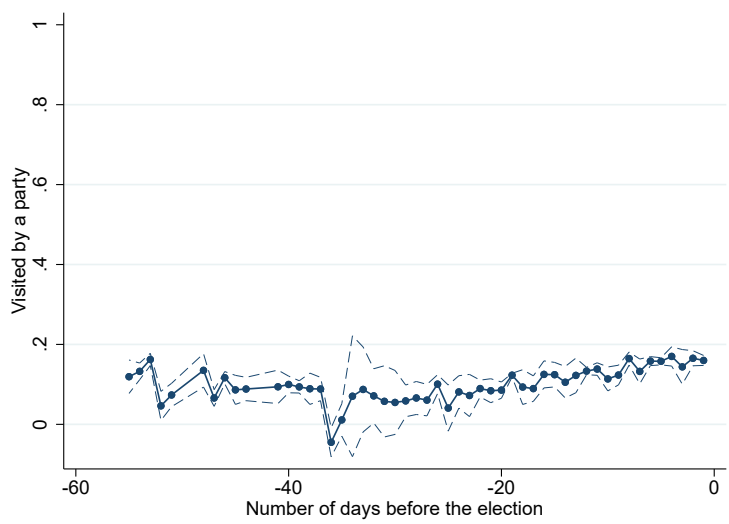

Notes: We show point estimates and 95\% confidence intervals from specifications in the form of equation [1], regressing different forms of media consumption, political discussions, and partisan communication on 60 fixed effects indicating the number of days relative to the election, election fixed effects and fixed effects for the day of the week in which the pre-electoral survey took place. The sample includes all respondents surveyed before the election who said that they intended to vote. The outcomes are dummies for getting information frequently from newspapers $(\mathrm{N}=147,119)$, TV $(\mathrm{N}=140,040)$, radio $(\mathrm{N}=101,015)$, and the Internet $(\mathrm{N}=119,596)$, having seen election polls recently $(\mathrm{N}=38,355)$, discussing politics frequently with others $(\mathrm{N}=103,805)$, having been contacted by a party recently $(\mathrm{N}=59,259)$, and having been visited at home by a party recently $(\mathrm{N}=41,301)$.

Figure A.11: Vote choice consistency and debate dates

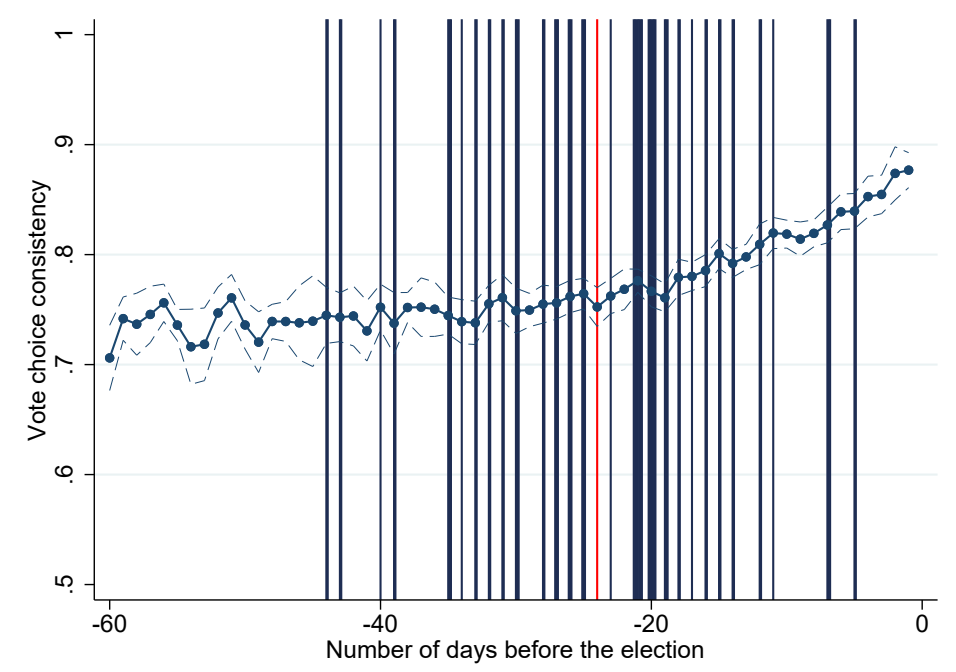

Notes: Each debate is represented by a vertical bar. Thicker bars correspond to dates in which debates were held in multiple elections. On average, debates were held 24 days before the election. This average distance to the election is represented by a red vertical bar. Other notes as in Figure I. 
Figure A.12: Debates' effects on consistency in policy preferences, issue salience, and beliefs on candidates

(a) Consistency in policy preferences

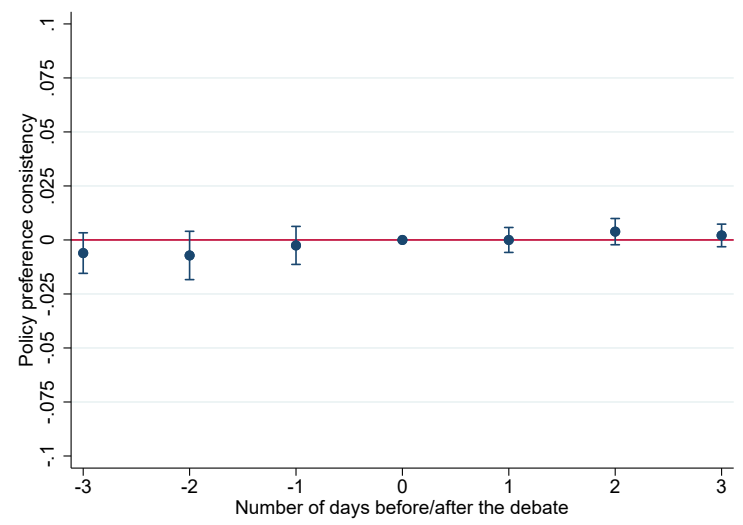

(b) Consistency in issue salience

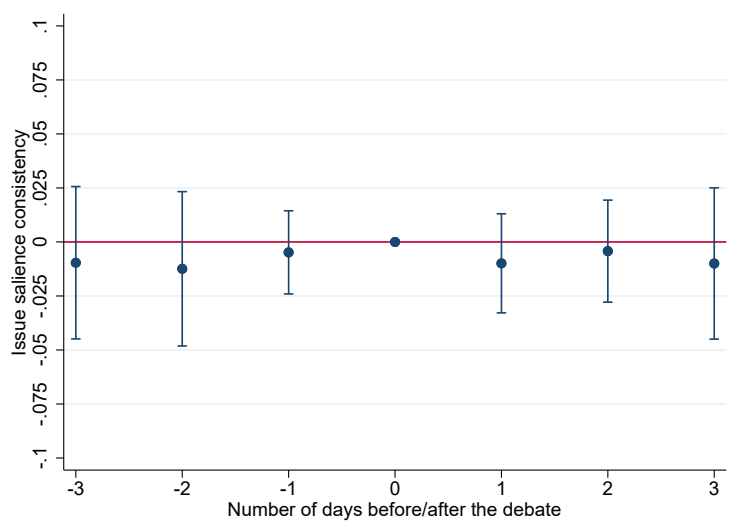

(c) Consistency in beliefs on candidates

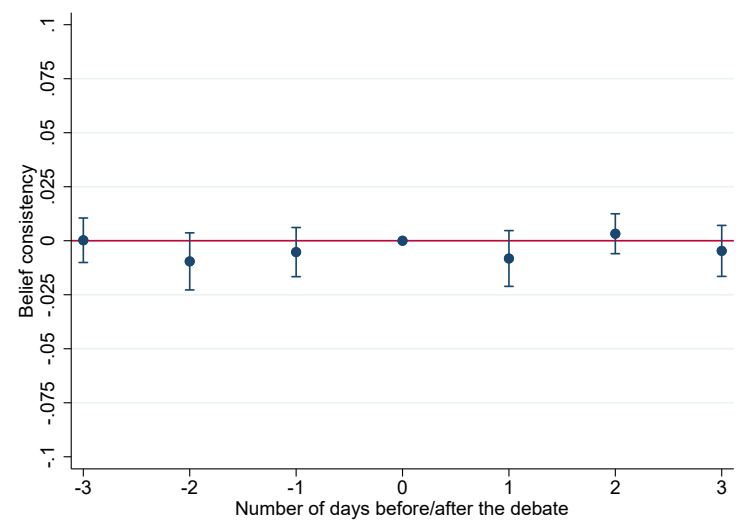

Notes: We show point estimates and 95\% confidence intervals from specifications in the form of equation [8], regressing consistency in policy preferences, issue salience and beliefs on candidates on dummy variables for being surveyed one, two, or three days before the debate, as well as dummies for being surveyed one, two, or three days after the debate. We also include dummies for being surveyed four days or more before or after the debate, respectively, and omit the dummy for being surveyed on the day of the debate. We control for debate $\times$ question (Figures A.12a and A.12c) or debate $\times$ election (Figure A.12b) fixed effects as well as fixed effects for the number of days relative to the election, for the day of the week in which the pre-electoral survey took place, and for the number of days separating the pre- and post-electoral survey. Standard errors are adjusted for clustering at the debate level. There are 12 debates $(\mathrm{N}=346,231)$ in Figure A.12a, seven debates $(\mathrm{N}=51,821)$ in Figure A.12b, and 16 debates $(\mathrm{N}=558,194)$ in Figure A.12c. 
Figure A.13: Debate-specific effects on vote choice consistency

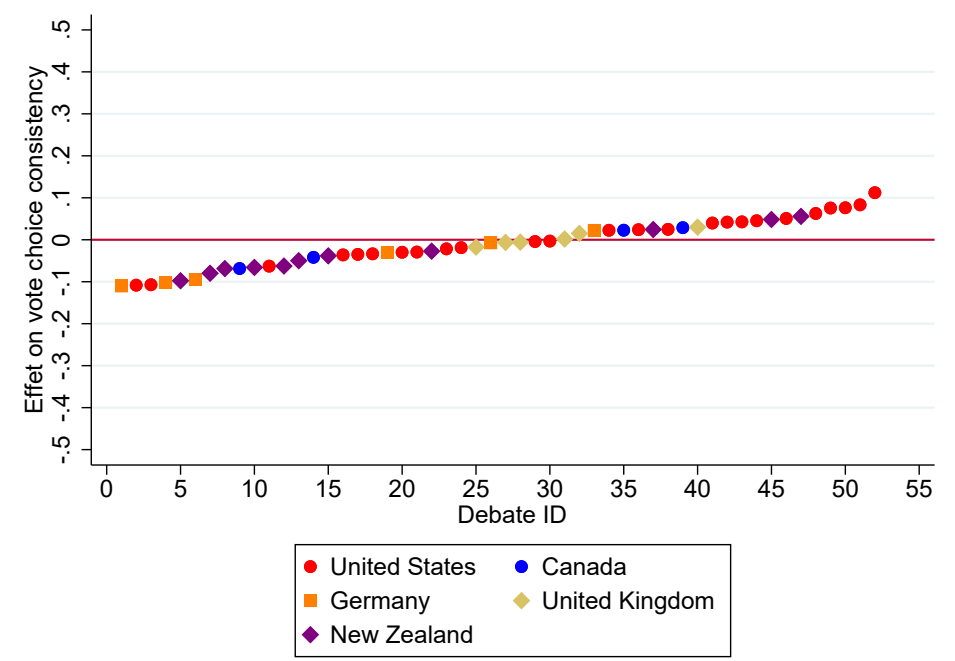

Notes: We show the mean value of the three debate-specific post-debate dummies for each debate separately and in ascending order, from a specification in the form of [8] where each relative day dummy is interacted with a full set of debate $\times$ election indicators. The outcome is vote choice consistency and we control for debate $\times$ election fixed effects as well as fixed effects for the number of days relative to the election, for the day of the week in which the pre-electoral survey took place, and for the number of days separating the post-electoral survey from the election. Debates covered both by the ANES and the NAES or held before elections with multiple ballots are represented by separate coefficients. Surveys with 10 or fewer respondents on the day of the debate or on any of the three days following it are excluded, as the corresponding estimates would be particularly likely to capture outcome differences across days due to sampling error rather than true effects. $\mathrm{N}=52$. 
Figure A.14: Debate-specific effects on distance to final vote shares

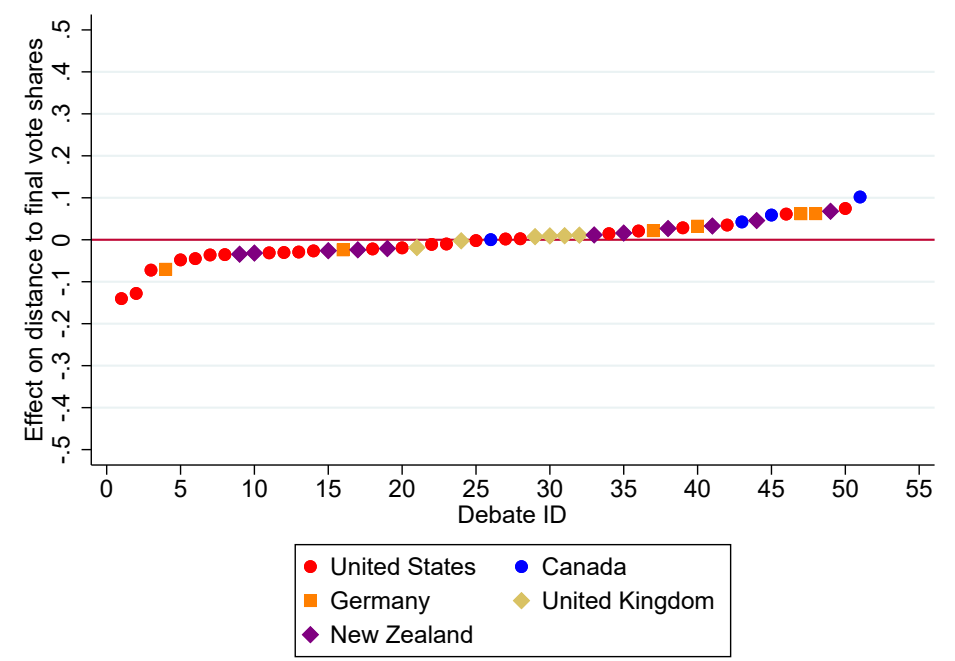

Notes: We show the mean value of the three debate-specific post-debate dummies for each debate separately and in ascending order, from a specification in the form of [9] where each relative day dummy is interacted with a full set of debate $\times$ election indicators. The outcome is the distance between predicted and final vote shares and we control for debate $\times$ election fixed effects, fixed effects for the number of days relative to the election and for the day of the week in which the pre-electoral survey took place, and the average number of days separating the post-electoral survey from the election. Other notes as in Appendix Figure A.13. 


\section{Figure A.15: Disasters' effects on vote choice consistency}

(a) Vote choice consistency

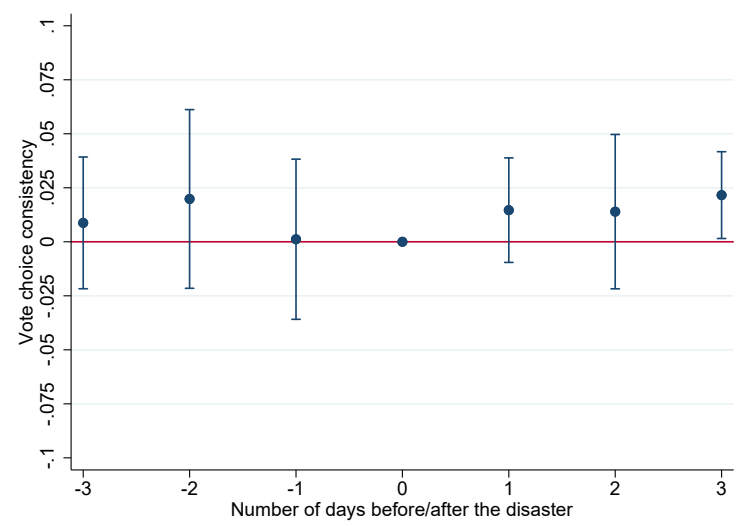

(b) Vote intention

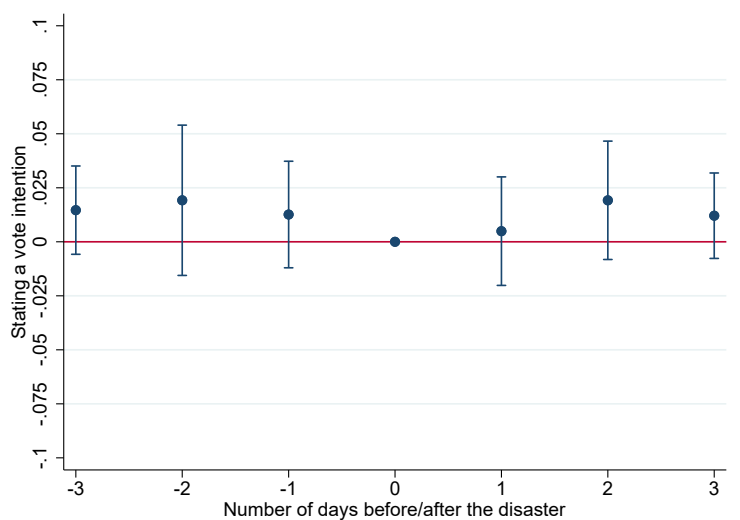

(c) Conditional consistency

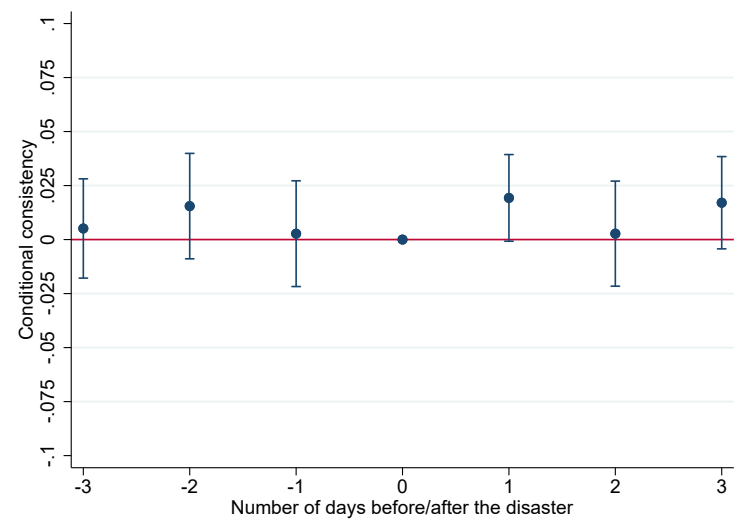

Notes: We show point estimates and 95\% confidence intervals from specifications in the form of equation [8], regressing vote choice consistency, vote intention, and conditional vote choice consistency on dummy variables for being surveyed one, two, or three days before the disaster, as well as dummies for being surveyed one, two, or three days after the disaster. We also include dummies for being surveyed four days or more before or after the disaster, respectively, and omit the dummy for being surveyed on the day of the disaster. We control for disaster $\times$ election fixed effects as well as fixed effects for the number of days relative to the election and for the day of the week in which the pre-electoral survey took place. In Figures A.15a and A.15c, we also control for fixed effects for the number of days separating the post-electoral survey from the election. Standard errors are adjusted for clustering at the disaster level. $\mathrm{N}=85,098 ; 112,988$; and 77,402 , respectively. 
Figure A.16: Disasters' effects on aggregate vote shares

(a) Distance between predicted and final vote shares

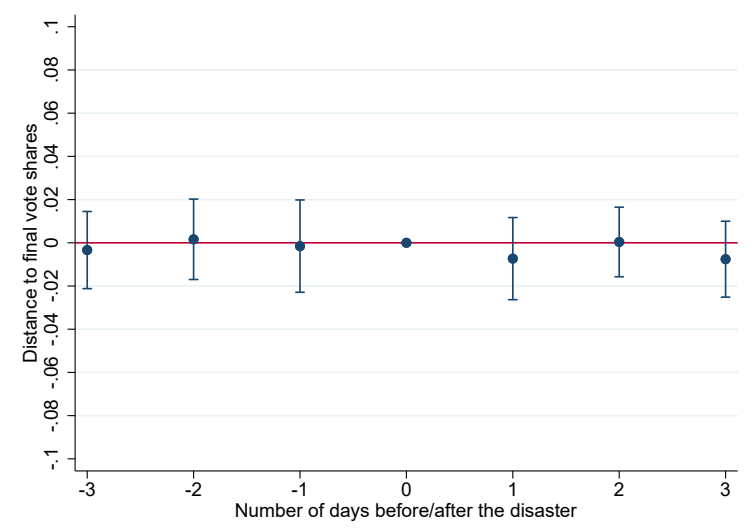

(b) Daily change in predicted vote shares

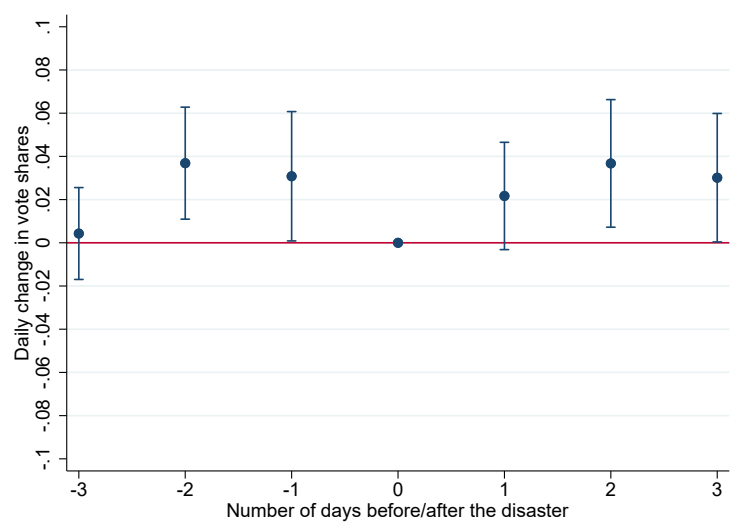

Notes: We show point estimates and 95\% confidence intervals from specifications in the form of equation [9], using the distance between predicted and final vote shares and daily change in predicted vote shares as outcomes. We control for disaster $\times$ election fixed effects as well as fixed effects for the number of days relative to the election and for the day of the week in which the pre-electoral survey took place. We also control for the average number of days separating the post-electoral survey from the election in Figure A.16a. N=2,130 and 2,119, respectively. Other notes as in Appendix Figure A.15.

Table A.19: Campaign exposure over time

\begin{tabular}{|c|c|c|c|c|c|c|c|c|}
\hline & Newspapers & Television & Radio & Internet & Polls & $\begin{array}{c}\text { Political } \\
\text { discussions } \\
\end{array}$ & $\begin{array}{c}\text { Contact by } \\
\text { a party } \\
\end{array}$ & $\begin{array}{l}\text { Visit by } \\
\text { a party }\end{array}$ \\
\hline & (1) & (2) & (3) & (4) & (5) & (6) & (7) & (8) \\
\hline Time & $\begin{array}{c}0.0004 \\
(0.0003)\end{array}$ & $\begin{array}{c}0.0007^{* * *} \\
(0.0002)\end{array}$ & $\begin{array}{c}0.0007^{* *} \\
(0.0003)\end{array}$ & $\begin{array}{c}0.0006^{* *} \\
(0.0002)\end{array}$ & $\begin{array}{c}0.0046^{* *} \\
(0.0018)\end{array}$ & $\begin{array}{c}0.0042^{* * *} \\
(0.0003)\end{array}$ & $\begin{array}{c}0.0043^{* *} \\
(0.0016)\end{array}$ & $\begin{array}{c}0.0030^{* *} \\
(0.0010)\end{array}$ \\
\hline Observations & 147119 & 140040 & 101015 & 119596 & 38355 & 103805 & 59259 & 41301 \\
\hline$R^{2}$ & 0.139 & 0.189 & 0.109 & 0.091 & 0.084 & 0.097 & 0.137 & 0.017 \\
\hline Mean at day -1 & 0.3715 & 0.5162 & 0.2676 & 0.2372 & 0.7424 & 0.5591 & 0.4770 & 0.1599 \\
\hline Election fixed effects & $\mathrm{x}$ & $\mathrm{x}$ & $\mathrm{x}$ & $\mathrm{x}$ & $\mathrm{x}$ & $\mathrm{x}$ & $\mathrm{x}$ & $\mathrm{x}$ \\
\hline Individual controls & $\mathrm{x}$ & $\mathrm{x}$ & $\mathrm{x}$ & $\mathrm{x}$ & $\mathrm{x}$ & $\mathrm{x}$ & $\mathrm{x}$ & $\mathrm{x}$ \\
\hline
\end{tabular}

Notes: Standard errors clustered at the survey level are in parentheses $(* * *, * *, *$ indicate significance at 1,5 , and $10 \%$, respectively). Time is defined as negative the number of days separating the pre-electoral survey from the election. The outcomes are dummies for getting information frequently from newspapers, TV, radio, and the Internet, having seen election polls recently, discussing politics frequently with others, having been contacted by a party recently, and having been visited by a party recently. The sample includes all respondents surveyed before the election who said that they intended to vote. Individual controls include fixed effects for the day of the week in which the pre-electoral survey took place. 


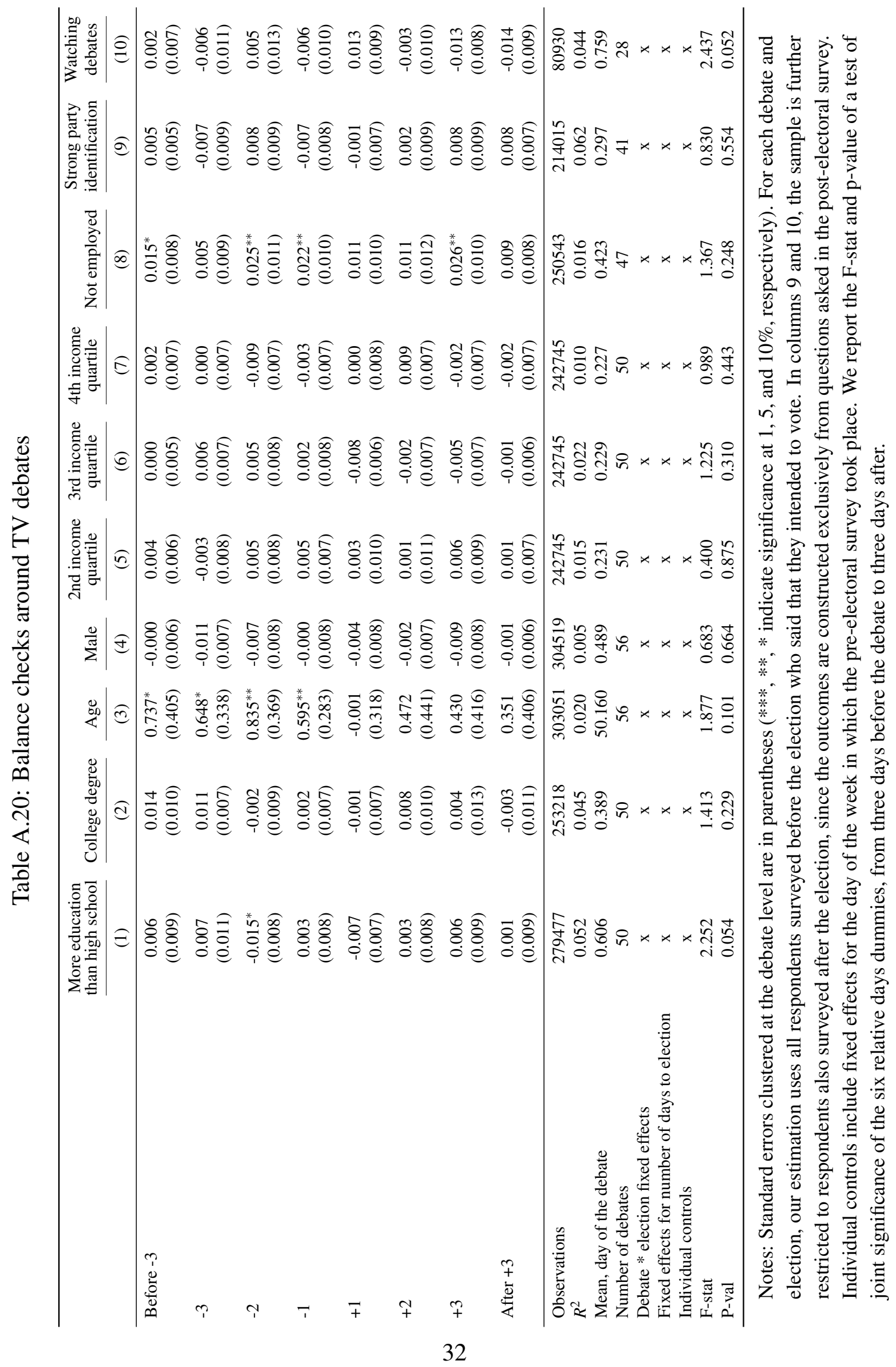




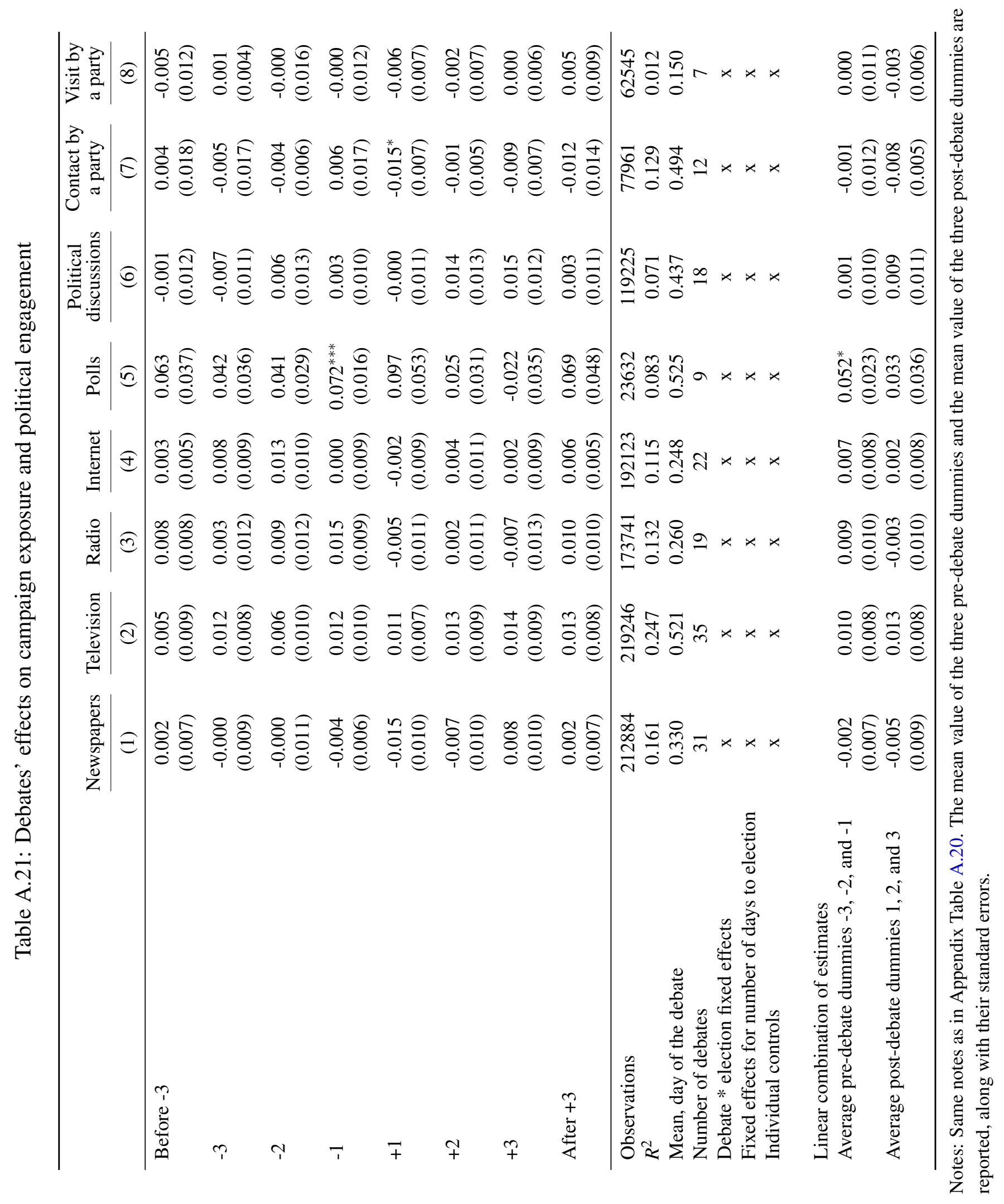


Table A.22: Sample selection around debates

\begin{tabular}{|c|c|c|c|c|}
\hline & Turnout intention & $\begin{array}{c}\text { Sample, } \\
\text { vote intention } \\
\end{array}$ & $\begin{array}{c}\text { Sample, vote } \\
\text { choice consistency }\end{array}$ & $\begin{array}{c}\text { Post-electoral } \\
\text { reinterview rate }\end{array}$ \\
\hline & (1) & (2) & (3) & (4) \\
\hline Before -3 & $\begin{array}{c}-0.002 \\
(0.008)\end{array}$ & $\begin{array}{l}-0.002 \\
(0.009)\end{array}$ & $\begin{array}{c}0.005 \\
(0.008)\end{array}$ & $\begin{array}{l}-0.001 \\
(0.007)\end{array}$ \\
\hline-3 & $\begin{array}{c}0.010 \\
(0.009)\end{array}$ & $\begin{array}{c}0.009 \\
(0.009)\end{array}$ & $\begin{array}{c}0.008 \\
(0.009)\end{array}$ & $\begin{array}{c}0.000 \\
(0.007)\end{array}$ \\
\hline-2 & $\begin{array}{c}0.002 \\
(0.006)\end{array}$ & $\begin{array}{c}0.003 \\
(0.006)\end{array}$ & $\begin{array}{c}0.009 \\
(0.008)\end{array}$ & $\begin{array}{c}0.006 \\
(0.006)\end{array}$ \\
\hline-1 & $\begin{array}{l}-0.005 \\
(0.007)\end{array}$ & $\begin{array}{l}-0.002 \\
(0.007)\end{array}$ & $\begin{array}{c}0.001 \\
(0.008)\end{array}$ & $\begin{array}{c}0.001 \\
(0.006)\end{array}$ \\
\hline+1 & $\begin{array}{c}0.009 \\
(0.007)\end{array}$ & $\begin{array}{c}0.009 \\
(0.007)\end{array}$ & $\begin{array}{c}0.010 \\
(0.007)\end{array}$ & $\begin{array}{l}-0.003 \\
(0.008)\end{array}$ \\
\hline+2 & $\begin{array}{c}0.009 \\
(0.007)\end{array}$ & $\begin{array}{c}0.009 \\
(0.008)\end{array}$ & $\begin{array}{c}0.014 \\
(0.010)\end{array}$ & $\begin{array}{l}-0.006 \\
(0.007)\end{array}$ \\
\hline+3 & $\begin{array}{c}0.002 \\
(0.007)\end{array}$ & $\begin{array}{c}0.006 \\
(0.007)\end{array}$ & $\begin{array}{l}0.013^{*} \\
(0.007)\end{array}$ & $\begin{array}{l}-0.002 \\
(0.008)\end{array}$ \\
\hline After +3 & $\begin{array}{c}0.006 \\
(0.008) \\
\end{array}$ & $\begin{array}{c}0.006 \\
(0.009) \\
\end{array}$ & $\begin{array}{c}0.010 \\
(0.009) \\
\end{array}$ & $\begin{array}{c}-0.005 \\
(0.006)\end{array}$ \\
\hline Observations & 396349 & 396349 & 329783 & 396349 \\
\hline$R^{2}$ & 0.065 & 0.073 & 0.036 & 0.107 \\
\hline Mean, day of the debate & 0.835 & 0.821 & 0.794 & 0.862 \\
\hline Number of debates & 56 & 56 & 56 & 56 \\
\hline Debate $*$ election fixed effects & $\mathrm{x}$ & $\mathrm{x}$ & $\mathrm{x}$ & $\mathrm{x}$ \\
\hline Fixed effects for number of days to election & $\mathrm{x}$ & $\mathrm{x}$ & $\mathrm{x}$ & $\mathrm{x}$ \\
\hline Individual controls & $\mathrm{x}$ & $\mathrm{x}$ & $\mathrm{x}$ & $\mathrm{x}$ \\
\hline \multicolumn{5}{|l|}{ Linear combination of estimates } \\
\hline Average pre-debate dummies $-3,-2$, and -1 & $\begin{array}{c}0.002 \\
(0.007)\end{array}$ & $\begin{array}{c}0.003 \\
(0.007)\end{array}$ & $\begin{array}{c}0.006 \\
(0.007)\end{array}$ & $\begin{array}{c}0.002 \\
(0.005)\end{array}$ \\
\hline Average post-debate dummies 1,2 , and 3 & $\begin{array}{c}0.007 \\
(0.006)\end{array}$ & $\begin{array}{c}0.008 \\
(0.006)\end{array}$ & $\begin{array}{l}0.012^{*} \\
(0.007)\end{array}$ & $\begin{array}{c}-0.004 \\
(0.007)\end{array}$ \\
\hline
\end{tabular}

Notes: Standard errors clustered at the debate level are in parentheses $(* * *, * *, *$ indicate significance at 1,5 , and $10 \%$, respectively). In column 1, the sample includes all respondents surveyed before the election who were asked if they intended to vote, and the outcome is a dummy equal to 1 if the respondent said yes. In column 2, the sample includes all respondents surveyed before the election who were asked if they intended to vote, and the outcome is a dummy equal to 1 if the respondent said yes and answered the vote intention question (including if they said they did not know whom they would vote for). In column 3, the sample includes all respondents surveyed before and after the election who were asked if they intended to vote, in the first survey, and if they actually voted, in the second. The outcome is a dummy equal to 1 if the respondent said that they intended to vote and answered the vote intention question, in the first survey, and reported that they actually voted and gave a vote choice declaration, in the second. In column 4, the sample includes all respondents surveyed before the election who were asked if they intended to vote, and the outcome is a dummy equal to 1 if the respondent appears in the post-electoral survey. Individual controls include fixed effects for the day of the week in which the pre-electoral survey took place and, in column 3, fixed effects for the number of days separating the post-electoral survey from the election. Other notes as in Table III. 
Table A.23: Debates' effects on consistency in policy preferences, issue salience, and beliefs on candidates

\begin{tabular}{|c|c|c|c|c|c|c|}
\hline & \multicolumn{2}{|c|}{$\begin{array}{l}\text { Consistency in } \\
\text { policy preferences }\end{array}$} & \multicolumn{2}{|c|}{$\begin{array}{l}\text { Consistency in } \\
\text { issue salience }\end{array}$} & \multicolumn{2}{|c|}{$\begin{array}{c}\text { Consistency in } \\
\text { beliefs on candidates }\end{array}$} \\
\hline & (1) & (2) & (3) & (4) & (5) & (6) \\
\hline Before -3 & $\begin{array}{l}-0.001 \\
(0.002)\end{array}$ & $\begin{array}{l}-0.001 \\
(0.002)\end{array}$ & $\begin{array}{l}-0.012 \\
(0.009)\end{array}$ & $\begin{array}{l}-0.011 \\
(0.008)\end{array}$ & $\begin{array}{l}-0.005 \\
(0.006)\end{array}$ & $\begin{array}{l}-0.006 \\
(0.006)\end{array}$ \\
\hline-3 & $\begin{array}{l}-0.006 \\
(0.004)\end{array}$ & $\begin{array}{l}-0.006 \\
(0.004)\end{array}$ & $\begin{array}{l}-0.010 \\
(0.014)\end{array}$ & $\begin{array}{l}-0.009 \\
(0.014)\end{array}$ & $\begin{array}{l}0.000 \\
(0.005)\end{array}$ & $\begin{array}{c}0.001 \\
(0.005)\end{array}$ \\
\hline-2 & $\begin{array}{l}-0.007 \\
(0.005)\end{array}$ & $\begin{array}{l}-0.006 \\
(0.005)\end{array}$ & $\begin{array}{l}-0.012 \\
(0.015)\end{array}$ & $\begin{array}{l}-0.011 \\
(0.014)\end{array}$ & $\begin{array}{l}-0.010 \\
(0.006)\end{array}$ & $\begin{array}{l}-0.010 \\
(0.006)\end{array}$ \\
\hline-1 & $\begin{array}{l}-0.003 \\
(0.004)\end{array}$ & $\begin{array}{l}-0.002 \\
(0.003)\end{array}$ & $\begin{array}{l}-0.005 \\
(0.008)\end{array}$ & $\begin{array}{l}-0.004 \\
(0.007)\end{array}$ & $\begin{array}{l}-0.005 \\
(0.005)\end{array}$ & $\begin{array}{l}-0.005 \\
(0.005)\end{array}$ \\
\hline+1 & $\begin{array}{l}-0.000 \\
(0.003)\end{array}$ & $\begin{array}{l}-0.000 \\
(0.002)\end{array}$ & $\begin{array}{l}-0.010 \\
(0.009)\end{array}$ & $\begin{array}{l}-0.010 \\
(0.010)\end{array}$ & $\begin{array}{l}-0.008 \\
(0.006)\end{array}$ & $\begin{array}{l}-0.008 \\
(0.006)\end{array}$ \\
\hline+2 & $\begin{array}{c}0.004 \\
(0.003)\end{array}$ & $\begin{array}{l}0.003 \\
(0.003)\end{array}$ & $\begin{array}{l}-0.004 \\
(0.010)\end{array}$ & $\begin{array}{l}-0.004 \\
(0.009)\end{array}$ & $\begin{array}{l}0.003 \\
(0.004)\end{array}$ & $\begin{array}{l}0.003 \\
(0.004)\end{array}$ \\
\hline+3 & $\begin{array}{c}0.002 \\
(0.002)\end{array}$ & $\begin{array}{l}0.003 \\
(0.003)\end{array}$ & $\begin{array}{l}-0.010 \\
(0.014)\end{array}$ & $\begin{array}{l}-0.009 \\
(0.014)\end{array}$ & $\begin{array}{l}-0.005 \\
(0.006)\end{array}$ & $\begin{array}{l}-0.004 \\
(0.005)\end{array}$ \\
\hline After +3 & $\begin{array}{l}-0.005 \\
(0.003)\end{array}$ & $\begin{array}{l}-0.005 \\
(0.003)\end{array}$ & $\begin{array}{c}0.001 \\
(0.009)\end{array}$ & $\begin{array}{c}0.002 \\
(0.009)\end{array}$ & $\begin{array}{c}0.002 \\
(0.003)\end{array}$ & $\begin{array}{c}0.002 \\
(0.003)\end{array}$ \\
\hline Observations & 346231 & 346231 & 51821 & 51821 & 558194 & 558194 \\
\hline$R^{2}$ & 0.048 & 0.054 & 0.069 & 0.074 & 0.092 & 0.100 \\
\hline Mean, day of the debate & 0.837 & 0.837 & 0.719 & 0.719 & 0.807 & 0.807 \\
\hline Number of debates & 12 & 12 & 7 & 7 & 16 & 16 \\
\hline Debate $*$ question fixed effects & $\mathrm{x}$ & $\mathrm{x}$ & & & $\mathrm{x}$ & $\mathrm{x}$ \\
\hline Debate * election fixed effects & & & $\mathrm{x}$ & $\mathrm{x}$ & & \\
\hline Fixed effects for number of days to election & $\mathrm{x}$ & $\mathrm{x}$ & $\mathrm{x}$ & $\mathrm{x}$ & $\mathrm{x}$ & $\mathrm{x}$ \\
\hline Individual controls & $\mathrm{x}$ & $\mathrm{x}$ & $\mathrm{x}$ & $\mathrm{x}$ & $\mathrm{x}$ & $\mathrm{x}$ \\
\hline Sociodemographic controls & & $\mathrm{x}$ & & $\mathrm{x}$ & & $\mathrm{x}$ \\
\hline Linear combination of estimates & & & & & & \\
\hline Average pre-debate dummies $-3,-2$, and -1 & $\begin{array}{l}-0.005 \\
(0.004)\end{array}$ & $\begin{array}{l}-0.005 \\
(0.004)\end{array}$ & $\begin{array}{l}-0.009 \\
(0.011)\end{array}$ & $\begin{array}{l}-0.008 \\
(0.010)\end{array}$ & $\begin{array}{l}-0.005 \\
(0.005)\end{array}$ & $\begin{array}{l}-0.005 \\
(0.005)\end{array}$ \\
\hline Average post-debate dummies 1,2 , and 3 & $\begin{array}{c}0.002 \\
(0.001)\end{array}$ & $\begin{array}{c}0.002 \\
(0.002)\end{array}$ & $\begin{array}{l}-0.008 \\
(0.009)\end{array}$ & $\begin{array}{l}-0.007 \\
(0.009)\end{array}$ & $\begin{array}{l}-0.003 \\
(0.005)\end{array}$ & $\begin{array}{l}-0.003 \\
(0.005)\end{array}$ \\
\hline
\end{tabular}

Notes: Standard errors clustered at the debate level are in parentheses $(* * *, * *, *$ indicate significance at 1,5 , and $10 \%$, respectively). In columns 1 and 2, we use one observation per respondent per policy question. In columns 5 and 6 , we use one observation per respondent per belief question. Other notes as in Table III. 
Table A.24: Debates' effects on vote choice consistency across debate and election types

\begin{tabular}{|c|c|c|c|c|c|}
\hline \multirow[b]{2}{*}{ Debate type } & \multicolumn{5}{|c|}{ Vote choice onsistency } \\
\hline & $\begin{array}{c}\text { (1) } \\
\text { First vs. } \\
\text { next debate }\end{array}$ & $\begin{array}{c}\text { (2) } \\
\text { Close vs. } \\
\text { less-close race }\end{array}$ & $\begin{array}{c}\text { (3) } \\
\text { Fluctuating vs. } \\
\text { stable race }\end{array}$ & $\begin{array}{c}\text { (4) } \\
\text { U.S. vs. } \\
\text { other countries }\end{array}$ & $\begin{array}{c}\text { (5) } \\
\text { Plurality vs. } \\
\text { proportional rule }\end{array}$ \\
\hline$-3 *$ type-b & $\begin{array}{c}-0.011 \\
(0.008)\end{array}$ & $\begin{array}{l}-0.009 \\
(0.012)\end{array}$ & $\begin{array}{c}-0.007 \\
(0.007)\end{array}$ & $\begin{array}{c}-0.014 \\
(0.009)\end{array}$ & $\begin{array}{c}-0.027 \\
(0.021)\end{array}$ \\
\hline$-2 *$ type-b & $\begin{array}{c}0.007 \\
(0.010)\end{array}$ & $\begin{array}{c}-0.004 \\
(0.013)\end{array}$ & $\begin{array}{c}0.007 \\
(0.012)\end{array}$ & $\begin{array}{c}-0.004 \\
(0.011)\end{array}$ & $\begin{array}{c}-0.021 \\
(0.021)\end{array}$ \\
\hline$-1 *$ type-b & $\begin{array}{c}0.003 \\
(0.009)\end{array}$ & $\begin{array}{c}-0.010 \\
(0.011)\end{array}$ & $\begin{array}{c}0.003 \\
(0.009)\end{array}$ & $\begin{array}{c}-0.002 \\
(0.010)\end{array}$ & $\begin{array}{c}-0.013 \\
(0.020)\end{array}$ \\
\hline+1 *type-b & $\begin{array}{c}-0.001 \\
(0.007)\end{array}$ & $\begin{array}{c}-0.008 \\
(0.010)\end{array}$ & $\begin{array}{c}0.000 \\
(0.007)\end{array}$ & $\begin{array}{c}-0.015 \\
(0.011)\end{array}$ & $\begin{array}{c}-0.055^{*} \\
(0.029)\end{array}$ \\
\hline$+2 *$ type-b & $\begin{array}{c}-0.007 \\
(0.010)\end{array}$ & $\begin{array}{c}0.003 \\
(0.013)\end{array}$ & $\begin{array}{c}-0.005 \\
(0.010)\end{array}$ & $\begin{array}{c}-0.013 \\
(0.011)\end{array}$ & $\begin{array}{c}-0.044^{*} \\
(0.023)\end{array}$ \\
\hline$+3 *$ type-b & $\begin{array}{l}-0.006 \\
(0.007)\end{array}$ & $\begin{array}{l}-0.001 \\
(0.010)\end{array}$ & $\begin{array}{l}-0.006 \\
(0.006)\end{array}$ & $\begin{array}{l}-0.008 \\
(0.008)\end{array}$ & $\begin{array}{l}-0.027 \\
(0.019)\end{array}$ \\
\hline$-3 *$ type-a & $\begin{array}{c}-0.010 \\
(0.012)\end{array}$ & $\begin{array}{c}-0.010 \\
(0.007)\end{array}$ & $\begin{array}{l}-0.016 \\
(0.013)\end{array}$ & $\begin{array}{c}0.002 \\
(0.011)\end{array}$ & $\begin{array}{c}-0.008 \\
(0.007)\end{array}$ \\
\hline$-2 *$ type-a & $\begin{array}{c}-0.025^{* *} \\
(0.011)\end{array}$ & $\begin{array}{l}-0.000 \\
(0.011)\end{array}$ & $\begin{array}{l}-0.018^{*} \\
(0.011)\end{array}$ & $\begin{array}{c}0.004 \\
(0.012)\end{array}$ & $\begin{array}{l}-0.000 \\
(0.010)\end{array}$ \\
\hline$-1 *$ type-a & $\begin{array}{c}-0.016 \\
(0.012)\end{array}$ & $\begin{array}{c}0.003 \\
(0.009)\end{array}$ & $\begin{array}{c}-0.014 \\
(0.013)\end{array}$ & $\begin{array}{c}-0.002 \\
(0.011)\end{array}$ & $\begin{array}{c}-0.002 \\
(0.008)\end{array}$ \\
\hline$+1 *$ type-a & $\begin{array}{c}-0.029^{*} \\
(0.016)\end{array}$ & $\begin{array}{c}-0.009 \\
(0.010)\end{array}$ & $\begin{array}{c}-0.024 \\
(0.015)\end{array}$ & $\begin{array}{c}0.003 \\
(0.012)\end{array}$ & $\begin{array}{c}-0.003 \\
(0.007)\end{array}$ \\
\hline$+2 *$ type-a & $\begin{array}{c}-0.012 \\
(0.011)\end{array}$ & $\begin{array}{c}-0.016^{*} \\
(0.009)\end{array}$ & $\begin{array}{c}-0.012 \\
(0.013)\end{array}$ & $\begin{array}{c}0.004 \\
(0.010)\end{array}$ & $\begin{array}{c}-0.003 \\
(0.008)\end{array}$ \\
\hline$+3 *$ type-a & $\begin{array}{c}-0.011 \\
(0.013)\end{array}$ & $\begin{array}{c}-0.010 \\
(0.008)\end{array}$ & $\begin{array}{c}-0.007 \\
(0.012)\end{array}$ & $\begin{array}{c}-0.002 \\
(0.010)\end{array}$ & $\begin{array}{c}-0.004 \\
(0.006)\end{array}$ \\
\hline Observations & 263681 & 263681 & 263681 & 263681 & 263681 \\
\hline$R^{2}$ & 0.077 & 0.077 & 0.077 & 0.077 & 0.077 \\
\hline Mean, day of the debate & 0.811 & 0.811 & 0.811 & 0.811 & 0.811 \\
\hline Number of debates & 56 & 56 & 56 & 56 & 56 \\
\hline Debate * election fixed effects & $\mathrm{x}$ & $\mathrm{x}$ & $\mathrm{x}$ & $\mathrm{x}$ & $\mathrm{x}$ \\
\hline Fixed effects for number of days to election & $\mathrm{x}$ & $\mathrm{x}$ & $\mathrm{x}$ & $\mathrm{x}$ & $\mathrm{x}$ \\
\hline Individual controls & $\mathrm{x}$ & $\mathrm{x}$ & $\mathrm{x}$ & $\mathrm{x}$ & $\mathrm{x}$ \\
\hline Sociodemographic controls & $\mathrm{x}$ & $\mathrm{x}$ & $\mathrm{x}$ & $\mathrm{x}$ & $\mathrm{x}$ \\
\hline \multicolumn{6}{|l|}{ Linear combination of estimates } \\
\hline Average pre-debate dummies for type-b & $\begin{array}{l}-0.000 \\
(0.008)\end{array}$ & $\begin{array}{l}-0.007 \\
(0.010)\end{array}$ & $\begin{array}{c}0.001 \\
(0.008)\end{array}$ & $\begin{array}{l}-0.007 \\
(0.009)\end{array}$ & $\begin{array}{l}-0.020 \\
(0.018)\end{array}$ \\
\hline Average post-debate dummies for type-b & $\begin{array}{c}-0.004 \\
(0.006)\end{array}$ & $\begin{array}{c}-0.002 \\
(0.009)\end{array}$ & $\begin{array}{l}-0.003 \\
(0.006)\end{array}$ & $\begin{array}{l}-0.012 \\
(0.008)\end{array}$ & $\begin{array}{c}-0.042^{* * *} \\
(0.015)\end{array}$ \\
\hline Average pre-debate dummies for type-a & $\begin{array}{l}-0.017 \\
(0.010)\end{array}$ & $\begin{array}{l}-0.002 \\
(0.008)\end{array}$ & $\begin{array}{l}-0.016 \\
(0.010)\end{array}$ & $\begin{array}{c}0.001 \\
(0.008)\end{array}$ & $\begin{array}{l}-0.003 \\
(0.007)\end{array}$ \\
\hline Average post-debate dummies for type-a & $\begin{array}{l}-0.017 \\
(0.011)\end{array}$ & $\begin{array}{l}-0.012 \\
(0.007)\end{array}$ & $\begin{array}{l}-0.014 \\
(0.010)\end{array}$ & $\begin{array}{c}0.002 \\
(0.009)\end{array}$ & $\begin{array}{l}-0.003 \\
(0.006)\end{array}$ \\
\hline
\end{tabular}

Notes: Standard errors clustered at the debate level are in parentheses $(* * *, * *, *$ indicate significance at 1, 5, and 10\%, respectively). We interact the relative days dummies with indicators for type-a debate or election (first debate, close race, fluctuating race, U.S. bipartisan system, and plurality rule) and type-b debate or election (next debates, less-close race, more stable race, multiparty system, and proportional rule). We define close races as elections for which the mean difference in vote shares between the two leading candidates over the five days before the debate is smaller than 10 percentage points, and fluctuating races as elections in which the mean daily change in vote shares (as defined in Section V.C) over the five days before the debate is higher than 10 percentage points. Dummies for being surveyed four days or more before or after the debate interacted with the type-a and type-b indicators were included in the regressions but are not shown, for presentation clarity. Other notes as in Table III, columns 1 and 2. 
Table A.25: Debates' effects on distance to final vote shares across debate and election types

\begin{tabular}{|c|c|c|c|c|c|}
\hline \multirow[b]{2}{*}{ Debate type } & \multicolumn{5}{|c|}{ Distance between predicted and final vote shares } \\
\hline & $\begin{array}{c}\text { (1) } \\
\text { First vs. } \\
\text { next debate }\end{array}$ & $\begin{array}{c}(2) \\
\text { Close vs. } \\
\text { less-close race }\end{array}$ & $\begin{array}{l}\text { (3) } \\
\text { Fluctuating vs. } \\
\text { stable race }\end{array}$ & $\begin{array}{c}\text { (4) } \\
\text { U.S. vs. } \\
\text { other countries }\end{array}$ & $\begin{array}{c}\text { (5) } \\
\text { Plurality vs. } \\
\text { proportional rule }\end{array}$ \\
\hline$-3 *$ type-b & $\begin{array}{l}-0.000 \\
(0.004)\end{array}$ & $\begin{array}{l}-0.007 \\
(0.006)\end{array}$ & $\begin{array}{c}0.001 \\
(0.004)\end{array}$ & $\begin{array}{c}0.002 \\
(0.005)\end{array}$ & $\begin{array}{l}-0.016 \\
(0.017)\end{array}$ \\
\hline$-2 *$ type-b & $\begin{array}{c}0.001 \\
(0.003)\end{array}$ & $\begin{array}{l}-0.003 \\
(0.006)\end{array}$ & $\begin{array}{l}-0.001 \\
(0.003)\end{array}$ & $\begin{array}{c}0.004 \\
(0.004)\end{array}$ & $\begin{array}{c}0.000 \\
(0.016)\end{array}$ \\
\hline$-1 *$ type-b & $\begin{array}{c}0.001 \\
(0.004)\end{array}$ & $\begin{array}{l}-0.006 \\
(0.007)\end{array}$ & $\begin{array}{l}-0.002 \\
(0.004)\end{array}$ & $\begin{array}{c}0.000 \\
(0.005)\end{array}$ & $\begin{array}{l}-0.020 \\
(0.016)\end{array}$ \\
\hline+1 *type-b & $\begin{array}{c}0.004 \\
(0.004)\end{array}$ & $\begin{array}{l}-0.006 \\
(0.005)\end{array}$ & $\begin{array}{c}0.005 \\
(0.004)\end{array}$ & $\begin{array}{l}0.006^{*} \\
(0.004)\end{array}$ & $\begin{array}{l}-0.013 \\
(0.015)\end{array}$ \\
\hline$+2 *$ type-b & $\begin{array}{l}0.008^{*} \\
(0.004)\end{array}$ & $\begin{array}{l}-0.009 \\
(0.006)\end{array}$ & $\begin{array}{c}0.004 \\
(0.005)\end{array}$ & $\begin{array}{c}0.007 \\
(0.005)\end{array}$ & $\begin{array}{l}-0.002 \\
(0.009)\end{array}$ \\
\hline$+3 *$ type-b & $\begin{array}{c}0.005 \\
(0.006)\end{array}$ & $\begin{array}{l}-0.004 \\
(0.006)\end{array}$ & $\begin{array}{c}0.003 \\
(0.006)\end{array}$ & $\begin{array}{c}0.003 \\
(0.005)\end{array}$ & $\begin{array}{l}-0.005 \\
(0.015)\end{array}$ \\
\hline$-3 *$ type-a & $\begin{array}{l}-0.000 \\
(0.008)\end{array}$ & $\begin{array}{c}0.005 \\
(0.005)\end{array}$ & $\begin{array}{l}-0.002 \\
(0.008)\end{array}$ & $\begin{array}{l}-0.006 \\
(0.006)\end{array}$ & $\begin{array}{c}0.003 \\
(0.004)\end{array}$ \\
\hline$-2 *$ type-a & $\begin{array}{l}-0.002 \\
(0.008)\end{array}$ & $\begin{array}{c}0.003 \\
(0.003)\end{array}$ & $\begin{array}{c}0.003 \\
(0.008)\end{array}$ & $\begin{array}{l}-0.008 \\
(0.006)\end{array}$ & $\begin{array}{c}0.001 \\
(0.003)\end{array}$ \\
\hline$-1 *$ type-a & $\begin{array}{l}-0.010 \\
(0.009)\end{array}$ & $\begin{array}{c}0.002 \\
(0.004)\end{array}$ & $\begin{array}{l}-0.001 \\
(0.010)\end{array}$ & $\begin{array}{l}-0.007 \\
(0.007)\end{array}$ & $\begin{array}{c}0.001 \\
(0.004)\end{array}$ \\
\hline+1 *type-a & $\begin{array}{c}-0.002 \\
(0.007)\end{array}$ & $\begin{array}{l}0.008^{*} \\
(0.004)\end{array}$ & $\begin{array}{c}-0.004 \\
(0.006)\end{array}$ & $\begin{array}{l}-0.006 \\
(0.007)\end{array}$ & $\begin{array}{c}0.004 \\
(0.004)\end{array}$ \\
\hline$+2 *$ type-a & $\begin{array}{c}-0.016^{* *} \\
(0.007)\end{array}$ & $\begin{array}{c}0.008 \\
(0.005)\end{array}$ & $\begin{array}{l}-0.005 \\
(0.007)\end{array}$ & $\begin{array}{l}-0.012^{*} \\
(0.006)\end{array}$ & $\begin{array}{c}0.001 \\
(0.004)\end{array}$ \\
\hline$+3 *$ type-a & $\begin{array}{l}-0.006 \\
(0.006)\end{array}$ & $\begin{array}{c}0.007 \\
(0.007)\end{array}$ & $\begin{array}{l}-0.001 \\
(0.007)\end{array}$ & $\begin{array}{l}-0.000 \\
(0.007)\end{array}$ & $\begin{array}{c}0.003 \\
(0.005)\end{array}$ \\
\hline Observations & 3802 & 3802 & 3802 & 3802 & 3802 \\
\hline$R^{2}$ & 0.582 & 0.581 & 0.583 & 0.587 & 0.584 \\
\hline Mean, day of the debate & 0.046 & 0.046 & 0.046 & 0.046 & 0.046 \\
\hline Number of debates & 56 & 56 & 56 & 56 & 56 \\
\hline Debate * election fixed effects & $\mathrm{x}$ & $\mathrm{x}$ & $\mathrm{x}$ & $\mathrm{x}$ & $\mathrm{x}$ \\
\hline Fixed effects for number of days to election & $\mathrm{x}$ & $\mathrm{x}$ & $\mathrm{x}$ & $\mathrm{x}$ & $\mathrm{x}$ \\
\hline Aggregate controls & $\mathrm{x}$ & $\mathrm{x}$ & $\mathrm{x}$ & $\mathrm{x}$ & $\mathrm{x}$ \\
\hline Sociodemographic controls & $\mathrm{x}$ & $\mathrm{x}$ & $\mathrm{x}$ & $\mathrm{x}$ & $\mathrm{x}$ \\
\hline Linear combination of estimates & & & & & \\
\hline Average pre-debate dummies for type-b & $\begin{array}{c}0.001 \\
(0.003)\end{array}$ & $\begin{array}{l}-0.005 \\
(0.006)\end{array}$ & $\begin{array}{l}-0.000 \\
(0.003)\end{array}$ & $\begin{array}{c}0.002 \\
(0.004)\end{array}$ & $\begin{array}{l}-0.012 \\
(0.014)\end{array}$ \\
\hline Average post-debate dummies for type-b & $\begin{array}{c}0.006 \\
(0.004)\end{array}$ & $\begin{array}{l}-0.006 \\
(0.004)\end{array}$ & $\begin{array}{c}0.004 \\
(0.004)\end{array}$ & $\begin{array}{c}0.005 \\
(0.004)\end{array}$ & $\begin{array}{l}-0.007 \\
(0.009)\end{array}$ \\
\hline Average pre-debate dummies for type-a & $\begin{array}{l}-0.004 \\
(0.007)\end{array}$ & $\begin{array}{c}0.003 \\
(0.003)\end{array}$ & $\begin{array}{l}-0.000 \\
(0.007)\end{array}$ & $\begin{array}{l}-0.007 \\
(0.005)\end{array}$ & $\begin{array}{c}0.001 \\
(0.003)\end{array}$ \\
\hline Average post-debate dummies for type-a & $\begin{array}{l}-0.008 \\
(0.005)\end{array}$ & $\begin{array}{c}0.008 \\
(0.005)\end{array}$ & $\begin{array}{l}-0.003 \\
(0.005)\end{array}$ & $\begin{array}{l}-0.006 \\
(0.006)\end{array}$ & $\begin{array}{c}0.003 \\
(0.003)\end{array}$ \\
\hline
\end{tabular}

Notes: Same notes as in Table IV, columns 1 and 2, and Appendix Table A.24. 
Table A.26: Debates' effects on vote choice consistency across voter types

\begin{tabular}{|c|c|c|c|c|c|c|c|}
\hline \multirow[b]{2}{*}{ Voter characteristic } & \multicolumn{7}{|c|}{ Vote choice consistency } \\
\hline & $\begin{array}{c}\text { (1) } \\
\text { Debate watchers vs. } \\
\text { non-watchers }\end{array}$ & $\begin{array}{c}\text { (2) } \\
\text { Strong vs. weak } \\
\text { party identification }\end{array}$ & $\begin{array}{l}\text { (3) } \\
\text { College degree vs. } \\
\text { no college degree }\end{array}$ & $\begin{array}{c}\text { (4) } \\
\text { Above median age } \\
\text { vs. below }\end{array}$ & $\begin{array}{c}\text { (5) } \\
\text { Male vs. } \\
\text { female }\end{array}$ & $\begin{array}{c}\text { (6) } \\
\text { Above median income } \\
\text { vs. below }\end{array}$ & $\begin{array}{c}\text { (7) } \\
\text { Not employed vs. } \\
\text { employed }\end{array}$ \\
\hline$-3 *$ type-b & $\begin{array}{l}-0.014 \\
(0.022)\end{array}$ & $\begin{array}{l}-0.006 \\
(0.008)\end{array}$ & $\begin{array}{l}-0.010 \\
(0.010)\end{array}$ & $\begin{array}{l}-0.017 \\
(0.011)\end{array}$ & $\begin{array}{l}-0.003 \\
(0.010)\end{array}$ & $\begin{array}{l}-0.004 \\
(0.014)\end{array}$ & $\begin{array}{l}-0.011 \\
(0.009)\end{array}$ \\
\hline$-2 *$ type-b & $\begin{array}{l}-0.002 \\
(0.024)\end{array}$ & $\begin{array}{c}0.018 \\
(0.013)\end{array}$ & $\begin{array}{l}-0.005 \\
(0.010)\end{array}$ & $\begin{array}{l}-0.009 \\
(0.014)\end{array}$ & $\begin{array}{c}0.012 \\
(0.012)\end{array}$ & $\begin{array}{c}0.010 \\
(0.014)\end{array}$ & $\begin{array}{l}-0.009 \\
(0.011)\end{array}$ \\
\hline$-1 *$ type-b & $\begin{array}{c}0.010 \\
(0.025)\end{array}$ & $\begin{array}{c}0.009 \\
(0.011)\end{array}$ & $\begin{array}{l}-0.004 \\
(0.011)\end{array}$ & $\begin{array}{l}-0.008 \\
(0.013)\end{array}$ & $\begin{array}{c}0.012 \\
(0.012)\end{array}$ & $\begin{array}{l}-0.002 \\
(0.016)\end{array}$ & $\begin{array}{l}-0.007 \\
(0.009)\end{array}$ \\
\hline$+1 *$ type-b & $\begin{array}{l}-0.032 \\
(0.022)\end{array}$ & $\begin{array}{c}0.007 \\
(0.009)\end{array}$ & $\begin{array}{l}-0.009 \\
(0.009)\end{array}$ & $\begin{array}{l}-0.021 \\
(0.013)\end{array}$ & $\begin{array}{l}-0.002 \\
(0.012)\end{array}$ & $\begin{array}{c}0.010 \\
(0.015)\end{array}$ & $\begin{array}{l}-0.017 \\
(0.012)\end{array}$ \\
\hline$+2 *$ type-b & $\begin{array}{c}-0.016 \\
(0.016)\end{array}$ & $\begin{array}{c}0.002 \\
(0.012)\end{array}$ & $\begin{array}{l}-0.020^{*} \\
(0.011)\end{array}$ & $\begin{array}{l}-0.004 \\
(0.013)\end{array}$ & $\begin{array}{l}-0.000 \\
(0.015)\end{array}$ & $\begin{array}{c}-0.012 \\
(0.015)\end{array}$ & $\begin{array}{c}-0.013 \\
(0.008)\end{array}$ \\
\hline$+3 *$ type-b & $\begin{array}{c}0.015 \\
(0.021)\end{array}$ & $\begin{array}{c}0.011 \\
(0.009)\end{array}$ & $\begin{array}{c}-0.011 \\
(0.009)\end{array}$ & $\begin{array}{l}-0.008 \\
(0.010)\end{array}$ & $\begin{array}{c}0.002 \\
(0.012)\end{array}$ & $\begin{array}{c}-0.011 \\
(0.017)\end{array}$ & $\begin{array}{c}-0.009 \\
(0.010)\end{array}$ \\
\hline$-3 *$ type-a & $\begin{array}{l}-0.002 \\
(0.012)\end{array}$ & $\begin{array}{l}-0.008 \\
(0.009)\end{array}$ & $\begin{array}{l}-0.007 \\
(0.008)\end{array}$ & $\begin{array}{l}-0.004 \\
(0.012)\end{array}$ & $\begin{array}{l}-0.016 \\
(0.010)\end{array}$ & $\begin{array}{l}-0.004 \\
(0.010)\end{array}$ & $\begin{array}{l}-0.005 \\
(0.014)\end{array}$ \\
\hline$-2 *$ type-a & $\begin{array}{l}-0.014 \\
(0.012)\end{array}$ & $\begin{array}{l}-0.025^{*} \\
(0.013)\end{array}$ & $\begin{array}{c}0.008 \\
(0.012)\end{array}$ & $\begin{array}{c}0.003 \\
(0.010)\end{array}$ & $\begin{array}{l}-0.016^{*} \\
(0.009)\end{array}$ & $\begin{array}{l}-0.000 \\
(0.012)\end{array}$ & $\begin{array}{c}0.005 \\
(0.013)\end{array}$ \\
\hline$-1 *$ type-a & $\begin{array}{l}-0.022^{*} \\
(0.013)\end{array}$ & $\begin{array}{l}-0.017^{*} \\
(0.010)\end{array}$ & $\begin{array}{c}0.010 \\
(0.010)\end{array}$ & $\begin{array}{c}0.002 \\
(0.010)\end{array}$ & $\begin{array}{c}-0.017^{* *} \\
(0.008)\end{array}$ & $\begin{array}{c}0.003 \\
(0.010)\end{array}$ & $\begin{array}{c}0.009 \\
(0.014)\end{array}$ \\
\hline$+1 *$ type-a & $\begin{array}{c}0.004 \\
(0.013)\end{array}$ & $\begin{array}{l}-0.021^{*} \\
(0.011)\end{array}$ & $\begin{array}{c}0.004 \\
(0.011)\end{array}$ & $\begin{array}{c}0.002 \\
(0.009)\end{array}$ & $\begin{array}{l}-0.016^{*} \\
(0.009)\end{array}$ & $\begin{array}{l}-0.003 \\
(0.011)\end{array}$ & $\begin{array}{c}0.002 \\
(0.010)\end{array}$ \\
\hline$+2 *$ type-a & $\begin{array}{c}0.005 \\
(0.010)\end{array}$ & $\begin{array}{c}-0.027^{* *} \\
(0.013)\end{array}$ & $\begin{array}{l}0.013^{*} \\
(0.007)\end{array}$ & $\begin{array}{l}-0.011 \\
(0.011)\end{array}$ & $\begin{array}{l}-0.016^{*} \\
(0.008)\end{array}$ & $\begin{array}{c}0.002 \\
(0.010)\end{array}$ & $\begin{array}{l}-0.010 \\
(0.014)\end{array}$ \\
\hline$+3 *$ type-a & $\begin{array}{l}-0.015 \\
(0.012)\end{array}$ & $\begin{array}{c}-0.030^{* *} \\
(0.015)\end{array}$ & $\begin{array}{l}-0.005 \\
(0.010)\end{array}$ & $\begin{array}{l}-0.004 \\
(0.007)\end{array}$ & $\begin{array}{l}-0.014^{*} \\
(0.007)\end{array}$ & $\begin{array}{l}-0.009 \\
(0.008)\end{array}$ & $\begin{array}{l}-0.005 \\
(0.014)\end{array}$ \\
\hline Observations & 85235 & 217168 & 214332 & 262830 & 263584 & 205284 & 219659 \\
\hline$R^{2}$ & 0.095 & 0.096 & 0.073 & 0.077 & 0.077 & 0.069 & 0.085 \\
\hline Mean, day of the debate & 0.810 & 0.816 & 0.817 & 0.811 & 0.811 & 0.816 & 0.807 \\
\hline Number of debates & 28 & 41 & 50 & 56 & 56 & 50 & 47 \\
\hline Debate $*$ election fixed effects & $\mathrm{x}$ & $\mathrm{x}$ & $\mathrm{x}$ & $\mathrm{x}$ & $\mathrm{x}$ & $\mathrm{x}$ & $\mathrm{x}$ \\
\hline Fixed effects for number of days to election & $\mathrm{x}$ & $\mathrm{x}$ & $\mathrm{x}$ & $\mathrm{x}$ & $\mathrm{x}$ & $\mathrm{x}$ & $\mathrm{x}$ \\
\hline Individual controls & $\mathrm{x}$ & $\mathrm{x}$ & $\mathrm{x}$ & $\mathrm{x}$ & $\mathrm{x}$ & $\mathrm{x}$ & $\mathrm{x}$ \\
\hline Sociodemographic controls & $\mathrm{x}$ & $\mathrm{x}$ & $\mathrm{x}$ & $\mathrm{x}$ & $\mathrm{x}$ & $\mathrm{x}$ & $\mathrm{x}$ \\
\hline \multicolumn{8}{|l|}{ Linear combination of estimates } \\
\hline Average pre-debate dummies for type-b & $\begin{array}{l}-0.002 \\
(0.021)\end{array}$ & $\begin{array}{c}0.007 \\
(0.009)\end{array}$ & $\begin{array}{l}-0.006 \\
(0.009)\end{array}$ & $\begin{array}{l}-0.011 \\
(0.012)\end{array}$ & $\begin{array}{c}0.007 \\
(0.010)\end{array}$ & $\begin{array}{c}0.001 \\
(0.013)\end{array}$ & $\begin{array}{l}-0.009 \\
(0.008)\end{array}$ \\
\hline Average post-debate dummies for type-b & $\begin{array}{l}-0.011 \\
(0.012)\end{array}$ & $\begin{array}{c}0.007 \\
(0.008)\end{array}$ & $\begin{array}{l}-0.013^{*} \\
(0.008)\end{array}$ & $\begin{array}{l}-0.011 \\
(0.010)\end{array}$ & $\begin{array}{l}-0.000 \\
(0.011)\end{array}$ & $\begin{array}{l}-0.004 \\
(0.014)\end{array}$ & $\begin{array}{l}-0.013^{*} \\
(0.007)\end{array}$ \\
\hline Average pre-debate dummies for type-a & $\begin{array}{l}-0.013 \\
(0.010)\end{array}$ & $\begin{array}{l}-0.017^{*} \\
(0.008)\end{array}$ & $\begin{array}{c}0.004 \\
(0.007)\end{array}$ & $\begin{array}{c}0.001 \\
(0.009)\end{array}$ & $\begin{array}{c}-0.016^{* *} \\
(0.007)\end{array}$ & $\begin{array}{l}-0.001 \\
(0.009)\end{array}$ & $\begin{array}{c}0.003 \\
(0.012)\end{array}$ \\
\hline Average post-debate dummies for type-a & $\begin{array}{l}-0.002 \\
(0.010)\end{array}$ & $\begin{array}{c}-0.026^{* *} \\
(0.012)\end{array}$ & $\begin{array}{c}0.004 \\
(0.007)\end{array}$ & $\begin{array}{l}-0.005 \\
(0.007)\end{array}$ & $\begin{array}{c}-0.015^{* * *} \\
(0.005)\end{array}$ & $\begin{array}{l}-0.003 \\
(0.008)\end{array}$ & $\begin{array}{l}-0.004 \\
(0.011)\end{array}$ \\
\hline
\end{tabular}

Notes: Standard errors clustered at the debate level are in parentheses $(* * *, * *, *$ indicate significance at 1,5 , and $10 \%$, respectively). We interact the relative days dummies with indicators for type-a voter (debate watcher, voter with strong party identification, with a college degree, above the median age, male, above the median income, and not employed) and type-b voter (non-debate watcher, voter with weak or no party identification, without college degree, below the median age, female, below the median income, and employed) and also control for the dummy for being a type-a voter, uninteracted. Dummies for being surveyed four days or more before or after the debate interacted with the type-a and type-b indicators were included in the regressions but are not shown, for presentation clarity. Other notes as in Table III, columns 1 and 2 . 
Table A.27: Debates' effects on distance to final vote shares across voter types

\begin{tabular}{|c|c|c|c|c|c|c|c|}
\hline \multirow[b]{2}{*}{ Voter characteristic } & \multicolumn{7}{|c|}{ Distance between predicted and final vote shares } \\
\hline & $\begin{array}{c}\text { (1) } \\
\text { Debate watchers vs. } \\
\text { non-watchers }\end{array}$ & $\begin{array}{c}\text { (2) } \\
\text { Strong vs. weak } \\
\text { party identification }\end{array}$ & $\begin{array}{l}\text { (3) } \\
\text { College degree vs. } \\
\text { no college degree }\end{array}$ & $\begin{array}{l}(4) \\
\text { Above median age } \\
\text { vs. below }\end{array}$ & $\begin{array}{l}\text { (5) } \\
\text { Male vs. } \\
\text { female }\end{array}$ & $\begin{array}{c}(6) \\
\text { Above median income } \\
\text { vs. below }\end{array}$ & $\begin{array}{l}\text { (7) } \\
\text { Not employed vs. } \\
\text { employed }\end{array}$ \\
\hline$-3 *$ type-b & $\begin{array}{l}-0.003 \\
(0.012)\end{array}$ & $\begin{array}{l}-0.004 \\
(0.004)\end{array}$ & $\begin{array}{l}-0.001 \\
(0.006)\end{array}$ & $\begin{array}{c}0.007 \\
(0.006)\end{array}$ & $\begin{array}{l}-0.003 \\
(0.007)\end{array}$ & $\begin{array}{c}-0.003 \\
(0.011)\end{array}$ & $\begin{array}{c}-0.004 \\
(0.004)\end{array}$ \\
\hline$-2 *$ type-b & $\begin{array}{c}0.017 \\
(0.018)\end{array}$ & $\begin{array}{c}-0.005 \\
(0.004)\end{array}$ & $\begin{array}{c}-0.002 \\
(0.005)\end{array}$ & $\begin{array}{c}0.011 \\
(0.007)\end{array}$ & $\begin{array}{c}-0.002 \\
(0.007)\end{array}$ & $\begin{array}{c}-0.001 \\
(0.008)\end{array}$ & $\begin{array}{c}0.003 \\
(0.006)\end{array}$ \\
\hline$-1 *$ type-b & $\begin{array}{c}0.014 \\
(0.012)\end{array}$ & $\begin{array}{c}-0.010^{*} \\
(0.005)\end{array}$ & $\begin{array}{c}-0.001 \\
(0.005)\end{array}$ & $\begin{array}{c}0.007 \\
(0.007)\end{array}$ & $\begin{array}{c}-0.010 \\
(0.007)\end{array}$ & $\begin{array}{c}-0.005 \\
(0.008)\end{array}$ & $\begin{array}{c}-0.003 \\
(0.008)\end{array}$ \\
\hline$+1 *$ type-b & $\begin{array}{c}0.004 \\
(0.019)\end{array}$ & $\begin{array}{c}-0.002 \\
(0.005)\end{array}$ & $\begin{array}{c}-0.002 \\
(0.006)\end{array}$ & $\begin{array}{c}0.004 \\
(0.007)\end{array}$ & $\begin{array}{c}-0.000 \\
(0.007)\end{array}$ & $\begin{array}{c}-0.002 \\
(0.011)\end{array}$ & $\begin{array}{c}0.005 \\
(0.006)\end{array}$ \\
\hline$+2 *$ type-b & $\begin{array}{c}0.012 \\
(0.014)\end{array}$ & $\begin{array}{l}-0.005 \\
(0.006)\end{array}$ & $\begin{array}{c}0.008 \\
(0.006)\end{array}$ & $\begin{array}{c}0.006 \\
(0.005)\end{array}$ & $\begin{array}{c}-0.003 \\
(0.007)\end{array}$ & $\begin{array}{c}0.008 \\
(0.008)\end{array}$ & $\begin{array}{c}0.003 \\
(0.006)\end{array}$ \\
\hline$+3 *$ type-b & $\begin{array}{c}0.021 \\
(0.014)\end{array}$ & $\begin{array}{c}-0.007^{*} \\
(0.004)\end{array}$ & $\begin{array}{c}0.001 \\
(0.006)\end{array}$ & $\begin{array}{c}0.007 \\
(0.008)\end{array}$ & $\begin{array}{c}-0.004 \\
(0.007)\end{array}$ & $\begin{array}{c}-0.005 \\
(0.007)\end{array}$ & $\begin{array}{c}0.006 \\
(0.008)\end{array}$ \\
\hline$-3 *$ type-a & $\begin{array}{c}-0.015^{*} \\
(0.008)\end{array}$ & $\begin{array}{c}0.006 \\
(0.005)\end{array}$ & $\begin{array}{c}-0.004 \\
(0.005)\end{array}$ & $\begin{array}{c}-0.005 \\
(0.007)\end{array}$ & $\begin{array}{c}-0.002 \\
(0.007)\end{array}$ & $\begin{array}{c}-0.003 \\
(0.006)\end{array}$ & $\begin{array}{c}0.001 \\
(0.010)\end{array}$ \\
\hline$-2 *$ type-a & $\begin{array}{c}-0.006 \\
(0.007)\end{array}$ & $\begin{array}{c}0.007 \\
(0.008)\end{array}$ & $\begin{array}{c}0.005 \\
(0.008)\end{array}$ & $\begin{array}{c}-0.007 \\
(0.005)\end{array}$ & $\begin{array}{c}0.003 \\
(0.005)\end{array}$ & $\begin{array}{c}0.003 \\
(0.007)\end{array}$ & $\begin{array}{c}-0.001 \\
(0.007)\end{array}$ \\
\hline$-1 *$ type-a & $\begin{array}{c}-0.019^{* *} \\
(0.008)\end{array}$ & $\begin{array}{c}0.004 \\
(0.009)\end{array}$ & $\begin{array}{c}0.002 \\
(0.007)\end{array}$ & $\begin{array}{c}-0.008 \\
(0.006)\end{array}$ & $\begin{array}{c}0.003 \\
(0.007)\end{array}$ & $\begin{array}{c}-0.004 \\
(0.007)\end{array}$ & $\begin{array}{c}-0.005 \\
(0.008)\end{array}$ \\
\hline$+1 *$ type-a & $\begin{array}{c}-0.014 \\
(0.009)\end{array}$ & $\begin{array}{l}0.016^{* *} \\
(0.008)\end{array}$ & $\begin{array}{c}0.002 \\
(0.007)\end{array}$ & $\begin{array}{c}-0.000 \\
(0.006)\end{array}$ & $\begin{array}{c}0.006 \\
(0.005)\end{array}$ & $\begin{array}{c}0.001 \\
(0.006)\end{array}$ & $\begin{array}{c}-0.005 \\
(0.008)\end{array}$ \\
\hline$+2 *$ type-a & $\begin{array}{c}-0.018^{* *} \\
(0.008)\end{array}$ & $\begin{array}{l}0.015^{*} \\
(0.008)\end{array}$ & $\begin{array}{l}-0.007 \\
(0.006)\end{array}$ & $\begin{array}{c}-0.003 \\
(0.005)\end{array}$ & $\begin{array}{c}0.008 \\
(0.006)\end{array}$ & $\begin{array}{c}-0.001 \\
(0.006)\end{array}$ & $\begin{array}{c}0.001 \\
(0.008)\end{array}$ \\
\hline$+3 *$ type-a & $\begin{array}{c}-0.013^{* *} \\
(0.006) \\
\end{array}$ & $\begin{array}{l}0.017^{* *} \\
(0.008) \\
\end{array}$ & $\begin{array}{c}0.006 \\
(0.007) \\
\end{array}$ & $\begin{array}{c}-0.004 \\
(0.005) \\
\end{array}$ & $\begin{array}{c}0.002 \\
(0.006) \\
\end{array}$ & $\begin{array}{c}0.005 \\
(0.007) \\
\end{array}$ & $\begin{array}{c}-0.005 \\
(0.007) \\
\end{array}$ \\
\hline Observations & 3503 & 4988 & 6608 & 7556 & 7553 & 6465 & 6637 \\
\hline$R^{2}$ & 0.321 & 0.511 & 0.435 & 0.456 & 0.464 & 0.439 & 0.462 \\
\hline Mean, day of the debate & 0.062 & 0.047 & 0.054 & 0.058 & 0.056 & 0.058 & 0.055 \\
\hline Number of debates & 28 & 41 & 50 & 56 & 56 & 50 & 47 \\
\hline Debate * election fixed effects & $\mathrm{x}$ & $\mathrm{x}$ & $\mathrm{x}$ & $\mathrm{x}$ & $\mathrm{x}$ & $\mathrm{x}$ & $\mathrm{x}$ \\
\hline Fixed effects for number of days to election & $\mathrm{x}$ & $\mathrm{x}$ & $\mathrm{x}$ & $\mathrm{x}$ & $\mathrm{x}$ & $\mathrm{x}$ & $\mathrm{x}$ \\
\hline Aggregate controls & $\mathrm{x}$ & $\mathrm{x}$ & $\mathrm{x}$ & $\mathrm{x}$ & $\mathrm{x}$ & $\mathrm{x}$ & $\mathrm{x}$ \\
\hline Sociodemographic controls & $\mathrm{x}$ & $\mathrm{x}$ & $\mathrm{x}$ & $\mathrm{x}$ & $\mathrm{x}$ & $\mathrm{x}$ & $\mathrm{x}$ \\
\hline Linear combination of estimates & & & & & & & \\
\hline Average pre-debate dummies for type-b & $\begin{array}{c}0.009 \\
(0.012)\end{array}$ & $\begin{array}{c}-0.007^{* *} \\
(0.003)\end{array}$ & $\begin{array}{c}-0.002 \\
(0.005)\end{array}$ & $\begin{array}{c}0.008 \\
(0.006)\end{array}$ & $\begin{array}{c}-0.005 \\
(0.006)\end{array}$ & $\begin{array}{c}-0.003 \\
(0.008)\end{array}$ & $\begin{array}{c}-0.001 \\
(0.005)\end{array}$ \\
\hline Average post-debate dummies for type-b & $\begin{array}{c}0.012 \\
(0.011)\end{array}$ & $\begin{array}{c}-0.005 \\
(0.004)\end{array}$ & $\begin{array}{c}0.002 \\
(0.005)\end{array}$ & $\begin{array}{c}0.006 \\
(0.006)\end{array}$ & $\begin{array}{c}-0.002 \\
(0.006)\end{array}$ & $\begin{array}{c}0.001 \\
(0.008)\end{array}$ & $\begin{array}{c}0.005 \\
(0.006)\end{array}$ \\
\hline Average pre-debate dummies for type-a & $\begin{array}{c}-0.013^{* *} \\
(0.006)\end{array}$ & $\begin{array}{c}0.006 \\
(0.006)\end{array}$ & $\begin{array}{c}0.001 \\
(0.005)\end{array}$ & $\begin{array}{l}-0.007 \\
(0.005)\end{array}$ & $\begin{array}{c}0.001 \\
(0.005)\end{array}$ & $\begin{array}{c}-0.001 \\
(0.005)\end{array}$ & $\begin{array}{c}-0.002 \\
(0.007)\end{array}$ \\
\hline Average post-debate dummies for type-a & $\begin{array}{c}-0.015^{* *} \\
(0.006)\end{array}$ & $\begin{array}{l}0.016^{* *} \\
(0.007)\end{array}$ & $\begin{array}{c}0.000 \\
(0.006)\end{array}$ & $\begin{array}{c}-0.002 \\
(0.004)\end{array}$ & $\begin{array}{c}0.006 \\
(0.005)\end{array}$ & $\begin{array}{c}0.002 \\
(0.005)\end{array}$ & $\begin{array}{c}-0.003 \\
(0.006)\end{array}$ \\
\hline
\end{tabular}

Notes: Same notes as in Table IV, columns 1 and 2, and Appendix Table A.26. 
Table A.28: Debates' effects on likelihood to vote for lesser-known candidates and on vote share concentration

\begin{tabular}{|c|c|c|c|c|c|c|c|c|}
\hline & \multicolumn{2}{|c|}{$\begin{array}{l}\text { Support for } \\
\text { challenger }\end{array}$} & \multicolumn{2}{|c|}{$\begin{array}{c}\text { Support for } \\
\text { small candidate }\end{array}$} & \multicolumn{2}{|c|}{$\begin{array}{c}\text { Support for } \\
\text { new party }\end{array}$} & \multicolumn{2}{|c|}{$\begin{array}{c}\text { Vote share } \\
\text { concentration }\end{array}$} \\
\hline & (1) & (2) & (3) & (4) & (5) & (6) & (7) & (8) \\
\hline Before -3 & $\begin{array}{c}0.002 \\
(0.006)\end{array}$ & $\begin{array}{c}0.003 \\
(0.007)\end{array}$ & $\begin{array}{c}0.006 \\
(0.006)\end{array}$ & $\begin{array}{c}0.006 \\
(0.007)\end{array}$ & $\begin{array}{l}-0.000 \\
(0.002)\end{array}$ & $\begin{array}{l}-0.000 \\
(0.002)\end{array}$ & $\begin{array}{l}-0.003 \\
(0.005)\end{array}$ & $\begin{array}{l}-0.002 \\
(0.005)\end{array}$ \\
\hline-3 & $\begin{array}{c}0.007 \\
(0.007)\end{array}$ & $\begin{array}{c}0.007 \\
(0.007)\end{array}$ & $\begin{array}{l}-0.001 \\
(0.007)\end{array}$ & $\begin{array}{c}0.000 \\
(0.007)\end{array}$ & $\begin{array}{c}0.001 \\
(0.003)\end{array}$ & $\begin{array}{c}0.001 \\
(0.003)\end{array}$ & $\begin{array}{l}-0.002 \\
(0.005)\end{array}$ & $\begin{array}{l}-0.002 \\
(0.005)\end{array}$ \\
\hline-2 & $\begin{array}{c}0.009 \\
(0.009)\end{array}$ & $\begin{array}{c}0.010 \\
(0.009)\end{array}$ & $\begin{array}{c}0.005 \\
(0.005)\end{array}$ & $\begin{array}{c}0.006 \\
(0.005)\end{array}$ & $\begin{array}{l}-0.003 \\
(0.002)\end{array}$ & $\begin{array}{l}-0.002 \\
(0.002)\end{array}$ & $\begin{array}{l}-0.003 \\
(0.005)\end{array}$ & $\begin{array}{l}-0.004 \\
(0.005)\end{array}$ \\
\hline-1 & $\begin{array}{c}0.001 \\
(0.007)\end{array}$ & $\begin{array}{c}0.002 \\
(0.008)\end{array}$ & $\begin{array}{c}0.002 \\
(0.007)\end{array}$ & $\begin{array}{c}0.003 \\
(0.007)\end{array}$ & $\begin{array}{c}0.001 \\
(0.002)\end{array}$ & $\begin{array}{c}0.001 \\
(0.002)\end{array}$ & $\begin{array}{l}-0.002 \\
(0.005)\end{array}$ & $\begin{array}{l}-0.002 \\
(0.005)\end{array}$ \\
\hline+1 & $\begin{array}{c}0.008 \\
(0.007)\end{array}$ & $\begin{array}{c}0.008 \\
(0.007)\end{array}$ & $\begin{array}{c}0.005 \\
(0.008)\end{array}$ & $\begin{array}{c}0.005 \\
(0.008)\end{array}$ & $\begin{array}{c}0.002 \\
(0.003)\end{array}$ & $\begin{array}{c}0.002 \\
(0.003)\end{array}$ & $\begin{array}{l}-0.004 \\
(0.006)\end{array}$ & $\begin{array}{l}-0.004 \\
(0.006)\end{array}$ \\
\hline+2 & $\begin{array}{c}0.003 \\
(0.008)\end{array}$ & $\begin{array}{c}0.004 \\
(0.008)\end{array}$ & $\begin{array}{c}0.007 \\
(0.007)\end{array}$ & $\begin{array}{c}0.007 \\
(0.007)\end{array}$ & $\begin{array}{c}0.003 \\
(0.003)\end{array}$ & $\begin{array}{c}0.003 \\
(0.003)\end{array}$ & $\begin{array}{c}-0.007 \\
(0.005)\end{array}$ & $\begin{array}{l}-0.006 \\
(0.005)\end{array}$ \\
\hline+3 & $\begin{array}{c}0.000 \\
(0.009)\end{array}$ & $\begin{array}{c}0.000 \\
(0.010)\end{array}$ & $\begin{array}{c}0.005 \\
(0.007)\end{array}$ & $\begin{array}{c}0.005 \\
(0.007)\end{array}$ & $\begin{array}{c}0.001 \\
(0.002)\end{array}$ & $\begin{array}{c}0.001 \\
(0.002)\end{array}$ & $\begin{array}{c}-0.004 \\
(0.006)\end{array}$ & $\begin{array}{l}-0.003 \\
(0.006)\end{array}$ \\
\hline After +3 & $\begin{array}{c}0.005 \\
(0.007) \\
\end{array}$ & $\begin{array}{c}0.005 \\
(0.008) \\
\end{array}$ & $\begin{array}{c}0.002 \\
(0.005) \\
\end{array}$ & $\begin{array}{c}0.002 \\
(0.005) \\
\end{array}$ & $\begin{array}{c}0.000 \\
(0.002)\end{array}$ & $\begin{array}{c}0.000 \\
(0.002)\end{array}$ & $\begin{array}{c}-0.001 \\
(0.005)\end{array}$ & $\begin{array}{l}-0.000 \\
(0.004)\end{array}$ \\
\hline Observations & 294615 & 294615 & 294615 & 294615 & 290799 & 290799 & 3802 & 3802 \\
\hline$R^{2}$ & 0.042 & 0.049 & 0.084 & 0.091 & 0.076 & 0.077 & 0.921 & 0.923 \\
\hline Mean, day of the debate & 0.634 & 0.634 & 0.148 & 0.148 & 0.007 & 0.007 & 0.324 & 0.324 \\
\hline Number of debates & 56 & 56 & 56 & 56 & 56 & 56 & 56 & 56 \\
\hline Debate $*$ election fixed effects & $\mathrm{x}$ & $\mathrm{x}$ & $\mathrm{x}$ & $\mathrm{x}$ & $\mathrm{x}$ & $\mathrm{x}$ & $\mathrm{x}$ & $\mathrm{x}$ \\
\hline Fixed effects for number of days to election & $\mathrm{x}$ & $\mathrm{x}$ & $\mathrm{x}$ & $\mathrm{x}$ & $\mathrm{x}$ & $\mathrm{x}$ & $\mathrm{x}$ & $\mathrm{x}$ \\
\hline Individual controls & $\mathrm{x}$ & $\mathrm{x}$ & $\mathrm{x}$ & $\mathrm{x}$ & $\mathrm{x}$ & $\mathrm{x}$ & $\mathrm{x}$ & $\mathrm{x}$ \\
\hline Sociodemographic controls & & $\mathrm{x}$ & & $\mathrm{x}$ & & $\mathrm{x}$ & & $\mathrm{x}$ \\
\hline \multicolumn{9}{|l|}{ Linear combination of estimates } \\
\hline Average pre-debate dummies $-3,-2$, and -1 & $\begin{array}{c}0.006 \\
(0.007)\end{array}$ & $\begin{array}{c}0.006 \\
(0.007)\end{array}$ & $\begin{array}{c}0.002 \\
(0.005)\end{array}$ & $\begin{array}{c}0.003 \\
(0.005)\end{array}$ & $\begin{array}{l}-0.000 \\
(0.002)\end{array}$ & $\begin{array}{l}-0.000 \\
(0.002)\end{array}$ & $\begin{array}{l}-0.003 \\
(0.005)\end{array}$ & $\begin{array}{l}-0.002 \\
(0.004)\end{array}$ \\
\hline Average post-debate dummies 1,2 , and 3 & $\begin{array}{c}0.004 \\
(0.006)\end{array}$ & $\begin{array}{c}0.004 \\
(0.006)\end{array}$ & $\begin{array}{c}0.006 \\
(0.006)\end{array}$ & $\begin{array}{c}0.006 \\
(0.006)\end{array}$ & $\begin{array}{c}0.002 \\
(0.002)\end{array}$ & $\begin{array}{c}0.002 \\
(0.002)\end{array}$ & $\begin{array}{l}-0.005 \\
(0.005)\end{array}$ & $\begin{array}{l}-0.004 \\
(0.005)\end{array}$ \\
\hline
\end{tabular}

Notes: Standard errors clustered at the debate level are in parentheses $(* * *, * *, *$ indicate significance at 1,5 , and $10 \%$, respectively). In columns 1 through 6, we use the set of respondents as defined in Appendix Table A.18, columns 1 through 6 . In columns 7 and 8, we use one observation per election per day, vote shares are computed based on the set of respondents used in Appendix Table A.18, columns 7 and 8, and we weight each observation by the number of respondents it was constructed from, relative to the total number of respondents surveyed at the same relative time to the debate. Other notes as in Table III, columns 3 and 4. 
Table A.29: Disasters' effects on vote choice consistency

\begin{tabular}{|c|c|c|c|c|c|c|}
\hline & \multicolumn{2}{|c|}{ Vote choice consistency } & \multicolumn{2}{|c|}{ Vote intention } & \multicolumn{2}{|c|}{ Conditional consistency } \\
\hline & (1) & (2) & (3) & (4) & (5) & (6) \\
\hline Before -3 & $\begin{array}{c}0.021 \\
(0.020)\end{array}$ & $\begin{array}{c}0.021 \\
(0.020)\end{array}$ & $\begin{array}{c}0.014 \\
(0.013)\end{array}$ & $\begin{array}{c}0.015 \\
(0.013)\end{array}$ & $\begin{array}{c}0.018 \\
(0.012)\end{array}$ & $\begin{array}{c}0.019 \\
(0.013)\end{array}$ \\
\hline-3 & $\begin{array}{c}0.009 \\
(0.015)\end{array}$ & $\begin{array}{c}0.009 \\
(0.015)\end{array}$ & $\begin{array}{c}0.015 \\
(0.010)\end{array}$ & $\begin{array}{c}0.015 \\
(0.010)\end{array}$ & $\begin{array}{c}0.005 \\
(0.011)\end{array}$ & $\begin{array}{c}0.005 \\
(0.011)\end{array}$ \\
\hline-2 & $\begin{array}{c}0.020 \\
(0.020)\end{array}$ & $\begin{array}{c}0.020 \\
(0.020)\end{array}$ & $\begin{array}{c}0.019 \\
(0.017)\end{array}$ & $\begin{array}{c}0.019 \\
(0.017)\end{array}$ & $\begin{array}{c}0.015 \\
(0.012)\end{array}$ & $\begin{array}{c}0.016 \\
(0.012)\end{array}$ \\
\hline-1 & $\begin{array}{c}0.001 \\
(0.018)\end{array}$ & $\begin{array}{c}0.001 \\
(0.018)\end{array}$ & $\begin{array}{c}0.013 \\
(0.012)\end{array}$ & $\begin{array}{c}0.012 \\
(0.012)\end{array}$ & $\begin{array}{c}0.003 \\
(0.012)\end{array}$ & $\begin{array}{c}0.002 \\
(0.012)\end{array}$ \\
\hline+1 & $\begin{array}{c}0.015 \\
(0.012)\end{array}$ & $\begin{array}{c}0.015 \\
(0.012)\end{array}$ & $\begin{array}{c}0.005 \\
(0.012)\end{array}$ & $\begin{array}{c}0.005 \\
(0.012)\end{array}$ & $\begin{array}{l}0.019^{*} \\
(0.010)\end{array}$ & $\begin{array}{l}0.019^{*} \\
(0.010)\end{array}$ \\
\hline+2 & $\begin{array}{c}0.014 \\
(0.017)\end{array}$ & $\begin{array}{c}0.014 \\
(0.018)\end{array}$ & $\begin{array}{c}0.019 \\
(0.013)\end{array}$ & $\begin{array}{c}0.020 \\
(0.014)\end{array}$ & $\begin{array}{c}0.003 \\
(0.012)\end{array}$ & $\begin{array}{c}0.003 \\
(0.012)\end{array}$ \\
\hline+3 & $\begin{array}{l}0.022^{* *} \\
(0.010)\end{array}$ & $\begin{array}{l}0.022^{* *} \\
(0.010)\end{array}$ & $\begin{array}{c}0.012 \\
(0.010)\end{array}$ & $\begin{array}{c}0.012 \\
(0.010)\end{array}$ & $\begin{array}{c}0.017 \\
(0.010)\end{array}$ & $\begin{array}{c}0.017 \\
(0.011)\end{array}$ \\
\hline After +3 & $\begin{array}{c}0.019 \\
(0.016)\end{array}$ & $\begin{array}{c}0.018 \\
(0.016)\end{array}$ & $\begin{array}{c}0.014 \\
(0.012)\end{array}$ & $\begin{array}{c}0.014 \\
(0.012)\end{array}$ & $\begin{array}{c}0.015 \\
(0.010)\end{array}$ & $\begin{array}{c}0.015 \\
(0.011)\end{array}$ \\
\hline Observations & 85098 & 85098 & 112988 & 112988 & 77402 & 77402 \\
\hline$R^{2}$ & 0.086 & 0.091 & 0.082 & 0.088 & 0.041 & 0.046 \\
\hline Mean, day of the disaster & 0.799 & 0.799 & 0.855 & 0.855 & 0.895 & 0.895 \\
\hline Number of disasters & 27 & 27 & 27 & 27 & 27 & 27 \\
\hline Disaster * election fixed effects & $\mathrm{x}$ & $\mathrm{x}$ & $\mathrm{x}$ & $\mathrm{x}$ & $\mathrm{x}$ & $\mathrm{x}$ \\
\hline Fixed effects for number of days to election & $\mathrm{x}$ & $\mathrm{x}$ & $\mathrm{x}$ & $\mathrm{x}$ & $\mathrm{x}$ & $\mathrm{x}$ \\
\hline Individual controls & $\mathrm{x}$ & $\mathrm{x}$ & $\mathrm{x}$ & $\mathrm{x}$ & $\mathrm{x}$ & $\mathrm{x}$ \\
\hline Sociodemographic controls & & $\mathrm{x}$ & & $\mathrm{x}$ & & $\mathrm{x}$ \\
\hline Linear combination of estimates & & & & & & \\
\hline Average pre-disaster dummies $-3,-2$, and -1 & $\begin{array}{c}0.010 \\
(0.017)\end{array}$ & $\begin{array}{c}0.010 \\
(0.017)\end{array}$ & $\begin{array}{c}0.015 \\
(0.012)\end{array}$ & $\begin{array}{c}0.015 \\
(0.012)\end{array}$ & $\begin{array}{c}0.008 \\
(0.010)\end{array}$ & $\begin{array}{c}0.008 \\
(0.011)\end{array}$ \\
\hline Average post-disaster dummies 1,2 , and 3 & $\begin{array}{c}0.017 \\
(0.011)\end{array}$ & $\begin{array}{c}0.017 \\
(0.011)\end{array}$ & $\begin{array}{c}0.012 \\
(0.010)\end{array}$ & $\begin{array}{c}0.012 \\
(0.010)\end{array}$ & $\begin{array}{c}0.013 \\
(0.009)\end{array}$ & $\begin{array}{c}0.013 \\
(0.009)\end{array}$ \\
\hline
\end{tabular}

Notes: Standard errors clustered at the disaster level are in parentheses $(* * *, * * *$ indicate significance at 1,5 , and $10 \%$, respectively). We use one observation per respondent and estimate specifications in the form of equation [8]. Individual controls include fixed effects for the day of the week in which the pre-electoral survey took place and, in columns 1, 2, 5, and 6, fixed effects for the number of days separating the post-electoral survey from the election. Sociodemographic controls include education (dummies indicating above high school education and college degree), gender, age, income quartiles, and employment status. The mean values of the three pre-disaster dummies and of the three post-disaster dummies are also reported, along with their standard errors. 
Table A.30: Disasters' effects on vote choice consistency, five-day window

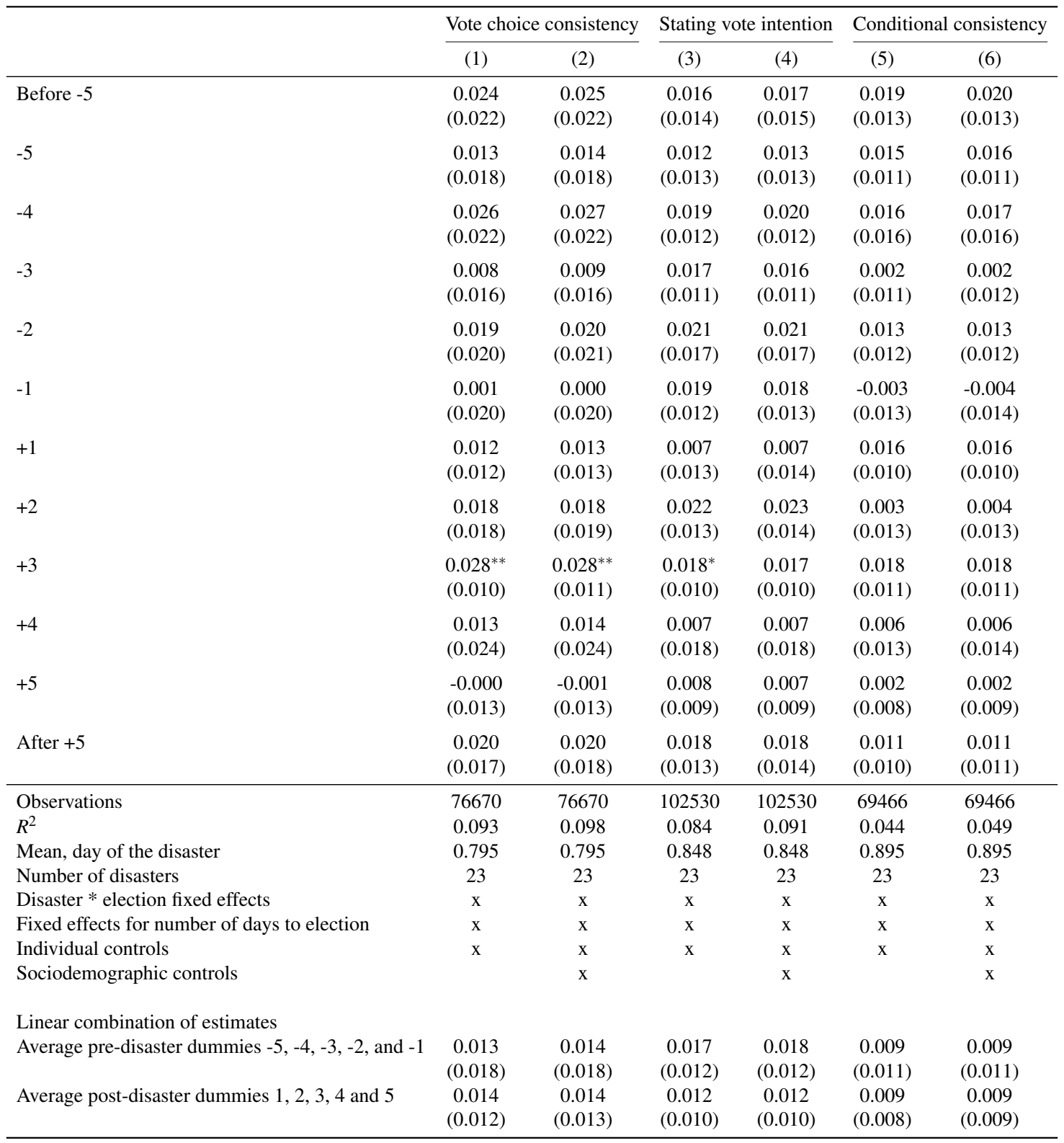

Notes: The set of relative days dummies includes dummy variables for being surveyed one, two, three, four, or five days before the disaster, as well as dummies for being surveyed one, two, three, four, or five days after the disaster. Disasters occurring less than five days from one another are excluded. Other notes as in Appendix Table A.29. 
Table A.31: Disasters' effects on aggregate vote shares

\begin{tabular}{|c|c|c|c|c|}
\hline & \multicolumn{2}{|c|}{$\begin{array}{l}\text { Distance between predicted } \\
\text { and final vote shares }\end{array}$} & \multicolumn{2}{|c|}{$\begin{array}{c}\text { Daily change in } \\
\text { predicted vote shares }\end{array}$} \\
\hline & (1) & (2) & (3) & (4) \\
\hline Before -3 & $\begin{array}{l}-0.012 \\
(0.007)\end{array}$ & $\begin{array}{l}-0.012 \\
(0.007)\end{array}$ & $\begin{array}{l}0.020^{*} \\
(0.011)\end{array}$ & $\begin{array}{l}0.021^{*} \\
(0.011)\end{array}$ \\
\hline-3 & $\begin{array}{l}-0.003 \\
(0.009)\end{array}$ & $\begin{array}{l}-0.003 \\
(0.008)\end{array}$ & $\begin{array}{c}0.004 \\
(0.010)\end{array}$ & $\begin{array}{c}0.005 \\
(0.010)\end{array}$ \\
\hline-2 & $\begin{array}{c}0.002 \\
(0.009)\end{array}$ & $\begin{array}{c}0.001 \\
(0.009)\end{array}$ & $\begin{array}{c}0.037^{* * *} \\
(0.013)\end{array}$ & $\begin{array}{c}0.037^{* * *} \\
(0.013)\end{array}$ \\
\hline-1 & $\begin{array}{l}-0.002 \\
(0.010)\end{array}$ & $\begin{array}{l}-0.002 \\
(0.010)\end{array}$ & $\begin{array}{l}0.031^{* *} \\
(0.015)\end{array}$ & $\begin{array}{l}0.031^{* *} \\
(0.015)\end{array}$ \\
\hline+1 & $\begin{array}{l}-0.007 \\
(0.009)\end{array}$ & $\begin{array}{l}-0.007 \\
(0.009)\end{array}$ & $\begin{array}{l}0.022^{*} \\
(0.012)\end{array}$ & $\begin{array}{l}0.022^{*} \\
(0.012)\end{array}$ \\
\hline+2 & $\begin{array}{c}0.000 \\
(0.008)\end{array}$ & $\begin{array}{l}-0.000 \\
(0.008)\end{array}$ & $\begin{array}{l}0.037^{* *} \\
(0.014)\end{array}$ & $\begin{array}{l}0.036^{* *} \\
(0.015)\end{array}$ \\
\hline+3 & $\begin{array}{l}-0.008 \\
(0.009)\end{array}$ & $\begin{array}{l}-0.008 \\
(0.008)\end{array}$ & $\begin{array}{l}0.030^{* *} \\
(0.014)\end{array}$ & $\begin{array}{l}0.030^{*} \\
(0.015)\end{array}$ \\
\hline After +3 & $\begin{array}{l}-0.006 \\
(0.008)\end{array}$ & $\begin{array}{l}-0.005 \\
(0.007)\end{array}$ & $\begin{array}{l}0.022^{*} \\
(0.012)\end{array}$ & $\begin{array}{l}0.022^{*} \\
(0.012)\end{array}$ \\
\hline Observations & 2130 & 2130 & 2119 & 2119 \\
\hline$R^{2}$ & 0.468 & 0.475 & 0.301 & 0.306 \\
\hline Mean, day of the disaster & 0.060 & 0.060 & 0.107 & 0.107 \\
\hline Number of disasters & 27 & 27 & 27 & 27 \\
\hline Disaster * election fixed effects & $\mathrm{x}$ & $\mathrm{x}$ & $\mathrm{x}$ & $\mathrm{x}$ \\
\hline Fixed effects for number of days to election & $\mathrm{x}$ & $\mathrm{x}$ & $\mathrm{x}$ & $\mathrm{x}$ \\
\hline Aggregate controls & $\mathrm{x}$ & $\mathrm{x}$ & $\mathrm{x}$ & $\mathrm{x}$ \\
\hline Sociodemographic controls & & $\mathrm{x}$ & & $\mathrm{x}$ \\
\hline Linear combination of estimates & & & & \\
\hline Average pre-disaster dummies $-3,-2$, and -1 & $\begin{array}{l}-0.001 \\
(0.008)\end{array}$ & $\begin{array}{l}-0.001 \\
(0.008)\end{array}$ & $\begin{array}{l}0.024^{* *} \\
(0.010)\end{array}$ & $\begin{array}{l}0.024^{* *} \\
(0.010)\end{array}$ \\
\hline Average post-disaster dummies 1,2 , and 3 & $\begin{array}{l}-0.005 \\
(0.007)\end{array}$ & $\begin{array}{l}-0.005 \\
(0.007)\end{array}$ & $\begin{array}{l}0.030^{* *} \\
(0.011)\end{array}$ & $\begin{array}{l}0.030^{* *} \\
(0.011)\end{array}$ \\
\hline
\end{tabular}

Notes: Standard errors clustered at the disaster level are in parentheses $(* * *, * *, *$ indicate significance at 1,5 , and $10 \%$, respectively). We use one observation per election per day and estimate specifications in the form of equation [9]. Aggregate controls include fixed effects for the day of the week in which the pre-electoral survey took place and, in columns 1 and 2, the average number of days separating the post-electoral survey from the election. Sociodemographic controls are averages of the sociodemographic variables included in Appendix Table A.29. Other notes as in Appendix Table A.29. 


\section{B Additional Information on the Data}

\section{B.1 Data References and Links to Surveys}

The references for the nationally representative surveys included in the sample and the links at which the corresponding data can be downloaded are as follows.

\section{B.1.1 Main sample}

\section{Austrian National Election Studies (AUTNES):}

2013: Kritzinger, Sylvia; Zeglovits, Eva; Aichholzer, Julian; Glantschnigg, Christian; Glinitzer, Konstantin; Johann, David; Thomas, Kathrin; Wagner, Markus (2017): AUTNES Preand Post Panel Study 2013. GESIS Data Archive, Cologne. ZA5859 Data file Version 2.0.1, doi:10.4232/1.12724.

This dataset can be downloaded at: https://www.autnes.at/en/data-download/.

\section{British Election Studies (BES):}

2001: Clarke, H. et al., British General Election Study, 2001; Cross-Section Survey. Colchester, Essex: UK Data Archive [distributor], March 2003.

2010: Whiteley, P.F. and Sanders, D., British Election Study, 2010: Face-to-Face Survey. Colchester, Essex: UK Data Archive [distributor], August 2014.

2015: Fieldhouse, E., J. Green., G. Evans., H. Schmitt, C. van der Eijk, J. Mellon and C. Prosser (2015) British Election Study Internet Panel Wave 5. DOI: 10.15127/1.293723.

2016: Evans, G., E. Fieldhouse., J. Green., H. Schmitt, C., van der Eijk., J. Mellon and C. Prosser (2016) British Election Study Internet Panel Wave 8 (2016 EU Referendum Study, Daily Campaign Survey). DOI: 10.15127/1.293723.

These datasets be downloaded at: https://www.britishelectionstudy.com/data/\#.XRlYB-hKhPY.

\section{Canadian Election Studies (CES):}

1988: Johnston, Richard, et al. Canadian Election Study, 1988 [Computer file]. Toronto, Canada: Institute for Social Research [producer], 1989. Ann Arbor, MI: Inter-university Consortium for Political and Social Research [distributor], 1990. 
1992-1993: Johnston, Richard, Andre Blais, Henry Brady, Elisabeth Gidengil, and Neil Nevitte. Canadian Election Study 1993: Incorporating the 1992 Referendum Survey on the Charlottetown Accord [Computer file]. ICPSR version. Vancouver, British Columbia: Richard Johnston, University of British Columbia/Montreal, Quebec: Andre Blais, University of Montreal/Berkeley, CA: Henry Brady, University of California at Berkeley/Montreal, Quebec: Elisabeth Gidengil, McGill University/Calgary, Alberta: Neil Nevitte, University of Calgary [producers], 1995. Ann Arbor, MI: Inter-university Consortium for Political and Social Research [distributor], 1995.

1997: Blais, Andre, Elisabeth Gidengil, Richard Nadeau, and Neil Nevitte. Canadian Election Study, 1997 [Computer file]. 3rd ICPSR version. Toronto, Ontario: York University, Institute for Social Research [producer], 1997. Ann Arbor, MI: Inter-university Consortium for Political and Social Research [distributor], 2000.

2000: Blais, Andre, Elisabeth Gidengil, Richard Nadeau, and Neil Nevitte. Canadian Election Study, 2000 [Computer file]. ICPSR version. Toronto, Ontario: York University, Institute for Social Research [producer], 2000. Ann Arbor, MI: Inter-university Consorti-um for Political and Social Research [distributor], 2004.

2004-2011: Fournier, Patrick, Fred Cutler, Stuart Soroka and Dietlind Stolle. 2011. The 20042011 Canadian Election Study. [dataset].

2015: Fournier, Patrick, Fred Cutler, Stuart Soroka and Dietlind Stolle. 2015. The 2015 Canadian Election Study. [dataset].

These datasets can be downloaded at: https://ces-eec.arts.ubc.ca/english-section/surveys/.

\section{Dutch Parliamentary Election Studies (DPES):}

1998: M. Kamp, (Universiteit Twente); C.W.A.M. Aarts (Universiteit Twente); H. van der Kolk (Universiteit Twente); J.J.A. Thomassen (Universiteit Twente); Stichting Kiezersonderzoek Nederland (SKON)(1998): Nationaal Kiezersonderzoek, NKO 1998. DANS.

2002: G.A. Irwin (University of Leiden); J.J.M. Holsteyn (University of Leiden); J.M. den Ridder (University of Leiden); Stichting Kiezersonderzoek Nederland (SKON) (2003): Nationaal Kiezersonderzoek, NKO 2002 2003. DANS.

2006: Kolk, Dr. H. van der (Universiteit Twente); Aarts, Prof.dr. C.W.A.M. (Universiteit Twente); Rosema, Dr. M. (Universiteit Twente); Stichting Kiezersonderzoek Nederland (SKON) (2006): Nationaal Kiezersonderzoek, NKO 2006. DANS.

These datasets can be downloaded at: 
https://www.surveydata.nl/browse-our-data/repository/dutch-parliamentary-election-studies28.

\section{German Longitudinal Election Studies (GLES):}

2009: Rattinger, Hans; Roßteutscher, Sigrid; Schmitt-Beck, Rüdiger; Weßels, Bernhard (2011): Rolling Cross-Section Campaign Survey with post- election Panel Wave (GLES 2009). GESIS Data Archive, Co-logne. ZA5303 Data file Version 6.0.0, doi: 10.4232/1.11604.

2013: Rattinger, Hans; Roßteutscher, Sigrid; Schmitt-Beck, Rüdiger; Weßels, Bernhard; Wolf, Christof (2014): Rolling Cross-Section Cam-paign Survey with Post-election Panel Wave (GLES 2013). GESIS Data Archive, Cologne. ZA5703 Data file Version 2.0.0, doi: 10.4232/1.11892.

2017: Roßteutscher, Sigrid; Schoen, Harald; Schmitt-Beck, Rüdiger; Weßels, Bernhard; Wolf, Christof; Staudt, Alexander (2019): Rolling Cross-Section Campaign Survey with Post-election Panel Wave (GLES 2017). GESIS Data Archive, Cologne: ZA6803 Data file Version 4.0.1, 10.4232/1.13213.

These datasets can be downloaded at: https://www.gesis.org/en/elections-home/gles/data/.

\section{Italian National Election Studies (ITANES):}

2013: Vezzoni, Cristiano. (2014). Italian National Election Survey 2013: A further step in a consolidating tradition. Rivista Italiana di Scienza Politica. 2014. 81-108. 10.1426/76399.

This dataset can be downloaded at: http://www.itanes.org/en/.

\section{Swiss Electoral Studies (SELECTS):}

2011: Selects: Swiss national election studies, Rolling Cross-Section (RCS) - 2011 [Dataset]. Distributed by FORS, Lausanne, 2012. www.selects.ch https://doi.org/10.23662/FORS-DS-596-.

2015: Selects: Panel / Rolling cross-section study - 2015 [Dataset]. Distributed by FORS, Lausanne, 2016. www.selects.ch.

These datasets can be downloaded at: https://forscenter.ch/projects/selects/.

\section{New Zealand Election Studies (NZES):}

1996: Vowles, J, Banducci, S, Karp, J, Aimer, P, Catt, H, Miller, R, and Denemark, D. 1996. New Zealand Election Study, 1990 [computer file].

1999: Vowles, J, Banducci, S, and Karp, J. 1999. New Zealand Election Study, 1999 [computer file].

2002: Vowles, J, Banducci, S, Karp, J, Aimer, P, and Miller, M. 2002. New Zealand Election Study, 2002 [computer file]. 
These datasets can be downloaded at: http://www.nzes.org/.

\section{Swedish National Election Studies (SNES):}

2014: Boije, Edvin, Oscarsson, Henrik \& Maria Oskarson (2016) The 2014 CSM campaign panel study. Dataset. University of Gothenburg: Swedish National Election Studies, The Department of Political Science.

This dataset can be downloaded at: https://valforskning.pol.gu.se/.

\section{American National Election Studies (ANES):}

1952: The data were made available by the Inter-university Consortium for Political Research. The data were originally collected by Angus Campbell, Gerald Gurin, and Warren Miller. Neither the original collectors of the data nor the consortium bear any responsibility for the analyses or interpretations presented here.

1956: The data were made available by the Inter-university Consortium for Political Research. The data for the SRC 1956 American National Election Study were originally collected by the Survey Research Center of the Institute for Social Research, the University of Michigan under a grant from the Rockefeller Foundation. Neither the original collectors of the data nor the consortium bear any responsibility for the analyses or interpretations presented here.

1960: The data were made available by the Inter-university Consortium for Political Research. The data for the Survey Research Center 1960 American National Election Study were originally collected by Angus Campbell, Philip Converse, Warren Miller, and Donald Stokes. Neither the original collectors of the data nor the consortium bear any responsibility for the analyses or interpretations presented here.

1964: The data were made available by the Inter-university Consortium for Political Research. The data were originally collected by the Survey Research Center Political Behavior Program. Neither the original collectors of the data nor the consortium bear any responsibility for the analyses or interpretations presented here.

1968: The data were made available by the Inter-university Consortium for Political Research. The data for the SRC 1968 American National Election Study were originally collected by the Political Behavior Program of the Survey Re-search Center, Institute for Social Research, the University of Michi-gan. Neither the original collectors of the data nor the consortium bear any responsibility for the analyses or interpretations presented here.

1972: The data were made available by the Inter-university Consortium for Political Research. The data for the CPS 1972 American National Election Study were originally collected by the 
Center for Political Studies of the Institute for Social Research, the University of Michigan under grants from the National Science Foundation and the National Institute for Mental Health. Neither the original collectors of the data nor the consortium bear any responsibility for the analyses or interpretations presented here.

1976: The data were made available by the Inter-university Consortium for Political and Social Re-search. The data for the CPS 1976 American National Election Study were originally collected by the Center for Political Studies of the Institute for Social Research, the University of Michigan under a grant from the National Science Foundation. Neither the original collectors of the data nor the consortium bear any responsibility for the analyses or interpretations presented here.

1980: The data were made available by the Inter-university Consortium for Political and Social Re-search. The data for the American National Election Study, 1980, were originally collected by the Center for Political Studies of the Institute for Social Research, the University of Michigan, for the National Election Studies, under the overall direction of Warren E. Miller; Maria Elena Sanchez was director of studies in 1980. The data were collected under a grant from the National Science Foundation. Neither the original collectors of the data nor the consortium bear any responsibility for the analyses or interpretations presented here.

1984: The data were made available by the Inter-university Consortium for Political and Social Re-search. The data for the American National Election Study, 1984, were originally collected by the Center for Political Studies of the Institute for Social Research, the University of Michigan, for the National Election Studies, under the overall direction of Warren E. Miller; Santa Traugott was director of studies in 1984. The data were collected under a grant from the national science foundation. Neither the collector of the original data nor the consortium bears any responsibility for the analyses or interpretations presented here.

1988: Miller, Warren E., and the National Election Studies. American National Election Study, 1988: Pre- and Post-Election Survey computer file. Ann Arbor, MI: Center for Political Studies, University of Michigan, 1989 original producer. Ann Arbor, Michigan: Inter-university Consortium for Political and Social Research, 1989 producer and distributor.

1992: Miller, Warren E., Donald R. Kinder, Steven J. Rosenstone, and the National Election Studies. American National Election Study, 1992: Pre- and Post-election survey [Computer file]. Conducted by University of Michigan, Center for Political Studies. ICPSR ed. Ann Arbor, MI: University of Michigan, Center for Political Studies, and Inter-university Consortium for Political 
and Social Research [producers], 1993. Ann Arbor, MI: Inter-university Consortium for Political and Social Research [distributor], 1993.

1996: The National Election Studies (www.umich.edu/ nes). The 1996 National Election Study [dataset]. Ann Arbor, MI: University of Michigan, Center for Political Studies [producer and distributor].

2000: Burns, Nancy, Donald R. Kinder, Steven J. Rosenstone, Virginia Sapiro, and the National Election Studies. National Election Studies, 2000:Pre-/Post-election Study [dataset]. Ann Arbor, MI: University of Michigan, Center for Political Studies [producer and distributor], 2001.

2004: The National Election Studies (www.umich.edu/ nes). THE 2004 National Election Study [dataset]. Ann Arbor, MI: University of Michigan, Center for Political Studies [producer and distributor]. These materials are based on work supported by the National Science Foundation under grant SES-0118451, and the University of Michigan. Any opinions, findings and conclusions or recommendations expressed in these materials are those of the author(s) and do not necessarily reflect the views of the funding organizations.

2008: Arthur Lupia, Jon A. Krosnick, Pat Luevano, Matthew DeBell, and Darrell Donakowski. 2009. User's Guide to the ANES 2008 Time Series Study. Ann Arbor, MI and Palo Alto, CA: the University of Michigan and Stanford University.

2012: ANES. 2014. User's Guide and Codebook for the ANES 2012 Time Series Study. Ann Arbor, MI and Palo Alto, CA: the University of Michigan and Stanford University.

2016: The American National Election Studies. These materials are based on work supported by the National Science Foundation under grant numbers SES 1444721, 2014-2017, the University of Michigan, and Stanford University.

These datasets can be downloaded at: https://electionstudies.org/data-center/.

\section{National Annenberg Election Surveys (NAES):}

2000-2004: Romer, Daniel, et al. Capturing campaign dynamics, 2000 and 2004: The national Annenberg election survey. University of Pennsylvania Press, 2006.

2008: Johnston, Richard. "Modeling campaign dynamics on the web in the 2008 National Annenberg Election Study." Journal of Elections, Public Opinion and Parties 18.4 (2008): 401412.

These datasets can be downloaded at: https://www.annenbergpublicpolicycenter.org/politicalcommunication/naes/. 


\section{B.1.2 Additional surveys}

\section{Cooperative Congressional Election Studies (CCES):}

2008: Ansolabehere, Stephen, Cooperative Congressional Election Study, 2008: Common Content. Release 4: July 15, 2011. Cambridge, MA: Harvard University.

2012: Ansolabehere, Stephen, Cooperative Congressional Election Study, 2012: Common Content. Release 1: April 15, 2013. Cambridge, MA: Harvard University.

2016: Ansolabehere, Stephen and Brian F. Schaner, Cooperative Congressional Election Study, 2016: Common Content. Release 2: August 4, 2017. Cambridge, MA: Harvard University.

These datasets can be downloaded at: http://cces.gov.harvard.edu.

\section{British Election Studies (BES), Pre-campaign surveys:}

2015: Fieldhouse, E., J. Green., G. Evans., H. Schmitt, C. van der Eijk, J. Mellon and C. Prosser (2015) British Election Study Internet Panel Wave 4. DOI: 10.5255/UKDA-SN-8202-2.

2016: Fieldhouse, E., J. Green., G. Evans., H. Schmitt, C. van der Eijk, J. Mellon and C. Prosser (2016) British Election Study Internet Panel Wave 7. DOI: 10.5255/UKDA-SN-8202-2.

These datasets can be downloaded https://www.britishelectionstudy.com/data/\#.XRIYB-hKhPY.

\section{National Annenberg Election Studies (NAES), Pre-campaign surveys:}

2000: Romer, Daniel, et al. Capturing campaign dynamics, 2000 and 2004: The national Annenberg election survey. University of Pennsylvania Press, 2006.

2008: Johnston, Richard. "Modeling campaign dynamics on the web in the 2008 National Annenberg Election Study." Journal of Elections, Public Opinion and Parties 18.4 (2008): 401412.

These datasets can be downloaded at: https://www.annenbergpublicpolicycenter.org/politicalcommunication/naes/.

\section{Swiss Electoral Studies (SELECTS), Pre-campaign surveys:}

2015: Selects: Panel / Rolling cross-section study - 2015 [Dataset]. Distributed by FORS, Lausanne, 2016. www.selects.ch.

This dataset can be downloaded at: https://forscenter.ch/projects/selects/.

\section{Swedish National Election Studies (SNES), Pre-campaign surveys:}


2014: Boije, Edvin, Oscarsson, Henrik \& Maria Oskarson (2016) The 2014 CSM campaign panel study. Dataset. University of Gothenburg: Swedish National Election Studies, The Department of Political Science.

This dataset can be downloaded at: https://valforskning.pol.gu.se/.

\section{B.2 Definition of Key Variables}

\section{B.2.1 Main outcomes}

Vote intention: Categorical variable indicating which candidate or party the respondent intends to vote for.

- This variable is constructed from questions in the pre-electoral survey of the type: "Who do you think you will vote for? Hillary Clinton, Donald Trump, Gary Johnson, Jill Stein, or someone else?" (ANES 2016) or "Which constituency candidate of which party will you give your first vote to in the federal election?" (GLES 2009).

- Possible values include answers of the type "blank" (for respondents who say they intend to vote blank or null) or "don't know" (for respondents who say they do not know whom they will vote for).

- The variable is set to missing for respondents who mention a candidate or party which does not appear among answers to the post-electoral vote choice question. We take the fact that they do not appear among answers to the post-electoral vote choice question as a sign that this option was not proposed in the post-electoral survey, so that comparing the respondent's pre-election vote intention and post-electoral vote choice would be uninformative. This rule also applies to answers of the type "other" (for respondents who state they intend to vote for another candidate or party) or "blank" (for respondents who state they intend to vote blank or null): we set the variable to missing for the answers "other" or "blank" when these answers do not appear among answers to the post-electoral vote choice question.

- When an answer "other" is available both in the pre- and post-electoral surveys, we keep it and treat it as a unique party. In that case, we also give the value "other" to respondents who say they intend to vote for small candidates who do not appear in the post-electoral survey.

- This variable is set to missing for people who respond "I will not vote" instead of naming a candidate or party.

- This variable, and all variables described below, are set to missing for respondents who refused to answer the question. 
Vote choice: Categorical variable indicating which candidate or party the respondent voted for.

- This variable is constructed from questions in the post-electoral survey of the type: "Who did you vote for? Hillary Clinton, Donald Trump, Gary Johnson, Jill Stein, or someone else?" (ANES 2016) or "Which constituency candidate of which party did you give your first vote to?" (GLES 2009).

- Possible values include answers of the type "blank" (for respondents who report that they voted blank or null).

- The variable is set to missing for people who respond "I don't know" to the question.

- The variable is set to missing for respondents who mention a candidate or party which does not appear among answers to the pre-electoral vote intention question, for the same reason as mentioned above. This rule also applies to answers of the type "other" (for respondents who report they voted for another candidate or party) or "blank" (for respondents who report they voted blank or null): we set the variable to missing for the answers "other" or "blank" when these answers do not appear among answers to the pre-electoral vote intention question.

- When an answer "other" is available both in the pre- and post-electoral surveys, we keep it and treat it as a unique party. In that case, we also give the value "other" to respondents who report they voted for small candidates who do not appear in the pre-electoral survey.

- This variable is set to missing for people who respond "I did not vote" instead of naming a candidate or party.

Turnout intention: Dummy equal to 1 if the respondent intends to vote, and 0 otherwise.

- This variable is constructed from questions in the pre-electoral survey of the type: "Many people vote at elections. Others don't get around to voting or don't take part in the election for other reasons. The next federal election will be held on 27 September. What will you do? Are you certain to vote, likely to vote, might you vote, or are you not likely or certain not to vote?" (GLES 2009) or "How about the election for President? Do you intend to vote for a candidate for President?" (ANES 2016).

- When the question in the survey proposes a range of answers, from answers of the type "certain not to vote" or 0 on a scale from 0 to 10 , to answers of the type "certain to vote" or 10 on the $0-10$ scale, the variable is set to 1 for respondents who give the highest answer (respondents who intend to vote with certainty) and to 0 for respondents who give any other answer, including respondents who say that they may vote but are not certain they will. This rule has the advantage of being easily applicable in a uniform way to surveys with very 
different response scales. In addition, in the vast majority of surveys, even the share of respondents who give the highest answer exceeds actual turnout by a substantial amount. In few surveys (e.g., ANES 1952-1968), the variable is set to 1 for respondents who give either the highest or the second highest answer ("yes, definitely" or "yes") as a very small share of respondents give the highest answer ("yes, definitely").

- When possible, this variable is specific to each ballot (in surveys asking questions about multiple ballots, e.g., the first and second vote in Germany) or to each office (in surveys asking questions about multiple offices, e.g., presidential and gubernatorial elections in the U.S.). The variable is then set to 0 both for respondents who do not intend to vote in the overall election and for those who intend to vote but not for that specific ballot or office.

- The variable is set to 0 for people who respond "I don't know" to the question.

- The variable is also set to 0 for people who respond "I will not vote" to the vote intention question, regardless of their answer to the turnout intention question.

Turnout declaration: Dummy equal to 1 if the respondent voted, and 0 otherwise.

- This variable is constructed from questions in the post-electoral survey of the type: "Many voters didn't get around to voting or did not participate in the federal election on 27 September for other reasons. What about you? Did you vote or not?" (GLES 2009) or "In talking to people about elections, we often find that a lot of people were not able to vote because they weren't registered, they were sick, or they just didn't have time. Which of the following statements best describes you: One, I did not vote (in the election this November); Two, I thought about voting this time, but didn't; Three, I usually vote, but didn't this time; or Four, I am sure I voted?" (ANES 2016).

- This variable is set to missing for people who respond "I don't know" to the question.

- This variable is set to 0 for people who respond "I did not vote" to the vote choice question, regardless of their answer to the turnout declaration question.

Certainty of vote intention: Numerical variable from 0 to 1 indicating how certain the respondent is to vote for the candidate or party they intend to vote for.

- This variable is constructed from questions asked in the pre-electoral survey of the type: "How certain are you that you would vote for this party?" (BES 2016), "Will you definitely vote for George W. Bush for president, or is there a chance you could change your mind and vote for someone else?" (NAES 2004), or "Would you say that your preference for this candidate is strong or not strong?" (ANES 1996). 
- When the certainty question in the survey proposes more than two answers ("certain" or "not certain"), this variable is normalized to range from 0 (for respondents who are not certain at all that they will vote for the candidate or party they intend to vote for) to 1 (for respondents who are certain they will vote for the candidate or party they intend to vote for).

- This variable is set to missing for people who respond "I don't know" to the question.

- In surveys that record respondents' vote intention certainty, this variable is set to 0 for people who responded "I don't know" to the vote intention question.

\section{B.2.2 Special cases}

Early voters: Some countries allow people to vote before Election Day, by casting their ballot in-person at a polling place or by mailing their ballot. In our sample, pre-electoral survey respondents were asked whether they voted early and for whom in the following surveys: AUTNES 2013, BES 2016, CES 2004-15, SELECTS 2011-15, GLES 2009-13, NAES 2000-08, ANES 2012-16. In some surveys, these questions were asked to all respondents; and in others, only to respondents surveyed sufficiently close to the election. Differently from other voters, early voters' pre-electoral answers report their actual vote choice, not their vote intention. In addition, their vote choice consistency is mechanically very high, as their pre-electoral vote intention is identical to their post-electoral vote choice, provided that they do not misrecall or misreport whom they voted for in any of the two surveys. Nonetheless, we keep early voters in the sample and treat the vote choice they report in the pre-electoral survey similarly to other respondents' vote intention. The reason is, first, that their high vote choice consistency adequately reflects the fact that they have already arrived at their final choice by the time in which they receive the pre-electoral survey. In fact, they felt sufficiently certain about it that they casted their ballot ahead of time. Second, the share of respondents who report they voted early naturally increases over time. But early voters likely differ from other voters on many dimensions, including the time at which they reach their final vote decision. Dropping them could therefore generate sample selection issues. Our treatment of early voters includes the following rules:

- Turnout intention is set to 1 for all early voters.

- Certainty of vote intention is set to 1 for all early voters, except those who say that they do not know whom they voted for, in which case certainty of vote intention is set to missing. 
- When early voters are not asked whether they voted and whom they voted for in the postelectoral survey, we set the post-electoral turnout declaration of these respondents equal to 1 , and their post-electoral vote choice equal to their recorded pre-electoral vote choice.

Unlikely voters: The vote intention variable is defined for all respondents who were asked this question, including those who are not certain that they will vote. In several surveys, likely and unlikely voters are asked separate questions, of the type "Which political party will you give your vote to in the federal election?" for respondents likely to vote and "Which political party would you vote for, assuming you voted at all?" for unlikely voters (GLES 2009). Our vote intention variable combines answers to both questions.

Undecided voters: In the BES 2001-15 surveys, pre-electoral survey respondents are asked whether they have already decided whom they will vote for before being asked whom they intend to vote for. For instance, BES 2001 first asks "If you do vote in the general election, have you decided which party you will vote for, or haven't you decided yet?" Voters who answer "yes" to that question are then asked "Which party is that?" while undecided voters who answer "no" are then asked "Which party do you think you are most likely to vote for?" Our vote intention variable combines answers to both of these questions. In BES 2016, CES 1988-2015, SELECTS 2011-15, NZES 1996-2002, and DPES 1998-2002, respondents who answer "I don't know" to the vote intention question are asked a second question of the type "Which party would you be most likely to vote for?" (NZES 1996). These respondents' answer would be treated as "don't know" in surveys that ask a single question. Therefore, to ensure that we treat vote intentions homogeneously across all surveys, we ignore their answer to the second question.

\section{B.2.3 Policy preferences, issue salience, and beliefs on candidates}

Pre-electoral policy preference: Numerical variable indicating the respondent's position on a policy issue before the election.

- This variable is constructed from questions about policy issues or policy proposals that allow for a range of answers ordered from one extreme position (e.g., "I do not agree at all" or "I am very unfavorable") to the opposite extreme position (e.g., "I agree very much" or "I am very favorable"). 
- This variable is constructed from questions that were asked both in the pre- and the postelectoral surveys, using the same wording and admitting the same answers in both surveys. The full list of policy questions included in our analysis is available in Table B.3.

- In some surveys (e.g., GLES 2009 or CES 1988), the variable combines answers to several versions of the same policy question that are asked to different subsamples of respondents.

- Possible values include answers of the type "don't know" (for respondents who state they do not have a preferred position on the issue).

Post-electoral policy preference: Numerical variable indicating the respondent's preferred position on a specific policy issue after the election.

- The variable is set to missing for people who respond "I don't know" to the question.

Pre-electoral most important issue: Categorical variable indicating which issue the respondent considers the most important before the election.

- This variable is constructed from questions that ask respondents to choose from a closed list of issues or from open-ended questions that allow respondents to provide their own answer. We only use questions of the latter type if respondents' answers were aggregated into a finite number of issues ex post in the survey data. We further aggregate respondents' answers into 10 larger categories: economic policy (e.g., 'inflation'), social policy (e.g., 'abortion'), foreign policy (e.g., 'Iraq war'), public safety (e.g., 'crime and violence'), civil rights (e.g., 'civil liberties'), moral values (e.g., 'decline of tradition'), institutions (e.g., 'country stability'), politics (e.g., 'integrity in politics'), electoral issues (e.g., 'low turnout'), and other.

- Possible values include answers of the type "don't know" (for respondents who state they do not know which issue they find the most important).

- We also include answers of the type "no issue" (for respondents who state that they do not find any issue important) or "other issue" (for respondents who mention an issue that is not on the list). These "no issue" and "other issue" answers are assigned to the "other" category.

Pre-electoral most important issue: Categorical variable indicating which issue the respondent considers the most important after the election.

- The variable is set to missing for people who respond "I don't know" to the question.

Pre-electoral belief on candidate: Variable indicating the respondent's belief about candidates' or parties' positions on specific policy issues and/or candidates' or parties' quality, before the election.

- This variable is constructed from questions of two different types: 
1. Numerical questions, which ask respondents to choose from a range of answers ordered from one extreme (e.g., "this party is very unfavorable to this policy proposal" or "this party is very incompetent") to the other (e.g., "this party is very favorable to this policy proposal" or "this party is very competent").

2. Categorical questions, which ask respondents to choose from the list of candidates or parties in the race, e.g., to identify which one would be the best to address the issue they deem the most important, or which one has a certain position on the issue of immigration.

- This variable is constructed from questions that were asked both in the pre- and the postelectoral surveys, using the same wording and allowing for the same list of answers. The full list of belief questions included in our analysis is available in Table B.4.

- Possible values include answers of the type "don't know" (for respondents who state they do not know the answer to the question).

- For questions of the second type, we also include answers of the type "no party" or "all parties".

Post-electoral belief on candidate: Variable indicating the respondent's belief about candidates' or parties' positions on specific policy issues and/or candidates' or parties' quality, after the election.

- The variable is set to missing for people who respond "I don't know" to the question.

\section{B.2.4 Sociodemographic characteristics}

Gender: Dummy variable equal to 1 if the respondent is a man, and 0 otherwise.

- This variable, and all other sociodemographic characteristics, is constructed from questions asked in the pre-electoral survey. If the characteristic was not recorded in the pre-electoral survey, we use questions asked in surveys that preceded the pre-electoral survey (in studies that survey respondents over multiple waves before the election) or questions asked in the post-electoral survey.

- This variable, and all other sociodemographic characteristics, is set to missing for people who respond "other" to the question.

Age: Respondent's age in number of years.

- One survey (ANES 1956) records age brackets instead of exact age in years. For that survey, the variable is set to the median age within each bracket. We use ANES surveys conducted in 
previous and following election years (1952 and 1960) to determine the median age among respondents selecting into the youngest bracket (below 21 years old) and the oldest bracket (65 years old and older).

More education than high school: Dummy variable equal to 1 if the respondent has completed more education than high school, and 0 otherwise.

- This variable is constructed from questions of the type: "At what age did you finish full-time education?" (BES 2001) or "What is the highest level of education that you have completed?" (CES 2015).

College degree: Dummy variable equal to 1 if the respondent has a college degree, and 0 otherwise. Income quartiles: Dummy variables (one for each quartile) equal to 1 if the respondent's income falls into the first (resp. second, third, and fourth) quartile of the income distribution (among respondents from the same survey), and 0 otherwise.

- This variable is constructed from questions of the type: "What is your total household income before taxes for the year 2014?" (CES 2015) or "How would you assess your current income situation? Would you say that you get along very well, get along well, get along with difficulty, get along with great difficulty?" (AUTNES 2013).

Employment status: Dummy variable equal to 1 if the respondent has a full-time or part-time employed job or is self-employed, and 0 otherwise.

- This variable is constructed from questions of the type: "Which of the following best describes your current situation?" (AUTNES 2013) or "We'd like to know if you are working now, or are you unemployed, retired, permanently disabled, a housewife, a student or what?" (ANES 1976). We do not use questions of the type: "Are you currently unemployed?", which give the same value to people who are currently employed and people outside the labor force.

- This variable is set to 0 for respondents who are currently enrolled as students or retired, even if they state they have a paid job as well.

\section{B.2.5 Media consumption, campaign exposure, and political engagement}

Newspapers: Dummy variable equal to 1 if the respondent's consumption of newspapers is high, and 0 otherwise. 
- This variable, and, unless specified, all other variables in this subsection, are constructed from questions asked in the pre-electoral survey exclusively.

- When possible, this variable is constructed from questions specific to political news of the type: "How often do you inform yourself about political events in Austria through newspapers?" (AUTNES 2013). When specific questions are unavailable, we use questions about general news.

- Some surveys ask respondents how frequently they read newspapers and how much attention they pay to political news in newspapers (e.g., NAES). In this case, the newspapers variable is set to 0 for respondents who never read newspapers and for respondents who read newspapers but do not pay any attention to political news.

- In many surveys, media questions propose more than two answers, from answers of the type "never" or "not at all" (for respondents who never read newspapers and/or who do not pay attention to political news in newspapers) to answers of the type "every day" or "a lot" (for respondents who read newspapers everyday and/or pay a lot of attention to political news in newspapers). When the possible number of answers $K$ is even, the newspapers variable is set to 1 for respondents who provide one of the $\frac{K}{2}$ highest answers, and 0 otherwise. When the possible number of answers $K$ is odd, the newspapers variable is set to 1 for respondents who provide one of the $\frac{K-1}{2}$ highest answers, and 0 otherwise.

- This variable is typically constructed from questions that ask respondents about their consumption of newspapers offline. However, for surveys conducted in the most recent election years, it is likely that respondents answer the newspaper question with both offline and online newspapers in mind. In a few surveys, the variable is constructed from questions that explicitly ask respondents about their consumption of newspapers both offline and online (e.g., BES 2016: "During the last seven days, on average how much time (if any) have you spent per day following news about politics or current affairs from newspapers (including online)?”).

TV News: Dummy variable equal to 1 if the respondent's consumption of TV news is high, and 0 otherwise.

- This variable is constructed from questions specific to news programs exclusively. We do not use questions that ask respondents about their consumption of other TV programs such as sport and entertainment. 
- Like for newspapers, some surveys ask respondents how frequently they watch TV news programs and how much attention they pay to political news on TV (e.g., NAES). In this case, the TV news variable is set to 0 for respondents who never watch TV, for respondents who never watch news programs on TV, and for respondents who watch news programs on TV but say that they do not pay any attention to political news.

Radio news: Dummy variable equal to 1 if the respondent's consumption of radio news is high, and 0 otherwise.

Online news: Dummy variable equal to 1 if the respondent's consumption of online news is high, and 0 otherwise.

- The variable is constructed from questions that ask respondents about their consumption of online news, broadly defined. In a few surveys, it is constructed from questions that ask about the respondent's consumption of news on Internet sites, excluding newspapers (e.g., BES 2016). In others, it is constructed from questions that ask about the respondent's consumption of online newspapers (e.g., ANES 2004).

Contact by campaign: Dummy variable equal to 1 if the respondent has recently been contacted by a candidate's or party's campaign, and 0 otherwise.

- The variable is constructed from questions that ask respondents if they have recently been contacted by any candidate, party member, or campaign activist, of the type: "In the past week, were you contacted in person or by telephone by any of the local candidates or party workers in your riding?" (CES 1992).

- When the survey specifies the mean of communication used by the candidate's or party's campaign to contact the respondent, the variable is constructed from questions referring to contact by mail, email, phone call, text message, and home visit. We exclude questions that ask respondents if they proactively engaged with a candidate's or party's campaign themselves, e.g., by attending a meeting or visiting a campaign office.

- When respondents are asked multiple contact questions, one for each candidate or party in the race, the variable is set to 0 for respondents who give a negative answer to all questions.

Visit by campaign: Dummy variable equal to 1 if the respondent has recently been visited at home by a candidate's or party's campaign, and 0 otherwise.

Polls: Dummy variable equal to 1 if the respondent has seen elections polls recently, and 0 otherwise. 
Political discussions: Dummy variable equal to 1 if the respondent reports a high propensity to discuss politics with others in the recent period, and 0 otherwise.

- The variable is constructed from questions of the type: "During the last week, roughly on how many days did you talk about politics with other people?" (BES 2015).

- In many surveys, the discussion question proposes more than two answers, from answers of the type "never" or "not at all" (for respondents who never discuss politics with others) to answers of the type "every day" or "a lot" (for respondents who discuss politics with others very often). When the possible number of answers $K$ is even, the discussion variable is set to 1 for respondents who provide one of the $\frac{K}{2}$ highest answers, and 0 otherwise. When the possible number of answers $K$ is odd, the variable is set to 1 for respondents who provide one of the $\frac{K-1}{2}$ highest answers, and 0 otherwise.

Strength of party identification: Dummy variable equal to 1 if the respondent strongly identifies with a party, and 0 otherwise.

- Unlike other variables described in this section, the strength of party identification variable is constructed from questions asked in the post-electoral survey exclusively.

- In many surveys, the question that asks respondents how strongly they identify with a party is preceded by a question that asks respondents which party they identify with. The variable on party identification strength is set to 0 for people who respond "no party" or - in the U.S. - "independent" to the former question.

- In many surveys, the strength of party identification question proposes more than two answers, from answers of the type "no party identification" or "not strong at all" (for respondents who do not strongly identify with a party) to answers of the type "very strong" (for respondents who strongly identify with a party). When the possible number of answers $K$ is even, the strength of party identification variable is set to 1 for respondents who provide one of the $\frac{K}{2}$ highest answers, and 0 otherwise. When the possible number of answers $K$ is odd, the variable is set to 1 for respondents who provide one of the $\frac{K-1}{2}$ highest answers, and 0 otherwise.

Party identification: Categorical variable indicating which party the respondent identifies with.

- Unlike other variables described in this section, the party identification variable is constructed both from questions asked in the post-electoral survey and questions asked in the post-electoral survey.

- The variable is set to missing for answers of the type "no party" or "I don't know." 
- The variable is set to missing for respondents who mention a candidate or party which does not appear among possible answers either to the pre-electoral vote intention question or to the post-electoral vote choice question. This rule also applies to answers of the type "other" (for respondents who state they identify with another party): we set the variable to missing for the answer "other" when this answer does not appear among answers to the post-electoral vote choice question.

- When the option "other" is available as a possible answer to the party identification question and to both the pre-electoral vote intention question and the post-electoral vote choice question, we keep it and treat it as any other party. In that case, we also give the value "other" to respondents who identify with small candidates who do not appear among possible answers either to the pre-electoral vote intention question or to the post-electoral vote choice question.

Debate watching: Dummy variable equal to 1 if the respondent has watched TV debates during the campaign, and 0 otherwise.

- Unlike other variables described in this section, the debate watching variable is constructed exclusively from questions asked in the post-electoral survey.

- The variable is constructed from questions that ask respondents (after the election) if they watched a specific TV debate or TV debates in general during the campaign. It is set to 0 for respondents who have not watched any debate during the campaign.

\section{B.2.6 Other variables}

Survey weight: Weight provided in the raw survey to accurately represent the population, centered around 1.

- Depending on their design, surveys provide weights for the sample of respondents surveyed before the election only, both for the sample of respondents surveyed before the election and for the sample of respondents surveyed after the election, or for the sample of respondents surveyed both before and after the election. To ensure consistency across surveys and across outcomes defined on different samples, we only use the weights given to respondents in the pre-electoral survey and ignore weights provided in the post-electoral survey. We assign a weight of 1 to each respondent when pre-electoral weights are not available. 
- Some surveys include multiple weight variables, designed to accurately represent different subpopulations (e.g., provincial and national weights in all CES surveys). We keep the weight variable designed to accurately represent the national population.

- Some surveys include multiple weight variables, assigned to respondents surveyed at different times (e.g., BES 2010 provides weekly and rolling daily weights). For consistency across surveys, we keep weight variables assigned to the full pre-electoral sample.

- Some surveys include multiple weight variables, corresponding to different weighting methods. We systematically checked the survey documentation and kept the most "standard" weight variable, as described by the survey's authors. For instance, GLES 2009 proposes eight different ways to weight the pre-electoral sample, based on different sociodemographic characteristics and/or geography. We keep the variable described as the "standard weight" in the documentation (pre_gstd), which is generated by the survey institute IPSOS and which is based on age, gender, federal state, and town size.

- In some surveys (e.g., ANES 1960), the weights are not centered around 1: they are either equal to 1 or larger than 1 for respondents underrepresented in the survey sample. We center these weights around 1 , for consistency with other surveys.

Vote decision during the campaign: Dummy variable equal to 1 if the respondent reports that they decided whom to vote for during the campaign.

- The variable is constructed from post-electoral questions asking respondents to recall when they decided whom to vote for. It is set to 1 for respondents who provide answers corresponding to any time period after the campaign started, and to 0 for respondents who provide answers corresponding to any time period before the campaign started. For instance, in the ANES surveys, we set the variable equal to 1 for respondents who fall in the category "a couple of months before the election" or any subsequent category, and 0 for respondents who fall in the category "two to three months before the election" or any previous category. In the CES surveys, the variable takes value 1 for respondents who give the answers "during the campaign" and "Election Day," and 0 for those who respond "before the campaign."

\section{B.3 Information on Disasters}

We identified disasters taking place during the campaign period with the EM-DAT International Disasters Database. The database is curated by the Centre for Research on the Epidemiology of 
Disasters (CRED) and compiles information from various sources, including UN agencies, nongovernmental organizations, insurance companies, research institutions, and press agencies. It includes natural and technological disasters that have occurred since 1900 across 100 countries and were selected according to the following criteria: they caused 10 deaths or more; they affected 100 people or more; they led to a declaration of a state of emergency; or they led to a call for international assistance.

The EM-DAT database has been used by other researchers, e.g., to study the macroeconomic consequences of disasters (Noy, 2009), the relationship between disasters' news coverage and U.S. aid relief (Eisensee and Stromberg, 2007), the impact of wage and aid shocks on political violence (Besley and Persson, 2011), and the effects of natural disasters on social norms (Winkler, 2021). It provides the start date of most disasters, which is crucial to our event study approach. The full list of disasters included in our sample is available in Appendix Table B.7.

\section{B.4 Debate Viewership}

We found data on actual debate viewership for 43 out of the 56 TV debates in our sample. For U.S. elections, we collected information on viewership for all presidential debates since 1960 from the website of the Commission on Presidential Debates (https://www.debates.org/), which reports data provided by Nielsen Media Research. For U.K. elections, we collected the TV ratings provided by the Guardian (for instance, see https://www.theguardian.com/media/2010/apr/30/leaders-debate-tv-ratings for the 2015 election). For Germany, we collected the TV ratings provided by DWDL (for instance, see https://www.dwdl.de/zahlenzentrale/63164/mehr_als_16_mio_sehen_tvduell_das_erste_triumphiert/ for the 2017 election). Finally, TV ratings for the only Austrian debate in our sample, which took place before the 2013 election, are from ORF (https://www.ots.at/presseaussendung/OTS_20130830_OTS0092/in-summe-1314-millionenweitester-seherkreis-sahen-erstes-tv-konfrontations-doppel-im-orf). We were unable to find ratings data for debates in Canada, the Netherlands, and New Zealand.

We divided these numbers by countries' yearly population size, obtained from World Bank Open Data (https://data.worldbank.org/). On average, debates in our sample for which we have TV ratings were viewed by $22 \%$ of the population, with a minimum of $8 \%$ (for the debate held between Gordon Brown, Nick Clegg, and David Cameron in the U.K. on 22 April, 2010) and a maximum 
of 37\% (for the debate held between Richard M. Nixon and John F. Kennedy in the U.S. on 26 September, 1960).

\section{B.5 Sampling Frame}

This section provides the full list of elections, surveys, policy and belief questions, candidates and parties, and TV debates included in our analysis. 
Table B.1: List of elections by country

(a) United States

\begin{tabular}{|c|c|c|c|c|c|c|c|}
\hline Survey & Election date & Election type & Voting rule & \# days before election & $\mathrm{N}$ pre-election & $\mathrm{N}$ pre- and post-election & Post-election: median lag \\
\hline ANES 1952 & $11 / 4 / 1952$ & Governor & Plurality & 50 & 753 & 610 & 19 \\
\hline ANES 1952 & $11 / 4 / 1952$ & Lower House & Plurality & 50 & 1230 & 888 & 19 \\
\hline ANES 1952 & $11 / 4 / 1952$ & President & Plurality & 50 & 1333 & 1108 & 19 \\
\hline ANES 1952 & $11 / 4 / 1952$ & Upper House & Plurality & 50 & 934 & 694 & 19 \\
\hline ANES 1956 & $11 / 6 / 1956$ & President & Plurality & 50 & 1304 & 1155 & 21 \\
\hline ANES 1960 & $11 / 8 / 1960$ & President & Plurality & 57 & 943 & 836 & 23 \\
\hline ANES 1964 & $11 / 3 / 1964$ & President & Plurality & 57 & 1410 & 1190 & 22 \\
\hline ANES 1968 & $11 / 5 / 1968$ & President & Plurality & 60 & 1302 & 1026 & 19 \\
\hline ANES 1972 & $11 / 7 / 1972$ & President & Plurality & 67 & 2117 & 1535 & 22 \\
\hline ANES 1976 & $11 / 2 / 1976$ & President & Plurality & 46 & 1522 & 1138 & 17 \\
\hline ANES 1980 & $11 / 4 / 1980$ & President & Plurality & 90 & 1196 & 896 & 18 \\
\hline ANES 1984 & $11 / 6 / 1984$ & President & Plurality & 63 & 1807 & 1336 & 11 \\
\hline ANES 1988 & $11 / 8 / 1988$ & President & Plurality & 63 & 1615 & 1170 & 13 \\
\hline ANES 1992 & $11 / 3 / 1992$ & President & Plurality & 63 & 2040 & 1609 & 27 \\
\hline ANES 1996 & $11 / 5 / 1996$ & Lower House & Plurality & 63 & 1316 & 945 & 12 \\
\hline ANES 1996 & $11 / 5 / 1996$ & President & Plurality & 63 & 1460 & 1107 & 12 \\
\hline ANES 2000 & $11 / 7 / 2000$ & President & Plurality & 63 & 1523 & 1121 & 14 \\
\hline ANES 2004 & $11 / 2 / 2004$ & President & Plurality & 56 & 1045 & 804 & 11 \\
\hline ANES 2008 & $11 / 4 / 2008$ & President & Plurality & 63 & 1925 & 1500 & 14 \\
\hline ANES 2012 & $11 / 6 / 2012$ & Governor & Plurality & 58 & 191 & 132 & 20 \\
\hline ANES 2012 & $11 / 6 / 2012$ & Lower House & Plurality & 58 & 1312 & 1001 & 20 \\
\hline ANES 2012 & $11 / 6 / 2012$ & President & Plurality & 58 & 1631 & 1290 & 20 \\
\hline ANES 2012 & $11 / 6 / 2012$ & Upper House & Plurality & 58 & 971 & 772 & 20 \\
\hline ANES 2016 & $11 / 8 / 2016$ & Governor & Plurality & 62 & 461 & 339 & 11 \\
\hline ANES 2016 & $11 / 8 / 2016$ & Lower House & Plurality & 62 & 2988 & 2117 & 11 \\
\hline ANES 2016 & $11 / 8 / 2016$ & President & Plurality & 62 & 3589 & 2665 & 11 \\
\hline ANES 2016 & $11 / 8 / 2016$ & Upper House & Plurality & 62 & 2187 & 1469 & 11 \\
\hline NAES 2000 & $11 / 7 / 2000$ & President & Plurality & 112 & 3156 & 2765 & 15 \\
\hline NAES 2004 & $11 / 2 / 2004$ & President & Plurality & 110 & 7351 & 6771 & 26 \\
\hline NAES 2008 & $11 / 4 / 2008$ & President & Plurality & 67 & 21093 & 15777 & 27 \\
\hline
\end{tabular}




\section{(b) Canada}

\begin{tabular}{|c|c|c|c|c|c|c|c|}
\hline Survey & Election date & Election type & Voting rule & \# days before election & N pre-election & $\mathrm{N}$ pre- and post-election & Post-election: median lag \\
\hline CES 1988 & $11 / 21 / 1988$ & Lower House & Plurality & 48 & 3043 & 2125 & 24 \\
\hline CES 1992 & 10/26/1992 & Referendum & Yes/No & 32 & 1781 & 1431 & 9 \\
\hline CES 1993 & $10 / 25 / 1993$ & Lower House & Plurality & 45 & 2916 & 2347 & 12 \\
\hline CES 1997 & $6 / 2 / 1997$ & Lower House & Plurality & 36 & 2671 & 1869 & 14 \\
\hline CES 2000 & $11 / 27 / 2000$ & Lower House & Plurality & 34 & 2405 & 1606 & 19 \\
\hline CES 2004 & $6 / 28 / 2004$ & Lower House & Plurality & 36 & 2607 & 1794 & 26 \\
\hline CES 2006 & $1 / 23 / 2006$ & Lower House & Plurality & 55 & 2754 & 2120 & 14 \\
\hline CES 2008 & $10 / 14 / 2008$ & Lower House & Plurality & 18 & 2149 & 1485 & 8 \\
\hline CES 2011 & $5 / 2 / 2011$ & Lower House & Plurality & 37 & 2849 & 2126 & 16 \\
\hline CES 2015 & 10/19/2015 & Lower House & Plurality & 69 & 7606 & 4863 & 11 \\
\hline
\end{tabular}

(c) Netherlands

\begin{tabular}{|c|c|c|c|c|c|c|c|}
\hline Survey & Election date & Election type & Voting rule & \# days before election & N pre-election & N pre- and post-election & Post-election: median lag \\
\hline \hline DPES 1998 & $5 / 6 / 1998$ & Lower House & Proportional & 39 & 1771 & 1501 & 16 \\
\hline DPES 2002 & $5 / 15 / 2002$ & Lower House & Proportional & 31 & 1805 & 1468 & 12 \\
\hline DPES 2006 & $11 / 22 / 2006$ & Lower House & Proportional & 43 & 2382 & 2133 & 7 \\
\hline
\end{tabular}

\section{(d) Germany}

\begin{tabular}{|c|c|c|c|c|c|c|c|}
\hline Survey & Election date & Election type & Voting rule & \# days before election & N pre-election & N pre- and post-election & Post-election: median lag \\
\hline \hline GLES 2009 & $9 / 27 / 2009$ & Lower House - 1st vote & Plurality & 60 & 4479 & 3009 \\
\hline GLES 2009 & $9 / 27 / 2009$ & Lower House - 2nd vote & Proportional & 60 & 4531 & 3089 \\
\hline GLES 2013 & $9 / 22 / 2013$ & Lower House - 1st vote & Plurality & 76 & 6131 & 4122 \\
\hline GLES 2013 & $9 / 22 / 2013$ & Lower House - 2nd vote & Proportional & 76 & 6217 & 4211 \\
\hline GLES 2017 & $9 / 24 / 2017$ & Lower House - 1st vote & Plurality & 62 & 6185 & 8 \\
\hline GLES 2017 & $9 / 24 / 2017$ & Lower House - 2nd vote & Proportional & 62 & 6257 & 3426 \\
\hline
\end{tabular}

\section{(e) Switzerland}

\begin{tabular}{|c|c|c|c|c|c|c|c|}
\hline Survey & Election date & Election type & Voting rule & \# days before election & N pre-election & N pre- and post-election & Post-election: median lag \\
\hline \hline SELECTS 2011 & $10 / 23 / 2011$ & Lower House & Proportional & 41 & 2777 & 2214 \\
\hline SELECTS 2015 & $10 / 18 / 2015$ & Lower House & Proportional & 62 & 5094 & 4 \\
\hline
\end{tabular}

(f) Sweden

\begin{tabular}{|c|c|c|c|c|c|c|c|}
\hline Survey & Election date & Election type & Voting rule & \# days before election & N pre-election & N pre- and post-election & Post-election: median lag \\
\hline \hline SNES 2014 & $05 / 25 / 2014$ & European Parliament & Proportional & 11 & 14096 & 12565 \\
\hline SNES 2014 & $09 / 14 / 2014$ & Lower House & Proportional & 12 & 14426 & 1 \\
\hline
\end{tabular}


(g) New Zealand

\begin{tabular}{|c|c|c|c|c|c|c|c|}
\hline Survey & Election date & Election type & Voting rule & \# days before election & N pre-election & N pre- and post-election & Post-election: median lag \\
\hline \hline NZES 1996 & $10 / 12 / 1996$ & Lower House - 1st vote & Plurality & 37 & 2100 & 1925 \\
\hline NZES 1996 & $10 / 12 / 1996$ & Lower House - 2nd vote & Proportional & 37 & 2093 & 1944 \\
\hline NZES 1999 & $11 / 27 / 1999$ & Lower House - 1st vote & Plurality & 40 & 2211 & 2074 \\
\hline NZES 1999 & $11 / 27 / 1999$ & Lower House - 2nd vote & Proportional & 40 & 2217 & 2131 \\
\hline NZES 2002 & $7 / 27 / 2002$ & Lower House - 1st vote & Plurality & 36 & 2068 & 23 \\
\hline NZES 2002 & $7 / 27 / 2002$ & Lower House - 2nd vote & Proportional & 36 & 2073 & 23 \\
\hline
\end{tabular}

(h) Italy

\begin{tabular}{|c|c|c|c|c|c|c|c|}
\hline Survey & Election date & Election type & Voting rule & \# days before election & N pre-election & N pre- and post-election & Post-election: median lag \\
\hline \hline ITANES 2013 & $2 / 24 / 2013$ & Lower House & Proportional & 50 & 1658 & 1478 \\
\hline
\end{tabular}

(i) Austria

\begin{tabular}{|c|c|c|c|c|c|c|c|}
\hline Survey & Election date & Election type & Voting rule & \# days before election & $\mathrm{N}$ pre-election & $\mathrm{N}$ pre- and post-election & Post-election: median lag \\
\hline AUTNES 2013 & $9 / 29 / 2013$ & Lower House & Proportional & 55 & 2441 & 1555 & 18 \\
\hline
\end{tabular}

(j) United Kingdom

\begin{tabular}{|c|c|c|c|c|c|c|c|}
\hline Survey & Election date & Election type & Voting rule & \# days before election & N pre-election & N pre- and post-election & Post-election: median lag \\
\hline \hline BES 2001 & $6 / 7 / 2001$ & Lower House & Plurality & 30 & 2737 & 2024 \\
\hline BES 2010 & $5 / 6 / 2010$ & Lower House & Plurality & 29 & 10701 & 9004 \\
\hline BES 2015 & $5 / 7 / 2015$ & Lower House & Plurality & 38 & 25917 & 23250 \\
\hline BES 2016 & $6 / 23 / 2016$ & Referendum & Yes/No & 48 & 29175 & 3 \\
\hline
\end{tabular}

Notes: The surveys included in the study are the American National Election Studies (ANES), the National Annenberg Election Surveys (NAES), the Austrian National Election Studies (AUTNES), the British Election Studies (BES), the Canadian Election Studies (CES), the Dutch Parliamentary Election Studies (DPES), the German Longitudinal Election Studies (GLES), the Italian National Election Studies (ITANES), the Swiss Electoral Studies (SELECTS), the New Zealand Election Studies (NZES), and the Swedish National Election Studies (SNES). In New Zealand and Sweden, Lower House refers to the only house in the country's unicameral parliament. Other columns report how many days before Election Day the survey started, the number of respondents who said that they intended to vote ( $\mathrm{N}$ pre-election), and the number of respondents surveyed before and after the election who said that they intended to vote, in the first survey, and who reported that they voted and gave a vote choice declaration, in the second ( $\mathrm{N}$ pre- and post-election). We also report the median number of days separating the post-electoral survey from the election. 
Table B.2: List of surveys by country

(a) United States

\begin{tabular}{|c|c|c|c|c|c|c|c|c|c|c|}
\hline Survey & Survey mode & $\begin{array}{c}\text { RCS } \\
\text { design }\end{array}$ & $\begin{array}{l}\text { Socio- } \\
\text { demographic } \\
\text { factors }\end{array}$ & $\begin{array}{c}\text { Media } \\
\text { consumption }\end{array}$ & $\begin{array}{l}\text { Contact } \\
\text { by party }\end{array}$ & $\begin{array}{c}\text { Party } \\
\text { identification }\end{array}$ & $\begin{array}{c}\text { Political } \\
\text { discussions }\end{array}$ & $\begin{array}{c}\text { Watching } \\
\text { debates }\end{array}$ & $\begin{array}{c}\text { Self- } \\
\text { reported } \\
\text { timing } \\
\text { of } \\
\text { decision }\end{array}$ & $\begin{array}{l}\text { Survey } \\
\text { weights }\end{array}$ \\
\hline ANES 1952 & Face-to-face & No & All & None & None & Some & No & No & Yes & No \\
\hline ANES 1956 & Face-to-face & No & All & None & None & Some & No & No & Yes & No \\
\hline ANES 1960 & Face-to-face & No & All & None & None & All & No & Yes & Yes & Yes \\
\hline ANES 1964 & Face-to-face & No & All & None & None & Some & No & No & Yes & Yes \\
\hline ANES 1968 & \begin{tabular}{|c|} 
Face-to-face/ \\
Mail
\end{tabular} & No & Some & None & None & Some & No & No & Yes & Yes \\
\hline ANES 1972 & $\begin{array}{c}\text { Face-to-face/ } \\
\text { Mail }\end{array}$ & No & All & None & None & Some & No & No & Yes & No \\
\hline ANES 1976 & Face-to-face & No & All & None & None & Some & No & Yes & Yes & Yes \\
\hline ANES 1980 & Face-to-face & No & All & Some & None & All & No & Yes & Yes & No \\
\hline ANES 1984 & \begin{tabular}{|c|}
$\begin{array}{c}\text { Face-to-face/ } \\
\text { Phone }\end{array}$ \\
\end{tabular} & No & All & Some & None & All & Yes & Yes & Yes & No \\
\hline ANES 1988 & Face-to-face & No & All & Some & None & Some & Yes & No & Yes & No \\
\hline ANES 1992 & \begin{tabular}{|c|}
$\begin{array}{c}\text { Face-to-face/ } \\
\text { Phone }\end{array}$ \\
\end{tabular} & No & Some & None & None & Some & No & No & Yes & Yes \\
\hline ANES 1996 & \begin{tabular}{|c|}
$\begin{array}{c}\text { Face-to-face/ } \\
\text { Phone }\end{array}$ \\
\end{tabular} & No & All & Some & None & All & No & No & Yes & Yes \\
\hline ANES 2000 & \begin{tabular}{|c|}
$\begin{array}{c}\text { Face-to-face/ } \\
\text { Phone }\end{array}$ \\
\end{tabular} & No & All & Some & None & Some & No & Yes & Yes & Yes \\
\hline ANES 2004 & Face-to-face & No & All & Some & None & Some & No & No & Yes & Yes \\
\hline ANES 2008 & Face-to-face & No & All & Some & None & Some & No & No & No & Yes \\
\hline ANES 2012 & Face-to-face & No & All & Some & None & All & No & No & No & Yes \\
\hline ANES 2016 & \begin{tabular}{|c|} 
Face-to-face/ \\
Online
\end{tabular} & No & Some & Some & None & Some & No & No & No & Yes \\
\hline NAES 2000 & Phone & Yes & All & Some & None & All & Yes & Yes & No & No \\
\hline NAES 2004 & Phone & Yes & All & Some & None & All & Yes & Yes & Yes & No \\
\hline NAES 2008 & Phone/Online & Yes & All & Some & None & All & No & No & Yes & No \\
\hline
\end{tabular}

(b) Austria

\begin{tabular}{|c|c|c|c|c|c|c|c|c|c|}
\hline Survey & Survey mode & $\begin{array}{c}\text { RCS } \\
\text { design }\end{array}$ & $\begin{array}{c}\text { Socio- } \\
\text { demographic } \\
\text { factors }\end{array}$ & $\begin{array}{c}\text { Media } \\
\text { consumption }\end{array}$ & $\begin{array}{c}\text { Contact } \\
\text { by party }\end{array}$ & $\begin{array}{c}\text { Party } \\
\text { identification }\end{array}$ & $\begin{array}{c}\text { Political } \\
\text { discussions } \\
\text { reported } \\
\text { timing } \\
\text { of } \\
\text { decision }\end{array}$ & $\begin{array}{c}\text { Survey } \\
\text { weights } \\
\text { debates }\end{array}$ \\
\hline \hline AUTNES 2013 & Phone & Yes & All & Some & All & Some & No & No & Yes \\
\hline
\end{tabular}

(c) Netherlands

\begin{tabular}{|c|c|c|c|c|c|c|c|c|c|c|}
\hline Survey & Survey mode & $\begin{array}{c}\text { RCS } \\
\text { design }\end{array}$ & $\begin{array}{l}\text { Socio- } \\
\text { demographic } \\
\text { factors }\end{array}$ & $\begin{array}{c}\text { Media } \\
\text { consumption }\end{array}$ & $\begin{array}{l}\text { Contact } \\
\text { by party }\end{array}$ & $\begin{array}{c}\text { Party } \\
\text { identification }\end{array}$ & $\begin{array}{c}\text { Political } \\
\text { discussions }\end{array}$ & $\begin{array}{l}\text { Watching } \\
\text { debates }\end{array}$ & $\begin{array}{c}\text { Self- } \\
\text { reported } \\
\text { timing } \\
\text { of } \\
\text { decision }\end{array}$ & $\begin{array}{l}\text { Survey } \\
\text { weights }\end{array}$ \\
\hline DPES 1998 & $\begin{array}{c}\text { Face-to-face/ } \\
\text { Phone }\end{array}$ & No & All & Some & None & Some & No & Yes & Yes & Yes \\
\hline DPES 2002 & Face-to-face & No & All & Some & None & Some & No & Yes & Yes & No \\
\hline DPES 2006 & Face-to-face & No & All & Some & None & Some & No & Yes & Yes & Yes \\
\hline
\end{tabular}


(d) Canada

\begin{tabular}{|c|c|c|c|c|c|c|c|c|c|c|}
\hline Survey & Survey mode & $\begin{array}{c}\text { RCS } \\
\text { design }\end{array}$ & $\begin{array}{l}\text { Socio- } \\
\text { demographic } \\
\text { factors }\end{array}$ & $\begin{array}{c}\text { Media } \\
\text { consumption }\end{array}$ & $\begin{array}{l}\text { Contact } \\
\text { by party }\end{array}$ & $\begin{array}{c}\text { Party } \\
\text { identification }\end{array}$ & $\begin{array}{l}\text { Political } \\
\text { discussions }\end{array}$ & $\begin{array}{c}\text { Watching } \\
\text { debates }\end{array}$ & $\begin{array}{c}\text { Self- } \\
\text { reported } \\
\text { timing } \\
\text { of } \\
\text { decision } \\
\end{array}$ & $\begin{array}{l}\text { Survey } \\
\text { weights }\end{array}$ \\
\hline CES 1988 & Phone & Yes & All & Some & None & All & Yes & Yes & Yes & Yes \\
\hline CES 1992 & Phone & Yes & All & Some & None & None & No & Yes & No & Yes \\
\hline CES 1993 & Phone & Yes & All & Some & Some & All & Yes & Yes & Yes & Yes \\
\hline CES 1997 & Phone & Yes & All & Some & None & All & Yes & Yes & Yes & Yes \\
\hline CES 2000 & Phone & Yes & All & Some & All & Some & Yes & Yes & Yes & Yes \\
\hline CES 2004 & Phone & Yes & All & Some & All & All & Yes & Yes & Yes & Yes \\
\hline CES 2006 & Phone & Yes & All & All & None & All & Yes & No & Yes & Yes \\
\hline CES 2008 & Phone & Yes & All & None & None & All & No & No & Yes & Yes \\
\hline CES 2011 & Phone & Yes & All & None & None & Some & No & No & Yes & Yes \\
\hline CES 2015 & Phone/Online & Yes & All & None & None & All & No & No & Yes & Yes \\
\hline
\end{tabular}

(e) Switzerland

\begin{tabular}{|c|c|c|c|c|c|c|c|c|c|c|}
\hline Survey & Survey mode & $\begin{array}{l}\text { RCS } \\
\text { design }\end{array}$ & $\begin{array}{l}\text { Socio- } \\
\text { demographic } \\
\text { factors }\end{array}$ & $\begin{array}{c}\text { Media } \\
\text { consumption }\end{array}$ & $\begin{array}{l}\text { Contact } \\
\text { by party }\end{array}$ & $\begin{array}{c}\text { Party } \\
\text { identification }\end{array}$ & $\begin{array}{c}\text { Political } \\
\text { discussions }\end{array}$ & $\begin{array}{c}\text { Watching } \\
\text { debates }\end{array}$ & $\begin{array}{c}\text { Self- } \\
\text { reported } \\
\text { timing } \\
\text { of } \\
\text { decision }\end{array}$ & $\begin{array}{l}\text { Survey } \\
\text { weights }\end{array}$ \\
\hline SELECTS 2011 & Phone & Yes & All & Some & None & Some & Yes & No & Yes & Yes \\
\hline SELECTS 2015 & Phone & Yes & All & Some & None & Some & Yes & No & No & Yes \\
\hline
\end{tabular}

(f) Italy

\begin{tabular}{|c|c|c|c|c|c|c|c|c|c|}
\hline Survey & Survey mode & $\begin{array}{c}\text { RCS } \\
\text { design }\end{array}$ & $\begin{array}{c}\text { Socio- } \\
\text { demographic } \\
\text { factors }\end{array}$ & $\begin{array}{c}\text { Media } \\
\text { consumption }\end{array}$ & $\begin{array}{c}\text { Contact } \\
\text { by party }\end{array}$ & $\begin{array}{c}\text { Party } \\
\text { identification }\end{array}$ & $\begin{array}{c}\text { Political } \\
\text { discussions } \\
\text { reported } \\
\text { timing } \\
\text { of } \\
\text { decision }\end{array}$ & $\begin{array}{c}\text { Survey } \\
\text { weights } \\
\text { debates }\end{array}$ \\
\hline \hline ITANES 2013 & Face-to-face & Yes & Some & Some & Some & None & No & No & Yes \\
\hline
\end{tabular}

(g) New Zealand

\begin{tabular}{|c|c|c|c|c|c|c|c|c|c|c|}
\hline Survey & Survey mode & $\begin{array}{c}\text { RCS } \\
\text { design }\end{array}$ & $\begin{array}{l}\text { Socio- } \\
\text { demographic } \\
\text { factors }\end{array}$ & $\begin{array}{c}\text { Media } \\
\text { consumption }\end{array}$ & $\begin{array}{l}\text { Contact } \\
\text { by party }\end{array}$ & $\begin{array}{c}\text { Party } \\
\text { identification }\end{array}$ & $\begin{array}{c}\text { Political } \\
\text { discussions }\end{array}$ & $\begin{array}{c}\text { Watching } \\
\text { debates }\end{array}$ & $\begin{array}{c}\text { Self- } \\
\text { reported } \\
\text { timing } \\
\text { of } \\
\text { decision }\end{array}$ & $\begin{array}{l}\text { Survey } \\
\text { weights }\end{array}$ \\
\hline NZES 1996 & Phone/Mail & Yes & All & None & None & Some & No & No & Yes & Yes \\
\hline NZES 1999 & Phone & Yes & All & Some & Some & All & No & No & Yes & Yes \\
\hline NZES 2002 & Phone & No & All & Some & None & All & Yes & No & Yes & Yes \\
\hline
\end{tabular}

(h) Sweden

\begin{tabular}{|c|c|c|c|c|c|c|c|c|c|c|}
\hline Survey & Survey mode & $\begin{array}{c}\text { RCS } \\
\text { design }\end{array}$ & $\begin{array}{l}\text { Socio- } \\
\text { demographic } \\
\text { factors }\end{array}$ & $\begin{array}{c}\text { Media } \\
\text { consumption }\end{array}$ & $\begin{array}{l}\text { Contact } \\
\text { by party }\end{array}$ & $\begin{array}{c}\text { Party } \\
\text { identification }\end{array}$ & $\begin{array}{c}\text { Political } \\
\text { discussions }\end{array}$ & $\begin{array}{c}\text { Watching } \\
\text { debates }\end{array}$ & $\begin{array}{c}\text { Self- } \\
\text { reported } \\
\text { timing } \\
\text { of } \\
\text { decision } \\
\end{array}$ & $\begin{array}{l}\text { Survey } \\
\text { weights }\end{array}$ \\
\hline SNES 2014 & Online & No & All & None & None & Some & No & No & Yes & No \\
\hline SNES 2014 & Online & No & All & None & All & None & No & Yes & Yes & No \\
\hline
\end{tabular}


(i) Germany

\begin{tabular}{|c|c|c|c|c|c|c|c|c|c|c|}
\hline Survey & Survey mode & $\begin{array}{l}\text { RCS } \\
\text { design }\end{array}$ & $\begin{array}{l}\text { Socio- } \\
\text { demographic } \\
\text { factors }\end{array}$ & $\begin{array}{c}\text { Media } \\
\text { consumption }\end{array}$ & $\begin{array}{l}\text { Contact } \\
\text { by party }\end{array}$ & $\begin{array}{c}\text { Party } \\
\text { identification }\end{array}$ & $\begin{array}{l}\text { Political } \\
\text { discussions }\end{array}$ & $\begin{array}{c}\text { Watching } \\
\text { debates }\end{array}$ & $\begin{array}{c}\text { Self- } \\
\text { reported } \\
\text { timing } \\
\text { of } \\
\text { decision } \\
\end{array}$ & $\begin{array}{l}\text { Survey } \\
\text { weights }\end{array}$ \\
\hline GLES 2009 & Phone & Yes & Some & Some & Some & All & Yes & Yes & Yes & Yes \\
\hline GLES 2013 & Phone & Yes & Some & Some & Some & All & Yes & Yes & Yes & Yes \\
\hline GLES 2017 & Phone & Yes & Some & Some & Some & All & Yes & Yes & Yes & Yes \\
\hline
\end{tabular}

(j) United Kingdom

\begin{tabular}{|c|c|c|c|c|c|c|c|c|c|c|}
\hline Survey & Survey mode & $\begin{array}{l}\text { RCS } \\
\text { design }\end{array}$ & $\begin{array}{l}\text { Socio- } \\
\text { demographic } \\
\text { factors }\end{array}$ & $\begin{array}{c}\text { Media } \\
\text { consumption }\end{array}$ & $\begin{array}{l}\text { Contact } \\
\text { by party }\end{array}$ & $\begin{array}{c}\text { Party } \\
\text { identification }\end{array}$ & $\begin{array}{c}\text { Political } \\
\text { discussions }\end{array}$ & $\begin{array}{l}\text { Watching } \\
\text { debates }\end{array}$ & $\begin{array}{c}\text { Self- } \\
\text { reported } \\
\text { timing } \\
\text { of } \\
\text { decision }\end{array}$ & $\begin{array}{l}\text { Survey } \\
\text { weights }\end{array}$ \\
\hline BES 2001 & Phone & Yes & Some & Some & None & All & No & No & No & Yes \\
\hline BES 2010 & Online & Yes & Some & None & All & All & No & No & Yes & Yes \\
\hline BES 2015 & Online & Yes & All & Some & All & All & Yes & No & No & Yes \\
\hline BES 2016 & Online & Yes & All & Some & All & Some & Yes & No & No & Yes \\
\hline
\end{tabular}

Notes: For each survey included in the study, we indicate: which survey mode was used; whether the survey is a rolling cross-section; whether all, some, or none of the selected sociodemographic factors and variables on media consumption, contact by a party, and the respondent's propensity to discuss politics with others are available in the pre-electoral survey; whether all, some, or none of the variables indicating which party the respondent identifies with and the strength of their party identification are available either in the pre-electoral or post-electoral survey; whether information on watching TV debates and self-reported timing of vote decision is available in the post-electoral survey; and whether survey weights are available in the pre-electoral survey. Other notes as in Appendix Table B.1. 


\section{Table B.3: List of policy questions by country}

(a) Sweden

\begin{tabular}{|c|c|l|}
\hline Survey & Year & Question \\
\hline \hline SNES & 2014 & $\begin{array}{l}\text { What is your opinion on the following proposal that has appeared in the political debate: introducing a } \\
\text { grade in order and behavior at school? }\end{array}$ \\
\hline
\end{tabular}

(b) United Kingdom

\begin{tabular}{|c|c|l|}
\hline Survey & Year & Question \\
\hline \hline BES & 2001 & $\begin{array}{l}\text { Thinking of the Single European Currency, which of the following statements on this card would come } \\
\text { closest to your own view? }\end{array}$ \\
\hline BES & 2016 & $\begin{array}{l}\text { Some people feel that Britain should do all it can to unite fully with the European Union. Other people feel } \\
\text { that Britain should do all it can to protect its independence from the European Union. Where would you } \\
\text { place yourself on this scale? }\end{array}$ \\
\hline BES & 2016 & $\begin{array}{l}\text { Some people think that the UK should allow many more immigrants to come to the UK to live and others } \\
\text { think that the UK should allow many fewer immigrants. Where would you place yourself on this scale? }\end{array}$ \\
\hline BES & 2016 & In politics people sometimes talk of left and right. Where would you place yourself on the following scale? \\
\hline
\end{tabular}


(c) United States

\begin{tabular}{|c|c|c|}
\hline Survey & Year & Question \\
\hline ANES & 1972 & $\begin{array}{l}\text { Some people believe a change in our whole form of government is needed to solve the problems facing our } \\
\text { country, while others feel no real change is necessary. Do you think a big change is needed in our form of } \\
\text { government, or should it be kept pretty much as it is? }\end{array}$ \\
\hline ANES & 1976 & $\begin{array}{l}\text { Some people feel that the government in Washington should see to it that every person has a job and a } \\
\text { good standard of living. Suppose that these people are at one end of this scale - at point number 1. Others } \\
\text { think the government should just let each person get ahead on his own. Suppose that these people are at } \\
\text { the other end -- at point number 7. And, of course, some other people have opinions in between. Where } \\
\text { would you place yourself on this scale, or haven't you thought much about this? }\end{array}$ \\
\hline NAES & 2004 & Making recent federal tax cuts permanent - do you favor or oppose this? \\
\hline NAES & 2004 & Do you favor or oppose increasing the $\$ 5.15$ minimum wage employers now must pay their workers? \\
\hline NAES & 2004 & $\begin{array}{l}\text { As far as you know, has the No Child Left Behind education law made American public schools much } \\
\text { better, somewhat better, somewhat worse, much worse, or hasn't it made a difference? }\end{array}$ \\
\hline NAES & 2004 & The federal government helping to pay for health insurance for all children - do you favor or oppose this? \\
\hline NAES & 2004 & $\begin{array}{l}\text { The federal government helping employers pay the cost of their workers' health insurance - do you favor } \\
\text { or oppose this? }\end{array}$ \\
\hline NAES & 2004 & $\begin{array}{l}\text { Who do you think will benefit more from the new Medicare prescription drug plan - seniors on Medicare } \\
\text { or the drug manufacturers? }\end{array}$ \\
\hline NAES & 2004 & $\begin{array}{l}\text { Changing the recently passed Medicare prescription drug law to allow re-importing drugs from Canada - } \\
\text { do you favor or oppose this? }\end{array}$ \\
\hline NAES & 2004 & $\begin{array}{l}\text { Do you favor or oppose allowing workers to invest some of their Social Security contributions in the stock } \\
\text { market? }\end{array}$ \\
\hline NAES & 2004 & $\begin{array}{l}\text { Do you think the US should keep military troops in Iraq until a stable government is established there, or } \\
\text { do you think the U.S. should bring its troops home as soon as possible? }\end{array}$ \\
\hline NAES & 2004 & Laws making it more difficult for a woman to get an abortion - do you favor or oppose this? \\
\hline NAES & 2004 & $\begin{array}{l}\text { Making additional stem cell lines from human embryos available for federally funded research on diseases } \\
\text { like Parkinson's - do you favor or oppose this? }\end{array}$ \\
\hline NAES & 2004 & $\begin{array}{l}\text { Would you favor or oppose an amendment to the U.S. Constitution saying that no state can allow two men } \\
\text { to marry each other or two women to marry each other? }\end{array}$ \\
\hline NAES & 2004 & Extending the federal law banning assault weapons - do you favor or oppose this? \\
\hline NAES & 2004 & $\begin{array}{l}\text { The government placing limits on how much people could collect when a jury finds that a doctor has } \\
\text { committed medical malpractice - do you favor or oppose this? }\end{array}$ \\
\hline
\end{tabular}


(d) United States (cont.)

\begin{tabular}{|c|c|c|}
\hline Survey & Year & Question \\
\hline NAES & 2008 & $\begin{array}{l}\text { I'm going to read you some options about federal income taxes. Please tell me which one comes closest to } \\
\text { your view on what we should be doing about federal income taxes: Taxes should be cut. Taxes should be } \\
\text { kept pretty much as they are. Taxes should be raised if necessary in order to maintain current federal } \\
\text { programs and services. }\end{array}$ \\
\hline NAES & 2008 & $\begin{array}{l}\text { Do you favor or oppose the federal government in Washington negotiating more free trade agreements like } \\
\text { NAFTA? }\end{array}$ \\
\hline NAES & 2008 & $\begin{array}{l}\text { I'm going to read you some plans for United States policy in Iraq. Please tell me which one comes closest } \\
\text { to your own position: The US should withdraw all troops from Iraq as soon as possible. The US should set } \\
\text { a deadline for withdrawing its troops if the Iraqi government doesn't show definite progress. The US } \\
\text { should keep its troops in Iraq until a stable government is established. }\end{array}$ \\
\hline NAES & 2008 & All in all, do you think the situation in Iraq was worth going to war over, or not? \\
\hline NAES & 2008 & $\begin{array}{l}\text { I'm going to read you a proposal some have made regarding immigration. Please tell me whether you } \\
\text { strongly favor, somewhat favor, somewhat oppose, or strongly oppose it: provide a path to citizenship for } \\
\text { some illegal aliens who agree to return to their home country for a period of time and pay substantial fines. }\end{array}$ \\
\hline NAES & 2008 & $\begin{array}{l}\text { I'm going to read you a proposal some have made regarding immigration. Please tell me whether you } \\
\text { strongly favor, somewhat favor, somewhat oppose, or strongly oppose it: increase border security by } \\
\text { building a fence along part of the US border with Mexico. }\end{array}$ \\
\hline NAES & 2008 & $\begin{array}{l}\text { Please tell me which of the following statements about abortion comes closest to your own view: Abortion } \\
\text { should be available to anyone who wants it. Abortion should be available, but with stricter limits than it is } \\
\text { now. Abortion should not be permitted except in cases of rape, incest, or when the life of the woman is at } \\
\text { risk. Abortion should not be permitted under any circumstances. }\end{array}$ \\
\hline NAES & 2008 & $\begin{array}{l}\text { There has been much talk recently about whether gays and lesbians should have the legal right to marry } \\
\text { someone of the same sex. Which of the following options comes closest to your position on this issue? I } \\
\text { support full marriage rights for gay and lesbian couples. I support civil unions or domestic partnerships, } \\
\text { but not gay marriage. I do not support any form of legal recognition of the relationships of gay and lesbian } \\
\text { couples. }\end{array}$ \\
\hline
\end{tabular}

\section{(e) Germany}

\begin{tabular}{|c|l|l|}
\hline Survey & Year & Question \\
\hline \hline GLES & 2009 & $\begin{array}{l}\text { Some people would like to see lower taxes even if that means some reduction in health, education and } \\
\text { social benefits; others would like to see more government spending on health, education and social } \\
\text { benefits even if it means some increases in taxes. How would you describe your own views on this issue? }\end{array}$ \\
\hline GLES & 2009 & $\begin{array}{l}\text { How would you describe your views on the issue of nuclear energy? Should more nuclear power stations } \\
\text { be built or should all nuclear power stations be closed down today? }\end{array}$ \\
\hline GLES & 2009 & $\begin{array}{l}\text { To what extent do you agree with the statement: "The German Armed Forces should be pulled out of } \\
\text { Afghanistan immediately"? }\end{array}$ \\
\hline
\end{tabular}


(f) Germany (cont.)

\begin{tabular}{|c|l|l|}
\hline Survey & Year & Question \\
\hline \hline GLES & 2013 & $\begin{array}{l}\text { And what do you think of the following statements: "Immigrants should be obliged to assimilate into the } \\
\text { German culture"? }\end{array}$ \\
\hline GLES & 2013 & $\begin{array}{l}\text { And what do you think of the following statements: "The government should take measures to reduce the } \\
\text { discrepancies in income"? }\end{array}$ \\
\hline GLES & 2013 & $\begin{array}{l}\text { And what do you think of the following statements: "In times of the European debt crisis, Germany should } \\
\text { provide financial support for the EU member states with financial and economic difficulties"? }\end{array}$ \\
\hline GLES & 2017 & $\begin{array}{l}\text { And what do you think of the following statements: "The government should take measures to reduce } \\
\text { discrepancies in income"? }\end{array}$ \\
\hline GLES & 2017 & $\begin{array}{l}\text { And what do you think of the following statements: "Germany should provide financial support for EU } \\
\text { member states experiencing financial and economic difficulties"? }\end{array}$ \\
\hline
\end{tabular}

(g) Canada

\begin{tabular}{|c|l|l|}
\hline Survey & Year & Question \\
\hline \hline CES & 1988 & $\begin{array}{l}\text { Now we would like to get your views on abortion. We know that this is a sensitive question. Of the } \\
\text { following three positions, which is closest to your own opinion: abortion should never be permitted or } \\
\text { should be a matter of the woman's personal choice? }\end{array}$ \\
\hline CES & 1988 & $\begin{array}{l}\text { Now I would like to ask you about the Meech Lake Accord, reached by the federal and provincial } \\
\text { governments. Do you support the accord or oppose it? }\end{array}$ \\
\hline CES & 1988 & $\begin{array}{l}\text { As we have already mentioned, the government has made a number of changes to the tax system. On the } \\
\text { whole, do you support or oppose these changes? }\end{array}$ \\
\hline CES & 1992 & $\begin{array}{l}\text { Do you agree or disagree with the proposal to recognize the right of Canada's aboriginal peoples to govern } \\
\text { themselves? }\end{array}$ \\
\hline CES & 1992 & $\begin{array}{l}\text { Quebec has been guaranteed one quarter of the seats in the House of Commons. Do you agree or disagree } \\
\text { with this proposal? }\end{array}$ \\
\hline CES & 1992 & $\begin{array}{l}\text { If you had to choose, should each province have an equal number of Senators or should bigger provinces } \\
\text { have more Senators? }\end{array}$ \\
\hline CES & 1992 & Does the agreement give the Senate too much, too little, or about the right amount of power? \\
\hline
\end{tabular}

Notes: We report the exact wording of all policy questions included in the study, based on the survey codebooks. These questions were asked using the same wording and proposed the same range of answers in the pre- and post-electoral surveys. Other notes as in Appendix Table B.1. 


\section{Table B.4: List of belief questions by country}

\section{(a) Germany}

\begin{tabular}{|c|c|c|}
\hline Survey & Year & Question \\
\hline GLES & 2009 & And which political party do you think is best able to solve the issue you find most important? \\
\hline GLES & 2009 & $\begin{array}{l}\text { In your view, using a scale from } 1 \text { to } 11 \text {, what is the position of the CDU on this socioeconomic } \\
\text { dimension? }\end{array}$ \\
\hline GLES & 2009 & In your view, using a scale from 1 to 11 , what is the position of the SPD on this socioeconomic dimension? \\
\hline GLES & 2009 & In your view, using a scale from 1 to 11 , what is the position of the FDP on this socioeconomic dimension? \\
\hline GLES & 2009 & $\begin{array}{l}\text { In your view, using a scale from } 1 \text { to } 11 \text {, what is the position of the Green Party on this socioeconomic } \\
\text { dimension? }\end{array}$ \\
\hline GLES & 2009 & $\begin{array}{l}\text { In your view, using a scale from } 1 \text { to } 11 \text {, what is the position of the Die Linke on this socioeconomic } \\
\text { dimension? }\end{array}$ \\
\hline GLES & 2009 & In your view, what is the position of the CDU on the use of nuclear energy? \\
\hline GLES & 2009 & In your view, what is the position of the SPD on the use of nuclear energy? \\
\hline GLES & 2009 & In your view, what is the position of the FDP on the use of nuclear energy? \\
\hline GLES & 2009 & In your view, what is the position of the Green Party on the use of nuclear energy? \\
\hline GLES & 2009 & In your view, what is the position of Die Linke on the use of nuclear energy? \\
\hline GLES & 2013 & And which political party do you think is best able to solve the issue you find most important? \\
\hline GLES & 2017 & And which political party do you think is best able to solve the issue you find most important? \\
\hline
\end{tabular}

\section{(b) United States}

\begin{tabular}{|c|c|l|}
\hline Survey & Year & Question \\
\hline \hline \multirow{2}{*}{ ANES } & 1976 & $\begin{array}{l}\text { Some people feel that the government in Washington should see to it that every person has a job and a } \\
\text { good standard of living. Suppose that these people are at one end of this scale - at point number 1. Others } \\
\text { think the government should just let each person get ahead on his own. Suppose that these people are at } \\
\text { the other end - at point number 7. And, of course, some other people have opinions in between. Where } \\
\text { would you place the Democratic Party on this scale? }\end{array}$ \\
\hline ANES & 1976 & Where would you place the Republican Party on this scale? \\
\hline ANES & 1976 & Where would you place Gerard Ford on this scale? \\
\hline ANES & 1976 & Where would you place Jimmy Carter on this scale? \\
\hline
\end{tabular}


(c) United States (cont.)

\begin{tabular}{|c|c|c|}
\hline Survey & Year & Question \\
\hline NAES & 2004 & $\begin{array}{l}\text { To the best of your knowledge, who favors making the recent tax cuts permanent - George W. Bush, John } \\
\text { Kerry, both, or neither? }\end{array}$ \\
\hline NAES & 2004 & $\begin{array}{l}\text { To the best of your knowledge, who favors eliminating tax breaks for overseas profits of American } \\
\text { corporations and using the money to cut corporate income taxes - George W. Bush, John Kerry, both, or } \\
\text { neither? }\end{array}$ \\
\hline NAES & 2004 & $\begin{array}{l}\text { To the best of your knowledge, which candidate favors increasing the } \$ 5.15 \text { minimum wage employers } \\
\text { must pay their workers - George W. Bush, John Kerry, both, or neither? }\end{array}$ \\
\hline NAES & 2004 & $\begin{array}{l}\text { To the best of your knowledge, who favors the federal government helping to pay for health insurance for } \\
\text { all children and helping employers pay the cost of the workers' health insurance - George W. Bush, John } \\
\text { Kerry, both, or neither? }\end{array}$ \\
\hline NAES & 2004 & $\begin{array}{l}\text { To the best of your knowledge, who favors changing the recently passed Medicare prescription drug law to } \\
\text { allow re-importing drugs from Canada - George W. Bush, John Kerry, both, or neither? }\end{array}$ \\
\hline NAES & 2004 & $\begin{array}{l}\text { To the best of your knowledge, which candidate favors allowing the federal government to negotiate with } \\
\text { drug companies for lower prescription drug prices for senior citizens - George W. Bush, John Kerry, both, } \\
\text { or neither? }\end{array}$ \\
\hline NAES & 2004 & $\begin{array}{l}\text { To the best of your knowledge, who favors allowing workers to invest some of their Social Security } \\
\text { contributions in the stock market - George W. Bush, John Kerry, both, or neither? }\end{array}$ \\
\hline NAES & 2004 & $\begin{array}{l}\text { To the best of your knowledge, who favors reinstating the military draft - George W. Bush, John Kerry, } \\
\text { both, or neither? }\end{array}$ \\
\hline NAES & 2004 & $\begin{array}{l}\text { To the best of your knowledge, who favors laws making it more difficult for a woman to get an abortion - } \\
\text { George W. Bush, John Kerry, both, or neither? }\end{array}$ \\
\hline NAES & 2004 & $\begin{array}{l}\text { To the best of your knowledge, which candidate wants to make additional stem cell lines from human } \\
\text { embryos available for federally funded research on diseases like Parkinson's - George W. Bush, John } \\
\text { Kerry, both, or neither? }\end{array}$ \\
\hline NAES & 2004 & $\begin{array}{l}\text { To the best of your knowledge, who urges Congress to extend the federal law banning assault weapons - } \\
\text { George W. Bush, John Kerry, both, or neither? }\end{array}$ \\
\hline NAES & 2004 & $\begin{array}{l}\text { To the best of your knowledge, which candidate favors placing limits on how much people can collect } \\
\text { when a jury finds that a doctor has committed medical malpractice - George W. Bush, John Kerry, both, or } \\
\text { neither? }\end{array}$ \\
\hline NAES & 2004 & To the best of your knowledge, who is a former prosecutor - George W. Bush, John Kerry, both, or neither? \\
\hline
\end{tabular}

\section{(d) Switzerland}

\begin{tabular}{|c|c|l|}
\hline Survey & Year & Question \\
\hline \hline SELECTS & 2011 & In your opinion, which party is the best qualified to resolve the issue you find the most important? \\
\hline
\end{tabular}


(e) United Kingdom

\begin{tabular}{|c|c|c|}
\hline Survey & Year & Question \\
\hline BES & 2010 & Which party is best able to handle the issue you find the most important? \\
\hline BES & 2010 & How well do you think the Labour government has handled Britain's education system? \\
\hline BES & 2010 & How well do you think the Labour government has handled immigration? \\
\hline BES & 2010 & How well do you think the Labour government has handled the National Health Service? \\
\hline BES & 2010 & How well do you think the Labour government has handled the current financial crisis? \\
\hline BES & 2010 & How well do you think the Labour government has handled the economy in general? \\
\hline BES & 2010 & How well do you think the Labour government has handled the level of taxation? \\
\hline BES & 2015 & Which party is best able to handle the issue you find the most important? \\
\hline BES & 2015 & How well do you think Conservatives are able to handle the single most important issue facing the country? \\
\hline BES & 2015 & What about the Labour Party? \\
\hline BES & 2015 & What about the Liberal Democrats? \\
\hline BES & 2015 & What about UKIP? \\
\hline BES & 2015 & What about the Green Party? \\
\hline BES & 2016 & $\begin{array}{l}\text { Some people think that the UK should allow many more immigrants to come to the UK to live and others } \\
\text { think that the UK should allow many fewer immigrants. Where would you place the Conservative party on } \\
\text { this scale? }\end{array}$ \\
\hline BES & 2016 & And where would you place the Labor party on this scale? \\
\hline BES & 2016 & And where would you place the Liberal Democrats on this scale? \\
\hline BES & 2016 & And where would you place the SNP on this scale? \\
\hline BES & 2016 & And where would you place Plaid Cymru on this scale? \\
\hline BES & 2016 & And where would you place UKIP on this scale? \\
\hline BES & 2016 & And where would you place the Greens on this scale? \\
\hline BES & 2016 & $\begin{array}{l}\text { Some people feel that Britain should do all it can to unite fully with the European Union. Other people feel } \\
\text { that Britain should do all it can to protect its independence from the European Union. Where would you } \\
\text { place the Conservative Party on this scale? }\end{array}$ \\
\hline BES & 2016 & And where would you place the Labour party on this scale? \\
\hline BES & 2016 & And where would you place the Liberal Democrats on this scale? \\
\hline BES & 2016 & And where would you place SNP on this scale? \\
\hline BES & 2016 & And where would you place Plaid Cymru on this scale? \\
\hline BES & 2016 & And where would you place UKIP on this scale? \\
\hline BES & 2016 & And where would you place the Greens on this scale? \\
\hline
\end{tabular}


(f) Canada

\begin{tabular}{|c|c|l|}
\hline Survey & Year & Question \\
\hline \hline CES & 2004 & Do you happen to recall which party is promising to get rid of the gun registry? \\
\hline CES & 2004 & Which party is promising to do away with the Federal Sales Tax on family essentials? \\
\hline CES & 2004 & Which party is promising to increase military spending by 2 billion dollars each year? \\
\hline CES & 2004 & Which party is promising to spend 250 million for fighting AIDS in poor countries? \\
\hline CES & 2004 & $\begin{array}{l}\text { Do you happen to recall which party is promising to spend } 4 \text { billion dollars to reduce waiting times for } \\
\text { surgeries? }\end{array}$ \\
\hline CES & 2004 & Which party is promising an inheritance tax on estates over 1 million dollars? \\
\hline
\end{tabular}

(g) Austria

\begin{tabular}{|c|l|l|}
\hline Survey & Year & Question \\
\hline \hline AUTNES & 2013 & Party best able to handle the issue you find the most important? \\
\hline AUTNES & 2013 & Party with best proposals: financial and euro crisis? \\
\hline AUTNES & 2013 & Party with best proposals: education? \\
\hline AUTNES & 2013 & Party with best proposals: unemployment? \\
\hline AUTNES & 2013 & Party with best proposals: immigration? \\
\hline AUTNES & 2013 & Party with best proposals: fighting corruption? \\
\hline AUTNES & 2013 & Party with most statements: financial and euro crisis? \\
\hline AUTNES & 2013 & Party with most statements: education? \\
\hline AUTNES & 2013 & Party with most statements: unemployment? \\
\hline AUTNES & 2013 & Party with most statements: immigration? \\
\hline AUTNES & 2013 & Party with most statements: fighting corruption? \\
\hline
\end{tabular}

Notes: We report the exact wording of all belief questions included in the study, based on the survey codebooks. These questions were asked using the same wording and proposed the same list of answers in the pre- and post-electoral surveys. Other notes as in Appendix Table B.1. 
Table B.5: List of candidates and parties by country

(a) United States 1952-1992

\begin{tabular}{|c|c|c|c|c|c|}
\hline Election date & Election type & Candidate & Incumbent & Small & $\mathrm{New}$ \\
\hline 4-Nov-52 & Governor & Democratic Party & N/A & No & No \\
\hline 4-Nov-52 & Governor & Republican Party & N/A & No & No \\
\hline 4-Nov-52 & Lower House & Democratic Party & Yes & No & No \\
\hline 4-Nov-52 & Lower House & Republican Party & No & No & No \\
\hline 4-Nov-52 & President & Adlai Stevenson & Yes & No & No \\
\hline 4-Nov-52 & President & Dwight D. Eisenhower & No & No & No \\
\hline 4-Nov-52 & Upper House & Democratic Party & Yes & No & No \\
\hline 4-Nov-52 & Upper House & Republican Party & No & No & No \\
\hline 6-Nov-56 & President & Adlai Stevenson & No & No & No \\
\hline 6-Nov-56 & President & Dwight D. Eisenhower & Yes & No & No \\
\hline 8-Nov-60 & President & John F. Kennedy & No & No & No \\
\hline 8-Nov-60 & President & Richard Nixon & Yes & No & No \\
\hline 3-Nov-64 & President & Lyndon B. Johnson & Yes & No & No \\
\hline 3-Nov-64 & President & Barry Goldwater & No & Yes & No \\
\hline 5-Nov-68 & President & Hubert Humphrey & Yes & No & No \\
\hline 5-Nov-68 & President & Richard Nixon & No & No & No \\
\hline 5-Nov-68 & President & George Wallace & No & Yes & No \\
\hline 7-Nov-72 & President & George McGovern & No & No & No \\
\hline 7-Nov-72 & President & Richard Nixon & Yes & No & No \\
\hline 7-Nov-72 & President & John G. Schmitz & No & Yes & No \\
\hline 2-Nov-76 & President & Jimmy Carter & No & No & No \\
\hline 2-Nov-76 & President & Gerald Ford & Yes & No & No \\
\hline 2-Nov-76 & President & Eugene McCarthy & No & Yes & No \\
\hline 2-Nov-76 & President & Lester Maddox & No & Yes & No \\
\hline 4-Nov-80 & President & Jimmy Carter & Yes & No & No \\
\hline 4-Nov-80 & President & Ronald Reagan & No & No & No \\
\hline 4-Nov-80 & President & John B. Anderson & No & Yes & No \\
\hline 6-Nov-84 & President & Walter Mondale & No & No & No \\
\hline 6-Nov-84 & President & Ronald Reagan & Yes & No & No \\
\hline 8-Nov-88 & President & Michael Dukakis & No & No & No \\
\hline 8-Nov-88 & President & George Bush & Yes & No & No \\
\hline 3-Nov-92 & President & George Bush & Yes & No & No \\
\hline 3-Nov-92 & President & Bill Clinton & No & No & No \\
\hline 3-Nov-92 & President & Ross Perot & No & Yes & No \\
\hline
\end{tabular}


(b) United States 1996-2016

\begin{tabular}{|c|c|c|c|c|c|}
\hline Election date & Election type & Candidate & Incumbent & Small & New \\
\hline 5-Nov-96 & Lower House & Democratic Party & No & No & No \\
\hline 5-Nov-96 & Lower House & Republican Party & Yes & No & No \\
\hline 5-Nov-96 & President & Bill Clinton & Yes & No & No \\
\hline 5-Nov-96 & President & Bob Dole & No & No & No \\
\hline 5-Nov-96 & President & Ross Perot & No & Yes & Yes \\
\hline 7-Nov-00 & President & Al Gore & Yes & No & No \\
\hline 7-Nov-00 & President & George W. Bush & No & No & No \\
\hline 7-Nov-00 & President & Pat Buchanan & No & Yes & No \\
\hline 7-Nov-00 & President & Ralph Nader & No & Yes & No \\
\hline 2-Nov-04 & President & John Kerry & No & No & No \\
\hline 2-Nov-04 & President & George W. Bush & Yes & No & No \\
\hline 2-Nov-04 & President & Ralph Nader & No & Yes & No \\
\hline 4-Nov-08 & President & Barack Obama & No & No & No \\
\hline 4-Nov-08 & President & Bob Barr & No & Yes & No \\
\hline 4-Nov-08 & President & John McCain & Yes & No & No \\
\hline 4-Nov-08 & President & Ralph Nader & No & Yes & No \\
\hline 6-Nov-12 & Governor & Democratic Party & Varies by state & No & No \\
\hline 6-Nov-12 & Governor & Republican Party & Varies by state & No & No \\
\hline 6-Nov-12 & Lower House & Democratic Party & No & No & No \\
\hline 6-Nov-12 & Lower House & Republican Party & Yes & No & No \\
\hline 6-Nov-12 & Lower House & Independent(s) & No & Yes & No \\
\hline 6-Nov-12 & President & Barack Obama & Yes & No & No \\
\hline 6-Nov-12 & President & Mitt Romney & No & No & No \\
\hline 6-Nov-12 & Upper House & Democratic Party & Yes & No & No \\
\hline 6-Nov-12 & Upper House & Republican Party & No & No & No \\
\hline 8-Nov-16 & Governor & Democratic Party & Varies by state & No & No \\
\hline $8-N o v-16$ & Governor & Republican Party & Varies by state & No & No \\
\hline 8-Nov-16 & Lower House & Democratic Party & No & No & No \\
\hline 8-Nov-16 & Lower House & Republican Party & Yes & No & No \\
\hline 8-Nov-16 & President & Hillary Clinton & Yes & No & No \\
\hline 8-Nov-16 & President & Donald Trump & No & No & No \\
\hline 8-Nov-16 & President & Gary Johnson & No & Yes & No \\
\hline 8-Nov-16 & President & Jill Stein & No & Yes & No \\
\hline 8-Nov-16 & Upper House & Democratic Party & No & No & No \\
\hline 8-Nov-16 & Upper House & Republican Party & Yes & No & No \\
\hline
\end{tabular}


(c) United Kingdom

\begin{tabular}{|c|c|c|c|c|c|}
\hline Election date & Election type & Candidate & Incumbent & Small & New \\
\hline 7-Jun-01 & Lower House & Conservative Party & No & No & No \\
\hline 7-Jun-01 & Lower House & Green Party & No & Yes & No \\
\hline 7-Jun-01 & Lower House & Labour Party & Yes & No & No \\
\hline 7-Jun-01 & Lower House & Liberal Democrat & No & Yes & No \\
\hline 7-Jun-01 & Lower House & Plaid Cymru & No & Yes & No \\
\hline 7-Jun-01 & Lower House & Scottish National Party & No & Yes & No \\
\hline 6-May-10 & Lower House & British National Party & No & Yes & No \\
\hline 6-May-10 & Lower House & Conservative Party & No & No & No \\
\hline 6-May-10 & Lower House & Green Party & No & Yes & No \\
\hline 6-May-10 & Lower House & Labour Party & Yes & No & No \\
\hline 6-May-10 & Lower House & Liberal Democrat & No & No & No \\
\hline 6-May-10 & Lower House & Plaid Cymru & No & Yes & No \\
\hline 6-May-10 & Lower House & Scottish National Party & No & Yes & No \\
\hline 6-May-10 & Lower House & United Kingdom Independence Party & No & Yes & No \\
\hline 7-May-15 & Lower House & British National Party & No & Yes & No \\
\hline 7-May-15 & Lower House & Conservative Party & Yes & No & No \\
\hline 7-May-15 & Lower House & Green Party & No & Yes & No \\
\hline 7-May-15 & Lower House & Labour Party & No & No & No \\
\hline 7-May-15 & Lower House & Liberal Democrat & No & Yes & No \\
\hline 7-May-15 & Lower House & Plaid Cymru & No & Yes & No \\
\hline 7-May-15 & Lower House & Scottish National Party & No & Yes & No \\
\hline 7-May-15 & Lower House & United Kingdom Independence Party & No & No & No \\
\hline 23-Jun-16 & Referendum & Leave the EU & N/A & N/A & N/A \\
\hline 23-Jun-16 & Referendum & Stay/Remain in the EU & N/A & N/A & N/A \\
\hline
\end{tabular}

(d) Austria

\begin{tabular}{|c|c|c|c|c|c|}
\hline Election date & Election type & Candidate & Incumbent & Small & New \\
\hline 29-Sep-13 & Lower House & Alliance for the Future of Austria & No & Yes & No \\
\hline 29-Sep-13 & Lower House & Freedom Party in Carinthia & No & Yes & No \\
\hline 29-Sep-13 & Lower House & Freedom Party & No & No & No \\
\hline 29-Sep-13 & Lower House & Communist Party & No & Yes & No \\
\hline 29-Sep-13 & Lower House & The New Austria and Liberal Forum & No & Yes & Yes \\
\hline 29-Sep-13 & Lower House & Austrian People's Party & No & No & No \\
\hline 29-Sep-13 & Lower House & Pirate Party & No & Yes & Yes \\
\hline 29-Sep-13 & Lower House & Social Democratic Party & Yes & No & No \\
\hline 29-Sep-13 & Lower House & Team Stronach & No & Yes & Yes \\
\hline 29-Sep-13 & Lower House & The Greens - The Green Alternative & No & No & No \\
\hline
\end{tabular}


(e) Italy

\begin{tabular}{|c|c|c|c|c|c|}
\hline Election date & Election type & Candidate & Incumbent & Small & New \\
\hline \hline $24-F e b-13$ & Lower House & Democratic Centre & No & Yes & Yes \\
\hline $24-F e b-13$ & Lower House & Act to Stop the Decline & No & Yes & Yes \\
\hline $24-F e b-13$ & Lower House & Future and Freedom & No & Yes & Yes \\
\hline $24-F e b-13$ & Lower House & Brothers of Italy & No & Yes & Yes \\
\hline $24-F e b-13$ & Lower House & The Right & No & Yes & Yes \\
\hline $24-F e b-13$ & Lower House & Northern League & No & No & No \\
\hline $24-F e b-13$ & Lower House & Five Star Movement & No & No & No \\
\hline $24-F e b-13$ & Lower House & Democratic Party & Yes & No \\
\hline $24-F e b-13$ & Lower House & The People of Freedom & No & Yes & No \\
\hline $24-F e b-13$ & Lower House & Civil Revolution & No & No & Yes \\
\hline $24-F e b-13$ & Lower House & Civic Choice & No & Yes & No \\
\hline $24-F e b-13$ & Lower House & Left Ecology Freedom & No \\
\hline $24-F e b-13$ & Lower House & Union of the Centre & No & No & No \\
\hline
\end{tabular}

(f) Canada (1988-1997)

\begin{tabular}{|c|c|c|c|c|c|}
\hline Election date & Election type & Candidate & Incumbent & Small & New \\
\hline \hline 21-Nov-88 & Lower House & Progressive Conservative Party & Yes & No & No \\
\hline 21-Nov-88 & Lower House & Liberal Party & No & No & No \\
\hline 21-Nov-88 & Lower House & New Democratic Party & No & No \\
\hline 26-Oct-92 & Referendum & No & N/A & N/A & N/A \\
\hline 26-Oct-92 & Referendum & Yes & No & No & Y/A \\
\hline 25-Oct-93 & Lower House & Yloc Québécois & Yes & No & No \\
\hline 25-Oct-93 & Lower House & Progressive Conservative Party & No & No \\
\hline 25-Oct-93 & Lower House & Liberal Party & No & Yes & No \\
\hline 25-Oct-93 & Lower House & New Democratic Party & No & No \\
\hline 25-Oct-93 & Lower House & Reform Party & No & No & No \\
\hline 2-Jun-97 & Lower House & Bloc Québécois & Yes & No & No \\
\hline 2-Jun-97 & Lower House & Liberal Party & No & No & No \\
\hline 2-Jun-97 & Lower House & New Democratic Party & No & No & No \\
\hline 2-Jun-97 & Lower House & Progressive Conservative Party & Reform Party & No & No \\
\hline 2-Jun-97 & Lower House & No & No & No & No \\
\hline
\end{tabular}


(g) Canada (2000-2015)

\begin{tabular}{|c|c|c|c|c|c|}
\hline Election date & Election type & Candidate & Incumbent & Small & New \\
\hline 27-Nov-00 & Lower House & Alliance Party & No & No & Yes \\
\hline 27-Nov-00 & Lower House & Bloc Québécois & No & Yes & No \\
\hline 27-Nov-00 & Lower House & Progressive Conservative Party & No & Yes & No \\
\hline 27-Nov-00 & Lower House & Liberal Party & Yes & No & No \\
\hline 27-Nov-00 & Lower House & New Democratic Party & No & Yes & No \\
\hline 28-Jun-04 & Lower House & Bloc Québécois & No & No & No \\
\hline 28-Jun-04 & Lower House & Conservative Party & No & No & Yes \\
\hline 28-Jun-04 & Lower House & Green Party & No & Yes & No \\
\hline 28-Jun-04 & Lower House & Liberal Party & Yes & No & No \\
\hline 28-Jun-04 & Lower House & Marijuana Party & No & Yes & No \\
\hline 28-Jun-04 & Lower House & Progressive Conservative Party & No & Yes & No \\
\hline 28-Jun-04 & Lower House & New Democratic Party & No & No & No \\
\hline 23-Jan-06 & Lower House & Bloc Québécois & No & No & No \\
\hline 23-Jan-06 & Lower House & Conservative Party & No & No & No \\
\hline 23-Jan-06 & Lower House & Green Party & No & Yes & No \\
\hline 23-Jan-06 & Lower House & Liberal Party & Yes & No & No \\
\hline 23-Jan-06 & Lower House & New Democratic Party & No & No & No \\
\hline $14-$ Oct-08 & Lower House & Bloc Québécois & No & No & No \\
\hline $14-$ Oct-08 & Lower House & Conservative Party & Yes & No & No \\
\hline $14-O c t-08$ & Lower House & Green Party & No & Yes & No \\
\hline $14-O c t-08$ & Lower House & Liberal Party & No & No & No \\
\hline $14-$ Oct-08 & Lower House & New Democratic Party & No & No & No \\
\hline 2-May-11 & Lower House & Bloc Québécois & No & No & No \\
\hline 2-May-11 & Lower House & Conservative Party & Yes & No & No \\
\hline 2-May-11 & Lower House & Green Party & No & Yes & No \\
\hline 2-May-11 & Lower House & Liberal Party & No & No & No \\
\hline 2-May-11 & Lower House & New Democratic Party & No & No & No \\
\hline 19-Oct-15 & Lower House & Bloc Québécois & No & Yes & No \\
\hline 19-Oct-15 & Lower House & Conservative Party & Yes & No & No \\
\hline 19-Oct-15 & Lower House & Green Party & No & Yes & No \\
\hline 19-Oct-15 & Lower House & Liberal Party & No & No & No \\
\hline 19-Oct-15 & Lower House & New Democratic Party & No & No & No \\
\hline
\end{tabular}


(h) Netherlands (1998-2002)

\begin{tabular}{|c|c|c|c|c|c|}
\hline Election date & Election type & Candidate & Incumbent & Small & New \\
\hline 6-May-98 & Lower House & General Elderly Alliance & No & Yes & No \\
\hline 6-May-98 & Lower House & Christian Democratic Appeal & No & No & No \\
\hline 6-May-98 & Lower House & Centre Democrats & No & Yes & No \\
\hline 6-May-98 & Lower House & Democrats 66 & No & Yes & No \\
\hline 6-May-98 & Lower House & The Greens & No & Yes & No \\
\hline 6-May-98 & Lower House & Reformed Political League & No & Yes & No \\
\hline 6-May-98 & Lower House & Green Left & No & Yes & No \\
\hline 6-May-98 & Lower House & Mobile Netherlands & No & Yes & Yes \\
\hline 6-May-98 & Lower House & Labour Party & Yes & No & No \\
\hline 6-May-98 & Lower House & Reforming Political Federation & No & Yes & No \\
\hline 6-May-98 & Lower House & Political Reformed Party & No & Yes & No \\
\hline 6-May-98 & Lower House & Socialist Party & No & Yes & No \\
\hline 6-May-98 & Lower House & Seniors 2000 & No & Yes & Yes \\
\hline 6-May-98 & Lower House & Union 55+ & No & Yes & No \\
\hline 6-May-98 & Lower House & Progressive Integration Party & No & Yes & N/A \\
\hline 6-May-98 & Lower House & People's Party for Freedom and Democracy & No & No & No \\
\hline 15-May-02 & Lower House & Christian Democratic Appeal & No & No & No \\
\hline 15-May-02 & Lower House & Christian Union & No & Yes & No \\
\hline 15-May-02 & Lower House & Democrats 66 & No & Yes & No \\
\hline 15-May-02 & Lower House & Green Left & No & Yes & No \\
\hline 15-May-02 & Lower House & Livable Netherlands & No & Yes & Yes \\
\hline 15-May-02 & Lower House & Pim Fortuyn List & No & No & Yes \\
\hline 15-May-02 & Lower House & Labour Party & Yes & No & No \\
\hline 15-May-02 & Lower House & Political Reformed Party & No & Yes & No \\
\hline 15-May-02 & Lower House & Socialist Party & No & Yes & No \\
\hline 15-May-02 & Lower House & People's Party for Freedom and Democracy & No & No & No \\
\hline 15-May-02 & Lower House & United Seniors Party & No & Yes & Yes \\
\hline
\end{tabular}


(i) Netherlands (2006)

\begin{tabular}{|c|c|c|c|c|c|}
\hline Election date & Election type & Candidate & Incumbent & Small & New \\
\hline 15-May-02 & Lower House & United Seniors Party & No & Yes & Yes \\
\hline 22-Nov-06 & Lower House & Christian Democratic Appeal & Yes & No & No \\
\hline 22-Nov-06 & Lower House & Christian Union & No & Yes & No \\
\hline 22-Nov-06 & Lower House & Democrats 66 & No & Yes & No \\
\hline 22-Nov-06 & Lower House & One Netherlands & No & Yes & Yes \\
\hline 22-Nov-06 & Lower House & Pim Fortuyn List & No & Yes & No \\
\hline 22-Nov-06 & Lower House & Green Left & No & Yes & No \\
\hline 22-Nov-06 & Lower House & Party for the Animals & No & Yes & No \\
\hline 22-Nov-06 & Lower House & Party for Freedom & No & Yes & Yes \\
\hline 22-Nov-06 & Lower House & Party for the Netherlands & No & Yes & Yes \\
\hline 22-Nov-06 & Lower House & Labour Party & No & No & No \\
\hline 22-Nov-06 & Lower House & Politically Reformed Party & No & Yes & No \\
\hline 22-Nov-06 & Lower House & Socialist Party & No & Yes & No \\
\hline 22-Nov-06 & Lower House & People's Party for Freedom and Democracy & No & No & No \\
\hline
\end{tabular}

(j) Germany (2009-2013)

\begin{tabular}{|c|c|c|c|c|c|}
\hline Election date & Election type & Candidate & Incumbent & Small & New \\
\hline 27-Sep-09 & Lower House & $\begin{array}{l}\text { Christian Democratic Union / Christian Social Union } \\
\text { in Bavaria }\end{array}$ & Yes & No & No \\
\hline 27-Sep-09 & Lower House & The Left & No & No & Yes \\
\hline 27-Sep-09 & Lower House & Free Democratic Party & No & Yes & No \\
\hline 27-Sep-09 & Lower House & Alliance 90s/The Greens & No & No & No \\
\hline 27-Sep-09 & Lower House & National Democratic Party of Germany & No & Yes & No \\
\hline 27-Sep-09 & Lower House & Pirate Party Germany & No & Yes & Yes \\
\hline 27-Sep-09 & Lower House & The Republicans & No & Yes & No \\
\hline 27-Sep-09 & Lower House & Social Democratic Party of Germany & No & No & No \\
\hline 22-Sep-13 & Lower House & Alternative for Germany & No & Yes & Yes \\
\hline 22-Sep-13 & Lower House & Christian Democratic Union & Yes & No & No \\
\hline 22-Sep-13 & Lower House & The Left & No & Yes & No \\
\hline 22-Sep-13 & Lower House & Free Democratic Party & No & Yes & No \\
\hline 22-Sep-13 & Lower House & Alliance 90s/The Greens & No & No & No \\
\hline 22-Sep-13 & Lower House & National Democratic Party of Germany & No & Yes & No \\
\hline 22-Sep-13 & Lower House & Pirate Party Germany & No & Yes & No \\
\hline 22-Sep-13 & Lower House & Social Demoratic Party of Germany & No & No & No \\
\hline
\end{tabular}


(k) Germany (2017)

\begin{tabular}{|c|c|c|c|c|c|}
\hline Election date & Election type & Candidate & Incumbent & Small & New \\
\hline \hline 24-Sep-17 & Lower House & Alternative for Germany & No & Yes & No \\
\hline $24-S e p-17$ & Lower House & $\begin{array}{c}\text { Christian Democratic Union / Christian Social Union } \\
\text { in Bavaria }\end{array}$ & Yes & No & No \\
\hline $24-S e p-17$ & Lower House & The Left & No & Yes & No \\
\hline 24-Sep-17 & Lower House & Free Democratic Party & No & Yes & No \\
\hline 24-Sep-17 & Lower House & Alliance 90s/The Greens & No & Yes & No \\
\hline 24-Sep-17 & Lower House & Social Democratic Party of Germany & No & No & No \\
\hline
\end{tabular}

(1) New Zealand (1996-1999)

\begin{tabular}{|c|c|c|c|c|c|}
\hline Election date & Election type & Candidate & Incumbent & Small & New \\
\hline 12-Oct-96 & Lower House & ACT & No & Yes & Yes \\
\hline $12-$ Oct-96 & Lower House & Alliance & No & No & No \\
\hline 12-Oct-96 & Lower House & Christian Coalition & No & Yes & Yes \\
\hline 12-Oct-96 & Lower House & Labour Party & No & No & No \\
\hline 12-Oct-96 & Lower House & McGillicuddy Serious & No & Yes & No \\
\hline 12-Oct-96 & Lower House & National Party & Yes & No & No \\
\hline 12-Oct-96 & Lower House & New Zealand First & No & No & No \\
\hline 12-Oct_96 & Lower House & Progressive Green & No & Yes & Yes \\
\hline 12-Oct-96 & Lower House & United & No & Yes & Yes \\
\hline 27-Nov-99 & Lower House & ACT & No & Yes & No \\
\hline 27-Nov-99 & Lower House & Alliance & No & Yes & No \\
\hline 27-Nov-99 & Lower House & Christian Heritage & No & Yes & No \\
\hline 27-Nov-99 & Lower House & Green Party & No & Yes & No \\
\hline 27-Nov-99 & Lower House & Labour Party & No & No & No \\
\hline 27-Nov-99 & Lower House & National Party & Yes & No & No \\
\hline 27-Nov-99 & Lower House & New Zealand First & No & Yes & No \\
\hline 27-Nov-99 & Lower House & United & No & Yes & No \\
\hline
\end{tabular}


(m) New Zealand (2002)

\begin{tabular}{|c|c|c|c|c|c|}
\hline Election date & Election type & Candidate & Incumbent & Small & New \\
\hline 27-Jul-02 & Lower House & National Party & No & No & No \\
\hline 27-Jul-02 & Lower House & ACT & No & Yes & No \\
\hline 27-Jul-02 & Lower House & Alliance & No & Yes & No \\
\hline 27-Jul-02 & Lower House & Christian Heritage & No & Yes & No \\
\hline 27-Jul-02 & Lower House & Green Party & No & Yes & No \\
\hline 27-Jul-02 & Lower House & Independent(s) & No & Yes & No \\
\hline 27-Jul-02 & Lower House & Jim Anderton's Progressive Party & No & Yes & Yes \\
\hline 27-Jul-02 & Lower House & New Zealand First & No & Yes & No \\
\hline 27-Jul-02 & Lower House & Outdoor Recreation & No & Yes & Yes \\
\hline 27-Jul-02 & Lower House & United Future & No & Yes & Yes \\
\hline 27-Jul-02 & Lower House & Labour Party & Yes & No & No \\
\hline
\end{tabular}

(n) Sweden

\begin{tabular}{|c|c|c|c|c|c|}
\hline Election date & Election type & Candidate & Incumbent & Small & New \\
\hline 25-May-14 & European & Centre Party & No & Yes & No \\
\hline 25-May-14 & European & Christian Democrats & No & Yes & No \\
\hline 25-May-14 & European & Feminist Initiative & No & No & No \\
\hline 25-May-14 & European & Green Party & No & No & No \\
\hline 25-May-14 & European & June List & No & Yes & No \\
\hline 25-May-14 & European & Left Party & No & No & No \\
\hline 25-May-14 & European & Moderate Party & No & Yes & No \\
\hline 25-May-14 & European & Liberal People's Party & No & No & No \\
\hline 25-May-14 & European & Pirate Party & No & Yes & No \\
\hline 25-May-14 & European & Social Democrats & Yes & No & No \\
\hline 25-May-14 & European & Sweden Democrats & No & Yes & No \\
\hline 14-Sept-2014 & Lower House & Centre Party & No & Yes & No \\
\hline 14-Sept-2014 & Lower House & Chrisitian Democrats & No & Yes & No \\
\hline 14-Sept-2014 & Lower House & Feminist Initiative & No & Yes & No \\
\hline 14-Sept-2014 & Lower House & Green Party & No & No & No \\
\hline 14-Sept-2014 & Lower House & Left Party & No & No & No \\
\hline 14-Sept-2014 & Lower House & Moderate Party & Yes & No & No \\
\hline 14-Sept-2014 & Lower House & Liberal People's Party & No & No & No \\
\hline 14-Sept-2014 & Lower House & Social Democrats & No & No & No \\
\hline 14-Sept-2014 & Lower House & Sweden Democrats & No & No & No \\
\hline
\end{tabular}


(o) Switzerland

\begin{tabular}{|c|c|c|c|c|c|}
\hline Election date & Election type & Candidate & Incumbent & Small & New \\
\hline 23-Oct-11 & Lower House & Conservative Democratic Party & No & Yes & Yes \\
\hline 23-Oct-11 & Lower House & Christian Democratic People's Party & No & No & No \\
\hline 23-Oct-11 & Lower House & FDP.The Liberals & No & No & No \\
\hline 23-Oct-11 & Lower House & Green Liberal Party & No & Yes & No \\
\hline 23-Oct-11 & Lower House & Green Party & No & Yes & No \\
\hline 23-Oct-11 & Lower House & Social Democratic Party & No & No & No \\
\hline 23-Oct-11 & Lower House & Swiss People's Party & Yes & No & No \\
\hline 18 -Oct-15 & Lower House & Conservative Democratic Party & No & Yes & No \\
\hline 18 -Oct-15 & Lower House & Christian Democratic People's Party & No & No & No \\
\hline 18-Oct-15 & Lower House & FDP.The Liberals & No & No & No \\
\hline $18-$ - ct-15 & Lower House & Green Liberal Party & No & Yes & No \\
\hline 18 -Oct-15 & Lower House & Green Party & No & Yes & No \\
\hline $18-$ Oct-15 & Lower House & Social Democratic Party & No & No & No \\
\hline $18-$-Oct-15 & Lower House & Swiss People's Party & Yes & No & No \\
\hline
\end{tabular}

Notes: We report the list of candidates or parties included as possible answers to questions on pre-electoral vote intention and post-electoral vote choice in each survey. We also report, for elections that are not referenda, whether they are the incumbent candidate (for presidential and gubernatorial elections) or party (for lower and upper house elections), whether they are a small candidate or party that had an average predicted vote share lower than $10 \%$ in the first five days of the survey, and whether the party (or candidate's party) was absent from any previous election of the same type. In elections for lower house and upper house, the incumbent is defined as the party that had a plurality of seats in the house before the election (in the U.S.) of the party of the incumbent prime minister (in all other countries). For gubernatorial election in the U.S., the incumbent is defined as the incumbent governor in each state, and is left blank when we do not know in which state the respondent is registered. Options such as "Other candidate" or "Blank/Invalid vote" are not reported in this list but included in some of our analyses. 
Table B.6: List of TV debates by country

(a) United States (1960-2004)

\begin{tabular}{|c|c|c|c|}
\hline Survey & Debate date & Election type & \# days before election \\
\hline ANES 1960 & 26-Sep & President & 43 \\
\hline ANES 1960 & 7-Oct & President & 32 \\
\hline ANES 1960 & 13-Oct & President & 26 \\
\hline ANES 1960 & 21-Oct & President & 18 \\
\hline ANES 1976 & 23-Sep & President & 40 \\
\hline ANES 1976 & 6-Oct & President & 27 \\
\hline ANES 1976 & 22-Oct & President & 11 \\
\hline ANES 1980 & 21-Sep & President & 44 \\
\hline ANES 1980 & 28-Oct & President & 7 \\
\hline ANES 1984 & 7-Oct & President & 30 \\
\hline ANES 1984 & 21-Oct & President & 16 \\
\hline ANES 1988 & 25-Sep & President & 44 \\
\hline ANES 1988 & 13-Oct & President & 26 \\
\hline ANES 1992 & 11-Oct & President & 23 \\
\hline ANES 1992 & 15-Oct & President & 19 \\
\hline ANES 1992 & 19-Oct & President & 15 \\
\hline ANES 1996 & 6-Oct & President & 30 \\
\hline ANES 1996 & 16-Oct & President & 20 \\
\hline ANES 2000 & 3-Oct & President & 35 \\
\hline NAES 2000 & $"$ & $"$ & $"$ \\
\hline ANES 2000 & 11-Oct & President & 27 \\
\hline NAES 2000 & $"$ & $"$ & $"$ \\
\hline ANES 2000 & 17-Oct & President & 21 \\
\hline NAES 2000 & $"$ & $"$ & $"$ \\
\hline ANES 2004 & 8-Oct & President & 25 \\
\hline NAES 2004 & $"$ & $"$ & $"$ \\
\hline ANES 2004 & 30-Sep & President & 33 \\
\hline NAES 2004 & $"$ & $"$ & $"$ \\
\hline ANES 2004 & 13-Oct & President & 20 \\
\hline NAES 2004 & $"$ & $"$ & $"$ \\
\hline
\end{tabular}


(b) United States (2004-2016)

\begin{tabular}{|c|c|c|c|}
\hline Survey & Debate date & Election type & \# days before election \\
\hline ANES 2008 & 26-Sep & President & 39 \\
\hline NAES 2008 & $"$ & $"$ & $"$ \\
\hline ANES 2008 & 7-Oct & President & 28 \\
\hline NAES 2008 & $"$ & $"$ & $"$ \\
\hline ANES 2008 & 15 -Oct & President & 20 \\
\hline NAES 2008 & $"$ & $"$ & $"$ \\
\hline ANES 2012 & 3-Oct & President & 34 \\
\hline ANES 2012 & $16-O c t$ & President & 21 \\
\hline ANES 2012 & 22-Oct & President & 15 \\
\hline ANES 2016 & 26-Sep & President & 43 \\
\hline ANES 2016 & 9-Oct & President & 30 \\
\hline ANES 2016 & 19-Oct & President & 20 \\
\hline
\end{tabular}

(c) Austria

\begin{tabular}{|c|c|c|c|}
\hline Survey & Debate date & Election type & \# days before election \\
\hline AUTNES 2013 & 29-Aug & Lower House & 31 \\
\hline
\end{tabular}

(d) United Kingdom

\begin{tabular}{|c|c|c|c|}
\hline Survey & Debate date & Election type & \# days before election \\
\hline BES 2010 & 15-Apr & Lower House & 21 \\
\hline BES 2010 & 22-Apr & Lower House & 14 \\
\hline BES 2010 & 29-Apr & Lower House & 7 \\
\hline BES 2015 & 2-Apr & Lower House & 35 \\
\hline BES 2015 & 16-Apr & Lower House & 21 \\
\hline BES 2015 & 30-Apr & Lower House & 7 \\
\hline
\end{tabular}

(e) Canada

\begin{tabular}{|c|c|c|c|}
\hline Survey & Debate date & Election type & Lower House \\
\hline CES 2015 & 17-Sep-2015 & Lower House & 32 \\
\hline CES 2015 & $24-$ Sep-2015 & Lower House & 25 \\
\hline CES 2015 & 28-Sep-2015 & Lower House & 21 \\
\hline
\end{tabular}


(f) Netherlands

\begin{tabular}{|c|c|c|c|}
\hline Survey & Debate date & Election type & \# days before election \\
\hline \hline DPES 1998 & 24-Apr-1998 & Lower House & 12 \\
\hline DPES 2002 & 27-Apr-2002 & Lower House & 19 \\
\hline DPES 2006 & 3-Nov-2006 & Lower House & 18 \\
\hline
\end{tabular}

(g) Germany

\begin{tabular}{|c|c|c|c|}
\hline Survey & Debate date & Election type & \# days before election \\
\hline \hline GLES 2009 & 13-Sep-2009 & Lower House & 21 \\
\hline GLES 2013 & 1-Sep-2013 & Lower House & 21 \\
\hline GLES 2017 & 3-Sep-2017 & Lower House & 214 \\
\hline
\end{tabular}

(h) New Zealand

\begin{tabular}{|c|c|c|c|}
\hline Survey & Debate date & Election type & \# days before election \\
\hline \hline NZES 1996 & 26-Sep-1996 & Lower House & 5 \\
\hline NZES 1996 & 7-Oct-1996 & Lower House & 31 \\
\hline NZES 1999 & 27-Oct-1999 House & 26 \\
\hline NZES 1999 & 1-Nov-1999 & Lower House & 12 \\
\hline NZES 2002 & 15-Jul-2002 & Lower House & 5 \\
\hline NZES 2002 & 22-Jul-2002 & Lower House & \\
\hline
\end{tabular}

Notes: For each TV debate included in the study, we indicate the date when the debate was held and the number of days separating the debate from the election. 
Table B.7: List of disasters by election

(a) United States

\begin{tabular}{|c|c|c|c|c|}
\hline Survey & Disaster date & Election type & \# days before election & Disaster type \\
\hline ANES 1964 & 9-Sept & President & 55 & Storm \\
\hline ANES 1972 & 30-Oct & President & 8 & Transport accident \\
\hline ANES 1976 & 24-Oct & President & 9 & Miscellaneous accident \\
\hline ANES 1984 & 11-Sept & President & 56 & Storm \\
\hline ANES 1992 & 05-Sept & President & 59 & Storm \\
\hline ANES 1992 & 11-Sept & President & 53 & Storm \\
\hline ANES 1992 & 29-Sept & President & 35 & Wildfire \\
\hline ANES 1992 & 03-Oct & President & 31 & Storm \\
\hline ANES 1992 & 15 -Oct & President & 19 & Storm \\
\hline ANES 2000 & 20-Sept & President & 48 & Storm \\
\hline NAES 2000 & " & $"$ & $"$ & $"$ \\
\hline ANES 2000 & 4-Oct & President & 34 & Storm \\
\hline NAES 2000 & $"$ & $"$ & $"$ & $"$ \\
\hline ANES 2000 & 28 -Oct & President & 10 & Miscellaneous accident \\
\hline NAES 2000 & $"$ & $"$ & $"$ & $"$ \\
\hline ANES 2000 & 02-Nov & President & 5 & Flood \\
\hline NAES 2000 & ” & ” & ” & ” \\
\hline ANES 2004 & 15-Sept & President & 48 & Storm \\
\hline NAES 2004 & ” & ” & " & ” \\
\hline ANES 2004 & 25-Sept & President & 38 & Storm \\
\hline NAES 2004 & $"$ & $"$ & $"$ & $"$ \\
\hline ANES 2004 & 30-Oct & President & 3 & Flood \\
\hline NAES 2004 & $"$ & $"$ & $"$ & $"$ \\
\hline ANES 2008 & 05-Oct & President & 30 & Transport accident \\
\hline NAES 2008 & $"$ & $"$ & $"$ & ” \\
\hline ANES 2012 & 28-Oct & President & 9 & Storm \\
\hline ANES 2016 & 19-Sept & President & 50 & Flood \\
\hline ANES 2016 & 29-Sept & President & 40 & Transport accident \\
\hline ANES 2016 & 08-Oct & President & 31 & Storm \\
\hline ANES 2016 & 23-Oct & President & 16 & Transport accident \\
\hline
\end{tabular}


(b) Canada

\begin{tabular}{|c|c|c|c|c|}
\hline Survey & Event date & Election type & \# days before election & Disaster type \\
\hline \hline CES 1997 & 29-May & Lower House & 4 & Wildfire \\
\hline CES 2006 & 30-Nov & Lower House & 54 & Miscellaneous accident \\
\hline CES 2011 & 01-Apr & Lower House & 28 & Flood \\
\hline
\end{tabular}

(c) Germany

\begin{tabular}{|c|c|c|c|c|}
\hline Survey & Event date & Election type & \# days before election & Disaster type \\
\hline \hline GLES 2013 & 27-July & Lower House & 57 & Storm \\
\hline GLES 2017 & 18-Aug & Lower House & 37 & Storm \\
\hline
\end{tabular}

Notes: For each disaster included in the study, we indicate the date when the disaster started, the number of days separating that date from the election, and the type of disaster.

Table B.8: List of surveys with pre-campaign waves

\begin{tabular}{|c|c|c|c|c|c|c|}
\hline Survey & Country & $\begin{array}{c}\text { Election } \\
\text { type }\end{array}$ & $\begin{array}{c}\text { Survey } \\
\text { mode }\end{array}$ & $\begin{array}{c}\text { RCS } \\
\text { design }\end{array}$ & $\begin{array}{c}\text { \# days } \\
\text { before } \\
\text { election }\end{array}$ & $\begin{array}{c}\text { N pre- } \\
\text { campaign }\end{array}$ \\
\hline \hline BES 2015 & United Kingdom & $\begin{array}{c}\text { Lower } \\
\text { House }\end{array}$ & Online & No & 64 & 9 \\
\hline BES 2016 & United Kingdom & Referendum & Online & No & 70 & 8761 \\
\hline NAES 2000 & United States & President & Phone & Yes & 217 & 1089 \\
\hline NAES 2008 & United States & President & Phone/Online & No & 216 & 18739 \\
\hline $\begin{array}{c}\text { SELECTS } \\
2015\end{array}$ & Switzerland & $\begin{array}{c}\text { Lower } \\
\text { House }\end{array}$ & Phone & No & 127 & 6607 \\
\hline SNES 2014 & Sweden & $\begin{array}{c}\text { European } \\
\text { Parliament }\end{array}$ & Online & No & 76 & 1212 \\
\hline
\end{tabular}

Notes: For each pre-campaign survey that started more than 60 days before the election, we indicate: which survey mode was used; whether it is a rolling cross-section; how many days before Election Day it started; and the number of respondents surveyed more than 60 days before the election who said that they intended to vote in the pre-campaign survey (N pre-campaign). Other notes as in Appendix Tables B.1 and B.2. 
Table B.9: List of swing states in the U.S. by election year

\begin{tabular}{|c|c|c|c|c|c|c|c|c|c|}
\hline 1956 & \multicolumn{2}{|c|}{1960} & \multicolumn{2}{|c|}{1964} & \multicolumn{2}{|c|}{1968} & \multicolumn{2}{|c|}{1972} & 1976 \\
\hline Missouri & \multicolumn{2}{|c|}{ Hawaii } & \multicolumn{2}{|c|}{ Arizona } & \multicolumn{2}{|c|}{ Missouri } & \multicolumn{2}{|c|}{ Minnesota } & California \\
\hline Tennessee & \multicolumn{2}{|c|}{ Illinois } & \multicolumn{2}{|c|}{ Idaho } & \multicolumn{2}{|c|}{ Texas } & \multicolumn{2}{|c|}{ Rhode Island } & Connnecticut \\
\hline North Carolina & \multicolumn{2}{|c|}{ Missouri } & \multicolumn{2}{|c|}{ Florida } & \multicolumn{2}{|c|}{ Maryland } & \multicolumn{2}{|c|}{ South Dakota } & Illinois \\
\hline Arkansas & \multicolumn{2}{|c|}{ California } & \multicolumn{2}{|c|}{ Nebraska } & \multicolumn{2}{|c|}{ Washington } & \multicolumn{2}{|c|}{ Massachusetts } & Maine \\
\hline Minnesota & \multicolumn{2}{|c|}{ New Mexico } & \multicolumn{2}{|c|}{ Virginia } & \multicolumn{2}{|c|}{ New Jersey } & \multicolumn{2}{|c|}{ Wisconsin } & Michigan \\
\hline West Virginia & \multicolumn{2}{|c|}{ New Jersey } & & & & & Ore & & Nevada \\
\hline Washington & Min & sota & & & & & Calif & nia & New Hampshire \\
\hline Kentucky & Del & are & & & & & $\mathrm{Mic}$ & $\operatorname{san}$ & New Jersey \\
\hline Oklahoma & & & Tenı & see & Cali & rnia & & & New Mexico \\
\hline Delaware & & & South & kota & Del & vare & New & ork & Oregon \\
\hline & & & & & & & & & \\
\hline Mass & setts & & sota & $\mathrm{Wa}$ & & & & & icky \\
\hline Ten & & Mas & usetts & & & Nort & rolina & & ada \\
\hline & & Rho & sland & Pent & ania & New & pshire & & gia \\
\hline & & & and & & & & & & ado \\
\hline Mis & ppi & Pen & vania & & & & & & inia \\
\hline $\mathrm{Ke}$ & & & & & & & & & ona \\
\hline South & olina & & ork & & & & rsey & Ten & ssee \\
\hline & & & $\sin$ & & & & & & tana \\
\hline North & olina & Wes & ginia & & & & & Soutl & akota \\
\hline & & & & & & & & North & arolina \\
\hline & & & & & & & & & \\
\hline & & & $\sin$ & & & & & & gia \\
\hline New & xico & & & Nortl & blina & Nort & rolina & & ona \\
\hline Wis & & $\mathrm{Ner}$ & xico & & & & & Wis & $n \sin$ \\
\hline & & New & pshire & & & & & Penn & jvania \\
\hline & & & & & & & do & North & arolina \\
\hline New $\mathrm{H}$ & oshire & Pen & vania & & & Pen & vania & & ada \\
\hline Mir & & & & & & New & pshire & & igan \\
\hline & & & gan & & & & & & ida \\
\hline & & & & Sout & kota & & & & as \\
\hline & & & ddo & & & & $\sin$ & Mir & esota \\
\hline
\end{tabular}

Notes: For each election date in the sample of U.S. elections (except for the 1952 election, for which we do not know the location of respondents and cannot determine if they live in a swing state), swing states are defined as the ten states where in which the vote share difference between the top two presidential candidates was the closest, based on the electoral results in Dave Leip's Atlas of U.S. Presidential Elections (https://uselectionatlas.org/). 


\section{Additional Robustness Checks}

\section{C.1 Wild Cluster Bootstrap Standard Errors}

Table C.1: Vote choice consistency and distance to final vote shares, wild cluster bootstrap

\begin{tabular}{|c|c|c|c|c|c|c|c|c|}
\hline & \multicolumn{2}{|c|}{$\begin{array}{l}\text { Vote choice } \\
\text { consistency }\end{array}$} & \multicolumn{2}{|c|}{$\begin{array}{c}\text { Vote } \\
\text { intention }\end{array}$} & \multicolumn{2}{|c|}{$\begin{array}{l}\text { Conditional } \\
\text { consistency }\end{array}$} & \multicolumn{2}{|c|}{$\begin{array}{l}\text { Distance between predicted } \\
\text { and final vote shares }\end{array}$} \\
\hline & (1) & (2) & (3) & (4) & (5) & (6) & (7) & (8) \\
\hline Time & $\begin{array}{c}0.0025^{* * *} \\
{[0.00]}\end{array}$ & $\begin{array}{c}0.0061^{* * *} \\
{[0.00]}\end{array}$ & $\begin{array}{c}0.0010^{* * *} \\
{[0.00]}\end{array}$ & $\begin{array}{c}0.0031^{* * *} \\
{[0.00]}\end{array}$ & $\begin{array}{c}0.0018^{* * *} \\
{[0.00]}\end{array}$ & $\begin{array}{c}0.0038^{* * *} \\
{[0.00]}\end{array}$ & $\begin{array}{c}-0.0008^{* * *} \\
{[0.00]}\end{array}$ & $\begin{array}{c}-0.0013^{* *} \\
{[0.04]}\end{array}$ \\
\hline Time $^{2}$ & & $\begin{array}{c}0.0001^{* * *} \\
{[0.00]}\end{array}$ & & $\begin{array}{c}0.0000^{* * *} \\
{[0.00]}\end{array}$ & & $\begin{array}{c}0.0000^{* * *} \\
{[0.00]}\end{array}$ & & $\begin{array}{c}-0.0000 \\
{[0.17]}\end{array}$ \\
\hline Observations & 200916 & 200916 & 253489 & 253489 & 178176 & 178176 & 3125 & 3125 \\
\hline$R^{2}$ & 0.070 & 0.071 & 0.072 & 0.073 & 0.041 & 0.041 & 0.520 & 0.523 \\
\hline Mean at day -1 & 0.8768 & 0.8768 & 0.9157 & 0.9157 & 0.9346 & 0.9346 & 0.0324 & 0.0324 \\
\hline Election fixed effects & $\mathrm{x}$ & $\mathrm{x}$ & $\mathrm{x}$ & $\mathrm{x}$ & $\mathrm{x}$ & $\mathrm{x}$ & $\mathrm{x}$ & $\mathrm{x}$ \\
\hline Individual controls & $\mathrm{x}$ & $\mathrm{x}$ & $\mathrm{x}$ & $\mathrm{x}$ & $\mathrm{x}$ & $\mathrm{x}$ & & \\
\hline Aggregate controls & & & & & & & $\mathrm{x}$ & $\mathrm{x}$ \\
\hline Number of replications & 1000 & 1000 & 1000 & 1000 & 1000 & 1000 & 1000 & 1000 \\
\hline
\end{tabular}

Notes: We use the wild cluster bootstrap procedure proposed by Cameron et al. (2008) to allow for correlation of the error terms at the survey level, and report the corresponding p-value in brackets. We use 1,000 bootstrap replications. Other notes as in Table I. 
Table C.2: Drivers of vote choice formation, wild cluster bootstrap

(a) Mean vote choice consistency

\begin{tabular}{lcccc}
\hline & $(1)$ & $(2)$ & $(3)$ & $(4)$ \\
\hline Mean consistency in policy preferences & -0.103 & & & -0.138 \\
& {$[0.37]$} & & & {$[0.25]$} \\
Mean consistency in issue salience & & $0.255^{* *}$ & & $0.247^{* *}$ \\
& & {$[0.02]$} & & {$[0.03]$} \\
Mean consistency in beliefs on candidates & & & $0.134^{*}$ & $0.126^{*}$ \\
& & & {$[0.05]$} & {$[0.10]$} \\
\hline Observations & 3129 & 3129 & 3129 & 3129 \\
$R^{2}$ & 0.807 & 0.809 & 0.808 & 0.810 \\
Election fixed effects & $\mathrm{X}$ & $\mathrm{X}$ & $\mathrm{X}$ & $\mathrm{X}$ \\
Fixed effects for number of days to election & $\mathrm{X}$ & $\mathrm{X}$ & $\mathrm{X}$ & $\mathrm{x}$ \\
Aggregate controls & $\mathrm{X}$ & $\mathrm{X}$ & $\mathrm{X}$ & $\mathrm{X}$ \\
Number of replications & 1000 & 1000 & 1000 & 1000 \\
\hline
\end{tabular}

(b) Mean probability of stating a vote intention

\begin{tabular}{lcccc}
\hline & $(1)$ & $(2)$ & $(3)$ & $(4)$ \\
\hline Mean probability of stating a policy preference & 0.005 & & & -0.027 \\
& {$[0.97]$} & & & {$[0.86]$} \\
Mean probability of stating a salient issue & & $0.200^{* * *}$ & & $0.203^{* * *}$ \\
& & {$[0.00]$} & & {$[0.00]$} \\
Mean probability of stating a belief on candidates & & & $0.234^{* * *}$ & $0.237^{* * *}$ \\
& & & {$[0.01]$} & {$[0.00]$} \\
\hline Observations & 3144 & 3144 & 3144 & 3144 \\
$R^{2}$ & 0.840 & 0.840 & 0.841 & 0.841 \\
Election fixed effects & $\mathrm{x}$ & $\mathrm{x}$ & $\mathrm{x}$ & $\mathrm{x}$ \\
Fixed effects for number of days to election & $\mathrm{x}$ & $\mathrm{x}$ & $\mathrm{x}$ & $\mathrm{x}$ \\
Aggregate controls & $\mathrm{X}$ & $\mathrm{X}$ & $\mathrm{x}$ & $\mathrm{x}$ \\
Number of replications & 1000 & 1000 & 1000 & 1000 \\
\hline
\end{tabular}

Notes: Same notes as in Table II and Appendix Table C.1. 
Table C.3: Debates' effects on vote choice consistency, wild cluster bootstrap

\begin{tabular}{|c|c|c|c|c|c|c|}
\hline & \multicolumn{2}{|c|}{ Vote choice consistency } & \multicolumn{2}{|c|}{ Vote intention } & \multicolumn{2}{|c|}{ Conditional consistency } \\
\hline & (1) & (2) & (3) & (4) & (5) & (6) \\
\hline Before -3 & $\begin{array}{c}-0.014^{* *} \\
{[0.03]}\end{array}$ & $\begin{array}{c}-0.015^{* *} \\
{[0.01]}\end{array}$ & $\begin{array}{l}0.003 \\
{[0.61]}\end{array}$ & $\begin{array}{l}0.002 \\
{[0.69]}\end{array}$ & $\begin{array}{c}-0.015^{* *} \\
{[0.02]}\end{array}$ & $\begin{array}{c}-0.016^{* *} \\
{[0.02]}\end{array}$ \\
\hline-3 & $\begin{array}{l}-0.009 \\
{[0.17]}\end{array}$ & $\begin{array}{l}-0.010 \\
{[0.15]}\end{array}$ & $\begin{array}{l}0.003 \\
{[0.61]}\end{array}$ & $\begin{array}{l}0.003 \\
{[0.63]}\end{array}$ & $\begin{array}{l}-0.005 \\
{[0.46]}\end{array}$ & $\begin{array}{l}-0.006 \\
{[0.42]}\end{array}$ \\
\hline-2 & $\begin{array}{l}-0.001 \\
{[0.87]}\end{array}$ & $\begin{array}{l}-0.002 \\
{[0.78]}\end{array}$ & $\begin{array}{l}0.007 \\
{[0.15]}\end{array}$ & $\begin{array}{l}0.007 \\
{[0.15]}\end{array}$ & $\begin{array}{l}-0.004 \\
{[0.64]}\end{array}$ & $\begin{array}{l}-0.004 \\
{[0.58]}\end{array}$ \\
\hline-1 & $\begin{array}{l}-0.001 \\
{[0.82]}\end{array}$ & $\begin{array}{l}-0.002 \\
{[0.74]}\end{array}$ & $\begin{array}{l}0.005 \\
{[0.38]}\end{array}$ & $\begin{array}{l}0.005 \\
{[0.45]}\end{array}$ & $\begin{array}{l}-0.001 \\
{[0.91]}\end{array}$ & $\begin{array}{l}-0.002 \\
{[0.79]}\end{array}$ \\
\hline+1 & $\begin{array}{l}-0.009 \\
{[0.26]}\end{array}$ & $\begin{array}{l}-0.009 \\
{[0.26]}\end{array}$ & $\begin{array}{l}0.007 \\
{[0.38]}\end{array}$ & $\begin{array}{l}0.007 \\
{[0.35]}\end{array}$ & $\begin{array}{l}-0.008 \\
{[0.29]}\end{array}$ & $\begin{array}{l}-0.008 \\
{[0.29]}\end{array}$ \\
\hline+2 & $\begin{array}{l}-0.007 \\
{[0.35]}\end{array}$ & $\begin{array}{l}-0.008 \\
{[0.30]}\end{array}$ & $\begin{array}{l}0.002 \\
{[0.80]}\end{array}$ & $\begin{array}{l}0.001 \\
{[0.85]}\end{array}$ & $\begin{array}{l}-0.007 \\
{[0.35]}\end{array}$ & $\begin{array}{l}-0.008 \\
{[0.32]}\end{array}$ \\
\hline+3 & $\begin{array}{l}-0.006 \\
{[0.30]}\end{array}$ & $\begin{array}{l}-0.006 \\
{[0.27]}\end{array}$ & $\begin{array}{l}0.007 \\
{[0.14]}\end{array}$ & $\begin{array}{l}0.007 \\
{[0.14]}\end{array}$ & $\begin{array}{l}-0.006 \\
{[0.25]}\end{array}$ & $\begin{array}{l}-0.006 \\
{[0.22]}\end{array}$ \\
\hline After +3 & $\begin{array}{l}-0.002 \\
{[0.69]}\end{array}$ & $\begin{array}{l}-0.003 \\
{[0.62]}\end{array}$ & $\begin{array}{l}0.008 \\
{[0.19]}\end{array}$ & $\begin{array}{l}0.008 \\
{[0.21]}\end{array}$ & $\begin{array}{l}-0.005 \\
{[0.35]}\end{array}$ & $\begin{array}{l}-0.005 \\
{[0.29]}\end{array}$ \\
\hline Observations & 263681 & 263681 & 330621 & 330621 & 240826 & 240826 \\
\hline$R^{2}$ & 0.072 & 0.077 & 0.069 & 0.076 & 0.042 & 0.044 \\
\hline Mean, day of the debate & 0.811 & 0.811 & 0.811 & 0.811 & 0.887 & 0.887 \\
\hline Number of debates & 56 & 56 & 56 & 56 & 56 & 56 \\
\hline Debate $*$ election fixed effects & $\mathrm{x}$ & $\mathrm{x}$ & $\mathrm{x}$ & $\mathrm{x}$ & $\mathrm{x}$ & $\mathrm{x}$ \\
\hline Fixed effects for number of days to election & $\mathrm{x}$ & $\mathrm{x}$ & $\mathrm{x}$ & $\mathrm{x}$ & $\mathrm{x}$ & $\mathrm{x}$ \\
\hline Individual controls & $\mathrm{x}$ & $\mathrm{x}$ & $\mathrm{x}$ & $\mathrm{x}$ & $\mathrm{x}$ & $\mathrm{x}$ \\
\hline Sociodemographic controls & & $\mathrm{x}$ & & $\mathrm{x}$ & & $\mathrm{x}$ \\
\hline Linear combination of estimates & & & & & & \\
\hline Average pre-debate dummies $-3,-2$, and -1 & $\begin{array}{l}-0.004 \\
{[0.58]}\end{array}$ & $\begin{array}{l}-0.005 \\
{[0.48]}\end{array}$ & $\begin{array}{l}0.005 \\
{[0.25]}\end{array}$ & $\begin{array}{l}0.005 \\
{[0.27]}\end{array}$ & $\begin{array}{l}-0.003 \\
{[0.58]}\end{array}$ & $\begin{array}{l}-0.004 \\
{[0.51]}\end{array}$ \\
\hline Average post-debate dummies 1,2 , and 3 & $\begin{array}{l}-0.007 \\
{[0.18]}\end{array}$ & $\begin{array}{l}-0.008 \\
{[0.16]}\end{array}$ & $\begin{array}{c}0.005 \\
{[0.33]}\end{array}$ & $\begin{array}{c}0.005 \\
{[0.31]}\end{array}$ & $\begin{array}{l}-0.007 \\
{[0.23]}\end{array}$ & $\begin{array}{l}-0.007 \\
{[0.21]}\end{array}$ \\
\hline Number of replications & 1000 & 1000 & 1000 & 1000 & 1000 & 1000 \\
\hline
\end{tabular}

Notes: We use the wild cluster bootstrap procedure proposed by Cameron et al. (2008) to allow for correlation of the error terms at the debate level, and report the corresponding p-value in brackets. We use 1,000 bootstrap replications. Other notes as in Table III. 
Table C.4: Debates' effects on aggregate vote shares, wild cluster bootstrap

\begin{tabular}{|c|c|c|c|c|}
\hline & \multicolumn{2}{|c|}{$\begin{array}{l}\text { Distance between predicted } \\
\text { and final vote shares }\end{array}$} & \multicolumn{2}{|c|}{$\begin{array}{l}\text { Daily change in } \\
\text { predicted vote shares }\end{array}$} \\
\hline & (1) & (2) & (3) & (4) \\
\hline Before -3 & $\begin{array}{l}0.005 \\
{[0.25]}\end{array}$ & $\begin{array}{l}0.006 \\
{[0.20]}\end{array}$ & $\begin{array}{l}0.009 \\
{[0.16]}\end{array}$ & $\begin{array}{l}0.007 \\
{[0.25]}\end{array}$ \\
\hline-3 & $\begin{array}{l}-0.001 \\
{[0.80]}\end{array}$ & $\begin{array}{l}0.000 \\
{[0.98]}\end{array}$ & $\begin{array}{l}-0.003 \\
{[0.79]}\end{array}$ & $\begin{array}{l}-0.004 \\
{[0.70]}\end{array}$ \\
\hline-2 & $\begin{array}{l}-0.000 \\
{[0.97]}\end{array}$ & $\begin{array}{l}0.000 \\
{[0.91]}\end{array}$ & $\begin{array}{l}0.001 \\
{[0.95]}\end{array}$ & $\begin{array}{r}-0.001 \\
{[0.90]}\end{array}$ \\
\hline-1 & $\begin{array}{r}-0.003 \\
{[0.41]}\end{array}$ & $\begin{array}{l}-0.002 \\
{[0.64]}\end{array}$ & $\begin{array}{c}0.013^{* *} \\
{[0.03]}\end{array}$ & $\begin{array}{l}0.012^{*} \\
{[0.06]}\end{array}$ \\
\hline+1 & $\begin{array}{l}0.002 \\
{[0.55]}\end{array}$ & $\begin{array}{l}0.002 \\
{[0.50]}\end{array}$ & $\begin{array}{l}0.008 \\
{[0.26]}\end{array}$ & $\begin{array}{l}0.006 \\
{[0.42]}\end{array}$ \\
\hline+2 & $\begin{array}{l}0.000 \\
{[0.97]}\end{array}$ & $\begin{array}{l}0.001 \\
{[0.84]}\end{array}$ & $\begin{array}{c}0.022^{* *} \\
{[0.05]}\end{array}$ & $\begin{array}{c}0.021^{* *} \\
{[0.05]}\end{array}$ \\
\hline+3 & $\begin{array}{c}0.001 \\
{[0.83]}\end{array}$ & $\begin{array}{l}0.002 \\
{[0.66]}\end{array}$ & $\begin{array}{l}0.011 \\
{[0.29]}\end{array}$ & $\begin{array}{l}0.009 \\
{[0.37]}\end{array}$ \\
\hline After +3 & $\begin{array}{l}0.002 \\
{[0.64]}\end{array}$ & $\begin{array}{l}0.002 \\
{[0.55]}\end{array}$ & $\begin{array}{l}0.006 \\
{[0.22]}\end{array}$ & $\begin{array}{l}0.005 \\
{[0.31]}\end{array}$ \\
\hline Observations & 3802 & 3802 & 3749 & 3749 \\
\hline$R^{2}$ & 0.575 & 0.581 & 0.470 & 0.477 \\
\hline Mean, day of the debate & 0.046 & 0.046 & 0.085 & 0.085 \\
\hline Number of debates & 56 & 56 & 56 & 56 \\
\hline Debate * election fixed effects & $\mathrm{x}$ & $\mathrm{x}$ & $\mathrm{x}$ & $\mathrm{x}$ \\
\hline Fixed effects for number of days to election & $\mathrm{x}$ & $\mathrm{x}$ & $\mathrm{x}$ & $\mathrm{x}$ \\
\hline Aggregate controls & $\mathrm{x}$ & $\mathrm{x}$ & $\mathrm{x}$ & $\mathrm{x}$ \\
\hline Sociodemographic controls & & $\mathrm{x}$ & & $\mathrm{x}$ \\
\hline \multicolumn{5}{|l|}{ Linear combination of estimates } \\
\hline Average pre-debate dummies $-3,-2$, and -1 & $\begin{array}{l}-0.001 \\
{[0.63]}\end{array}$ & $\begin{array}{l}-0.000 \\
{[0.88]}\end{array}$ & $\begin{array}{l}0.004 \\
{[0.63]}\end{array}$ & $\begin{array}{l}0.002 \\
{[0.79]}\end{array}$ \\
\hline Average post-debate dummies 1,2 , and 3 & $\begin{array}{l}0.001 \\
{[0.76]}\end{array}$ & $\begin{array}{l}0.002 \\
{[0.60]}\end{array}$ & $\begin{array}{l}0.014 \\
{[0.11]}\end{array}$ & $\begin{array}{l}0.012 \\
{[0.17]}\end{array}$ \\
\hline Number of replications & 1000 & 1000 & 1000 & 1000 \\
\hline
\end{tabular}

Notes: Same notes as in Table IV and Appendix Table C.3. 


\section{C.2 Standard Errors Adjusted for Clustering at the Election Date Level}

Table C.5: Vote choice consistency and distance to final vote shares, election date clusters

\begin{tabular}{|c|c|c|c|c|c|c|c|c|}
\hline & \multicolumn{2}{|c|}{$\begin{array}{l}\text { Vote choice } \\
\text { consistency }\end{array}$} & \multicolumn{2}{|c|}{$\begin{array}{c}\text { Vote } \\
\text { intention }\end{array}$} & \multicolumn{2}{|c|}{$\begin{array}{l}\text { Conditional } \\
\text { consistency }\end{array}$} & \multicolumn{2}{|c|}{$\begin{array}{l}\text { Distance between predicted } \\
\text { and final vote shares }\end{array}$} \\
\hline & (1) & (2) & (3) & (4) & (5) & (6) & (7) & (8) \\
\hline Time & $\begin{array}{c}0.0025^{* * *} \\
(0.0003)\end{array}$ & $\begin{array}{c}0.0061^{* * *} \\
(0.0008)\end{array}$ & $\begin{array}{c}0.0010^{* * *} \\
(0.0002)\end{array}$ & $\begin{array}{c}0.0031^{* * *} \\
(0.0005)\end{array}$ & $\begin{array}{c}0.0018^{* * *} \\
(0.0003)\end{array}$ & $\begin{array}{c}0.0038^{* * *} \\
(0.0007)\end{array}$ & $\begin{array}{c}-0.0008^{* * *} \\
(0.0002)\end{array}$ & $\begin{array}{c}-0.0013^{* * *} \\
(0.0005)\end{array}$ \\
\hline Time $^{2}$ & & $\begin{array}{c}0.0001^{* * *} \\
(0.0000)\end{array}$ & & $\begin{array}{c}0.0000^{* * *} \\
(0.0000)\end{array}$ & & $\begin{array}{c}0.0000^{* * *} \\
(0.0000)\end{array}$ & & $\begin{array}{c}-0.0000 \\
(0.0000)\end{array}$ \\
\hline Observations & 200916 & 200916 & 253489 & 253489 & 178176 & 178176 & 3125 & 3125 \\
\hline$R^{2}$ & 0.070 & 0.071 & 0.072 & 0.073 & 0.041 & 0.041 & 0.520 & 0.523 \\
\hline Mean at day -1 & 0.8768 & 0.8768 & 0.9157 & 0.9157 & 0.9346 & 0.9346 & 0.0324 & 0.0324 \\
\hline Election fixed effects & $\mathrm{x}$ & $\mathrm{x}$ & $\mathrm{x}$ & $\mathrm{x}$ & $\mathrm{x}$ & $\mathrm{x}$ & $\mathrm{x}$ & $\mathrm{x}$ \\
\hline Individual controls & $\mathrm{x}$ & $\mathrm{x}$ & $\mathrm{x}$ & $\mathrm{x}$ & $\mathrm{x}$ & $\mathrm{x}$ & & \\
\hline Aggregate controls & & & & & & & $\mathrm{x}$ & $\mathrm{x}$ \\
\hline
\end{tabular}

Notes: Standard errors are adjusted for clustering at the election date level. Other notes as in Table I. 
Table C.6: Drivers of vote choice formation, election date clusters

(a) Mean vote choice consistency

\begin{tabular}{lcccc}
\hline & \multicolumn{3}{c}{ Vote choice consistency } \\
\cline { 2 - 5 } & $(1)$ & $(2)$ & $(3)$ & $(4)$ \\
\hline Daily mean consistency in policy preferences & -0.103 & & & -0.138 \\
& $(0.115)$ & & & $(0.121)$ \\
Daily mean consistency in issue salience & & $0.255^{* *}$ & & $0.247^{* *}$ \\
& & $(0.095)$ & & $(0.095)$ \\
Daily mean consistency in beliefs on candidates & & & $0.134^{* *}$ & $0.126^{* *}$ \\
& & & $(0.063)$ & $(0.063)$ \\
\hline Observations & 3129 & 3129 & 3129 & 3129 \\
$R^{2}$ & 0.807 & 0.809 & 0.808 & 0.810 \\
Election fixed effects & $\mathrm{X}$ & $\mathrm{x}$ & $\mathrm{x}$ & $\mathrm{x}$ \\
Fixed effects for number of days to election & $\mathrm{x}$ & $\mathrm{x}$ & $\mathrm{x}$ & $\mathrm{x}$ \\
Aggregate controls & $\mathrm{x}$ & $\mathrm{x}$ & $\mathrm{x}$ & $\mathrm{x}$ \\
\hline
\end{tabular}

(b) Mean probability of stating a vote intention

\begin{tabular}{lcccc}
\hline & \multicolumn{3}{c}{ Mean probability of stating a vote intention } \\
\cline { 2 - 5 } & $(1)$ & $(2)$ & $(3)$ & $(4)$ \\
\hline Daily mean probability of stating a policy preference & 0.005 & & & -0.027 \\
& $(0.151)$ & & & $(0.150)$ \\
Daily probability of stating an important issue & & $0.200^{* * *}$ & & $0.203^{* * *}$ \\
& & $(0.053)$ & & $(0.052)$ \\
Daily mean probability of stating a belief on candidates & & & $0.234^{* * *}$ & $0.237^{* * *}$ \\
& & & $(0.076)$ & $(0.075)$ \\
\hline Observations & & & 3144 & 3144 \\
$R^{2}$ & 0.840 & 0.840 & 0.841 & 0.841 \\
Election fixed effects & $\mathrm{x}$ & $\mathrm{x}$ & $\mathrm{x}$ & $\mathrm{x}$ \\
Fixed effects for number of days to election & $\mathrm{x}$ & $\mathrm{x}$ & $\mathrm{x}$ & $\mathrm{x}$ \\
Aggregate controls & $\mathrm{x}$ & $\mathrm{x}$ & $\mathrm{x}$ & $\mathrm{x}$ \\
\hline
\end{tabular}

Notes: Same notes as in Table II and Appendix Table C.5. 
Table C.7: Debates' effects on vote choice consistency, election date clusters

\begin{tabular}{|c|c|c|c|c|c|c|}
\hline & \multicolumn{2}{|c|}{ Vote choice consistency } & \multicolumn{2}{|c|}{ Vote intention } & \multicolumn{2}{|c|}{ Conditional consistency } \\
\hline & (1) & (2) & (3) & (4) & (5) & (6) \\
\hline Before -3 & $\begin{array}{c}-0.014^{* *} \\
(0.007)\end{array}$ & $\begin{array}{c}-0.015^{* *} \\
(0.007)\end{array}$ & $\begin{array}{c}0.003 \\
(0.004)\end{array}$ & $\begin{array}{c}0.002 \\
(0.004)\end{array}$ & $\begin{array}{c}-0.015^{* *} \\
(0.006)\end{array}$ & $\begin{array}{c}-0.016^{* *} \\
(0.006)\end{array}$ \\
\hline-3 & $\begin{array}{l}-0.009 \\
(0.005)\end{array}$ & $\begin{array}{l}-0.010^{*} \\
(0.005)\end{array}$ & $\begin{array}{c}0.003 \\
(0.005)\end{array}$ & $\begin{array}{c}0.003 \\
(0.005)\end{array}$ & $\begin{array}{l}-0.005 \\
(0.005)\end{array}$ & $\begin{array}{l}-0.006 \\
(0.005)\end{array}$ \\
\hline-2 & $\begin{array}{c}-0.001 \\
(0.006)\end{array}$ & $\begin{array}{l}-0.002 \\
(0.006)\end{array}$ & $\begin{array}{l}0.007^{*} \\
(0.004)\end{array}$ & $\begin{array}{l}0.007^{*} \\
(0.004)\end{array}$ & $\begin{array}{l}-0.004 \\
(0.005)\end{array}$ & $\begin{array}{l}-0.004 \\
(0.006)\end{array}$ \\
\hline-1 & $\begin{array}{c}-0.001 \\
(0.006)\end{array}$ & $\begin{array}{l}-0.002 \\
(0.006)\end{array}$ & $\begin{array}{c}0.005 \\
(0.004)\end{array}$ & $\begin{array}{c}0.005 \\
(0.003)\end{array}$ & $\begin{array}{l}-0.001 \\
(0.005)\end{array}$ & $\begin{array}{l}-0.002 \\
(0.006)\end{array}$ \\
\hline+1 & $\begin{array}{c}-0.009 \\
(0.008)\end{array}$ & $\begin{array}{l}-0.009 \\
(0.008)\end{array}$ & $\begin{array}{c}0.007 \\
(0.005)\end{array}$ & $\begin{array}{c}0.007 \\
(0.005)\end{array}$ & $\begin{array}{c}-0.008 \\
(0.007)\end{array}$ & $\begin{array}{c}-0.008 \\
(0.007)\end{array}$ \\
\hline+2 & $\begin{array}{c}-0.007 \\
(0.007)\end{array}$ & $\begin{array}{l}-0.008 \\
(0.007)\end{array}$ & $\begin{array}{c}0.002 \\
(0.004)\end{array}$ & $\begin{array}{c}0.001 \\
(0.004)\end{array}$ & $\begin{array}{c}-0.007 \\
(0.006)\end{array}$ & $\begin{array}{l}-0.008 \\
(0.006)\end{array}$ \\
\hline+3 & $\begin{array}{l}-0.006 \\
(0.006)\end{array}$ & $\begin{array}{l}-0.006 \\
(0.006)\end{array}$ & $\begin{array}{l}0.007^{*} \\
(0.004)\end{array}$ & $\begin{array}{l}0.007^{*} \\
(0.004)\end{array}$ & $\begin{array}{l}-0.006 \\
(0.007)\end{array}$ & $\begin{array}{l}-0.006 \\
(0.007)\end{array}$ \\
\hline After +3 & $\begin{array}{c}-0.002 \\
(0.006)\end{array}$ & $\begin{array}{l}-0.003 \\
(0.006)\end{array}$ & $\begin{array}{l}0.008^{*} \\
(0.004)\end{array}$ & $\begin{array}{c}0.008 \\
(0.004)\end{array}$ & $\begin{array}{l}-0.005 \\
(0.005)\end{array}$ & $\begin{array}{l}-0.005 \\
(0.005)\end{array}$ \\
\hline Observations & 263681 & 263681 & 330621 & 330621 & 240826 & 240826 \\
\hline$R^{2}$ & 0.072 & 0.077 & 0.069 & 0.076 & 0.042 & 0.044 \\
\hline Mean, day of the debate & 0.811 & 0.811 & 0.896 & 0.896 & 0.887 & 0.887 \\
\hline Number of debates & 56 & 56 & 56 & 56 & 56 & 56 \\
\hline Debate $*$ election fixed effects & $\mathrm{x}$ & $\mathrm{x}$ & $\mathrm{x}$ & $\mathrm{x}$ & $\mathrm{x}$ & $\mathrm{x}$ \\
\hline Fixed effects for number of days to election & $\mathrm{x}$ & $\mathrm{x}$ & $\mathrm{x}$ & $\mathrm{x}$ & $\mathrm{x}$ & $\mathrm{x}$ \\
\hline Individual controls & $\mathrm{x}$ & $\mathrm{x}$ & $\mathrm{x}$ & $\mathrm{x}$ & $\mathrm{x}$ & $\mathrm{x}$ \\
\hline Sociodemographic controls & & $\mathrm{x}$ & & $\mathrm{x}$ & & $\mathrm{x}$ \\
\hline Linear combination of estimates & & & & & & \\
\hline Average pre-debate dummies $-3,-2$, and -1 & $\begin{array}{c}-0.004 \\
(0.005)\end{array}$ & $\begin{array}{l}-0.005 \\
(0.005)\end{array}$ & $\begin{array}{c}0.005 \\
(0.003)\end{array}$ & $\begin{array}{c}0.005 \\
(0.003)\end{array}$ & $\begin{array}{c}-0.003 \\
(0.004)\end{array}$ & $\begin{array}{l}-0.004 \\
(0.004)\end{array}$ \\
\hline Average post-debate dummies 1,2 , and 3 & $\begin{array}{c}-0.007 \\
(0.006)\end{array}$ & $\begin{array}{l}-0.008 \\
(0.006)\end{array}$ & $\begin{array}{c}0.005 \\
(0.004)\end{array}$ & $\begin{array}{c}0.005 \\
(0.004)\end{array}$ & $\begin{array}{c}-0.007 \\
(0.006)\end{array}$ & $\begin{array}{l}-0.007 \\
(0.006)\end{array}$ \\
\hline
\end{tabular}

Notes: Standard errors are adjusted for clustering at the election date level. Other notes as in Table III. 
Table C.8: Debates' effects on aggregate vote shares, election date clusters

\begin{tabular}{|c|c|c|c|c|}
\hline & \multicolumn{2}{|c|}{$\begin{array}{l}\text { Distance between predicted } \\
\text { and final vote shares }\end{array}$} & \multicolumn{2}{|c|}{$\begin{array}{l}\text { Daily change in } \\
\text { predicted vote shares }\end{array}$} \\
\hline & (1) & (2) & (3) & (4) \\
\hline Before -3 & $\begin{array}{c}0.005 \\
(0.003)\end{array}$ & $\begin{array}{c}0.006 \\
(0.004)\end{array}$ & $\begin{array}{l}0.009^{* *} \\
(0.004)\end{array}$ & $\begin{array}{c}0.007 \\
(0.005)\end{array}$ \\
\hline-3 & $\begin{array}{l}-0.001 \\
(0.003)\end{array}$ & $\begin{array}{c}0.000 \\
(0.004)\end{array}$ & $\begin{array}{l}-0.003 \\
(0.007)\end{array}$ & $\begin{array}{l}-0.004 \\
(0.006)\end{array}$ \\
\hline-2 & $\begin{array}{l}-0.000 \\
(0.004)\end{array}$ & $\begin{array}{c}0.000 \\
(0.004)\end{array}$ & $\begin{array}{c}0.001 \\
(0.008)\end{array}$ & $\begin{array}{l}-0.001 \\
(0.009)\end{array}$ \\
\hline-1 & $\begin{array}{l}-0.003 \\
(0.005)\end{array}$ & $\begin{array}{l}-0.002 \\
(0.005)\end{array}$ & $\begin{array}{l}0.013^{*} \\
(0.007)\end{array}$ & $\begin{array}{c}0.012 \\
(0.007)\end{array}$ \\
\hline+1 & $\begin{array}{c}0.002 \\
(0.004)\end{array}$ & $\begin{array}{c}0.002 \\
(0.004)\end{array}$ & $\begin{array}{l}0.008^{*} \\
(0.004)\end{array}$ & $\begin{array}{c}0.006 \\
(0.005)\end{array}$ \\
\hline+2 & $\begin{array}{c}0.000 \\
(0.004)\end{array}$ & $\begin{array}{c}0.001 \\
(0.005)\end{array}$ & $\begin{array}{c}0.022^{* * *} \\
(0.006)\end{array}$ & $\begin{array}{c}0.021^{* * *} \\
(0.007)\end{array}$ \\
\hline+3 & $\begin{array}{c}0.001 \\
(0.005)\end{array}$ & $\begin{array}{c}0.002 \\
(0.006)\end{array}$ & $\begin{array}{c}0.011 \\
(0.008)\end{array}$ & $\begin{array}{c}0.009 \\
(0.008)\end{array}$ \\
\hline After +3 & $\begin{array}{c}0.002 \\
(0.004)\end{array}$ & $\begin{array}{c}0.002 \\
(0.004)\end{array}$ & $\begin{array}{c}0.006 \\
(0.005)\end{array}$ & $\begin{array}{c}0.005 \\
(0.005)\end{array}$ \\
\hline Observations & 3802 & 3802 & 3749 & 3749 \\
\hline$R^{2}$ & 0.575 & 0.581 & 0.470 & 0.477 \\
\hline Mean, day of the debate & 0.046 & 0.046 & 0.085 & 0.085 \\
\hline Number of debates & 56 & 56 & 56 & 56 \\
\hline Debate * election fixed effects & $\mathrm{x}$ & $\mathrm{x}$ & $\mathrm{x}$ & $\mathrm{x}$ \\
\hline Fixed effects for number of days to election & $\mathrm{x}$ & $\mathrm{x}$ & $\mathrm{x}$ & $\mathrm{x}$ \\
\hline Aggregate controls & $\mathrm{x}$ & $\mathrm{x}$ & $\mathrm{x}$ & $\mathrm{x}$ \\
\hline Sociodemographic controls & & $\mathrm{x}$ & & $\mathrm{x}$ \\
\hline Linear combination of estimates & & & & \\
\hline Average pre-debate dummies $-3,-2$, and -1 & $\begin{array}{l}-0.001 \\
(0.004)\end{array}$ & $\begin{array}{l}-0.000 \\
(0.004)\end{array}$ & $\begin{array}{c}0.004 \\
(0.006)\end{array}$ & $\begin{array}{c}0.002 \\
(0.007)\end{array}$ \\
\hline Average post-debate dummies 1,2 , and 3 & $\begin{array}{c}0.001 \\
(0.004)\end{array}$ & $\begin{array}{c}0.002 \\
(0.004)\end{array}$ & $\begin{array}{l}0.014^{* *} \\
(0.005)\end{array}$ & $\begin{array}{l}0.012^{* *} \\
(0.005)\end{array}$ \\
\hline
\end{tabular}

Notes: Same notes as in Table IV and Appendix Table C.7. 


\section{C.3 Survey Weights}

To replicate the individual-level results from Figure I, columns 1 through 6 of Table I, and Table III, we weight each respondent by their survey weight, divided by the sum of weights assigned to respondents from the same survey who were surveyed on the same day. This method ensures that, on average, all respondents surveyed at the same time relative to the election have a weight of 1, which is important for the replication of Figure I. Indeed, it guarantees that the estimated coefficient $\beta_{1}$ in equation [1] corresponds exactly to the (weighted) average outcome among respondents surveyed one day before the election. To replicate the aggregate-level results from Figure III, columns 7 and 8 of Table I, and Table IV, we compute daily predicted and final vote shares as the sum of survey weights assigned to respondents voting for a given party, over the total sum of weights assigned to respondents from the same survey and surveyed on the same day. We further weight each election*day observation by the sum of survey weights assigned to respondents it was constructed from, relative to the total sum of weights assigned to respondents surveyed at the same relative time to the election. This step allows us to give more weight to observations measured more precisely, as we already do in our main specification. Finally, to replicate the intermediation results from Table II, we compute all mean quantities as weighted daily averages of the outcome of interest (e.g., vote choice consistency or policy preference consistency) where each respondent is weighted by their survey weight, divided by the sum of weights assigned to respondents from the same survey who were surveyed on the same day. Then, as in other aggregate-level specifications, we weight each election*day observation by the sum of survey weights assigned to respondents it was constructed from, relative to the total sum of weights assigned to respondents surveyed at the same relative time to the election.

All results are shown in Figure C.1 as well as Tables C.9 through C.12. 
Figure C.1: Vote choice consistency and distance to final vote shares, with survey weights

(a) Vote choice consistency

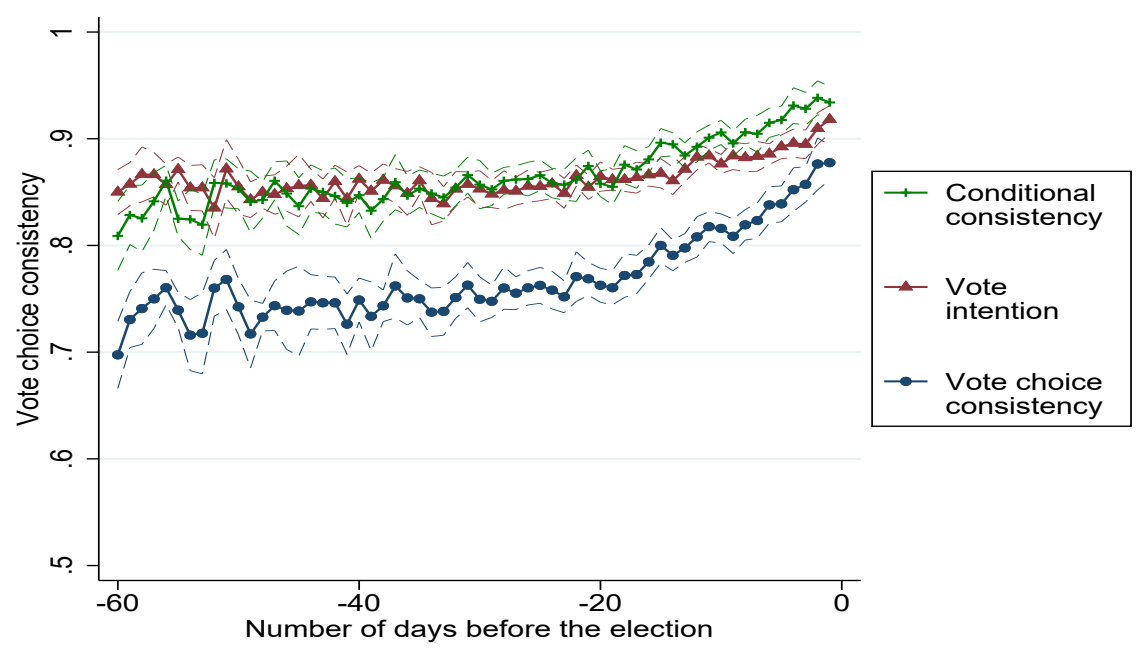

(b) Distance to final vote shares

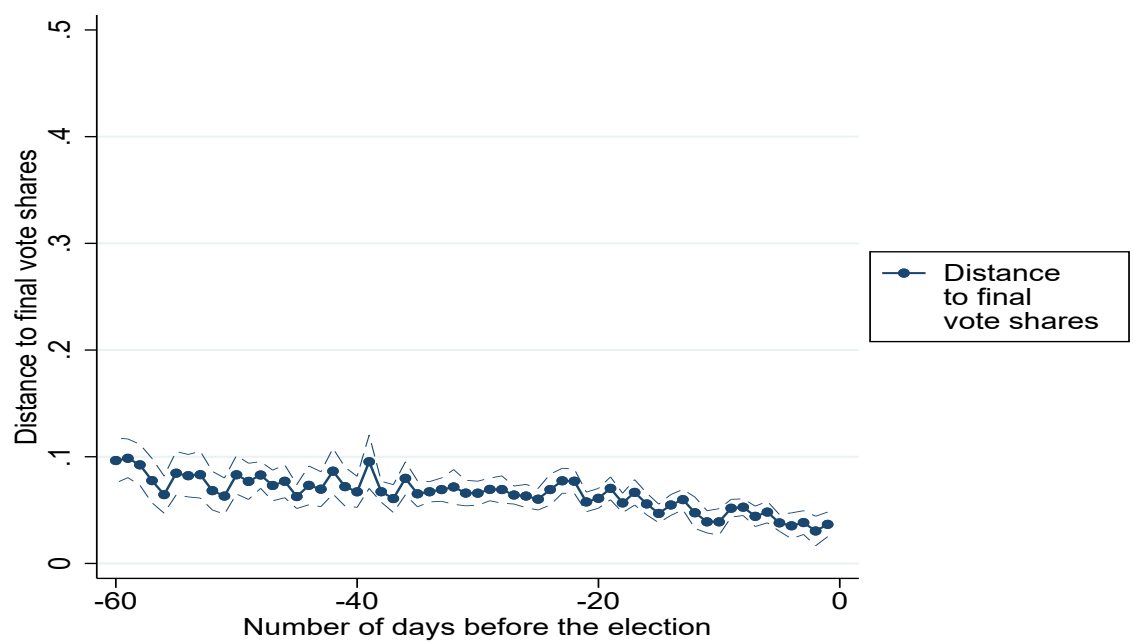

Notes: In Figure C.1a, each observation is weighted by the respondent's survey weight, divided by the sum of weights assigned to respondents from the same survey who were surveyed on the same day. Respondents whose survey weight is missing are excluded. In Figure C.1b, vote shares are computed as the sum of survey weights assigned to respondents voting for a given candidate over the total sum of weights assigned to respondents from the same survey who were surveyed on the same day. We use one observation per election per day and we weight each observation by the sum of survey weights assigned to respondents it was constructed from, relative to the total sum of survey weights assigned to respondents surveyed at the same relative time to the election. Other notes as in Figures I and III. 
Table C.9: Vote choice consistency and distance to final vote shares, with survey weights

\begin{tabular}{|c|c|c|c|c|c|c|c|c|}
\hline & \multicolumn{2}{|c|}{$\begin{array}{l}\text { Vote choice } \\
\text { consistency }\end{array}$} & \multicolumn{2}{|c|}{$\begin{array}{c}\text { Vote } \\
\text { intention }\end{array}$} & \multicolumn{2}{|c|}{$\begin{array}{l}\text { Conditional } \\
\text { consistency }\end{array}$} & \multicolumn{2}{|c|}{$\begin{array}{l}\text { Distance between predicted } \\
\text { and final vote shares }\end{array}$} \\
\hline & (1) & (2) & (3) & (4) & (5) & (6) & (7) & (8) \\
\hline Time & $\begin{array}{c}0.0024^{* * *} \\
(0.0003)\end{array}$ & $\begin{array}{c}0.0062^{* * *} \\
(0.0008)\end{array}$ & $\begin{array}{c}0.0009^{* * *} \\
(0.0002)\end{array}$ & $\begin{array}{c}0.0031^{* * *} \\
(0.0005)\end{array}$ & $\begin{array}{c}0.0018^{* * *} \\
(0.0002)\end{array}$ & $\begin{array}{c}0.0041^{* * *} \\
(0.0007)\end{array}$ & $\begin{array}{c}-0.0008^{* * *} \\
(0.0002)\end{array}$ & $\begin{array}{c}-0.0015^{* * *} \\
(0.0005)\end{array}$ \\
\hline Time $^{2}$ & & $\begin{array}{c}0.0001^{* * *} \\
(0.0000)\end{array}$ & & $\begin{array}{c}0.0000^{* * *} \\
(0.0000)\end{array}$ & & $\begin{array}{c}0.0000^{* * *} \\
(0.0000)\end{array}$ & & $\begin{array}{l}-0.0000^{*} \\
(0.0000)\end{array}$ \\
\hline Observations & 200375 & 200375 & 252859 & 252859 & 177722 & 177722 & 3125 & 3125 \\
\hline$R^{2}$ & 0.070 & 0.072 & 0.074 & 0.074 & 0.041 & 0.042 & 0.491 & 0.494 \\
\hline Mean at day -1 & 0.8776 & 0.8776 & 0.9181 & 0.9181 & 0.9340 & 0.9340 & 0.0366 & 0.0366 \\
\hline Election fixed effects & $\mathrm{x}$ & $\mathrm{x}$ & $\mathrm{x}$ & $\mathrm{x}$ & $\mathrm{x}$ & $\mathrm{x}$ & $\mathrm{x}$ & $\mathrm{x}$ \\
\hline Individual controls & $\mathrm{x}$ & $\mathrm{x}$ & $\mathrm{x}$ & $\mathrm{x}$ & $\mathrm{x}$ & $\mathrm{x}$ & & \\
\hline Aggreghdfeate controls & & & & & & & $\mathrm{x}$ & $\mathrm{x}$ \\
\hline
\end{tabular}

Notes: In columns 1 through 6, each observation is weighted by the respondent's survey weight, divided by the sum of weights assigned to respondents from the same survey who were surveyed on the same day. Respondents whose survey weight is missing are excluded. In columns 7 and 8, vote shares are computed as the sum of survey weights assigned to respondents voting for a given candidate over the total sum of weights assigned to respondents from the same survey who were surveyed on the same day. Other notes as in Table I. 
Table C.10: Drivers of vote choice formation, with survey weights

(a) Mean vote choice consistency

\begin{tabular}{lcccc}
\hline & \multicolumn{3}{c}{ Mean vote choice consistency } \\
\cline { 2 - 5 } & $(1)$ & $(2)$ & $(3)$ & $(4)$ \\
\hline Mean consistency in policy preferences & $0.249^{* *}$ & & & $0.179^{* *}$ \\
& $(0.097)$ & & & $(0.086)$ \\
Mean consistency in issue salience & & $0.268^{* * *}$ & & $0.248^{* *}$ \\
& & $(0.099)$ & & $(0.099)$ \\
Mean consistency in beliefs on candidates & & & $0.207^{* * *}$ & $0.163^{* * *}$ \\
& & & $(0.045)$ & $(0.044)$ \\
\hline Observations & 3129 & 3129 & 3129 & 3129 \\
$R^{2}$ & 0.728 & 0.729 & 0.729 & 0.731 \\
Election fixed effects & $\mathrm{x}$ & $\mathrm{x}$ & $\mathrm{x}$ & $\mathrm{x}$ \\
Fixed effects for number of days to election & $\mathrm{x}$ & $\mathrm{x}$ & $\mathrm{x}$ & $\mathrm{x}$ \\
Aggregate controls & $\mathrm{x}$ & $\mathrm{x}$ & $\mathrm{x}$ & $\mathrm{x}$ \\
\hline
\end{tabular}

(b) Mean probability of stating a vote intention

\begin{tabular}{lcccc}
\hline & \multicolumn{3}{c}{ Mean probability of stating a vote intention } \\
\cline { 2 - 6 } & $(1)$ & $(2)$ & $(3)$ & $(4)$ \\
\hline Mean probability of stating a policy preference & 0.073 & & & 0.023 \\
& $(0.140)$ & & & $(0.111)$ \\
Mean probability of stating a salient issue & & $0.278^{* * *}$ & & $0.278^{* * *}$ \\
& & $(0.101)$ & & $(0.102)$ \\
Mean probability of stating a belief on candidates & & & $0.215^{* * *}$ & $0.211^{* * *}$ \\
& & & $(0.044)$ & $(0.043)$ \\
\hline Observations & 3144 & 3144 & 3144 & 3144 \\
$R^{2}$ & 0.731 & 0.732 & 0.732 & 0.733 \\
Election fixed effects & $\mathrm{x}$ & $\mathrm{x}$ & $\mathrm{x}$ & $\mathrm{x}$ \\
Fixed effects for number of days to election & $\mathrm{x}$ & $\mathrm{x}$ & $\mathrm{x}$ & $\mathrm{x}$ \\
Aggregate controls & $\mathrm{x}$ & $\mathrm{x}$ & $\mathrm{x}$ & $\mathrm{x}$ \\
\hline
\end{tabular}

Notes: We compute all mean quantities as weighted daily averages of the outcome of interest (e.g., vote choice consistency or policy preference consistency) where each respondent is weighted by their survey weight, divided by the sum of weights assigned to respondents from the same survey who were surveyed on the same day. We use one observation per election per day and we weight each observation by the sum of survey weights assigned to respondents it was constructed from, relative to the total sum of survey weights assigned to respondents surveyed at the same relative time to the election. Other notes as in Table II. 
Table C.11: Debates' effects on vote choice consistency, with survey weights

\begin{tabular}{|c|c|c|c|c|c|c|}
\hline & \multicolumn{2}{|c|}{ Vote choice consistency } & \multicolumn{2}{|c|}{ Vote intention } & \multicolumn{2}{|c|}{ Conditional consistency } \\
\hline & (1) & (2) & (3) & (4) & (5) & (6) \\
\hline Before -3 & $\begin{array}{l}-0.013^{*} \\
(0.007)\end{array}$ & $\begin{array}{l}-0.014^{*} \\
(0.008)\end{array}$ & $\begin{array}{c}0.002 \\
(0.005)\end{array}$ & $\begin{array}{c}0.001 \\
(0.005)\end{array}$ & $\begin{array}{c}-0.014^{* *} \\
(0.006)\end{array}$ & $\begin{array}{c}-0.015^{* *} \\
(0.006)\end{array}$ \\
\hline-3 & $\begin{array}{l}-0.008 \\
(0.008)\end{array}$ & $\begin{array}{l}-0.009 \\
(0.008)\end{array}$ & $\begin{array}{c}0.004 \\
(0.006)\end{array}$ & $\begin{array}{c}0.004 \\
(0.006)\end{array}$ & $\begin{array}{l}-0.005 \\
(0.007)\end{array}$ & $\begin{array}{l}-0.006 \\
(0.007)\end{array}$ \\
\hline-2 & $\begin{array}{c}0.001 \\
(0.011)\end{array}$ & $\begin{array}{c}0.000 \\
(0.011)\end{array}$ & $\begin{array}{l}0.010^{*} \\
(0.006)\end{array}$ & $\begin{array}{l}0.010^{*} \\
(0.006)\end{array}$ & $\begin{array}{l}-0.004 \\
(0.009)\end{array}$ & $\begin{array}{l}-0.005 \\
(0.009)\end{array}$ \\
\hline-1 & $\begin{array}{c}0.004 \\
(0.009)\end{array}$ & $\begin{array}{c}0.003 \\
(0.009)\end{array}$ & $\begin{array}{c}0.010 \\
(0.006)\end{array}$ & $\begin{array}{c}0.009 \\
(0.006)\end{array}$ & $\begin{array}{c}0.000 \\
(0.006)\end{array}$ & $\begin{array}{l}-0.001 \\
(0.006)\end{array}$ \\
\hline+1 & $\begin{array}{l}-0.009 \\
(0.009)\end{array}$ & $\begin{array}{l}-0.010 \\
(0.009)\end{array}$ & $\begin{array}{c}0.005 \\
(0.007)\end{array}$ & $\begin{array}{c}0.006 \\
(0.007)\end{array}$ & $\begin{array}{c}-0.008 \\
(0.007)\end{array}$ & $\begin{array}{l}-0.008 \\
(0.007)\end{array}$ \\
\hline+2 & $\begin{array}{l}-0.007 \\
(0.009)\end{array}$ & $\begin{array}{l}-0.008 \\
(0.009)\end{array}$ & $\begin{array}{c}0.002 \\
(0.006)\end{array}$ & $\begin{array}{c}0.002 \\
(0.006)\end{array}$ & $\begin{array}{c}-0.008 \\
(0.008)\end{array}$ & $\begin{array}{l}-0.009 \\
(0.008)\end{array}$ \\
\hline+3 & $\begin{array}{l}-0.006 \\
(0.008)\end{array}$ & $\begin{array}{l}-0.007 \\
(0.008)\end{array}$ & $\begin{array}{l}0.009^{*} \\
(0.005)\end{array}$ & $\begin{array}{l}0.009^{*} \\
(0.005)\end{array}$ & $\begin{array}{l}-0.007 \\
(0.006)\end{array}$ & $\begin{array}{l}-0.007 \\
(0.006)\end{array}$ \\
\hline After +3 & $\begin{array}{c}-0.002 \\
(0.007)\end{array}$ & $\begin{array}{l}-0.003 \\
(0.007)\end{array}$ & $\begin{array}{c}0.008 \\
(0.005)\end{array}$ & $\begin{array}{c}0.007 \\
(0.005)\end{array}$ & $\begin{array}{l}-0.004 \\
(0.005)\end{array}$ & $\begin{array}{l}-0.005 \\
(0.005)\end{array}$ \\
\hline Observations & 263677 & 263677 & 330617 & 330617 & 240822 & 240822 \\
\hline$R^{2}$ & 0.075 & 0.080 & 0.072 & 0.079 & 0.044 & 0.047 \\
\hline Mean, day of the debate & 0.812 & 0.812 & 0.801 & 0.801 & 0.888 & 0.888 \\
\hline Number of debates & 56 & 56 & 56 & 56 & 56 & 56 \\
\hline Debate $*$ election fixed effects & $\mathrm{x}$ & $\mathrm{x}$ & $\mathrm{x}$ & $\mathrm{x}$ & $\mathrm{x}$ & $\mathrm{x}$ \\
\hline Fixed effects for number of days to election & $\mathrm{x}$ & $\mathrm{x}$ & $\mathrm{x}$ & $\mathrm{x}$ & $\mathrm{x}$ & $\mathrm{x}$ \\
\hline Individual controls & $\mathrm{x}$ & $\mathrm{x}$ & $\mathrm{x}$ & $\mathrm{x}$ & $\mathrm{x}$ & $\mathrm{x}$ \\
\hline Sociodemographic controls & & $\mathrm{x}$ & & $\mathrm{x}$ & & $\mathrm{x}$ \\
\hline Linear combination of estimates & & & & & & \\
\hline Average pre-debate dummies $-3,-2$, and -1 & $\begin{array}{l}-0.001 \\
(0.008)\end{array}$ & $\begin{array}{l}-0.002 \\
(0.008)\end{array}$ & $\begin{array}{c}0.008 \\
(0.005)\end{array}$ & $\begin{array}{c}0.008 \\
(0.005)\end{array}$ & $\begin{array}{c}-0.003 \\
(0.006)\end{array}$ & $\begin{array}{l}-0.004 \\
(0.006)\end{array}$ \\
\hline Average post-debate dummies 1,2 , and 3 & $\begin{array}{l}-0.008 \\
(0.008)\end{array}$ & $\begin{array}{l}-0.008 \\
(0.008)\end{array}$ & $\begin{array}{c}0.006 \\
(0.005)\end{array}$ & $\begin{array}{c}0.006 \\
(0.005)\end{array}$ & $\begin{array}{c}-0.007 \\
(0.006)\end{array}$ & $\begin{array}{l}-0.008 \\
(0.006)\end{array}$ \\
\hline
\end{tabular}

Notes: Each observation is weighted by the respondent's survey weight, divided by the sum of weights among respondents from the same survey who were surveyed on the same day. Respondents whose survey weight is missing are excluded. Other notes as in Table III. 
Table C.12: Debates' effects on aggregate vote shares, with survey weights

\begin{tabular}{|c|c|c|c|c|}
\hline & \multicolumn{2}{|c|}{$\begin{array}{l}\text { Distance between predicted } \\
\text { and final vote shares }\end{array}$} & \multicolumn{2}{|c|}{$\begin{array}{c}\text { Daily change in } \\
\text { predicted vote shares }\end{array}$} \\
\hline & (1) & (2) & (3) & (4) \\
\hline Before -3 & $\begin{array}{c}0.005 \\
(0.004)\end{array}$ & $\begin{array}{c}0.005 \\
(0.004)\end{array}$ & $\begin{array}{c}0.001 \\
(0.008)\end{array}$ & $\begin{array}{c}0.001 \\
(0.008)\end{array}$ \\
\hline-3 & $\begin{array}{l}-0.000 \\
(0.005)\end{array}$ & $\begin{array}{c}0.000 \\
(0.005)\end{array}$ & $\begin{array}{l}-0.010 \\
(0.010)\end{array}$ & $\begin{array}{l}-0.010 \\
(0.010)\end{array}$ \\
\hline-2 & $\begin{array}{c}0.000 \\
(0.004)\end{array}$ & $\begin{array}{c}0.000 \\
(0.004)\end{array}$ & $\begin{array}{l}-0.008 \\
(0.009)\end{array}$ & $\begin{array}{l}-0.010 \\
(0.009)\end{array}$ \\
\hline-1 & $\begin{array}{l}-0.002 \\
(0.005)\end{array}$ & $\begin{array}{l}-0.002 \\
(0.005)\end{array}$ & $\begin{array}{c}0.004 \\
(0.007)\end{array}$ & $\begin{array}{c}0.004 \\
(0.007)\end{array}$ \\
\hline+1 & $\begin{array}{c}0.002 \\
(0.005)\end{array}$ & $\begin{array}{c}0.002 \\
(0.005)\end{array}$ & $\begin{array}{c}0.001 \\
(0.010)\end{array}$ & $\begin{array}{l}-0.002 \\
(0.010)\end{array}$ \\
\hline+2 & $\begin{array}{c}0.004 \\
(0.006)\end{array}$ & $\begin{array}{c}0.004 \\
(0.006)\end{array}$ & $\begin{array}{c}0.018 \\
(0.013)\end{array}$ & $\begin{array}{c}0.018 \\
(0.013)\end{array}$ \\
\hline+3 & $\begin{array}{l}-0.001 \\
(0.005)\end{array}$ & $\begin{array}{l}-0.001 \\
(0.005)\end{array}$ & $\begin{array}{c}0.001 \\
(0.011)\end{array}$ & $\begin{array}{l}-0.000 \\
(0.011)\end{array}$ \\
\hline After +3 & $\begin{array}{c}0.002 \\
(0.004)\end{array}$ & $\begin{array}{c}0.002 \\
(0.004)\end{array}$ & $\begin{array}{c}0.002 \\
(0.007)\end{array}$ & $\begin{array}{c}0.001 \\
(0.007)\end{array}$ \\
\hline Observations & 3802 & 3802 & 3749 & 3749 \\
\hline$R^{2}$ & 0.569 & 0.572 & 0.476 & 0.482 \\
\hline Mean, day of the debate & 0.048 & 0.048 & 0.100 & 0.100 \\
\hline Number of debates & 56 & 56 & 56 & 56 \\
\hline Debate * election fixed effects & $\mathrm{x}$ & $\mathrm{x}$ & $\mathrm{x}$ & $\mathrm{x}$ \\
\hline Fixed effects for number of days to election & $\mathrm{x}$ & $\mathrm{x}$ & $\mathrm{x}$ & $\mathrm{x}$ \\
\hline Aggregate controls & $\mathrm{x}$ & $\mathrm{x}$ & $\mathrm{x}$ & $\mathrm{x}$ \\
\hline Sociodemographic controls & & $\mathrm{x}$ & & $\mathrm{x}$ \\
\hline \multicolumn{5}{|l|}{ Linear combination of estimates } \\
\hline Average pre-debate dummies $-3,-2$, and -1 & $\begin{array}{l}-0.001 \\
(0.004)\end{array}$ & $\begin{array}{l}-0.000 \\
(0.004)\end{array}$ & $\begin{array}{l}-0.004 \\
(0.008)\end{array}$ & $\begin{array}{l}-0.005 \\
(0.008)\end{array}$ \\
\hline Average post-debate dummies 1,2 , and 3 & $\begin{array}{c}0.002 \\
(0.004)\end{array}$ & $\begin{array}{c}0.002 \\
(0.004)\end{array}$ & $\begin{array}{c}0.007 \\
(0.011)\end{array}$ & $\begin{array}{c}0.005 \\
(0.010)\end{array}$ \\
\hline
\end{tabular}

Notes: Vote shares are computed as the sum of survey weights assigned to respondents voting for a given candidate over the total sum of weights assigned to respondents from the same survey who were surveyed on the same day. Other notes as in Table IV. 


\section{C.4 Sociodemographic Controls}

Figure C.2: Vote choice consistency and distance to final vote shares, with sociodemographic controls

(a) Vote choice consistency

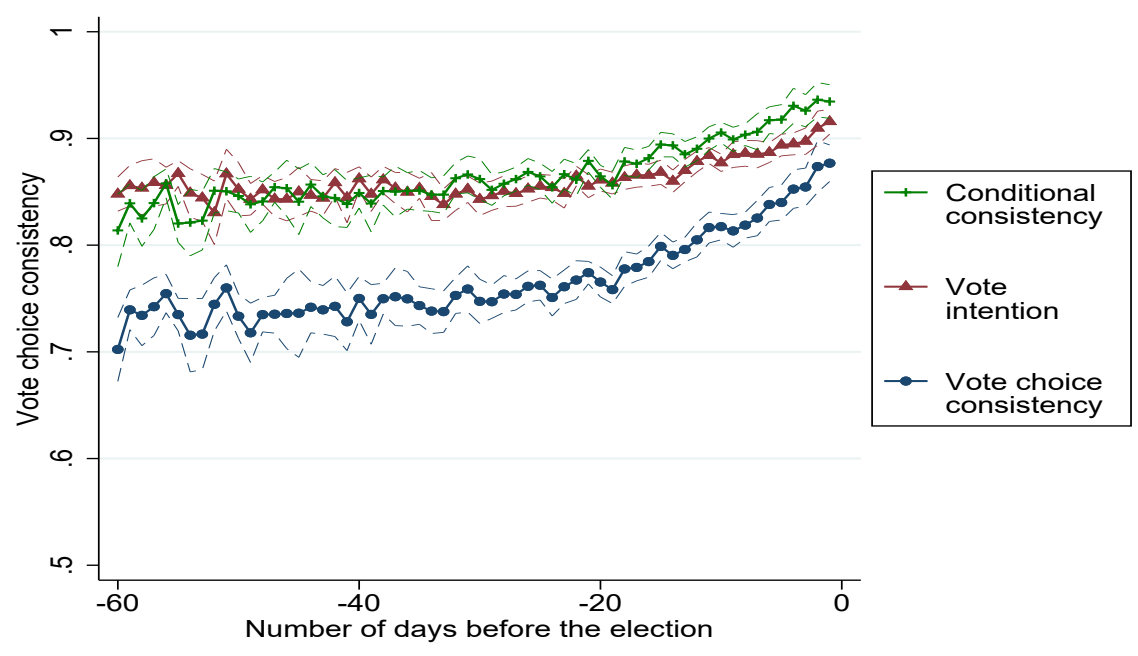

(b) Distance to final vote shares

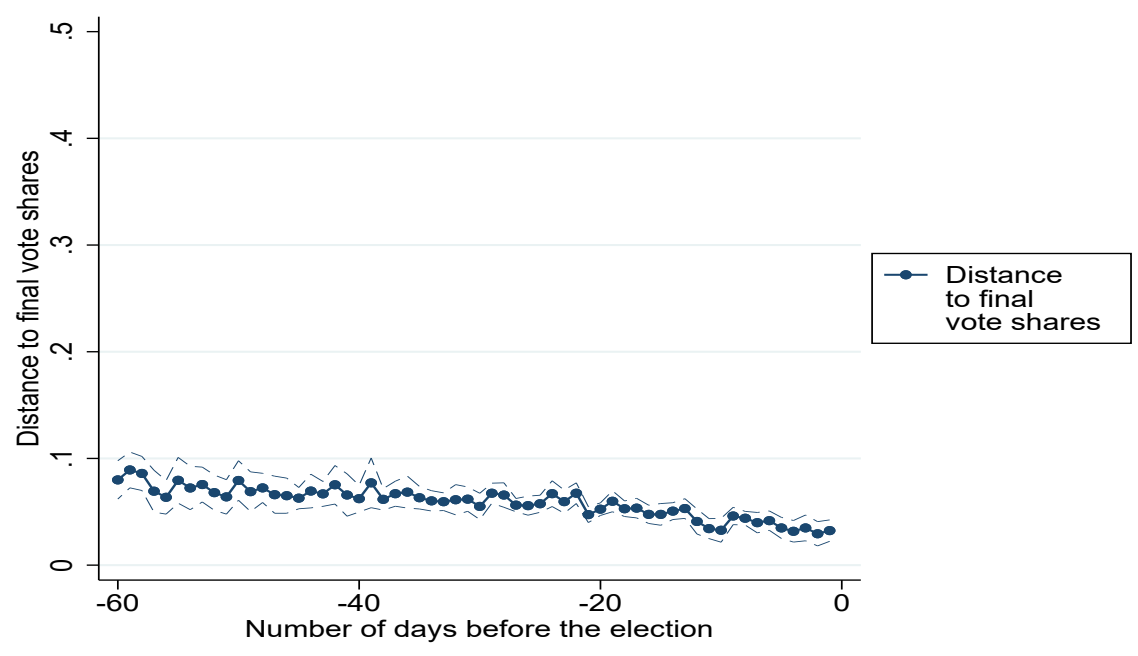

Notes: Each sociodemographic characteristic from Appendix Table A.10 and a dummy indicating whether it is missing are included. Other notes as in Figures I and III. 
Table C.13: Vote choice consistency and distance to final vote shares, with sociodemographic controls

\begin{tabular}{|c|c|c|c|c|c|c|c|c|}
\hline & \multicolumn{2}{|c|}{$\begin{array}{l}\text { Vote choice } \\
\text { consistency }\end{array}$} & \multicolumn{2}{|c|}{$\begin{array}{c}\text { Vote } \\
\text { intention }\end{array}$} & \multicolumn{2}{|c|}{$\begin{array}{l}\text { Conditional } \\
\text { consistency }\end{array}$} & \multicolumn{2}{|c|}{$\begin{array}{l}\text { Distance between predicted } \\
\text { and final vote shares }\end{array}$} \\
\hline & (1) & (2) & (3) & (4) & (5) & (6) & (7) & (8) \\
\hline Time & $\begin{array}{r}0.0025^{* * *} \\
(0.0003)\end{array}$ & $\begin{array}{l}0.0062^{* * *} \\
(0.0008)\end{array}$ & $\begin{array}{r}0.0010^{* * *} \\
(0.0002)\end{array}$ & $\begin{array}{c}0.0032^{* * *} \\
(0.0005)\end{array}$ & $\begin{array}{r}0.0018^{* * *} \\
(0.0003)\end{array}$ & $\begin{array}{c}0.0039^{* * *} \\
(0.0007)\end{array}$ & $\begin{array}{c}-0.0008^{* * *} \\
(0.0002)\end{array}$ & $\begin{array}{c}-0.0013^{* * *} \\
(0.0005)\end{array}$ \\
\hline Time $^{2}$ & & $\begin{array}{c}0.0001^{* * *} \\
(0.0000)\end{array}$ & & $\begin{array}{c}0.0000^{* * *} \\
(0.0000)\end{array}$ & & $\begin{array}{c}0.0000^{* * *} \\
(0.0000)\end{array}$ & & $\begin{array}{l}-0.0000 \\
(0.0000)\end{array}$ \\
\hline Observations & 200916 & 200916 & 253489 & 253489 & 178176 & 178176 & 3125 & 3125 \\
\hline$R^{2}$ & 0.075 & 0.077 & 0.080 & 0.080 & 0.043 & 0.043 & 0.522 & 0.524 \\
\hline Mean at day -1 & 0.8768 & 0.8768 & 0.9157 & 0.9157 & 0.9346 & 0.9346 & 0.0324 & 0.0324 \\
\hline Election fixed effects & $\mathrm{x}$ & $\mathrm{x}$ & $\mathrm{x}$ & $\mathrm{x}$ & $\mathrm{x}$ & $\mathrm{x}$ & $\mathrm{x}$ & $\mathrm{x}$ \\
\hline Individual controls & $\mathrm{x}$ & $\mathrm{x}$ & $\mathrm{x}$ & $\mathrm{x}$ & $\mathrm{x}$ & $\mathrm{x}$ & & \\
\hline Aggregate controls & & & & & & & $\mathrm{x}$ & $\mathrm{x}$ \\
\hline Sociodemographic controls & $\mathrm{x}$ & $\mathrm{x}$ & $\mathrm{x}$ & $\mathrm{x}$ & $\mathrm{x}$ & $\mathrm{x}$ & $\mathrm{x}$ & $\mathrm{x}$ \\
\hline
\end{tabular}

Notes: Each sociodemographic characteristic from Appendix Table A.10 and a dummy indicating whether it is missing are included. Other notes as in Table I. 
Table C.14: Drivers of vote choice formation, with sociodemographic controls

(a) Mean vote choice consistency

\begin{tabular}{lcccc}
\hline & \multicolumn{4}{c}{ Mean vote choice consistency } \\
\cline { 2 - 5 } & $(1)$ & $(2)$ & $(3)$ & $(4)$ \\
\hline Daily mean consistency in policy preferences & -0.107 & & & -0.140 \\
& $(0.119)$ & & & $(0.125)$ \\
Daily mean consistency in issue salience & & $0.260^{* * *}$ & & $0.252^{* *}$ \\
& & $(0.096)$ & & $(0.096)$ \\
Daily mean consistency in beliefs on candidates & & & $0.132^{* *}$ & $0.124^{*}$ \\
& & & $(0.065)$ & $(0.065)$ \\
\hline Observations & 3129 & 3129 & 3129 & 3129 \\
$R^{2}$ & 0.809 & 0.810 & 0.809 & 0.811 \\
Election fixed effects & $\mathrm{x}$ & $\mathrm{x}$ & $\mathrm{x}$ & $\mathrm{x}$ \\
Fixed effects for number of days to election & $\mathrm{x}$ & $\mathrm{x}$ & $\mathrm{x}$ & $\mathrm{x}$ \\
Aggregate controls & $\mathrm{x}$ & $\mathrm{x}$ & $\mathrm{x}$ & $\mathrm{x}$ \\
Sociodemographic controls & $\mathrm{x}$ & $\mathrm{x}$ & $\mathrm{x}$ & $\mathrm{x}$ \\
\hline
\end{tabular}

(b) Mean probability of stating a vote intention

\begin{tabular}{lcccc}
\hline & \multicolumn{3}{l}{ Mean probability of stating a vote intention } \\
\cline { 2 - 5 } & $(1)$ & $(2)$ & $(3)$ & $(4)$ \\
\hline Daily mean probability of stating a policy preference & -0.016 & & & -0.044 \\
& $(0.150)$ & & & $(0.150)$ \\
Daily probability of stating an important issue & & $0.201^{* * *}$ & & $0.204^{* * *}$ \\
& & $(0.056)$ & & $(0.055)$ \\
Daily mean probability of stating a belief on candidates & & & $0.221^{* * *}$ & $0.226^{* * *}$ \\
& & & $(0.082)$ & $(0.080)$ \\
\hline Observations & 3144 & 3144 & 3144 & 3144 \\
$R^{2}$ & 0.842 & 0.843 & 0.843 & 0.844 \\
Election fixed effects & $\mathrm{x}$ & $\mathrm{x}$ & $\mathrm{x}$ & $\mathrm{x}$ \\
Fixed effects for number of days to election & $\mathrm{x}$ & $\mathrm{x}$ & $\mathrm{x}$ & $\mathrm{x}$ \\
Aggregate controls & $\mathrm{x}$ & $\mathrm{x}$ & $\mathrm{x}$ & $\mathrm{x}$ \\
Sociodemographic controls & $\mathrm{x}$ & $\mathrm{x}$ & $\mathrm{x}$ & $\mathrm{x}$ \\
\hline
\end{tabular}

Notes: Same notes as in Table II and Appendix Table C.13. We control for the daily average of each sociodemographic characteristic from Appendix Table A.10. 


\section{C.5 Rolling Cross-Sections}

Figure C.3: Vote choice consistency and distance to final vote shares, rolling cross-sections

(a) Vote choice consistency

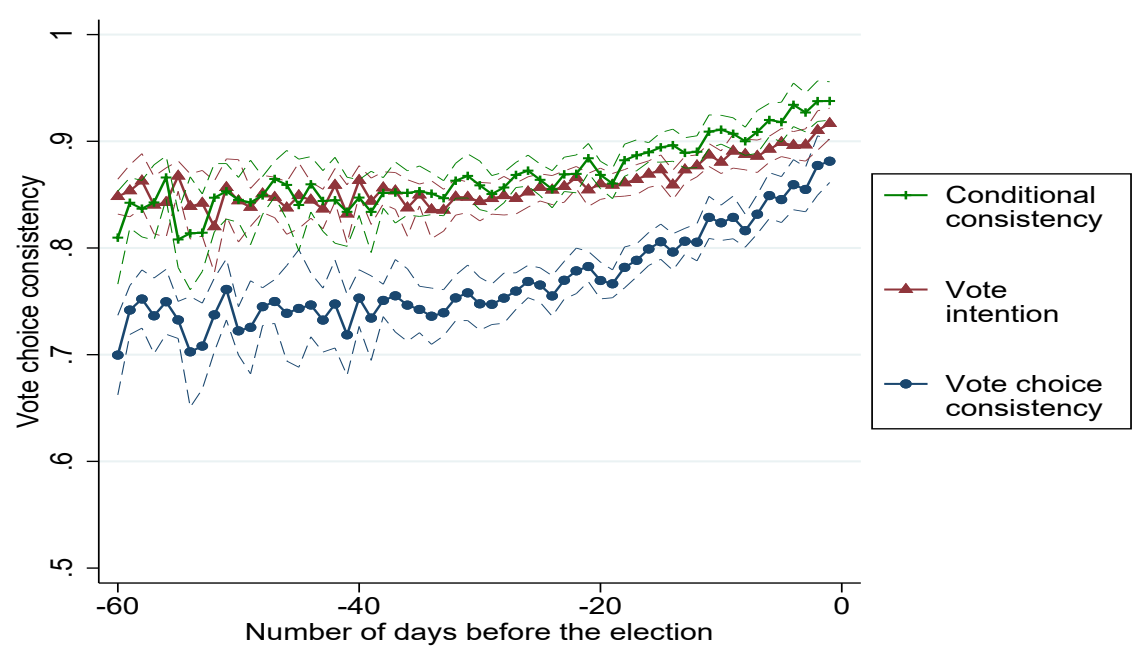

(b) Distance to final vote shares

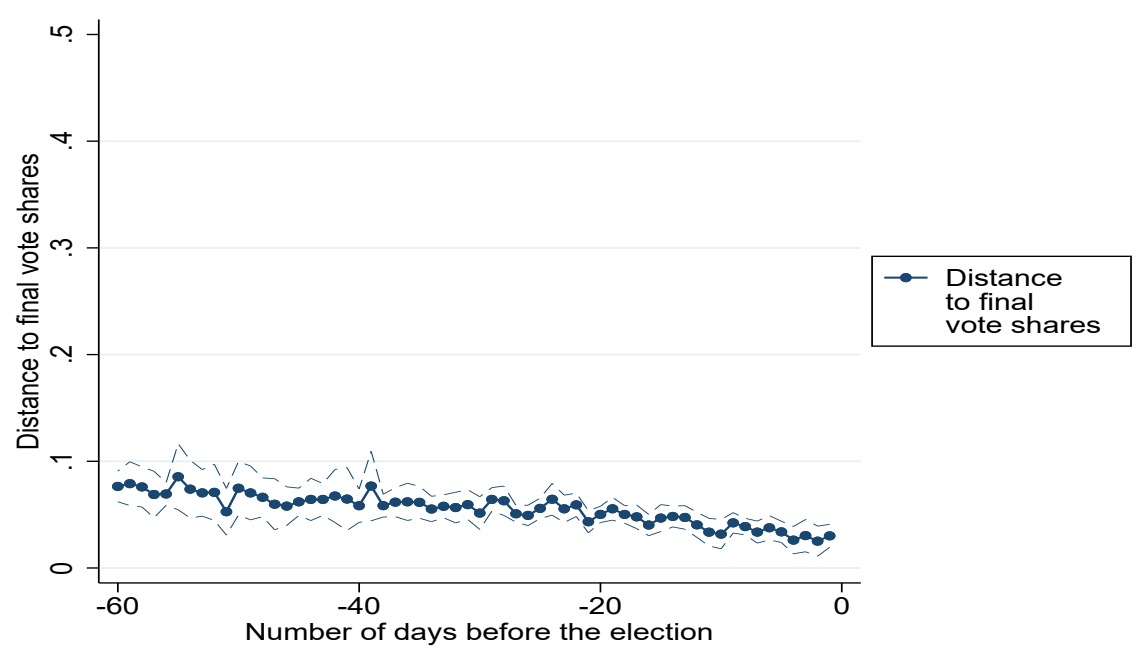

Notes: The sample is restricted to the 31 surveys designed as rolling cross-sections. Other notes as in Figures I and III. 
Table C.15: Vote choice consistency and distance to final vote shares, rolling cross-sections

\begin{tabular}{|c|c|c|c|c|c|c|c|c|}
\hline & \multicolumn{2}{|c|}{$\begin{array}{l}\text { Vote choice } \\
\text { consistency }\end{array}$} & \multicolumn{2}{|c|}{$\begin{array}{c}\text { Vote } \\
\text { intention }\end{array}$} & \multicolumn{2}{|c|}{$\begin{array}{l}\text { Conditional } \\
\text { consistency }\end{array}$} & \multicolumn{2}{|c|}{$\begin{array}{l}\text { Distance between predicted } \\
\text { and final vote shares }\end{array}$} \\
\hline & (1) & (2) & (3) & (4) & (5) & (6) & (7) & (8) \\
\hline Time & $\begin{array}{c}0.0028^{* * *} \\
(0.0004)\end{array}$ & $\begin{array}{c}0.0062^{* * *} \\
(0.0010)\end{array}$ & $\begin{array}{c}0.0012^{* * *} \\
(0.0002)\end{array}$ & $\begin{array}{c}0.0034^{* * *} \\
(0.0007)\end{array}$ & $\begin{array}{c}0.0019^{* * *} \\
(0.0003)\end{array}$ & $\begin{array}{c}0.0038^{* * *} \\
(0.0008)\end{array}$ & $\begin{array}{c}-0.0008^{* * *} \\
(0.0002)\end{array}$ & $\begin{array}{c}-0.0013^{* *} \\
(0.0005)\end{array}$ \\
\hline Time $^{2}$ & & $\begin{array}{c}0.0001^{* * *} \\
(0.0000)\end{array}$ & & $\begin{array}{c}0.0000^{* * *} \\
(0.0000)\end{array}$ & & $\begin{array}{c}0.0000^{* * *} \\
(0.0000)\end{array}$ & & $\begin{array}{c}-0.0000 \\
(0.0000)\end{array}$ \\
\hline Observations & 136211 & 136211 & 175514 & 175514 & 120611 & 120611 & 1418 & 1418 \\
\hline$R^{2}$ & 0.083 & 0.084 & 0.075 & 0.075 & 0.049 & 0.050 & 0.611 & 0.613 \\
\hline Mean at day -1 & 0.8814 & 0.8814 & 0.9166 & 0.9166 & 0.9378 & 0.9378 & 0.0302 & 0.0302 \\
\hline Election fixed effects & $\mathrm{x}$ & $\mathrm{x}$ & $\mathrm{x}$ & $\mathrm{x}$ & $\mathrm{x}$ & $\mathrm{x}$ & $\mathrm{x}$ & $\mathrm{x}$ \\
\hline Individual controls & $\mathrm{x}$ & $\mathrm{x}$ & $\mathrm{x}$ & $\mathrm{x}$ & $\mathrm{x}$ & $\mathrm{x}$ & & \\
\hline Aggregate controls & & & & & & & $\mathrm{x}$ & $\mathrm{x}$ \\
\hline
\end{tabular}

Notes: The sample is restricted to the 31 surveys designed as rolling cross-sections. Other notes as in Table I. 
Table C.16: Drivers of vote choice formation, rolling cross-sections

(a) Mean vote choice consistency

\begin{tabular}{lcccc}
\hline & \multicolumn{3}{c}{ Mean vote choice consistency } \\
\cline { 2 - 5 } & $(1)$ & $(2)$ & $(3)$ & $(4)$ \\
\hline Mean consistency in policy preferences & -0.273 & & & -0.303 \\
& $(0.221)$ & & & $(0.220)$ \\
Mean consistency in issue salience & & $0.229^{* *}$ & & $0.226^{* *}$ \\
& & $(0.093)$ & & $(0.090)$ \\
Mean consistency in beliefs on candidates & & & 0.092 & 0.092 \\
& & & $(0.064)$ & $(0.061)$ \\
\hline Observations & 1418 & 1418 & 1418 & 1418 \\
$R^{2}$ & 0.854 & 0.856 & 0.854 & 0.857 \\
Election fixed effects & $\mathrm{x}$ & $\mathrm{x}$ & $\mathrm{x}$ & $\mathrm{x}$ \\
Fixed effects for number of days to election & $\mathrm{x}$ & $\mathrm{x}$ & $\mathrm{x}$ & $\mathrm{x}$ \\
Aggregate controls & $\mathrm{x}$ & $\mathrm{x}$ & $\mathrm{x}$ & $\mathrm{x}$ \\
\hline
\end{tabular}

(b) Mean probability of stating a vote intention

\begin{tabular}{lcccc}
\hline & \multicolumn{3}{l}{ Mean probability of stating a vote intention } \\
\cline { 2 - 5 } & $(1)$ & $(2)$ & $(3)$ & $(4)$ \\
\hline Mean probability of stating a policy preference & -0.116 & & & -0.168 \\
& $(0.246)$ & & & $(0.233)$ \\
Mean probability of stating a salient issue & & $0.191^{* * *}$ & & $0.192^{* * *}$ \\
& & $(0.068)$ & & $(0.065)$ \\
Mean probability of stating a belief on candidates & & & $0.201^{* *}$ & $0.217^{* * *}$ \\
& & & $(0.081)$ & $(0.075)$ \\
\hline Observations & 1418 & 1418 & 1418 & 1418 \\
$R^{2}$ & 0.877 & 0.878 & 0.878 & 0.879 \\
Election fixed effects & $\mathrm{X}$ & $\mathrm{X}$ & $\mathrm{X}$ & $\mathrm{X}$ \\
Fixed effects for number of days to election & $\mathrm{X}$ & $\mathrm{x}$ & $\mathrm{x}$ & $\mathrm{x}$ \\
Aggregate controls & $\mathrm{x}$ & $\mathrm{x}$ & $\mathrm{x}$ & $\mathrm{x}$ \\
\hline
\end{tabular}

Notes: Same notes as in Table II and Appendix Table C.15. 
Table C.17: Debates' effects on vote choice consistency, rolling cross-sections

\begin{tabular}{|c|c|c|c|c|c|c|}
\hline & \multicolumn{2}{|c|}{ Vote choice consistency } & \multicolumn{2}{|c|}{ Vote intention } & \multicolumn{2}{|c|}{ Conditional consistency } \\
\hline & (1) & (2) & (3) & $(4)$ & (5) & (6) \\
\hline Before -3 & $\begin{array}{c}-0.017^{* *} \\
(0.007)\end{array}$ & $\begin{array}{c}-0.017^{* *} \\
(0.008)\end{array}$ & $\begin{array}{c}0.002 \\
(0.006)\end{array}$ & $\begin{array}{c}0.001 \\
(0.006)\end{array}$ & $\begin{array}{c}-0.016^{* *} \\
(0.007)\end{array}$ & $\begin{array}{c}-0.017^{* *} \\
(0.007)\end{array}$ \\
\hline-3 & $\begin{array}{l}-0.010 \\
(0.008)\end{array}$ & $\begin{array}{c}-0.010 \\
(0.008)\end{array}$ & $\begin{array}{c}0.008 \\
(0.006)\end{array}$ & $\begin{array}{c}0.008 \\
(0.006)\end{array}$ & $\begin{array}{l}-0.010 \\
(0.008)\end{array}$ & $\begin{array}{l}-0.010 \\
(0.008)\end{array}$ \\
\hline-2 & $\begin{array}{c}-0.001 \\
(0.011)\end{array}$ & $\begin{array}{c}-0.002 \\
(0.010)\end{array}$ & $\begin{array}{c}0.007 \\
(0.006)\end{array}$ & $\begin{array}{c}0.006 \\
(0.006)\end{array}$ & $\begin{array}{c}-0.002 \\
(0.009)\end{array}$ & $\begin{array}{l}-0.003 \\
(0.009)\end{array}$ \\
\hline-1 & $\begin{array}{l}-0.005 \\
(0.010)\end{array}$ & $\begin{array}{l}-0.006 \\
(0.010)\end{array}$ & $\begin{array}{c}0.005 \\
(0.008)\end{array}$ & $\begin{array}{c}0.004 \\
(0.008)\end{array}$ & $\begin{array}{l}-0.004 \\
(0.006)\end{array}$ & $\begin{array}{l}-0.005 \\
(0.006)\end{array}$ \\
\hline+1 & $\begin{array}{l}-0.013 \\
(0.009)\end{array}$ & $\begin{array}{l}-0.013 \\
(0.009)\end{array}$ & $\begin{array}{c}0.009 \\
(0.008)\end{array}$ & $\begin{array}{c}0.009 \\
(0.008)\end{array}$ & $\begin{array}{l}-0.013 \\
(0.008)\end{array}$ & $\begin{array}{c}-0.013 \\
(0.008)\end{array}$ \\
\hline+2 & $\begin{array}{l}-0.015 \\
(0.010)\end{array}$ & $\begin{array}{l}-0.015 \\
(0.010)\end{array}$ & $\begin{array}{l}-0.001 \\
(0.006)\end{array}$ & $\begin{array}{l}-0.002 \\
(0.006)\end{array}$ & $\begin{array}{l}-0.012 \\
(0.009)\end{array}$ & $\begin{array}{c}-0.012 \\
(0.009)\end{array}$ \\
\hline+3 & $\begin{array}{l}-0.005 \\
(0.007)\end{array}$ & $\begin{array}{l}-0.006 \\
(0.007)\end{array}$ & $\begin{array}{l}0.010^{*} \\
(0.005)\end{array}$ & $\begin{array}{l}0.009^{*} \\
(0.005)\end{array}$ & $\begin{array}{l}-0.009 \\
(0.006)\end{array}$ & $\begin{array}{l}-0.009 \\
(0.006)\end{array}$ \\
\hline After +3 & $\begin{array}{l}-0.005 \\
(0.008)\end{array}$ & $\begin{array}{l}-0.006 \\
(0.008)\end{array}$ & $\begin{array}{c}0.009 \\
(0.007)\end{array}$ & $\begin{array}{c}0.008 \\
(0.007)\end{array}$ & $\begin{array}{l}-0.008 \\
(0.006)\end{array}$ & $\begin{array}{c}-0.008 \\
(0.006)\end{array}$ \\
\hline Observations & 211105 & 211105 & 264252 & 264252 & 192493 & 192493 \\
\hline$R^{2}$ & 0.074 & 0.078 & 0.071 & 0.078 & 0.040 & 0.042 \\
\hline Mean, day of the debate & 0.810 & 0.810 & 0.892 & 0.892 & 0.886 & 0.886 \\
\hline Number of debates & 27 & 27 & 27 & 27 & 27 & 27 \\
\hline Debate * election fixed effects & $\mathrm{x}$ & $\mathrm{x}$ & $\mathrm{x}$ & $\mathrm{x}$ & $\mathrm{x}$ & $\mathrm{x}$ \\
\hline Fixed effects for number of days to election & $\mathrm{x}$ & $\mathrm{x}$ & $\mathrm{x}$ & $\mathrm{x}$ & $\mathrm{x}$ & $\mathrm{x}$ \\
\hline Individual controls & $\mathrm{x}$ & $\mathrm{x}$ & $\mathrm{x}$ & $\mathrm{x}$ & $\mathrm{x}$ & $\mathrm{x}$ \\
\hline Sociodemographic controls & & $\mathrm{x}$ & & $\mathrm{x}$ & & $\mathrm{x}$ \\
\hline Linear combination of estimates & & & & & & \\
\hline Average pre-debate dummies $-3,-2$, and -1 & $\begin{array}{c}-0.005 \\
(0.008)\end{array}$ & $\begin{array}{l}-0.006 \\
(0.008)\end{array}$ & $\begin{array}{c}0.006 \\
(0.005)\end{array}$ & $\begin{array}{c}0.006 \\
(0.005)\end{array}$ & $\begin{array}{l}-0.005 \\
(0.007)\end{array}$ & $\begin{array}{c}-0.006 \\
(0.007)\end{array}$ \\
\hline Average post-debate dummies 1,2 , and 3 & $\begin{array}{c}-0.011 \\
(0.007)\end{array}$ & $\begin{array}{c}-0.011 \\
(0.007)\end{array}$ & $\begin{array}{c}0.006 \\
(0.006)\end{array}$ & $\begin{array}{c}0.006 \\
(0.006)\end{array}$ & $\begin{array}{c}-0.011 \\
(0.007)\end{array}$ & $\begin{array}{l}-0.011 \\
(0.007)\end{array}$ \\
\hline
\end{tabular}

Notes: The sample is restricted to the 27 debates covered by surveys designed as rolling cross-sections. Other notes as in Table III. 
Table C.18: Debates' effects on aggregate vote shares, rolling cross-sections

\begin{tabular}{|c|c|c|c|c|}
\hline & \multicolumn{2}{|c|}{$\begin{array}{l}\text { Distance between predicted } \\
\text { and final vote shares }\end{array}$} & \multicolumn{2}{|c|}{$\begin{array}{l}\text { Daily change in } \\
\text { predicted vote shares }\end{array}$} \\
\hline & (1) & (2) & (3) & (4) \\
\hline Before -3 & $\begin{array}{l}0.008^{*} \\
(0.004)\end{array}$ & $\begin{array}{l}0.009^{*} \\
(0.005)\end{array}$ & $\begin{array}{c}0.011 \\
(0.007)\end{array}$ & $\begin{array}{c}0.010 \\
(0.007)\end{array}$ \\
\hline-3 & $\begin{array}{c}0.004 \\
(0.004)\end{array}$ & $\begin{array}{c}0.006 \\
(0.005)\end{array}$ & $\begin{array}{c}0.007 \\
(0.010)\end{array}$ & $\begin{array}{c}0.007 \\
(0.011)\end{array}$ \\
\hline-2 & $\begin{array}{c}0.004 \\
(0.003)\end{array}$ & $\begin{array}{c}0.006 \\
(0.004)\end{array}$ & $\begin{array}{c}0.009 \\
(0.007)\end{array}$ & $\begin{array}{c}0.008 \\
(0.007)\end{array}$ \\
\hline-1 & $\begin{array}{c}0.002 \\
(0.004)\end{array}$ & $\begin{array}{c}0.005 \\
(0.005)\end{array}$ & $\begin{array}{c}0.019^{* * *} \\
(0.006)\end{array}$ & $\begin{array}{c}0.019^{* * *} \\
(0.006)\end{array}$ \\
\hline+1 & $\begin{array}{c}0.005 \\
(0.004)\end{array}$ & $\begin{array}{c}0.006 \\
(0.004)\end{array}$ & $\begin{array}{c}0.007 \\
(0.007)\end{array}$ & $\begin{array}{c}0.006 \\
(0.007)\end{array}$ \\
\hline+2 & $\begin{array}{c}0.007 \\
(0.004)\end{array}$ & $\begin{array}{c}0.008 \\
(0.005)\end{array}$ & $\begin{array}{l}0.021^{* *} \\
(0.010)\end{array}$ & $\begin{array}{l}0.021^{* *} \\
(0.010)\end{array}$ \\
\hline+3 & $\begin{array}{c}0.006 \\
(0.005)\end{array}$ & $\begin{array}{c}0.008 \\
(0.006)\end{array}$ & $\begin{array}{l}0.014^{*} \\
(0.008)\end{array}$ & $\begin{array}{c}0.014 \\
(0.008)\end{array}$ \\
\hline After +3 & $\begin{array}{c}0.005 \\
(0.004)\end{array}$ & $\begin{array}{c}0.005 \\
(0.004)\end{array}$ & $\begin{array}{c}0.007 \\
(0.005)\end{array}$ & $\begin{array}{c}0.006 \\
(0.005)\end{array}$ \\
\hline Observations & 1689 & 1689 & 1665 & 1665 \\
\hline$R^{2}$ & 0.668 & 0.678 & 0.604 & 0.609 \\
\hline Mean, day of the debate & 0.040 & 0.040 & 0.071 & 0.071 \\
\hline Number of debates & 27 & 27 & 27 & 27 \\
\hline Debate * election fixed effects & $\mathrm{x}$ & $\mathrm{x}$ & $\mathrm{x}$ & $\mathrm{x}$ \\
\hline Fixed effects for number of days to election & $\mathrm{x}$ & $\mathrm{x}$ & $\mathrm{x}$ & $\mathrm{x}$ \\
\hline Aggregate controls & $\mathrm{x}$ & $\mathrm{x}$ & $\mathrm{x}$ & $\mathrm{x}$ \\
\hline Sociodemographic controls & & $\mathrm{x}$ & & $\mathrm{x}$ \\
\hline Linear combination of estimates & & & & \\
\hline Average pre-debate dummies $-3,-2$, and -1 & $\begin{array}{c}0.004 \\
(0.003)\end{array}$ & $\begin{array}{c}0.006 \\
(0.004)\end{array}$ & $\begin{array}{l}0.012^{*} \\
(0.006)\end{array}$ & $\begin{array}{l}0.011^{*} \\
(0.006)\end{array}$ \\
\hline Average post-debate dummies 1,2 , and 3 & $\begin{array}{l}0.006^{*} \\
(0.003)\end{array}$ & $\begin{array}{l}0.007^{*} \\
(0.004)\end{array}$ & $\begin{array}{l}0.014^{*} \\
(0.007)\end{array}$ & $\begin{array}{l}0.014^{*} \\
(0.007)\end{array}$ \\
\hline
\end{tabular}

Notes: Same notes as in Table IV and Appendix Table C.17. 


\section{C.6 Including Unlikely Voters}

Figure C.4: Vote choice consistency and distance to final vote shares, including unlikely voters

(a) Vote choice consistency

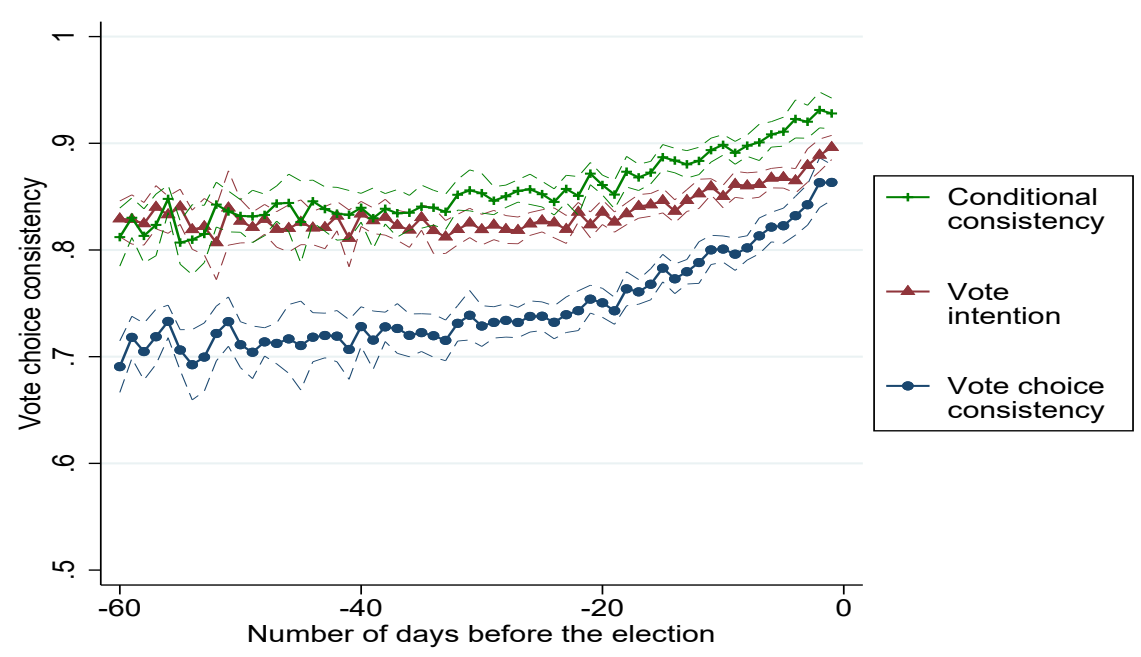

(b) Distance to final vote shares

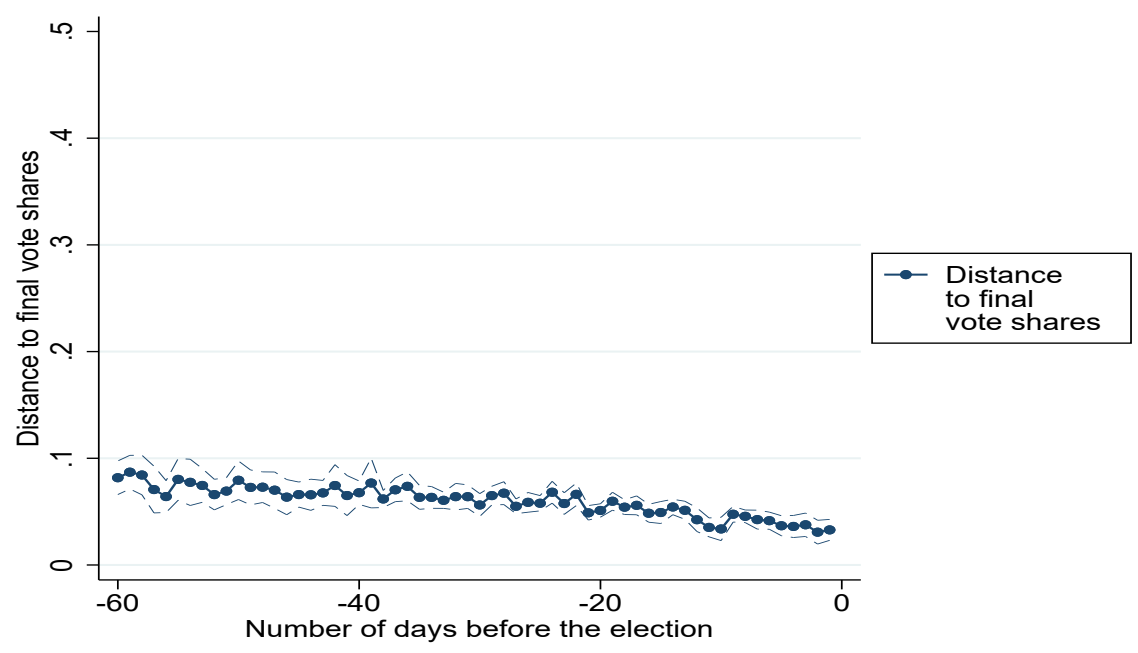

Notes: The sample includes all respondents who were asked whom they intended to vote for, including those who said they were unlikely to vote. Other notes as in Figures I and III. 
Table C.19: Vote choice consistency and distance to final vote shares, including unlikely voters

\begin{tabular}{|c|c|c|c|c|c|c|c|c|}
\hline & \multicolumn{2}{|c|}{$\begin{array}{l}\text { Vote choice } \\
\text { consistency }\end{array}$} & \multicolumn{2}{|c|}{$\begin{array}{c}\text { Vote } \\
\text { intention }\end{array}$} & \multicolumn{2}{|c|}{$\begin{array}{l}\text { Conditional } \\
\text { consistency }\end{array}$} & \multicolumn{2}{|c|}{$\begin{array}{l}\text { Distance between predicted } \\
\text { and final vote shares }\end{array}$} \\
\hline & (1) & (2) & (3) & (4) & (5) & (6) & (7) & (8) \\
\hline Time & $\begin{array}{c}0.0027^{* * *} \\
(0.0003)\end{array}$ & $\begin{array}{c}0.0066^{* * *} \\
(0.0007)\end{array}$ & $\begin{array}{c}0.0011^{* * *} \\
(0.0002)\end{array}$ & $\begin{array}{c}0.0037^{* * *} \\
(0.0005)\end{array}$ & $\begin{array}{c}0.0019^{* * *} \\
(0.0003)\end{array}$ & $\begin{array}{c}0.0040^{* * *} \\
(0.0007)\end{array}$ & $\begin{array}{c}-0.0008^{* * *} \\
(0.0002)\end{array}$ & $\begin{array}{c}-0.0013^{* * *} \\
(0.0004)\end{array}$ \\
\hline Time $^{2}$ & & $\begin{array}{c}0.0001^{* * *} \\
(0.0000)\end{array}$ & & $\begin{array}{c}0.0000^{* * *} \\
(0.0000)\end{array}$ & & $\begin{array}{c}0.0000^{* * *} \\
(0.0000)\end{array}$ & & $\begin{array}{l}-0.0000 \\
(0.0000)\end{array}$ \\
\hline Observations & 218269 & 218269 & 293913 & 293913 & 190927 & 190927 & 3125 & 3125 \\
\hline$R^{2}$ & 0.069 & 0.071 & 0.065 & 0.066 & 0.042 & 0.042 & 0.537 & 0.539 \\
\hline Mean at day -1 & 0.8633 & 0.8633 & 0.8961 & 0.8961 & 0.9280 & 0.9280 & 0.0329 & 0.0329 \\
\hline Election fixed effects & $\mathrm{x}$ & $\mathrm{x}$ & $\mathrm{x}$ & $\mathrm{x}$ & $\mathrm{x}$ & $\mathrm{x}$ & $\mathrm{x}$ & $\mathrm{x}$ \\
\hline Individual controls & $\mathrm{x}$ & $\mathrm{x}$ & $\mathrm{x}$ & $\mathrm{x}$ & $\mathrm{x}$ & $\mathrm{x}$ & & \\
\hline $\begin{array}{l}\text { Aggreghdfeate controls } \\
\text { Sociodemographic controls }\end{array}$ & & & & & & & $\mathrm{x}$ & $\mathrm{x}$ \\
\hline
\end{tabular}

Notes: The sample includes all respondents who were asked whom they intended to vote for, including those who said they were unlikely to vote. Other notes as in Table I. 
Table C.20: Drivers of vote choice formation, including unlikely voters

(a) Mean vote choice consistency

\begin{tabular}{lcccc}
\hline & \multicolumn{3}{c}{ Mean vote choice consistency } \\
\cline { 2 - 5 } & $(1)$ & $(2)$ & $(3)$ & $(4)$ \\
\hline Mean consistency in policy preferences & -0.066 & & & -0.104 \\
& $(0.104)$ & & & $(0.109)$ \\
Mean consistency in issue salience & & $0.255^{* * *}$ & & $0.245^{* *}$ \\
& & $(0.093)$ & & $(0.092)$ \\
Mean consistency in beliefs on candidates & & & $0.157^{* *}$ & $0.147^{* *}$ \\
& & & $(0.067)$ & $(0.066)$ \\
\hline Observations & 3129 & 3129 & 3129 & 3129 \\
$R^{2}$ & 0.820 & 0.822 & 0.821 & 0.823 \\
Election fixed effects & $\mathrm{X}$ & $\mathrm{x}$ & $\mathrm{x}$ & $\mathrm{x}$ \\
Fixed effects for number of days to election & $\mathrm{X}$ & $\mathrm{X}$ & $\mathrm{x}$ & $\mathrm{x}$ \\
Aggregate controls & $\mathrm{x}$ & $\mathrm{x}$ & $\mathrm{x}$ & $\mathrm{x}$ \\
\hline
\end{tabular}

(b) Mean probability of stating a vote intention

\begin{tabular}{lcccc}
\hline & \multicolumn{3}{l}{ Mean probability of stating a vote intention } \\
\cline { 2 - 5 } & $(1)$ & $(2)$ & $(3)$ & $(4)$ \\
\hline Mean probability of stating a policy preference & 0.162 & & & 0.114 \\
& $(0.160)$ & & & $(0.146)$ \\
Mean probability of stating a salient issue & & $0.197^{* * *}$ & & $0.206^{* * *}$ \\
& & $(0.046)$ & & $(0.047)$ \\
Mean probability of stating a belief on candidates & & & $0.318^{* * *}$ & $0.313^{* * *}$ \\
& & & $(0.066)$ & $(0.067)$ \\
\hline Observations & 3144 & 3144 & 3144 & 3144 \\
$R^{2}$ & 0.841 & 0.841 & 0.843 & 0.843 \\
Election fixed effects & $\mathrm{x}$ & $\mathrm{x}$ & $\mathrm{x}$ & $\mathrm{x}$ \\
Fixed effects for number of days to election & $\mathrm{x}$ & $\mathrm{x}$ & $\mathrm{x}$ & $\mathrm{x}$ \\
Aggregate controls & $\mathrm{x}$ & $\mathrm{x}$ & $\mathrm{x}$ & $\mathrm{x}$ \\
\hline
\end{tabular}

Notes: Same notes as in Table II and Appendix Table C.19. 
Table C.21: Debates' effects on vote choice consistency, including unlikely voters

\begin{tabular}{|c|c|c|c|c|c|c|}
\hline & \multicolumn{2}{|c|}{ Vote choice consistency } & \multicolumn{2}{|c|}{ Vote intention } & \multicolumn{2}{|c|}{ Conditional consistency } \\
\hline & (1) & (2) & (3) & (4) & (5) & (6) \\
\hline Before -3 & $\begin{array}{c}-0.015^{* *} \\
(0.007)\end{array}$ & $\begin{array}{c}-0.016^{* *} \\
(0.007)\end{array}$ & $\begin{array}{l}-0.001 \\
(0.005)\end{array}$ & $\begin{array}{l}-0.002 \\
(0.005)\end{array}$ & $\begin{array}{c}-0.015^{* * *} \\
(0.005)\end{array}$ & $\begin{array}{c}-0.016^{* * *} \\
(0.005)\end{array}$ \\
\hline-3 & $\begin{array}{l}-0.009 \\
(0.006)\end{array}$ & $\begin{array}{l}-0.010 \\
(0.007)\end{array}$ & $\begin{array}{c}0.002 \\
(0.006)\end{array}$ & $\begin{array}{c}0.001 \\
(0.006)\end{array}$ & $\begin{array}{l}-0.004 \\
(0.006)\end{array}$ & $\begin{array}{l}-0.005 \\
(0.006)\end{array}$ \\
\hline-2 & $\begin{array}{c}-0.004 \\
(0.008)\end{array}$ & $\begin{array}{c}-0.005 \\
(0.008)\end{array}$ & $\begin{array}{c}0.002 \\
(0.005)\end{array}$ & $\begin{array}{c}0.002 \\
(0.005)\end{array}$ & $\begin{array}{c}-0.005 \\
(0.006)\end{array}$ & $\begin{array}{l}-0.006 \\
(0.006)\end{array}$ \\
\hline-1 & $\begin{array}{c}-0.007 \\
(0.007)\end{array}$ & $\begin{array}{c}-0.008 \\
(0.007)\end{array}$ & $\begin{array}{c}0.001 \\
(0.006)\end{array}$ & $\begin{array}{c}0.001 \\
(0.006)\end{array}$ & $\begin{array}{c}-0.004 \\
(0.006)\end{array}$ & $\begin{array}{l}-0.005 \\
(0.006)\end{array}$ \\
\hline+1 & $\begin{array}{c}-0.010 \\
(0.008)\end{array}$ & $\begin{array}{c}-0.010 \\
(0.008)\end{array}$ & $\begin{array}{c}0.006 \\
(0.007)\end{array}$ & $\begin{array}{c}0.006 \\
(0.007)\end{array}$ & $\begin{array}{c}-0.009 \\
(0.007)\end{array}$ & $\begin{array}{l}-0.009 \\
(0.007)\end{array}$ \\
\hline+2 & $\begin{array}{c}-0.009 \\
(0.009)\end{array}$ & $\begin{array}{l}-0.011 \\
(0.009)\end{array}$ & $\begin{array}{l}-0.000 \\
(0.006)\end{array}$ & $\begin{array}{l}-0.001 \\
(0.006)\end{array}$ & $\begin{array}{l}-0.008 \\
(0.007)\end{array}$ & $\begin{array}{l}-0.009 \\
(0.007)\end{array}$ \\
\hline+3 & $\begin{array}{l}-0.005 \\
(0.006)\end{array}$ & $\begin{array}{l}-0.006 \\
(0.006)\end{array}$ & $\begin{array}{c}0.004 \\
(0.005)\end{array}$ & $\begin{array}{c}0.004 \\
(0.005)\end{array}$ & $\begin{array}{l}-0.005 \\
(0.005)\end{array}$ & $\begin{array}{l}-0.006 \\
(0.005)\end{array}$ \\
\hline After +3 & $\begin{array}{c}-0.002 \\
(0.007)\end{array}$ & $\begin{array}{c}-0.003 \\
(0.007)\end{array}$ & $\begin{array}{c}0.005 \\
(0.006)\end{array}$ & $\begin{array}{c}0.005 \\
(0.006)\end{array}$ & $\begin{array}{l}-0.004 \\
(0.005)\end{array}$ & $\begin{array}{l}-0.005 \\
(0.005)\end{array}$ \\
\hline Observations & 284942 & 284942 & 378317 & 378317 & 257507 & 257507 \\
\hline$R^{2}$ & 0.073 & 0.079 & 0.066 & 0.077 & 0.042 & 0.045 \\
\hline Mean, day of the debate & 0.795 & 0.795 & 0.878 & 0.878 & 0.880 & 0.880 \\
\hline Number of debates & 56 & 56 & 56 & 56 & 56 & 56 \\
\hline Debate $*$ election fixed effects & $\mathrm{x}$ & $\mathrm{x}$ & $\mathrm{x}$ & $\mathrm{x}$ & $\mathrm{x}$ & $\mathrm{x}$ \\
\hline Fixed effects for number of days to election & $\mathrm{x}$ & $\mathrm{x}$ & $\mathrm{x}$ & $\mathrm{x}$ & $\mathrm{x}$ & $\mathrm{x}$ \\
\hline Individual controls & $\mathrm{x}$ & $\mathrm{x}$ & $\mathrm{x}$ & $\mathrm{x}$ & $\mathrm{x}$ & $\mathrm{x}$ \\
\hline Sociodemographic controls & & $\mathrm{x}$ & & $\mathrm{x}$ & & $\mathrm{x}$ \\
\hline Linear combination of estimates & & & & & & \\
\hline Average pre-debate dummies $-3,-2$, and -1 & $\begin{array}{c}-0.006 \\
(0.006)\end{array}$ & $\begin{array}{l}-0.007 \\
(0.006)\end{array}$ & $\begin{array}{c}0.002 \\
(0.005)\end{array}$ & $\begin{array}{c}0.002 \\
(0.005)\end{array}$ & $\begin{array}{l}-0.005 \\
(0.005)\end{array}$ & $\begin{array}{l}-0.006 \\
(0.005)\end{array}$ \\
\hline Average post-debate dummies 1,2 , and 3 & $\begin{array}{c}-0.008 \\
(0.007)\end{array}$ & $\begin{array}{c}-0.009 \\
(0.006)\end{array}$ & $\begin{array}{c}0.003 \\
(0.006)\end{array}$ & $\begin{array}{c}0.003 \\
(0.006)\end{array}$ & $\begin{array}{l}-0.007 \\
(0.005)\end{array}$ & $\begin{array}{l}-0.008 \\
(0.005)\end{array}$ \\
\hline
\end{tabular}

Notes: The sample includes all respondents who were asked whom they intended to vote for, including those who said they were unlikely to vote. Other notes as in Table III. 
Table C.22: Debates' effects on aggregate vote shares, including unlikely voters

\begin{tabular}{|c|c|c|c|c|}
\hline & \multicolumn{2}{|c|}{$\begin{array}{l}\text { Distance between predicted } \\
\text { and final vote shares }\end{array}$} & \multicolumn{2}{|c|}{$\begin{array}{c}\text { Daily change in } \\
\text { predicted vote shares }\end{array}$} \\
\hline & (1) & (2) & (3) & (4) \\
\hline Before -3 & $\begin{array}{c}0.002 \\
(0.004)\end{array}$ & $\begin{array}{c}0.003 \\
(0.004)\end{array}$ & $\begin{array}{c}0.005 \\
(0.005)\end{array}$ & $\begin{array}{c}0.004 \\
(0.006)\end{array}$ \\
\hline-3 & $\begin{array}{l}-0.002 \\
(0.004)\end{array}$ & $\begin{array}{l}-0.001 \\
(0.004)\end{array}$ & $\begin{array}{l}-0.005 \\
(0.008)\end{array}$ & $\begin{array}{l}-0.006 \\
(0.008)\end{array}$ \\
\hline-2 & $\begin{array}{l}-0.004 \\
(0.003)\end{array}$ & $\begin{array}{l}-0.003 \\
(0.003)\end{array}$ & $\begin{array}{l}-0.001 \\
(0.008)\end{array}$ & $\begin{array}{l}-0.003 \\
(0.008)\end{array}$ \\
\hline-1 & $\begin{array}{l}-0.004 \\
(0.004)\end{array}$ & $\begin{array}{l}-0.003 \\
(0.004)\end{array}$ & $\begin{array}{c}0.008 \\
(0.005)\end{array}$ & $\begin{array}{c}0.008 \\
(0.006)\end{array}$ \\
\hline+1 & $\begin{array}{c}0.001 \\
(0.004)\end{array}$ & $\begin{array}{c}0.002 \\
(0.004)\end{array}$ & $\begin{array}{c}0.008 \\
(0.005)\end{array}$ & $\begin{array}{c}0.006 \\
(0.005)\end{array}$ \\
\hline+2 & $\begin{array}{l}-0.004 \\
(0.004)\end{array}$ & $\begin{array}{l}-0.004 \\
(0.004)\end{array}$ & $\begin{array}{l}0.017^{* *} \\
(0.008)\end{array}$ & $\begin{array}{l}0.016^{* *} \\
(0.008)\end{array}$ \\
\hline+3 & $\begin{array}{c}0.000 \\
(0.004)\end{array}$ & $\begin{array}{c}0.001 \\
(0.004)\end{array}$ & $\begin{array}{l}0.013^{*} \\
(0.007)\end{array}$ & $\begin{array}{c}0.012 \\
(0.007)\end{array}$ \\
\hline After +3 & $\begin{array}{l}-0.001 \\
(0.003)\end{array}$ & $\begin{array}{c}0.000 \\
(0.003)\end{array}$ & $\begin{array}{c}0.006 \\
(0.004)\end{array}$ & $\begin{array}{c}0.005 \\
(0.004)\end{array}$ \\
\hline Observations & 3802 & 3802 & 3753 & 3753 \\
\hline$R^{2}$ & 0.589 & 0.594 & 0.480 & 0.488 \\
\hline Mean, day of the debate & 0.049 & 0.049 & 0.082 & 0.082 \\
\hline Number of debates & 56 & 56 & 56 & 56 \\
\hline Debate * election fixed effects & $\mathrm{x}$ & $\mathrm{x}$ & $\mathrm{x}$ & $\mathrm{x}$ \\
\hline Fixed effects for number of days to election & $\mathrm{x}$ & $\mathrm{x}$ & $\mathrm{x}$ & $\mathrm{x}$ \\
\hline Aggregate controls & $\mathrm{x}$ & $\mathrm{x}$ & $\mathrm{x}$ & $\mathrm{x}$ \\
\hline Sociodemographic controls & & $\mathrm{x}$ & & $\mathrm{x}$ \\
\hline Linear combination of estimates & & & & \\
\hline Average pre-debate dummies $-3,-2$, and -1 & $\begin{array}{l}-0.003 \\
(0.003)\end{array}$ & $\begin{array}{l}-0.002 \\
(0.003)\end{array}$ & $\begin{array}{c}0.001 \\
(0.006)\end{array}$ & $\begin{array}{l}-0.000 \\
(0.006)\end{array}$ \\
\hline Average post-debate dummies 1,2 , and 3 & $\begin{array}{l}-0.001 \\
(0.003)\end{array}$ & $\begin{array}{l}-0.000 \\
(0.003)\end{array}$ & $\begin{array}{l}0.013^{* *} \\
(0.005)\end{array}$ & $\begin{array}{l}0.011^{* *} \\
(0.005)\end{array}$ \\
\hline
\end{tabular}

Notes: Same notes as in Table IV and Appendix Table C.21. 


\section{C.7 Excluding Surveys with the Largest Decrease in Reinterview Rate}

Figure C.5: Vote choice consistency and distance to final vote shares, excluding the surveys with the largest decrease in reinterview rate

(a) Vote choice consistency

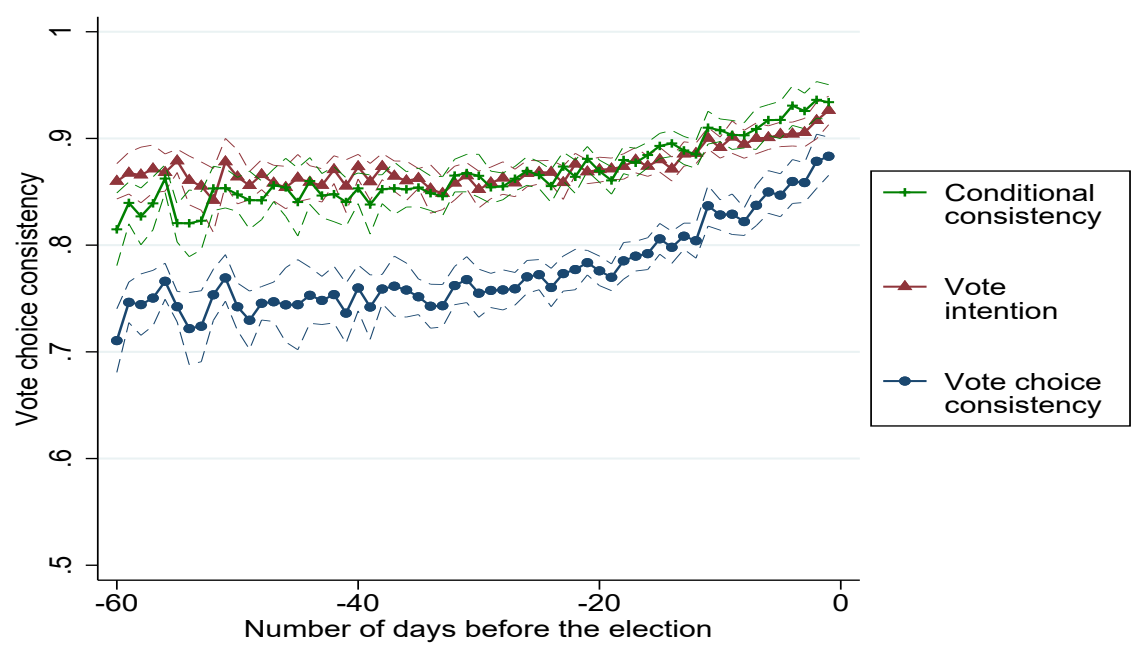

(b) Distance to final vote shares

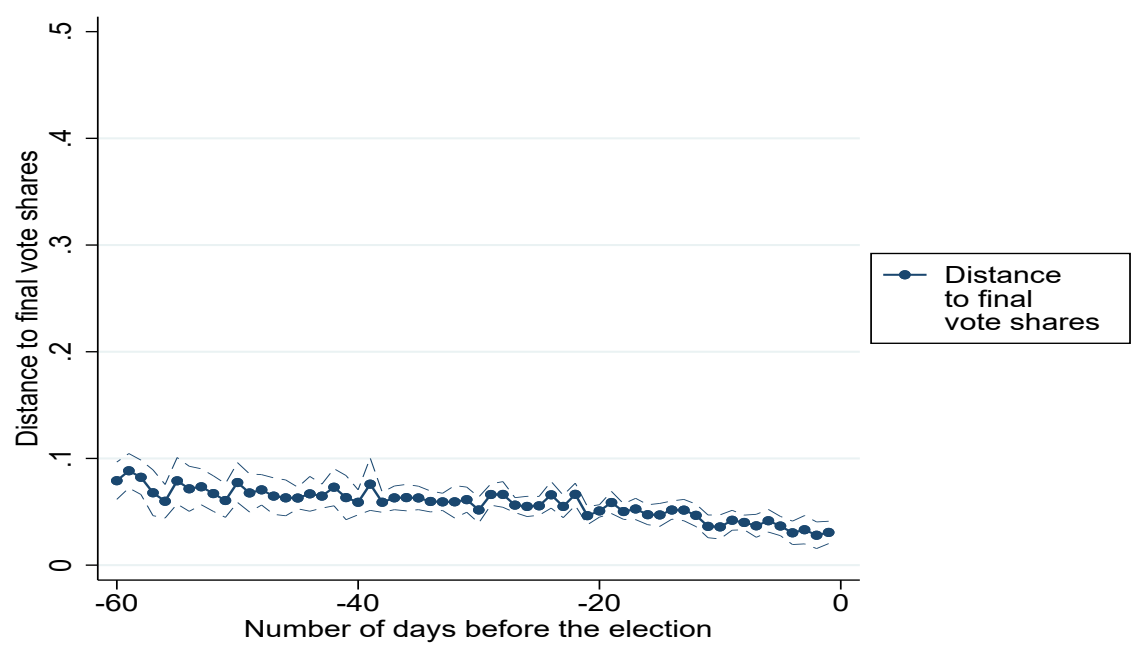

Notes: We drop the quartile of the surveys with the most negative trends in the probability that a respondent surveyed in the pre-electoral survey appears in the post-electoral survey. Other notes as in Figures I and III. 
Table C.23: Vote choice consistency and distance to final vote shares, excluding the surveys with the largest decrease in reinterview rate

\begin{tabular}{|c|c|c|c|c|c|c|c|c|}
\hline & \multicolumn{2}{|c|}{$\begin{array}{l}\text { Vote choice } \\
\text { consistency }\end{array}$} & \multicolumn{2}{|c|}{$\begin{array}{c}\text { Vote } \\
\text { intention }\end{array}$} & \multicolumn{2}{|c|}{$\begin{array}{l}\text { Conditional } \\
\text { consistency }\end{array}$} & \multicolumn{2}{|c|}{$\begin{array}{c}\text { Distance between predictec } \\
\text { and final vote shares }\end{array}$} \\
\hline & $(1)$ & $(2)$ & (3) & $(4)$ & (5) & $(6)$ & (7) & (8) \\
\hline Time & $\begin{array}{c}0.0025^{* * *} \\
(0.0003)\end{array}$ & $\begin{array}{c}0.0061^{* * *} \\
(0.0008)\end{array}$ & $\begin{array}{c}0.0010^{* * *} \\
(0.0002)\end{array}$ & $\begin{array}{c}0.0032^{* * *} \\
(0.0006)\end{array}$ & $\begin{array}{c}0.0018^{* * *} \\
(0.0003)\end{array}$ & $\begin{array}{c}0.0037^{* * *} \\
(0.0007)\end{array}$ & $\begin{array}{c}-0.0008^{* * *} \\
(0.0002)\end{array}$ & $\begin{array}{c}-0.0013^{* * *} \\
(0.0005)\end{array}$ \\
\hline Time $^{2}$ & & $\begin{array}{c}0.0001^{* * *} \\
(0.0000)\end{array}$ & & $\begin{array}{c}0.0000^{* * *} \\
(0.0000)\end{array}$ & & $\begin{array}{c}0.0000^{* * *} \\
(0.0000)\end{array}$ & & $\begin{array}{l}-0.0000 \\
(0.0000)\end{array}$ \\
\hline Observations & 162886 & 162886 & 208502 & 208502 & 145050 & 145050 & 2805 & 2805 \\
\hline$R^{2}$ & 0.080 & 0.082 & 0.079 & 0.080 & 0.047 & 0.047 & 0.524 & 0.526 \\
\hline Mean at day -1 & 0.8833 & 0.8833 & 0.9262 & 0.9262 & 0.9340 & 0.9340 & 0.0307 & 0.0307 \\
\hline Election fixed effects & $\mathrm{x}$ & $\mathrm{x}$ & $\mathrm{x}$ & $\mathrm{x}$ & $\mathrm{x}$ & $\mathrm{x}$ & $\mathrm{x}$ & $\mathrm{x}$ \\
\hline Individual controls & $\mathrm{x}$ & $\mathrm{x}$ & $\mathrm{x}$ & $\mathrm{x}$ & $\mathrm{x}$ & $\mathrm{x}$ & & \\
\hline Aggregate controls & & & & & & & $\mathrm{x}$ & $\mathrm{x}$ \\
\hline
\end{tabular}

Notes: We drop the quartile of the surveys with the most negative trends in the probability that a respondent surveyed in the pre-electoral survey appears in the post-electoral survey. Other notes as in Table I. 
Table C.24: Drivers of vote choice formation, excluding the surveys with the largest decrease in reinterview rate

(a) Mean vote choice consistency

\begin{tabular}{lcccc}
\hline & \multicolumn{3}{c}{ Mean vote choice consistency } \\
\cline { 2 - 5 } & $(1)$ & $(2)$ & $(3)$ & $(4)$ \\
\hline Mean consistency in policy preferences & -0.119 & & & -0.149 \\
& $(0.133)$ & & & $(0.138)$ \\
Mean consistency in issue salience & & $0.261^{* *}$ & & $0.258^{* *}$ \\
& & $(0.111)$ & & $(0.110)$ \\
Mean consistency in beliefs on candidates & & & 0.102 & 0.098 \\
& & & $(0.087)$ & $(0.088)$ \\
\hline Observations & 2806 & 2806 & 2806 & 2806 \\
$R^{2}$ & 0.809 & 0.811 & 0.809 & 0.811 \\
Election fixed effects & $\mathrm{x}$ & $\mathrm{X}$ & $\mathrm{x}$ & $\mathrm{x}$ \\
Fixed effects for number of days to election & $\mathrm{x}$ & $\mathrm{x}$ & $\mathrm{x}$ & $\mathrm{x}$ \\
Aggregate controls & $\mathrm{x}$ & $\mathrm{x}$ & $\mathrm{x}$ & $\mathrm{x}$ \\
\hline
\end{tabular}

(b) Mean probability of stating a vote intention

\begin{tabular}{lcccc}
\hline & \multicolumn{4}{l}{ Mean probability of stating a vote intention } \\
\cline { 2 - 6 } & $(1)$ & $(2)$ & $(3)$ & $(4)$ \\
\hline Mean probability of stating a policy preference & -0.035 & & & -0.085 \\
& $(0.193)$ & & & $(0.181)$ \\
Mean probability of stating a salient issue & & $0.184^{* *}$ & & $0.179^{* *}$ \\
& & $(0.073)$ & & $(0.071)$ \\
Mean probability of stating a belief on candidates & & & $0.203^{*}$ & $0.211^{*}$ \\
& & & $(0.117)$ & $(0.113)$ \\
\hline Observations & 2821 & 2821 & 2821 & 2821 \\
$R^{2}$ & 0.838 & 0.838 & 0.839 & 0.839 \\
Election fixed effects & $\mathrm{x}$ & $\mathrm{x}$ & $\mathrm{x}$ & $\mathrm{x}$ \\
Fixed effects for number of days to election & $\mathrm{x}$ & $\mathrm{x}$ & $\mathrm{x}$ & $\mathrm{x}$ \\
Aggregate controls & $\mathrm{x}$ & $\mathrm{x}$ & $\mathrm{x}$ & $\mathrm{x}$ \\
\hline
\end{tabular}

Notes: Same notes as in Table II and Appendix Table C.23. 


\section{C.8 Event Study with Five-Day Window}

Table C.25: Debates' effects on vote choice consistency, five-day window

\begin{tabular}{|c|c|c|c|c|c|c|}
\hline & \multicolumn{2}{|c|}{ Vote choice consistency } & \multicolumn{2}{|c|}{ Stating vote intention } & \multicolumn{2}{|c|}{ Conditional consistency } \\
\hline & (1) & (2) & (3) & (4) & $(5)$ & (6) \\
\hline Before -5 & $\begin{array}{c}-0.018^{* *} \\
(0.007)\end{array}$ & $\begin{array}{c}-0.019^{* *} \\
(0.007)\end{array}$ & $\begin{array}{l}-0.002 \\
(0.005)\end{array}$ & $\begin{array}{l}-0.003 \\
(0.005)\end{array}$ & $\begin{array}{c}-0.015^{* *} \\
(0.006)\end{array}$ & $\begin{array}{c}-0.016^{* *} \\
(0.006)\end{array}$ \\
\hline-5 & $\begin{array}{l}-0.012 \\
(0.008)\end{array}$ & $\begin{array}{l}-0.013 \\
(0.008)\end{array}$ & $\begin{array}{c}0.005 \\
(0.004)\end{array}$ & $\begin{array}{c}0.004 \\
(0.004)\end{array}$ & $\begin{array}{c}-0.015^{* *} \\
(0.008)\end{array}$ & $\begin{array}{c}-0.016^{* *} \\
(0.008)\end{array}$ \\
\hline-4 & $\begin{array}{l}-0.014^{*} \\
(0.008)\end{array}$ & $\begin{array}{l}-0.015^{*} \\
(0.008)\end{array}$ & $\begin{array}{l}-0.001 \\
(0.005)\end{array}$ & $\begin{array}{l}-0.001 \\
(0.005)\end{array}$ & $\begin{array}{l}-0.010 \\
(0.009)\end{array}$ & $\begin{array}{l}-0.011 \\
(0.009)\end{array}$ \\
\hline-3 & $\begin{array}{l}-0.006 \\
(0.007)\end{array}$ & $\begin{array}{l}-0.007 \\
(0.007)\end{array}$ & $\begin{array}{c}0.001 \\
(0.006)\end{array}$ & $\begin{array}{c}0.000 \\
(0.006)\end{array}$ & $\begin{array}{l}-0.001 \\
(0.007)\end{array}$ & $\begin{array}{l}-0.002 \\
(0.007)\end{array}$ \\
\hline-2 & $\begin{array}{c}0.001 \\
(0.009)\end{array}$ & $\begin{array}{l}-0.000 \\
(0.009)\end{array}$ & $\begin{array}{l}0.008^{*} \\
(0.004)\end{array}$ & $\begin{array}{l}0.008^{*} \\
(0.004)\end{array}$ & $\begin{array}{l}-0.001 \\
(0.007)\end{array}$ & $\begin{array}{l}-0.002 \\
(0.007)\end{array}$ \\
\hline-1 & $\begin{array}{c}0.001 \\
(0.006)\end{array}$ & $\begin{array}{c}0.001 \\
(0.006)\end{array}$ & $\begin{array}{c}0.005 \\
(0.004)\end{array}$ & $\begin{array}{c}0.005 \\
(0.004)\end{array}$ & $\begin{array}{c}0.002 \\
(0.005)\end{array}$ & $\begin{array}{c}0.002 \\
(0.005)\end{array}$ \\
\hline+1 & $\begin{array}{l}-0.007 \\
(0.007)\end{array}$ & $\begin{array}{l}-0.007 \\
(0.007)\end{array}$ & $\begin{array}{c}0.008 \\
(0.006)\end{array}$ & $\begin{array}{c}0.008 \\
(0.006)\end{array}$ & $\begin{array}{l}-0.006 \\
(0.007)\end{array}$ & $\begin{array}{l}-0.006 \\
(0.007)\end{array}$ \\
\hline+2 & $\begin{array}{l}-0.006 \\
(0.009)\end{array}$ & $\begin{array}{l}-0.007 \\
(0.009)\end{array}$ & $\begin{array}{c}0.001 \\
(0.005)\end{array}$ & $\begin{array}{l}-0.000 \\
(0.005)\end{array}$ & $\begin{array}{l}-0.004 \\
(0.008)\end{array}$ & $\begin{array}{l}-0.005 \\
(0.008)\end{array}$ \\
\hline+3 & $\begin{array}{l}-0.004 \\
(0.007)\end{array}$ & $\begin{array}{l}-0.004 \\
(0.006)\end{array}$ & $\begin{array}{c}0.005 \\
(0.005)\end{array}$ & $\begin{array}{c}0.005 \\
(0.005)\end{array}$ & $\begin{array}{l}-0.003 \\
(0.006)\end{array}$ & $\begin{array}{l}-0.003 \\
(0.006)\end{array}$ \\
\hline+4 & $\begin{array}{c}0.002 \\
(0.007)\end{array}$ & $\begin{array}{c}0.002 \\
(0.007)\end{array}$ & $\begin{array}{c}0.003 \\
(0.004)\end{array}$ & $\begin{array}{c}0.002 \\
(0.004)\end{array}$ & $\begin{array}{c}0.004 \\
(0.007)\end{array}$ & $\begin{array}{c}0.003 \\
(0.007)\end{array}$ \\
\hline+5 & $\begin{array}{l}-0.008 \\
(0.008)\end{array}$ & $\begin{array}{l}-0.008 \\
(0.008)\end{array}$ & $\begin{array}{l}-0.001 \\
(0.005)\end{array}$ & $\begin{array}{l}-0.001 \\
(0.005)\end{array}$ & $\begin{array}{l}-0.004 \\
(0.007)\end{array}$ & $\begin{array}{l}-0.004 \\
(0.007)\end{array}$ \\
\hline After +5 & $\begin{array}{l}-0.003 \\
(0.007)\end{array}$ & $\begin{array}{c}-0.004 \\
(0.007)\end{array}$ & $\begin{array}{c}0.005 \\
(0.005)\end{array}$ & $\begin{array}{c}0.004 \\
(0.005)\end{array}$ & $\begin{array}{l}-0.003 \\
(0.006)\end{array}$ & $\begin{array}{l}-0.004 \\
(0.006)\end{array}$ \\
\hline Observations & 225519 & 225519 & 280927 & 280927 & 207744 & 207744 \\
\hline$R^{2}$ & 0.064 & 0.068 & 0.066 & 0.073 & 0.038 & 0.040 \\
\hline Mean, day of the debate & 0.827 & 0.827 & 0.913 & 0.913 & 0.891 & 0.891 \\
\hline Number of debates & 45 & 45 & 45 & 45 & 45 & 45 \\
\hline Debate * election fixed effects & $\mathrm{x}$ & $\mathrm{x}$ & $\mathrm{x}$ & $\mathrm{x}$ & $\mathrm{x}$ & $\mathrm{x}$ \\
\hline Fixed effects for number of days to election & $\mathrm{x}$ & $\mathrm{x}$ & $\mathrm{x}$ & $\mathrm{x}$ & $\mathrm{x}$ & $\mathrm{x}$ \\
\hline Individual controls & $\mathrm{x}$ & $\mathrm{x}$ & $\mathrm{x}$ & $\mathrm{x}$ & $\mathrm{x}$ & $\mathrm{x}$ \\
\hline Sociodemographic controls & & $\mathrm{x}$ & & $\mathrm{x}$ & & $\mathrm{x}$ \\
\hline \multicolumn{7}{|l|}{ Linear combination of estimates } \\
\hline Average pre-debate dummies $-5,-4,-3,-2$, and -1 & $\begin{array}{c}-0.006 \\
(0.006)\end{array}$ & $\begin{array}{l}-0.007 \\
(0.006)\end{array}$ & $\begin{array}{c}0.004 \\
(0.004)\end{array}$ & $\begin{array}{c}0.003 \\
(0.004)\end{array}$ & $\begin{array}{l}-0.005 \\
(0.006)\end{array}$ & $\begin{array}{l}-0.006 \\
(0.006)\end{array}$ \\
\hline Average post-debate dummies $1,2,3,4$ and 5 & $\begin{array}{c}-0.004 \\
(0.006)\end{array}$ & $\begin{array}{l}-0.005 \\
(0.006)\end{array}$ & $\begin{array}{c}0.003 \\
(0.004)\end{array}$ & $\begin{array}{c}0.003 \\
(0.004)\end{array}$ & $\begin{array}{l}-0.003 \\
(0.005)\end{array}$ & $\begin{array}{l}-0.003 \\
(0.005)\end{array}$ \\
\hline
\end{tabular}

Notes: The set of relative days dummies includes dummy variables for being surveyed one, two, three, four, or five days before the debate, as well as dummies for being surveyed one, two, three, four, or five days after the debate. Debates held less than five days from one another are excluded. Other notes as in Table III. 
Table C.26: Debates' effect on aggregate vote shares, five-day window

\begin{tabular}{|c|c|c|c|c|}
\hline & \multicolumn{2}{|c|}{$\begin{array}{l}\text { Distance between predicted } \\
\text { and final vote shares }\end{array}$} & \multicolumn{2}{|c|}{$\begin{array}{l}\text { Daily change in } \\
\text { predicted vote shares }\end{array}$} \\
\hline & (1) & (2) & (3) & (4) \\
\hline Before -5 & $\begin{array}{c}0.005 \\
(0.004)\end{array}$ & $\begin{array}{c}0.005 \\
(0.004)\end{array}$ & $\begin{array}{c}0.008 \\
(0.007)\end{array}$ & $\begin{array}{c}0.006 \\
(0.007)\end{array}$ \\
\hline-5 & $\begin{array}{l}-0.003 \\
(0.005)\end{array}$ & $\begin{array}{l}-0.002 \\
(0.005)\end{array}$ & $\begin{array}{c}0.013 \\
(0.011)\end{array}$ & $\begin{array}{c}0.011 \\
(0.011)\end{array}$ \\
\hline-4 & $\begin{array}{c}0.004 \\
(0.004)\end{array}$ & $\begin{array}{c}0.004 \\
(0.004)\end{array}$ & $\begin{array}{c}0.003 \\
(0.009)\end{array}$ & $\begin{array}{c}0.002 \\
(0.009)\end{array}$ \\
\hline-3 & $\begin{array}{l}-0.003 \\
(0.004)\end{array}$ & $\begin{array}{l}-0.003 \\
(0.004)\end{array}$ & $\begin{array}{l}-0.003 \\
(0.011)\end{array}$ & $\begin{array}{l}-0.004 \\
(0.011)\end{array}$ \\
\hline-2 & $\begin{array}{l}-0.003 \\
(0.003)\end{array}$ & $\begin{array}{l}-0.002 \\
(0.003)\end{array}$ & $\begin{array}{l}-0.001 \\
(0.010)\end{array}$ & $\begin{array}{l}-0.003 \\
(0.010)\end{array}$ \\
\hline-1 & $\begin{array}{c}-0.007^{* *} \\
(0.003)\end{array}$ & $\begin{array}{l}-0.007^{*} \\
(0.004)\end{array}$ & $\begin{array}{c}0.010 \\
(0.006)\end{array}$ & $\begin{array}{c}0.009 \\
(0.007)\end{array}$ \\
\hline+1 & $\begin{array}{l}-0.000 \\
(0.003)\end{array}$ & $\begin{array}{c}0.000 \\
(0.003)\end{array}$ & $\begin{array}{c}0.010 \\
(0.007)\end{array}$ & $\begin{array}{c}0.008 \\
(0.008)\end{array}$ \\
\hline+2 & $\begin{array}{l}-0.004 \\
(0.004)\end{array}$ & $\begin{array}{l}-0.003 \\
(0.004)\end{array}$ & $\begin{array}{c}0.019 \\
(0.012)\end{array}$ & $\begin{array}{c}0.017 \\
(0.012)\end{array}$ \\
\hline+3 & $\begin{array}{l}-0.003 \\
(0.004)\end{array}$ & $\begin{array}{l}-0.002 \\
(0.004)\end{array}$ & $\begin{array}{c}0.008 \\
(0.010)\end{array}$ & $\begin{array}{c}0.006 \\
(0.010)\end{array}$ \\
\hline+4 & $\begin{array}{l}-0.003 \\
(0.004)\end{array}$ & $\begin{array}{l}-0.003 \\
(0.004)\end{array}$ & $\begin{array}{l}-0.004 \\
(0.007)\end{array}$ & $\begin{array}{l}-0.005 \\
(0.007)\end{array}$ \\
\hline+5 & $\begin{array}{c}0.002 \\
(0.003)\end{array}$ & $\begin{array}{c}0.002 \\
(0.003)\end{array}$ & $\begin{array}{l}-0.005 \\
(0.008)\end{array}$ & $\begin{array}{l}-0.006 \\
(0.008)\end{array}$ \\
\hline After +5 & $\begin{array}{l}-0.002 \\
(0.004)\end{array}$ & $\begin{array}{l}-0.002 \\
(0.004)\end{array}$ & $\begin{array}{c}0.006 \\
(0.007)\end{array}$ & $\begin{array}{c}0.004 \\
(0.007)\end{array}$ \\
\hline Observations & 3010 & 3010 & 2971 & 2971 \\
\hline$R^{2}$ & 0.568 & 0.573 & 0.504 & 0.511 \\
\hline Mean, day of the debate & 0.043 & 0.043 & 0.080 & 0.080 \\
\hline Number of debates & 45 & 45 & 45 & 45 \\
\hline Debate * election fixed effects & $\mathrm{x}$ & $\mathrm{x}$ & $\mathrm{x}$ & $\mathrm{x}$ \\
\hline Fixed effects for number of days to election & $\mathrm{x}$ & $\mathrm{x}$ & $\mathrm{x}$ & $\mathrm{x}$ \\
\hline Aggregate controls & $\mathrm{x}$ & $\mathrm{x}$ & $\mathrm{x}$ & $\mathrm{x}$ \\
\hline Sociodemographic controls & & $\mathrm{x}$ & & $\mathrm{x}$ \\
\hline Linear combination of estimates & & & & \\
\hline Average pre-debate dummies $-5,-4,-3,-2$, and -1 & $\begin{array}{l}-0.002 \\
(0.003)\end{array}$ & $\begin{array}{l}-0.002 \\
(0.003)\end{array}$ & $\begin{array}{c}0.005 \\
(0.008)\end{array}$ & $\begin{array}{c}0.003 \\
(0.008)\end{array}$ \\
\hline Average post-debate dummies $1,2,3,4$ and 5 & $\begin{array}{l}-0.002 \\
(0.003)\end{array}$ & $\begin{array}{l}-0.001 \\
(0.003)\end{array}$ & $\begin{array}{c}0.005 \\
(0.007)\end{array}$ & $\begin{array}{c}0.004 \\
(0.007)\end{array}$ \\
\hline
\end{tabular}

Notes: Same notes as in Table IV and Appendix Table C.25. 


\section{C.9 Event Study with Balanced Panel on Three-Day Window}

Table C.27: Debates' effects on vote choice consistency, balanced panel

\begin{tabular}{|c|c|c|c|c|c|c|}
\hline & \multicolumn{2}{|c|}{ Vote choice consistency } & \multicolumn{2}{|c|}{ Vote intention } & \multicolumn{2}{|c|}{ Conditional consistency } \\
\hline & (1) & (2) & (3) & (4) & (5) & (6) \\
\hline-3 & $\begin{array}{l}-0.008 \\
(0.009)\end{array}$ & $\begin{array}{l}-0.009 \\
(0.009)\end{array}$ & $\begin{array}{c}0.007 \\
(0.007)\end{array}$ & $\begin{array}{c}0.007 \\
(0.007)\end{array}$ & $\begin{array}{l}-0.007 \\
(0.008)\end{array}$ & $\begin{array}{l}-0.008 \\
(0.008)\end{array}$ \\
\hline-2 & $\begin{array}{l}-0.011 \\
(0.011)\end{array}$ & $\begin{array}{c}-0.012 \\
(0.011)\end{array}$ & $\begin{array}{c}0.009 \\
(0.008)\end{array}$ & $\begin{array}{c}0.009 \\
(0.008)\end{array}$ & $\begin{array}{l}-0.011 \\
(0.010)\end{array}$ & $\begin{array}{l}-0.012 \\
(0.010)\end{array}$ \\
\hline-1 & $\begin{array}{l}-0.010 \\
(0.012)\end{array}$ & $\begin{array}{c}-0.010 \\
(0.012)\end{array}$ & $\begin{array}{c}0.007 \\
(0.008)\end{array}$ & $\begin{array}{c}0.007 \\
(0.008)\end{array}$ & $\begin{array}{l}-0.002 \\
(0.009)\end{array}$ & $\begin{array}{l}-0.003 \\
(0.009)\end{array}$ \\
\hline+1 & $\begin{array}{c}-0.011 \\
(0.008)\end{array}$ & $\begin{array}{c}-0.011 \\
(0.008)\end{array}$ & $\begin{array}{c}0.014 \\
(0.009)\end{array}$ & $\begin{array}{c}0.014 \\
(0.009)\end{array}$ & $\begin{array}{l}-0.014^{*} \\
(0.008)\end{array}$ & $\begin{array}{l}-0.014^{*} \\
(0.008)\end{array}$ \\
\hline+2 & $\begin{array}{c}-0.020^{* *} \\
(0.009)\end{array}$ & $\begin{array}{c}-0.021^{* *} \\
(0.009)\end{array}$ & $\begin{array}{c}0.008 \\
(0.007)\end{array}$ & $\begin{array}{c}0.008 \\
(0.007)\end{array}$ & $\begin{array}{c}-0.024^{* * *} \\
(0.008)\end{array}$ & $\begin{array}{c}-0.025^{* * *} \\
(0.008)\end{array}$ \\
\hline+3 & $\begin{array}{c}-0.021^{* *} \\
(0.008)\end{array}$ & $\begin{array}{c}-0.022^{* *} \\
(0.008)\end{array}$ & $\begin{array}{l}0.011^{*} \\
(0.006)\end{array}$ & $\begin{array}{l}0.011^{*} \\
(0.006)\end{array}$ & $\begin{array}{c}-0.022^{* * *} \\
(0.008)\end{array}$ & $\begin{array}{c}-0.023^{* * *} \\
(0.008)\end{array}$ \\
\hline Observations & 41536 & 41536 & 50980 & 50980 & 37751 & 37751 \\
\hline$R^{2}$ & 0.062 & 0.066 & 0.066 & 0.073 & 0.036 & 0.038 \\
\hline Mean, day of the debate & 0.814 & 0.814 & 0.900 & 0.900 & 0.887 & 0.887 \\
\hline Number of debates & 54 & 54 & 54 & 54 & 53 & 53 \\
\hline Debate $*$ election fixed effects & $\mathrm{x}$ & $\mathrm{x}$ & $\mathrm{x}$ & $\mathrm{x}$ & $\mathrm{x}$ & $\mathrm{x}$ \\
\hline Fixed effects for number of days to election & $\mathrm{x}$ & $\mathrm{x}$ & $\mathrm{x}$ & $\mathrm{x}$ & $\mathrm{x}$ & $\mathrm{x}$ \\
\hline Individual controls & $\mathrm{x}$ & $\mathrm{x}$ & $\mathrm{x}$ & $\mathrm{x}$ & $\mathrm{x}$ & $\mathrm{x}$ \\
\hline Sociodemographic controls & & $\mathrm{x}$ & & $\mathrm{x}$ & & $\mathrm{x}$ \\
\hline \multicolumn{7}{|l|}{ Linear combination of estimates } \\
\hline Average pre-debate dummies $-3,-2$, and -1 & $\begin{array}{l}-0.010 \\
(0.009)\end{array}$ & $\begin{array}{l}-0.010 \\
(0.009)\end{array}$ & $\begin{array}{c}0.008 \\
(0.007)\end{array}$ & $\begin{array}{c}0.008 \\
(0.007)\end{array}$ & $\begin{array}{c}-0.007 \\
(0.008)\end{array}$ & $\begin{array}{c}-0.008 \\
(0.007)\end{array}$ \\
\hline Average post-debate dummies 1,2 , and 3 & $\begin{array}{c}-0.017^{* *} \\
(0.007)\end{array}$ & $\begin{array}{c}-0.018^{* *} \\
(0.007)\end{array}$ & $\begin{array}{l}0.011^{*} \\
(0.007)\end{array}$ & $\begin{array}{c}0.011 \\
(0.007)\end{array}$ & $\begin{array}{c}-0.020^{* * *} \\
(0.007)\end{array}$ & $\begin{array}{c}-0.020^{* * *} \\
(0.007)\end{array}$ \\
\hline
\end{tabular}

Notes: The sample is restricted to debates for which respondents are surveyed on each day within the -3/+3-days window. Respondents surveyed earlier than three days before the debate or later than three days after the debate are excluded. Debate fixed effects are replaced by election fixed effects. Other notes as in Table III. 
Table C.28: Debates' effects on aggregate vote shares, balanced panel

\begin{tabular}{|c|c|c|c|c|}
\hline & \multicolumn{2}{|c|}{$\begin{array}{l}\text { Distance between predicted } \\
\text { and final vote shares }\end{array}$} & \multicolumn{2}{|c|}{$\begin{array}{c}\text { Daily change in } \\
\text { predicted vote shares }\end{array}$} \\
\hline & (1) & (2) & (3) & (4) \\
\hline-3 & $\begin{array}{c}0.003 \\
(0.007)\end{array}$ & $\begin{array}{c}0.003 \\
(0.007)\end{array}$ & $\begin{array}{l}-0.008 \\
(0.011)\end{array}$ & $\begin{array}{l}-0.012 \\
(0.012)\end{array}$ \\
\hline-2 & $\begin{array}{c}0.004 \\
(0.007)\end{array}$ & $\begin{array}{c}0.004 \\
(0.007)\end{array}$ & $\begin{array}{l}-0.005 \\
(0.014)\end{array}$ & $\begin{array}{l}-0.011 \\
(0.015)\end{array}$ \\
\hline-1 & $\begin{array}{c}0.002 \\
(0.007)\end{array}$ & $\begin{array}{c}0.002 \\
(0.007)\end{array}$ & $\begin{array}{c}0.012 \\
(0.011)\end{array}$ & $\begin{array}{c}0.008 \\
(0.011)\end{array}$ \\
\hline+1 & $\begin{array}{c}0.004 \\
(0.006)\end{array}$ & $\begin{array}{c}0.003 \\
(0.006)\end{array}$ & $\begin{array}{c}0.008 \\
(0.009)\end{array}$ & $\begin{array}{c}0.003 \\
(0.008)\end{array}$ \\
\hline+2 & $\begin{array}{c}0.002 \\
(0.007)\end{array}$ & $\begin{array}{c}0.000 \\
(0.006)\end{array}$ & $\begin{array}{l}0.034^{* *} \\
(0.013)\end{array}$ & $\begin{array}{l}0.028^{* *} \\
(0.012)\end{array}$ \\
\hline+3 & $\begin{array}{c}0.004 \\
(0.007)\end{array}$ & $\begin{array}{c}0.003 \\
(0.007)\end{array}$ & $\begin{array}{c}0.014 \\
(0.015)\end{array}$ & $\begin{array}{c}0.011 \\
(0.014)\end{array}$ \\
\hline Observations & 490 & 490 & 483 & 483 \\
\hline$R^{2}$ & 0.662 & 0.670 & 0.611 & 0.628 \\
\hline Mean, day of the debate & 0.046 & 0.046 & 0.087 & 0.087 \\
\hline Number of debates & 53 & 53 & 52 & 52 \\
\hline Debate $*$ election fixed effects & $\mathrm{x}$ & $\mathrm{x}$ & $\mathrm{x}$ & $\mathrm{x}$ \\
\hline Fixed effects for number of days to election & $\mathrm{x}$ & $\mathrm{x}$ & $\mathrm{x}$ & $\mathrm{x}$ \\
\hline Aggregate controls & $\mathrm{x}$ & $\mathrm{x}$ & $\mathrm{x}$ & $\mathrm{x}$ \\
\hline Sociodemographic controls & & $\mathrm{x}$ & & $\mathrm{x}$ \\
\hline \multicolumn{5}{|l|}{ Linear combination of estimates } \\
\hline Average pre-debate dummies $-3,-2$, and -1 & $\begin{array}{c}0.003 \\
(0.006)\end{array}$ & $\begin{array}{c}0.003 \\
(0.006)\end{array}$ & $\begin{array}{l}-0.000 \\
(0.010)\end{array}$ & $\begin{array}{l}-0.005 \\
(0.011)\end{array}$ \\
\hline Average post-debate dummies 1,2 , and 3 & $\begin{array}{c}0.003 \\
(0.005)\end{array}$ & $\begin{array}{c}0.002 \\
(0.005)\end{array}$ & $\begin{array}{l}0.019^{*} \\
(0.010)\end{array}$ & $\begin{array}{c}0.014 \\
(0.009)\end{array}$ \\
\hline
\end{tabular}

Notes: Same notes as in Table IV and Appendix Table C.27. 


\section{C.10 Event Study with de Chaisemartin and D'Haultefoeuille (2020)'s Method}

Table C.29: Debates' effects on vote choice consistency, de Chaisemartin and D'Haultefoeuille (2020)'s method

\begin{tabular}{|c|c|c|c|c|c|c|}
\hline & \multicolumn{2}{|c|}{ Vote choice consistency } & \multicolumn{2}{|c|}{ Vote intention } & \multicolumn{2}{|c|}{ Conditional consistency } \\
\hline & (1) & (2) & (3) & (4) & (5) & (6) \\
\hline-3 & $\begin{array}{l}-0.002 \\
(0.011)\end{array}$ & $\begin{array}{l}-0.003 \\
(0.012)\end{array}$ & $\begin{array}{c}0.007 \\
(0.009)\end{array}$ & $\begin{array}{c}0.006 \\
(0.010)\end{array}$ & $\begin{array}{l}-0.004 \\
(0.010)\end{array}$ & $\begin{array}{l}-0.004 \\
(0.010)\end{array}$ \\
\hline-2 & $\begin{array}{c}0.011 \\
(0.017)\end{array}$ & $\begin{array}{c}0.010 \\
(0.017)\end{array}$ & $\begin{array}{c}0.012 \\
(0.008)\end{array}$ & $\begin{array}{c}0.009 \\
(0.008)\end{array}$ & $\begin{array}{c}0.004 \\
(0.020)\end{array}$ & $\begin{array}{c}0.007 \\
(0.021)\end{array}$ \\
\hline-1 & $\begin{array}{c}0.021 \\
(0.017)\end{array}$ & $\begin{array}{c}0.017 \\
(0.017)\end{array}$ & $\begin{array}{c}0.018 \\
(0.012)\end{array}$ & $\begin{array}{c}0.014 \\
(0.011)\end{array}$ & $\begin{array}{c}0.011 \\
(0.012)\end{array}$ & $\begin{array}{c}0.010 \\
(0.011)\end{array}$ \\
\hline+1 & $\begin{array}{l}-0.009 \\
(0.012)\end{array}$ & $\begin{array}{l}-0.011 \\
(0.012)\end{array}$ & $\begin{array}{c}0.007 \\
(0.010)\end{array}$ & $\begin{array}{c}0.006 \\
(0.010)\end{array}$ & $\begin{array}{l}-0.011 \\
(0.012)\end{array}$ & $\begin{array}{l}-0.011 \\
(0.012)\end{array}$ \\
\hline+2 & $\begin{array}{c}0.001 \\
(0.017)\end{array}$ & $\begin{array}{l}-0.003 \\
(0.017)\end{array}$ & $\begin{array}{c}0.001 \\
(0.008)\end{array}$ & $\begin{array}{l}-0.001 \\
(0.009)\end{array}$ & $\begin{array}{c}0.000 \\
(0.018)\end{array}$ & $\begin{array}{l}-0.002 \\
(0.017)\end{array}$ \\
\hline+3 & $\begin{array}{l}-0.005 \\
(0.010)\end{array}$ & $\begin{array}{l}-0.009 \\
(0.011)\end{array}$ & $\begin{array}{c}0.006 \\
(0.009)\end{array}$ & $\begin{array}{c}0.018 \\
(0.009)\end{array}$ & $\begin{array}{l}-0.010 \\
(0.009)\end{array}$ & $\begin{array}{l}-0.011 \\
(0.010)\end{array}$ \\
\hline Individual controls & $\mathrm{x}$ & $\mathrm{x}$ & $\mathrm{x}$ & $\mathrm{x}$ & $\mathrm{x}$ & $\mathrm{x}$ \\
\hline $\begin{array}{l}\text { Sociodemographic controls } \\
\text { Number of replications }\end{array}$ & 1000 & $\begin{array}{c}x \\
1000\end{array}$ & 1000 & $\begin{array}{c}x \\
1000\end{array}$ & 1000 & $\begin{array}{c}x \\
1000\end{array}$ \\
\hline Linear combination of estimates & & & & & & \\
\hline Average pre-debate dummies $-3,-2$, and -1 & $\begin{array}{c}0.010 \\
(0.012)\end{array}$ & $\begin{array}{c}0.008 \\
(0.012)\end{array}$ & $\begin{array}{l}0.012^{*} \\
(0.007)\end{array}$ & $\begin{array}{c}0.010 \\
(0.007)\end{array}$ & $\begin{array}{c}0.004 \\
(0.010)\end{array}$ & $\begin{array}{c}0.004 \\
(0.010)\end{array}$ \\
\hline Average post-debate dummies 1,2 , and 3 & $\begin{array}{l}-0.008 \\
(0.010)\end{array}$ & $\begin{array}{l}-0.008 \\
(0.010)\end{array}$ & $\begin{array}{c}0.004 \\
(0.008)\end{array}$ & $\begin{array}{c}0.002 \\
(0.008)\end{array}$ & $\begin{array}{l}-0.007 \\
(0.010)\end{array}$ & $\begin{array}{l}-0.008 \\
(0.010)\end{array}$ \\
\hline
\end{tabular}

Notes: We use the Stata command did_multiplegt to compute de Chaisemartin and D'Haultfœuille (2020)'s estimator. Other notes as in Table III. 
Table C.30: Debates' effects on aggregate vote shares, de Chaisemartin and D'Haultefoeuille (2020)'s method

\begin{tabular}{|c|c|c|c|c|}
\hline & \multicolumn{2}{|c|}{$\begin{array}{l}\text { Distance between predicted } \\
\text { and final vote shares }\end{array}$} & \multicolumn{2}{|c|}{$\begin{array}{c}\text { Daily change in } \\
\text { predicted vote shares }\end{array}$} \\
\hline & (1) & (2) & (3) & (4) \\
\hline-3 & $\begin{array}{c}0.000 \\
(0.014)\end{array}$ & $\begin{array}{c}0.001 \\
(0.014)\end{array}$ & $\begin{array}{c}0.004 \\
(0.012)\end{array}$ & $\begin{array}{c}0.002 \\
(0.012)\end{array}$ \\
\hline-2 & $\begin{array}{l}-0.015 \\
(0.012)\end{array}$ & $\begin{array}{l}-0.016 \\
(0.012)\end{array}$ & $\begin{array}{l}-0.004 \\
(0.013)\end{array}$ & $\begin{array}{l}-0.005 \\
(0.013)\end{array}$ \\
\hline-1 & $\begin{array}{c}0.006 \\
(0.013)\end{array}$ & $\begin{array}{c}0.005 \\
(0.013)\end{array}$ & $\begin{array}{c}0.015 \\
(0.014)\end{array}$ & $\begin{array}{c}0.016 \\
(0.014)\end{array}$ \\
\hline+1 & $\begin{array}{c}0.005 \\
(0.010)\end{array}$ & $\begin{array}{c}0.004 \\
(0.010)\end{array}$ & $\begin{array}{c}0.003 \\
(0.012)\end{array}$ & $\begin{array}{c}0.003 \\
(0.012)\end{array}$ \\
\hline+2 & $\begin{array}{c}0.003 \\
(0.023)\end{array}$ & $\begin{array}{c}0.002 \\
(0.022)\end{array}$ & $\begin{array}{c}0.024 \\
(0.024)\end{array}$ & $\begin{array}{c}0.024 \\
(0.025)\end{array}$ \\
\hline+3 & $\begin{array}{c}0.005 \\
(0.015)\end{array}$ & $\begin{array}{c}0.005 \\
(0.015)\end{array}$ & $\begin{array}{c}0.014 \\
(0.013)\end{array}$ & $\begin{array}{c}0.013 \\
(0.013)\end{array}$ \\
\hline $\begin{array}{l}\text { Aggregate controls } \\
\text { Sociodemographic controls } \\
\text { Number of replications }\end{array}$ & 1000 & $\begin{array}{c}x \\
x \\
1000\end{array}$ & $\begin{array}{c}x \\
1000\end{array}$ & $\begin{array}{c}x \\
x \\
1000\end{array}$ \\
\hline Linear combination of estimates & & & & \\
\hline Average pre-debate dummies $-3,-2$, and -1 & $\begin{array}{l}-0.003 \\
(0.010)\end{array}$ & $\begin{array}{l}-0.000 \\
(0.010)\end{array}$ & $\begin{array}{c}0.005 \\
(0.010)\end{array}$ & $\begin{array}{c}0.004 \\
(0.010)\end{array}$ \\
\hline Average post-debate dummies 1,2 , and 3 & $\begin{array}{c}0.004 \\
(0.012)\end{array}$ & $\begin{array}{c}0.004 \\
(0.011)\end{array}$ & $\begin{array}{c}0.014 \\
(0.013)\end{array}$ & $\begin{array}{c}0.013 \\
(0.013)\end{array}$ \\
\hline
\end{tabular}

Notes: Same notes as in Table IV and Appendix Table C.29.

\section{References}

de Chaisemartin, Clément and Xavier D'Haultfoeuille, “Two-Way Fixed Effects Estimators with Heterogeneous Treatment Effects," American Economic Review, 2020, 110 (9), 2964-2996. 